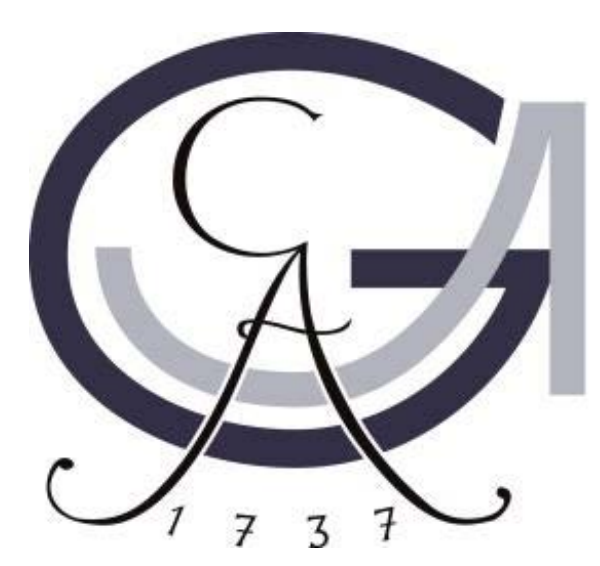

\title{
Strukturelle und funktionale Analyse der acetylierten kleinen GTPase Ran
}

\author{
Dissertation \\ zur Erlangung des mathematisch-naturwissenschaftlichen Doktorgrades \\ "Doctor rerum naturalium" \\ der Georg-August-Universität Göttingen \\ im Promotionsprogramm Biologie \\ der Georg-August University School of Science (GAUSS)
}

vorgelegt von

Daniel Gloth

aus Northeim

Göttingen, 2015 


\section{Betreuungsausschuss}

Prof. Dr. Ralf Ficner, Abteilung für molekulare Strukturbiologie, Institut für Mikrobiologie und Genetik

Jun.-Prof. Dr. Heinz Neumann, Angewandte Synthetische Biologie, Institut für Mikrobiologie und Genetik

Mitglieder der Prüfungskommission

Referent: Prof. Dr. Ralf Ficner, Abteilung für molekulare Strukturbiologie, Institut für Mikrobiologie und Genetik

Korreferent: Jun.-Prof. Dr. Heinz Neumann, Angewandte Synthetische Biologie, Institut für Mikrobiologie und Genetik

Weitere Mitglieder der Prüfungskommission:

Prof. Dr. Ralph Kehlenbach, Institut für Molekularbiologie, Zentrum Biochemie und Molekulare Zellbiologie

Prof. Dr. Kai Tittmann, Bioanalytik, Albrecht-von-Haller-Institut

Prof. Dr. Rolf Daniel, Genomische und Angewandte Mikrobiologie, Institut für Mikrobiologie und Genetik

PD Dr. Michael Hoppert, Allgemeine Mikrobiolgie, Institut für Mikrobiologie und Genetik

Tag der mündlichen Prüfung: 06.03.2015 


\section{Inhaltsverzeichnis}

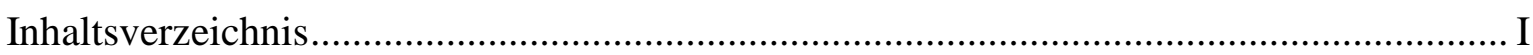

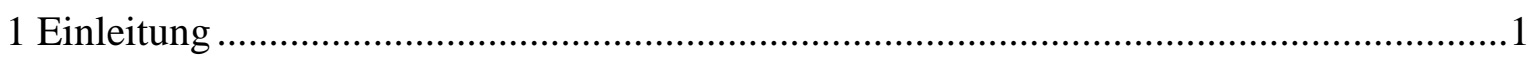

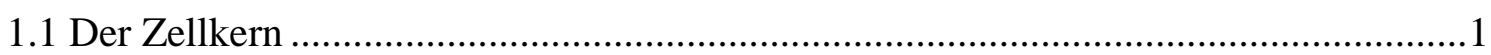

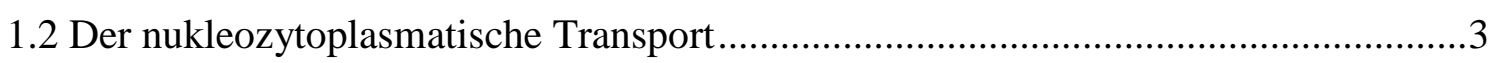

1.2.1 Der Kernporenkomplex................................................................................

1.2.2 Der rezeptorvermittelte Kerntransport ...........................................................

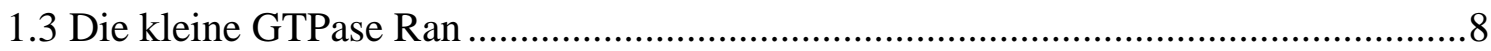

1.3.1 Der Ran Zyklus ..............................................................................................9

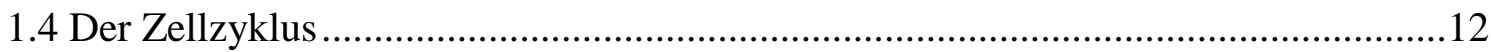

1.4.1 Die Interphase des Zellzyklus ......................................................................12

1.4.2 Die Mitotische Phase des Zellzyklus ....................................................................13

1.4.3 Die GTPase Ran in der Mitose ......................................................................14

1.5 Lysinacetylierung im Kerntransport ........................................................................16

1.5.1 Posttranslationale Acetylierung der Aminosäure Lysin.........................................18

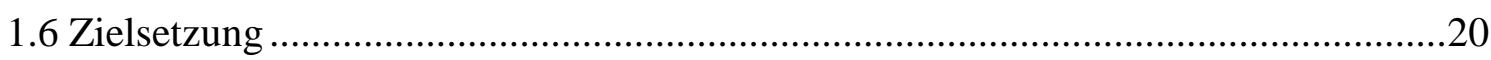

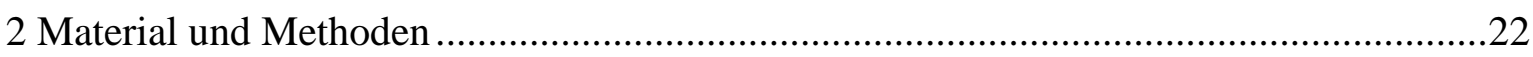

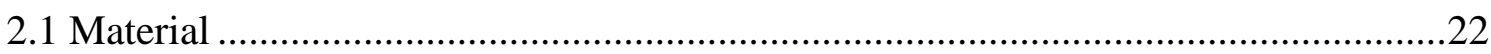

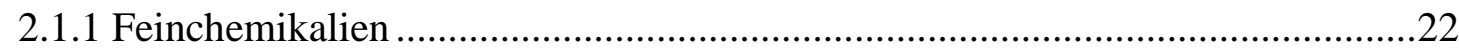

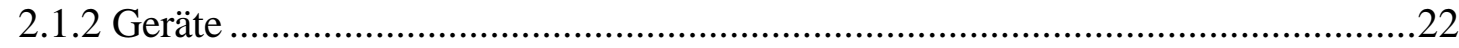

2.1.3 Chromatographiesäulen............................................................................23

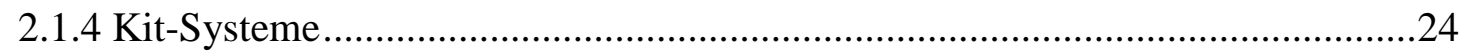

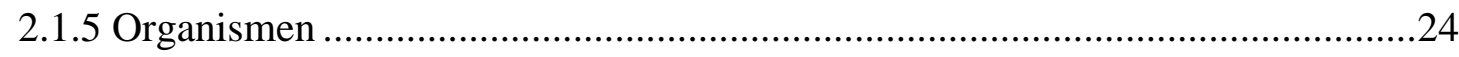

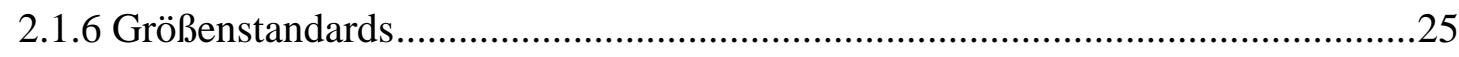

2.1.7 Enzyme und Inhibitoren ..............................................................................25

2.1.8 Plasmide und Vektoren .....................................................................................25

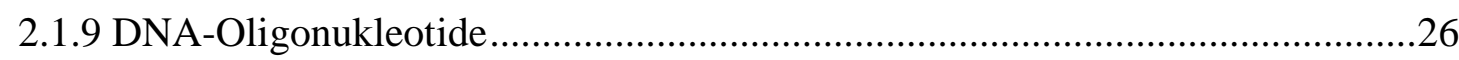




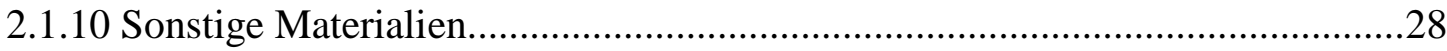

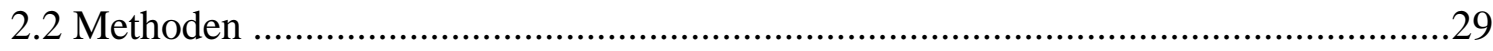

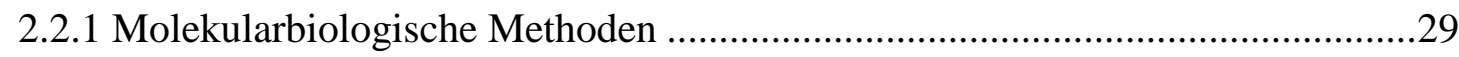

2.2.1.1 Polymerase-Kettenreaktion (PCR).....................................................29

2.2.1.2 Ortsgerichtete Mutagenese .................................................................... 30

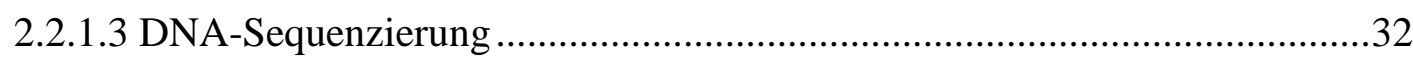

2.2.1.4 Spaltung von DNA mit Restriktionsendonukleasen .................................33

2.2.1.5 Ligation von DNA-Fragmenten in einen Zielvektor durch DNA-Ligasen..34

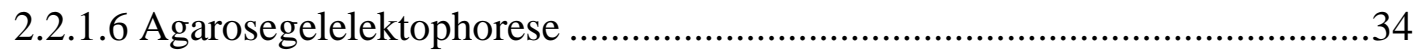

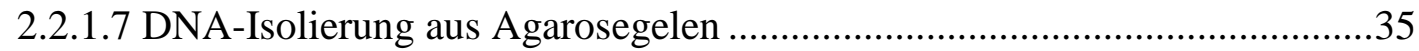

2.2.1.8 Genetische Codierung von Acetyllysin...................................................35

2.2.1.9 Klonierung der GTPase Ran verkürzt und in voller Länge in acetylierter

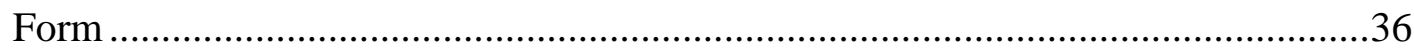

2.2.1.10 Klonierung des GTPase aktivierenden Protein RanGAP1 .........................37

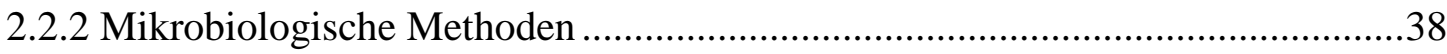

2.2.2.1 Herstellung von Flüssig- und Festmedien....................................................38

2.2.2.2 Herstellung chemisch kompetenter E.coli Zellen .....................................39

2.2.2.3 Transformation chemisch kompetenter E.coli Zellen ................................39

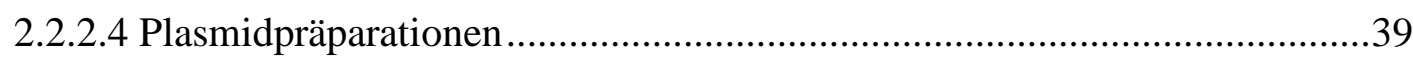

2.2.2.5 Expression rekombinanter Proteinein E. coli .............................................40

2.2.2.5.1 Expression von acetyliertem und nicht acetyliertem Ran (Homo

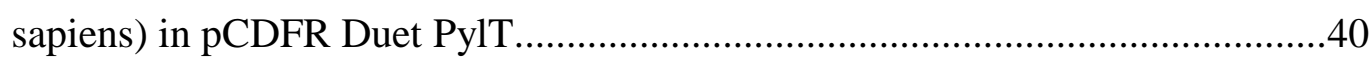

2.2.2.5.2 Expression von rekombinantem h.s. Crm1 ......................................41

2.2.2.5.3 Expression von rekombinantem SPN1............................................41

2.2.2.5.4 Expression von RanGAP1 (Mus musculus) ........................................41

2.2.2.6 Zellernte und Aufschluss einer E.coli Expressionskultur ...........................42

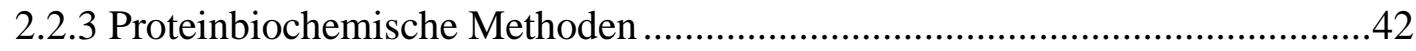

2.2.3.1 Chromatographische Trennmethoden ..................................................42 
2.2.3.1.1 Affinitätschromatographische Reinigung von Proteinen mit HistidinAffinitätssequenz. .43

2.2.3.1.2 Affinitätschromatographische Reinigung von Proteinen mit Glutathion-

S-Transferase. .43

2.2.3.1.3 Affinitätschromatographische Reinigung von Proteinen über HeparinSepharose .44

2.2.3.1.4 Umpuffern von Proteinlösung durch Entsalzungs-Säulen und Dialyse 44

2.2.3.1.5 Anionenaustauschchromatographie .45

2.2.3.1.6 Größenausschlusschromatographie .45

2.2.3.2 Beladung von Ran mit GTP .46

2.2.3.3 Analyse des Nucleotidladestatus über HPLCAnionenaustauschchromatographie ................................................................46

2.2.3.4 Diskontinuierliche Polyacrylamidgelelektrophorese von Proteinen .............47

2.2.3.5 Visualisierung von Proteinen durch Coomassie Brilliant Blue.....................48

2.2.3.6 Einengen von Proteinlösungen durch Zentrifugation ..................................48

2.2.3.7 Spaltung von Proteinen durch Proteasen....................................................48

2.2.3.8 Detektion von Proteinen über Westernblot .................................................49

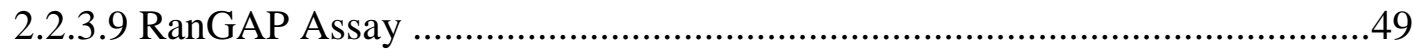

2.2.3.9.1 RanGAP Assay mit radioaktiv markiertem GTP ...............................50

2.2.3.9.2 RanGAP Assay mit Phosphat Sensor.................................................50

2.2.3.10 Ran Protektions Assay .........................................................................51

2.2.3.10.1 Ran Protektions Assay mit radioaktiv markiertem GTP .....................51

2.2.3.10.2 Ran Protektions Assay mit Phosphat Sensor ......................................51

2.2.3.10 Bindungsstudie des Exportkomplex Crm1:Spn1:acetyliertem RanGTP mittels analytischer Gelfiltration.......................................................................52

2.2.3.11 Bindungsstudien über Pulldown-Assays ..................................................53

2.2.4 Spektroskopische Methoden ........................................................................54

2.2.4.1 Konzentrationsbestimmung von Proteinlösungen......................................54

2.2.4.2 Konzentrationsbestimmung von Nukleinsäure-Lösungen ..........................54 


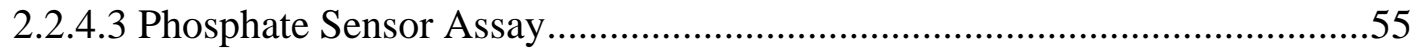

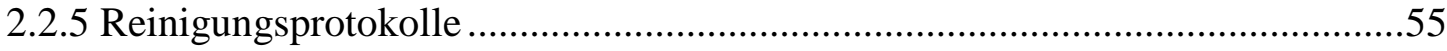

2.2.5.1 Ran (Homo sapiens) in pCDFR Duet PylT ..................................................55

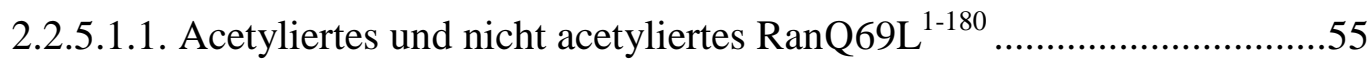

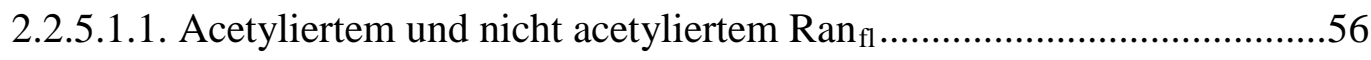

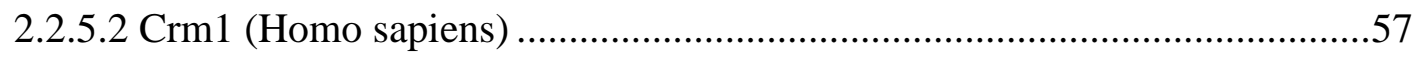

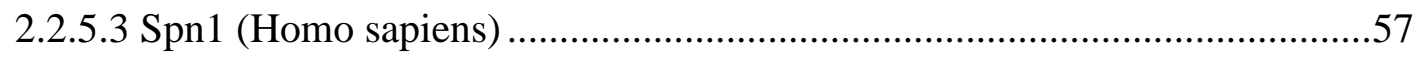

2.2.5.4 RanGAP1 (Mus musculus) in pGEX-6P-1 ...............................................58

2.2.5.5 Exportkomplex Crm1:SPN1: RanGTP .................................................58

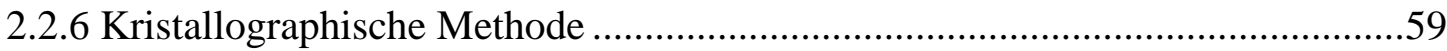

2.2.6.1 Kristallisation von Proteinen...................................................................59

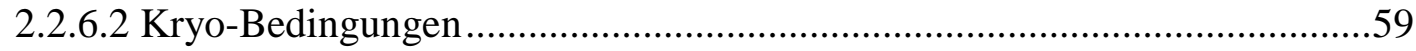

2.2.6.3 Röntgenbeugungsexperimente …............................................................60

2.2.6.4 Lösung des Phasenproblems durch Molekularen Ersatz..............................60

2.2.6.5 Modellbau und Strukturverfeinerung....................................................62

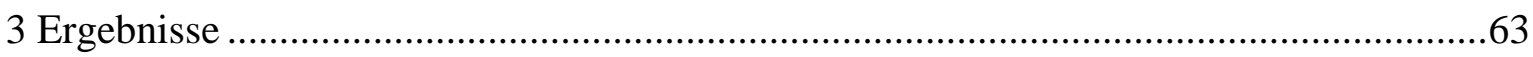

3.1 Die GTPase Ran verkürzt und in voller Länge in acetylierter Form ........................63

3.1.1 Expression und Reinigung von acetyliertem und nicht acetyliertem RanQ69L ${ }^{1-}$ 180

3.1.2 Expression und Reinigung von acetyliertem und nicht acetyliertem Vollängen Ran

3.2 Reinigung von Crm1 69

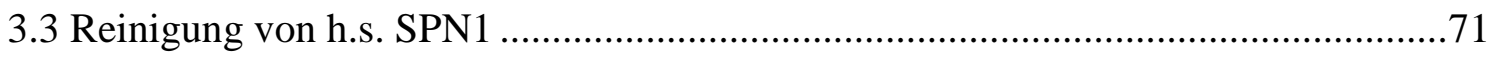

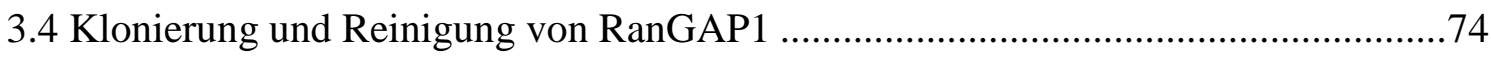

3.5 Strukturelle und funktionale Analyse des Exportkomplex Crm1:Spn1:RanGTP mit

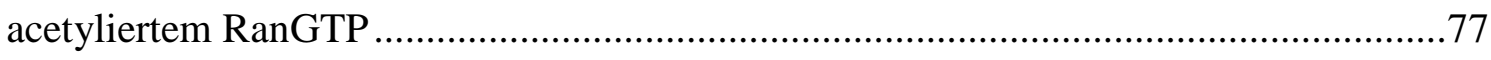

3.5.1 Bindungsstudie über Analytische Gelfiltration...............................................77

3.5.2 Bindungsstudie von acetyliertem RanQ69L ${ }^{1-180}$ K37Ac und K71Ac mit Transportrezeptoren über einen Pulldown-Assay.... 
3.5.3 Analyse der GTPase-Aktivität der RanGTP Acetyllysin Mutanten .83

3.5.3.1 Funktionale Analyse der GTPase Ran, der GAP-Assay . .85

3.5.3.2 Funktionale Analyse von acetyliertem RanGTP im Komplex mit Transportrezeptoren mittels radioaktiv markiertem GTP .86

3.5.3.3 Funktionale Analyse von acetyliertem RanGTP im Komplex mit Transportrezeptoren mittels Phosphatsensor. .88

3.5.4 Präparation und Kristallisation des Exportkomplexes mit acetyliertem RanQ69L ${ }^{1-180}$ an K71 und K99 .90

3.5.5 Röntgenbeugungsexperiment und Datenprozessierung (P. Neumann). .94

3.5.6 Strukturelle Analyse des Exportkomplex mit RanGTP Acetyllysinmutanten....96 3.5.6.1 Beschreibung des allgemeinen strukturellen Aufbaus des Exportkomplexe mit den RanQ69L ${ }^{1-180}$ Mutanten K71Ac und K99Ac ...............................................97

3.5.6.2 Betrachtung der acetylierten Lysin 71 und 99 97

3.5.6.3 Struktureller Einfluss ein Acetylgruppe auf das RanGTP im Komplex mit h.s.Crm1

4 Diskussion. 103

4.1 Expression und Reinigung beteiligter Komponenten 103

4.1.1 Die acetylierte GTPase Ran .... 105

4.1.2 Expression und Reinigung zur Analyse benötigter Proteine. 106

4.2 Biochemische und Strukturelle Bedeutung der Acetylierung der GTPase Ran.......107

4.3 Einordnung der Acetylierung der GTPase Ran in einen biologischen Kontext ......121

4.4 Ausblick 125

5 Zusammenfassung. 127

6 Summery 128

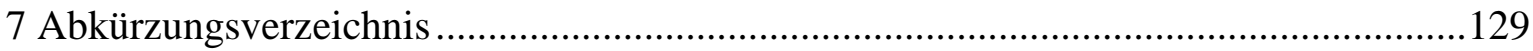

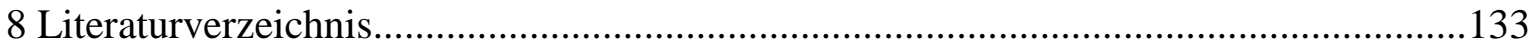

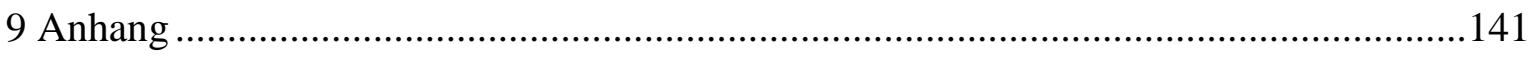

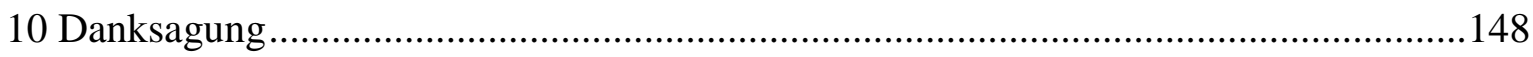

Lebenslauf. 


\section{Einleitung}

Zellen sind hoch komplexe Gebilde, in denen eine Vielzahl an Reaktionen ablaufen. Grundsätzlich werden zwei Zelltypen unterschieden, prokaryotische- und eukaryotische Zellen. Die einfacheren Organismen wie Bakterien und Archea werden zu den prokaryotischen Zellen gezählt. Komplexere Organismen wie Tiere und Pflanzen aber auch Algen und Pilze sind aus eukaryotischen Zellen aufgebaut. Gemeinsam sind beiden Zelltypen eine sie umgebende Plasmamembran, sowie das Zytosol, welches die Organellen der Zelle beinhaltet. Es bestehen allerdings auch Unterschiede zwischen diesen beiden Zelltypen, so weisen eukaryotische Zellen eine höhere Komplexität auf, welche sich durch das Vorhandensein verschiedener Zellkompartimente/Strukturen in diesen Zellen ausdrückt. Zu diesen zählen z.B. die Mitochondrien, Chloroplasten, der Golgi-Apparat oder Lysosomen. Der Hauptunterschied zwischen diesen beiden Zelltypen besteht im vorhanden sein eines echten Zellkerns (Nukleus, Abb. 1) bei eukaryotischen Zellen (griech. eu"echt" und karyon "Kern").

\subsection{Der Zellkern}

Der Zellkern bildet das Kontrollzentrum jeder eukaryotischen Zelle, aufgebaut aus einer Doppelmembran aus Lipiden, der Kernhülle (engl. nuclear envelope), durchsetzt mit großen Proteinkomplexen, den Kernporenkomplexen (engl. nuclear pore complex, NPC). Der Zellkern ist Träger der genetischen Information der Zelle, die in einem Komplex aus DNA und Proteinen, dem Chromatin gespeichert ist. Aus dem Chromatin bilden sich schließlich die Chromosomen der eukaryotischen Organismen. Die Ausbildung des Nukleus grenzt die genetische Information der Zelle, die DNA, vom Zytoplasma ab. Diese Gegebenheit führt zur Trennung von Prozessen wie der RNA-Biogenese (Transkription) und DNA-Replikation im Zellkern und der Protein-Biosynthese (Translation) im Zytoplasma. Die räumliche Trennung der Transkription von der Translation erhöht die Stabilität des Genoms, durch die Abgrenzung von Stoffwechselprozessen im Zytoplasma einerseits, ermöglicht aber andererseits auch eine spezifische und vielfältige Kontrolle der Genexpression auf verschiedenen Ebenen. Aus der Trennung der Prozesse der RNABiogenese und DNA-Replikation von der Protein-Biosynthese resultiert ein reger Austausch zwischen dem Karyoplasma und dem Zytoplasma. Proteine, wie 
Transkriptionsfaktoren, Polymerasen und spleißosomale Proteine, die Aufgaben im Zellkern erfüllen, müssen in diesen gelangen. Im Gegenzug ist es notwendig, dass im Kern entstehende RNA Spezies, wie messenger-RNA (mRNA), ribosomale RNA (rRNA) oder Transfer-RNA (tRNA) diesen verlassen um ihre jeweilige spezifische Funktion zu erfüllen (Abb. 1). So kommt es in jeder Sekunde zu einem Transfer von tausenden Makromolekülen über die Kernhülle (Chook et al., 1999; Conti and Izaurralde, 2001; Damelin et al., 2002; Fried and Kutay, 2003; Görlich and Kutay, 1999; Kuersten et al., 2001; Macara, 2001).

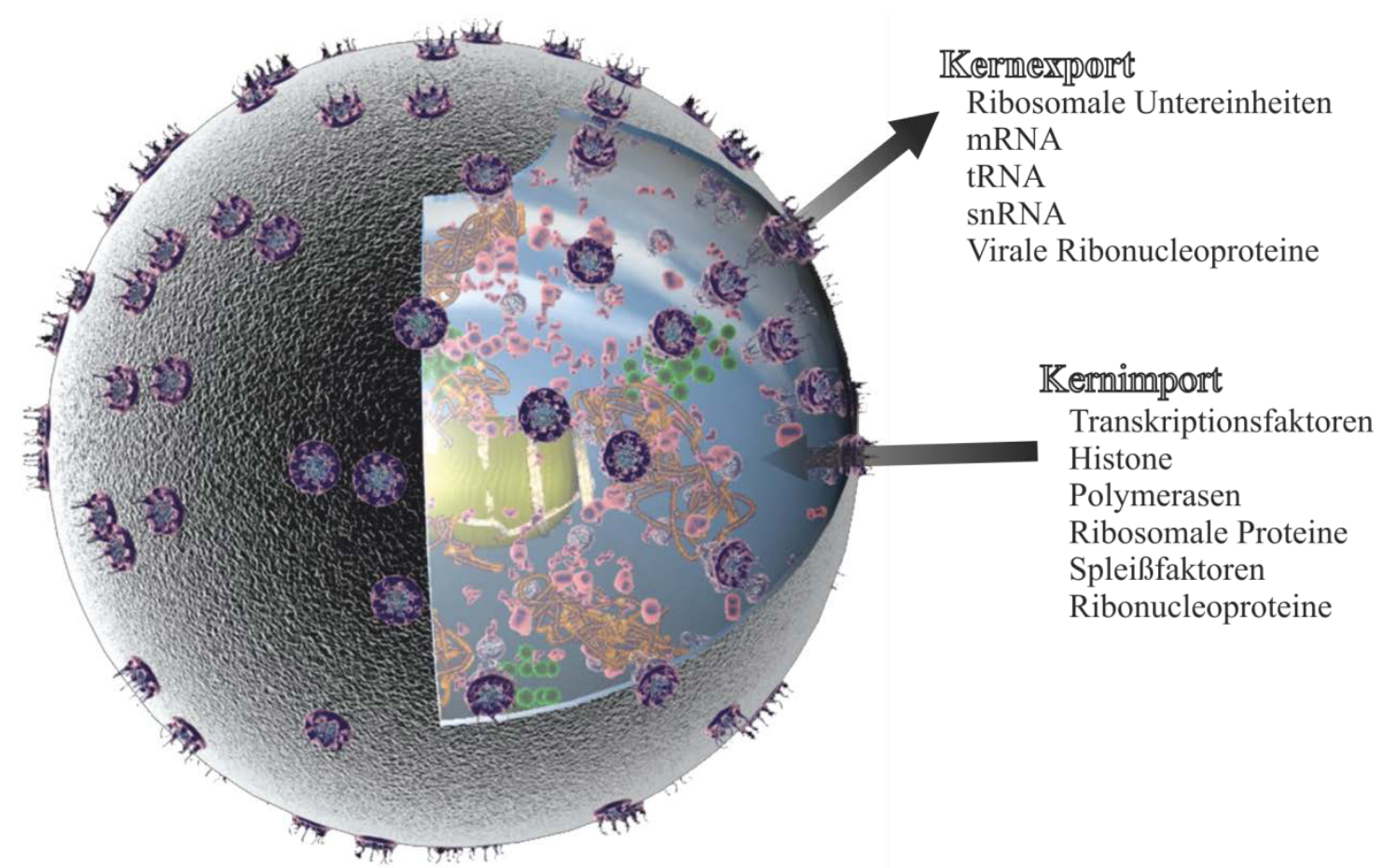

Abb. 1: Schematische Darstellung eines Zellkerns. Der Zellkern ist das zentrale Merkmal der eukaryotischen Zelle. Er stellt ein Kompartiment dieses Zelltyps dar und besteht aus der mit Kernporen durchsetzten Kernhülle. Die Kernhülle umschließt die gentische Information der Zellen in Form von Chromatin, aus dem die Chromosomen entstehen. Die Kernporen (NPC) erlauben den Transport von Makromolekülen über die Kernhülle unterteilt in Kernimport und Kernexport. Das Modell ist http://sspatel.googlepages.com; ㄷ 2005 Samir S. Patel entnommen.

Der Zellkern unterliegt einem für die Zelle essentiellen Prozess, der Zellkernteilung (Mitose). Dieser Prozess bildet einen eigenständigen Teil des Zellzyklus einer eukaryotischen Zelle. In diesem Vorgang wird die DNA im Zellkern verdoppelt, die Kernhülle zerfällt und die DNA wird aufgeteilt (Campbell, N. und Reece, J 6.Auflage, 2003). 


\subsection{Der nukleozytoplasmatische Transport}

Die Trennung von Transkription und Translation bietet nicht nur den Vorteil der Kontrolle der Genexpression, sie macht auch einen selektiven Transport zwischen dem Zellkern und dem Zytoplasma notwendig, damit die spezifische Zusammensetzung beider Kompartimente erhalten bleibt. Die Kernhülle erweist sich hierbei als eine Barriere, welche diese Aufgabe erfüllt und einen selektiven Transport gewährleistet. Auf diese Weise wird ein unspezifischer Eintritt von Makromolekülen in den Zellkern unterbunden (Stewart, 2007). Um einen selektiven Transport von Makromolekülen zwischen Zytoplasma und Zellkern über die Kernhülle zu ermöglichen sind die Kernporenkomplexe in diese Hülle eingelassen und bilden so einen wässerigen Kanal mit selektiven Eigenschaften (Maco et al., 2006; Schwartz, 2005; Tran and Wente, 2006). Moleküle mit einem Molekulargewicht bis $40 \mathrm{kDa}$ ist es möglich den Kernporenkomplex passiv zu durchqueren, Moleküle mit einem höheren Molekulargewicht interagieren mit löslichen Molekülen, den Transportrezeptoren, um den NPC passieren zu können. Der Prozess dieses selektiven Transportes zwischen Zytoplasma und Zellkern bezeichnet man als nukleozytoplasmatischen Transport (Cook et al., 2007; Stewart, 2007).

\subsubsection{Der Kernporenkomplex}

Der Kernporenkomplex ist ein makromolekularer Komplex aus über 30 verschiedenen Proteinen. Viele dieser Proteine liegen in mehrfachen Kopien vor und bilden eine achtfache Symmetrie (Cronshaw et al., 2002; Rout et al., 2000). Der NPC der Vertebraten besitzt eine Abmessung von ca. 1450 x $800 \AA$ und ein Molekulargewicht von ca. 100-125 MDa (Akey and Radermacher, 1993; Cronshaw et al., 2002; Yang et al., 1998).

Im Allgemeinen gliedert sich der NPC in mehrere Bereiche (Abb. 2). Auf der zytoplasmatischen Seite der Kernhülle befinden sich die zytoplasmatischen Filamenten, welche an der Erkennung und Bindung von Transportkomplexen beteiligt sind. In der Mitte des Komplexes befindet sich ein Gerüst, welches sich aus einem zytoplasmatischen Ring, einem Speichenring und einem nukleären Ring zusammensetzt. Dieses Gebilde umschließt den Zentralkanal, welcher den Transportprozess vermittelt. Auf der nukleären Seite befindet sich am NPC eine Korb ähnliche Struktur (engl. nuclear basket). Dies Struktur setzt sich dabei aus nukleären Filamenten zusammen, die sich am distalen Ende zu der Korb ähnlichen Struktur zusammen schließen und mit dem nukleären Ring des zentralen Kanals in Verbindung stehen (Beck et al., 2004, 2007; Sorokin et al., 2007). 
Der NPC ist über die Proteine gp210, POM121 und POM152 in der Kernhülle verankert (Panté and Aebi, 1996; Söderqvist et al., 1997). In der Mitte des zentralen Kanals befinden sich Kernporenproteine (Nups), die Phenylalanin-Glycin (FG) reiche Wiederholungen (FG-repeats) besitzen. Diese Proteine generieren durch die FG-repeats ein hydrophobes Netzwerk, welches den zentralen Kanal des NPC ausfüllt und den Eingang in den Nukleus darstellt, es entsteht somit eine hydrophobe Umgebung (Denning and Rexach, 2007; Frey and Görlich, 2009; Frey et al., 2006; Mohr et al., 2009).

A

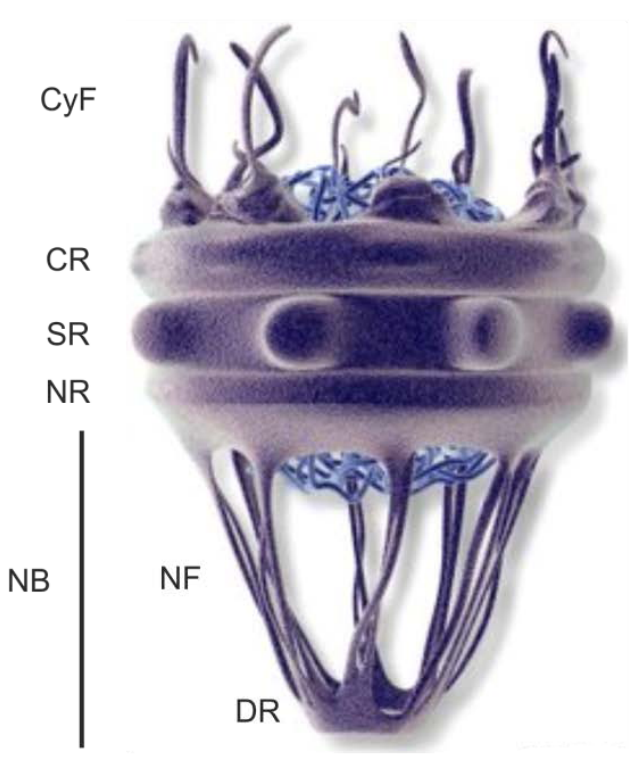

B

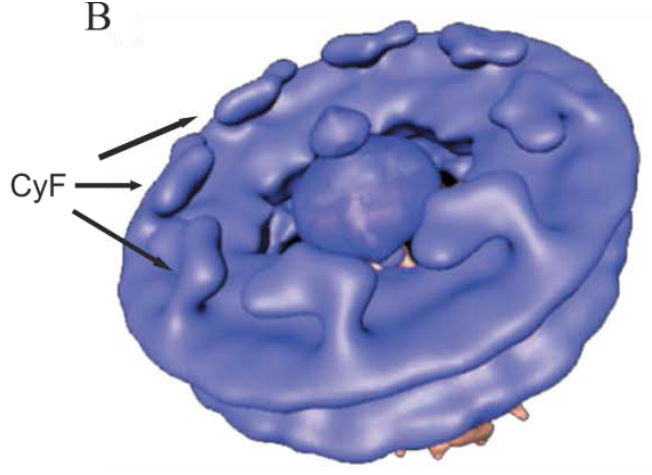

$\mathrm{C}$

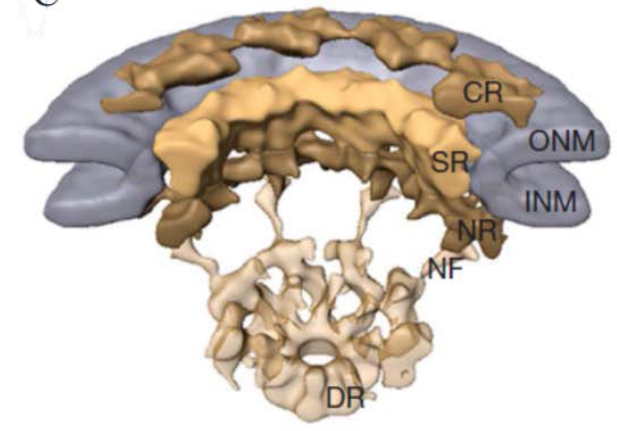

Abb. 2: Darstellung vom Aufbaus eines Kernporenkomplex (NPC). Schematische Darstellung eines Kernporenkomplex in Seitenansicht (A) und Rekonstruktion der Kernporenstruktur auf Basis von Kryo-Elektronentomatographie Daten (B und C). Der NPC gliedert sich auf der zytoplasmatischen Seite in die zytoplasmatischen Filamenten (CyF) am zytoplasmatischen Ring (CR). Ein zentraler Ring, der Speichenring (SR) verbindet den zytoplasmatischen Ring mit dem nukleären Ring (NR). Im Zellkern bildet der NPC eine korbähnliche Struktur, den nuclear basket (NB), aus den nukleären Filamenten (NF) und einem distalen Ring (DR). B) Sicht von der zytoplasmatischen Seite. C) Querschnitt durch den NPC in der Kernmembran (ONM= äußere Kernmembran, INM= innere Kernmembran). Das NPC Modell http://sspatel.googlepages.com; @ 2000-2006 Samir S. Patel entnommen. B modifiziert nach Beck et al., 2004, C entnommen Beck et al., 2007

Kleinere Moleküle bis zu einem Molekulargewicht von $40 \mathrm{kDa}$ können durch dieses hydrophobe Netzwerk passiv diffundieren. Größere Moleküle, hydrophile Proteine oder auch solche, deren Passage durch den Kernporenkomplex streng reguliert werden muss, 
werden durch das hydrophobe Netzwerk der Kernpore an der Passage durch den NPC gehindert (Cook et al., 2007; Paine et al., 1975; Peters, 2006; Weis, 2007). Um die Kernporenkomplexe passieren zu können, müssen Moleküle, welche größer als $40 \mathrm{kDa}$ sind, aktiv durch den NPC transportiert werden. Für diesen Vorgang sind lösliche Faktoren notwendig, die Transportrezeptoren (Cook et al., 2007; Stewart, 2006; Conti et al., 2005; Görlich und Kutay, 1999).

\subsubsection{Der rezeptorvermittelte Kerntransport}

Der Transport von Molekülen über $40 \mathrm{kDa}$ zwischen dem Zellkern und dem Zytoplasma wird von löslichen Faktoren, den Kerntransportrezeptoren, vermittelt. Es gibt drei Familien: 1. Ein komplexes ATP abhängiges mRNA Exportsystem, 2. Ein einfaches System zum Transport der kleinen GTPase Ran in den Kern bestehend aus einem Faktor und 3. Das Ran abhängige System der Importin $\beta$-Superfamilie. Die Mehrheit der Kerntransportrezeptoren zählt zu den Proteinen der 3. Familie, der Importin $\beta$-Superfamilie oder auch $\beta$-Karyopherine (Abb. 3). Sie lassen sich in zwei Klassen unterteilen, in Importrezeptoren (Importine) und in Exportrezeptoren (Exportine). Importine vermitteln den Import von Makromolekülen in den Zellkern, wohingegen Exportine den Export von Makromolekülen aus dem Zellkern in das Zytoplasma ausführen (Cook et al., 2007; Madrid and Weis, 2006) (Abb. 4). Die Proteine der Importinß-Superfamilie selbst bestehen aus einem sich wiederholenden Motiv, dem sogenannten HEAT-repeat ( $\underline{\text { Huntingtin, }}$

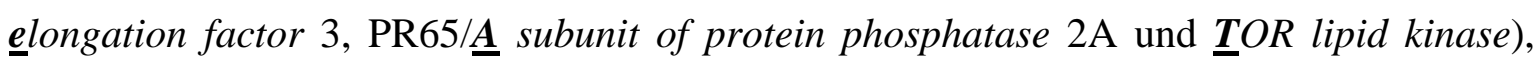
welches wiederum aus ungefähr 40 Aminosäuren besteht (Abb. 3A). Ein HEAT-repeat besteht aus zwei antiparallel verlaufenden $\alpha$-Helices (bekannt als A und B-Helix), die durch eine kurze Schleife von einander getrennt werden. Durch eine leichte Drehung und Neigung der beiden Helices eines HEAT-repeats zueinander entsteht die superhelikale Struktur der Transportrezeptoren (Chook and Blobel, 1999, 2001; Cingolani et al., 1999; Cook et al., 2007; Lee et al., 2005; Matsuura and Stewart, 2004; Vetter et al., 1999a).

Der am besten untersuchte Vertreter dieser Proteinfamilie ist in Abb. 3 dargestellt. Sie zeigt die Kristallstruktur des humanen Importin $\beta$ als cartoon- Modell, eingefärbt in rot und gelb nach der jeweiligen Helix des HEAT-repeat und deren Lage. Die Transportrezeptoren, sowie der NPC sind die Hauptkomponenten des Kerntransports.

Der Kerntransport an sich gliedert sich in den Import von Makromolekülen (Substrat auch als Cargo bezeichnet) in den Zellkern und in den Export von Makromolekülen aus dem Zellkern in das Zytoplasma (Abb. 4). 
A

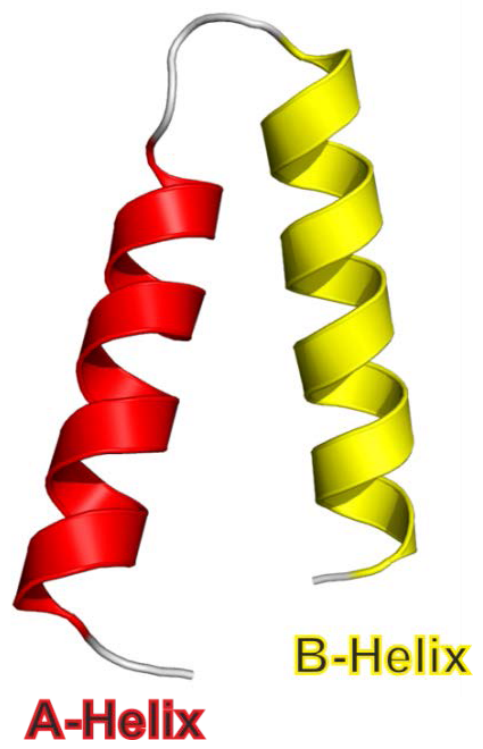

B

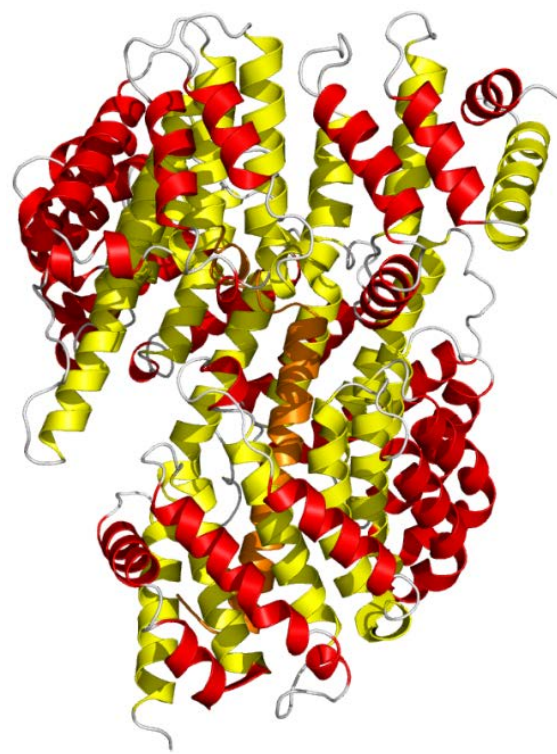

Abb. 3: Strukturelle Organisation von Transportproteinen der Importin $\beta$-Superfamilie. A) Typische Anordnung der zwei Helices eines HEAT-repeat Motivs. In der Cartoon Darstellung ist ein HEAT-repeat des Importin $\beta$ (Imp $\beta$ ) gezeigt (Cingolani et al., 1999). Typisch, die A-Helix (rot) bildet die äußere, konvexe Oberfläche des Moleküls und die B-Helix (gelb) die innere, konkave Oberfläche. A- und B-Helix interagieren hauptsächlich via hydrophober Seitenketten in der eingeschlossenen Spalte. Die kleine Neigung der A-Helix zur B-Helix führt letztlich zur Bildung der superhelikalen Struktur der $\beta$-Karyopherine. B) Dargestellt ist die Kristallstruktur von Importin $\beta$ im Komplex mit der Importin $\beta$-Bindedomäne von Importin $\alpha$ (orange) (IBB $\alpha$, Cingolani et al., 1999). IBB $\alpha$ ist als Cartoon-Modell gezeigt. Imp $\beta$ besteht aus 19 HEAT-repeats, das Molekül ist wie A) eingefärbt.

Die Transportrezeptoren binden ihre Transportsubstrate (Cargo, Abb.4) über Signalsequenzen. Im Kerntransport sind zwei Arten von Signalsequenzen notwendig, das

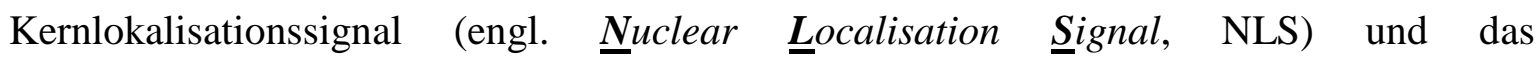

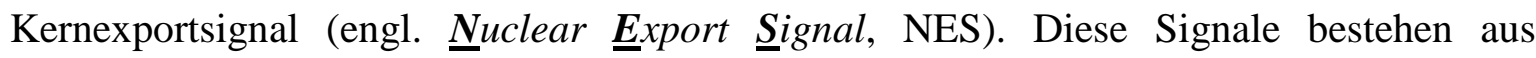

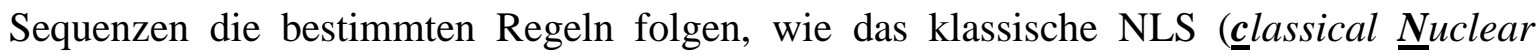
Localisation Signal, cNLS) aus einer kurzen Sequenz aus 7-8 Aminosäuren mit mindestens vier Lysinen, wie z.B. PKKKRKV (Kalderon et al., 1984; Lanford and Butel, 1984; Lanford et al., 1986) oder wie das NES mit einer Leucin reichen Sequenz, die vier typisch hydrophobe Aminosäuren beinhaltet. Außer dem cNLS und dem NES werden in der Zelle noch andere verwendet, wie z.B. das bpNLS (bipartite NLS(Robbins et al., 1991)) oder das M9-Transportsignal (Pollard et al., 1996), welches sowohl als Kernimportsignal als auch als Kernexportsignal fungiert, so dass ein Pendeln des Transportsubstrats zwischen Zytoplasma und Nukleus stattfinden kann. Transportrezeptoren binden ihr Substrat über die Signalsequenz des Substrats. Dies kann 
direkt zwischen dem Rezeptor und dem Substrat passieren oder indirekt über ein Adaptermolekül das die Interaktion von Rezeptor zu Cargo vermittelt (Fried and Kutay, 2003). Eine weitere, eher spezielle, Möglichkeit bietet ein Komplex aus zwei Transportrezeptoren, die ein Cargo binden (Baake et al., 2001; Bäuerle et al., 2002; Jäkel et al., 1999). Dabei wird das NLS von den Importinen gebunden, sowie das NES von den Exportinen.

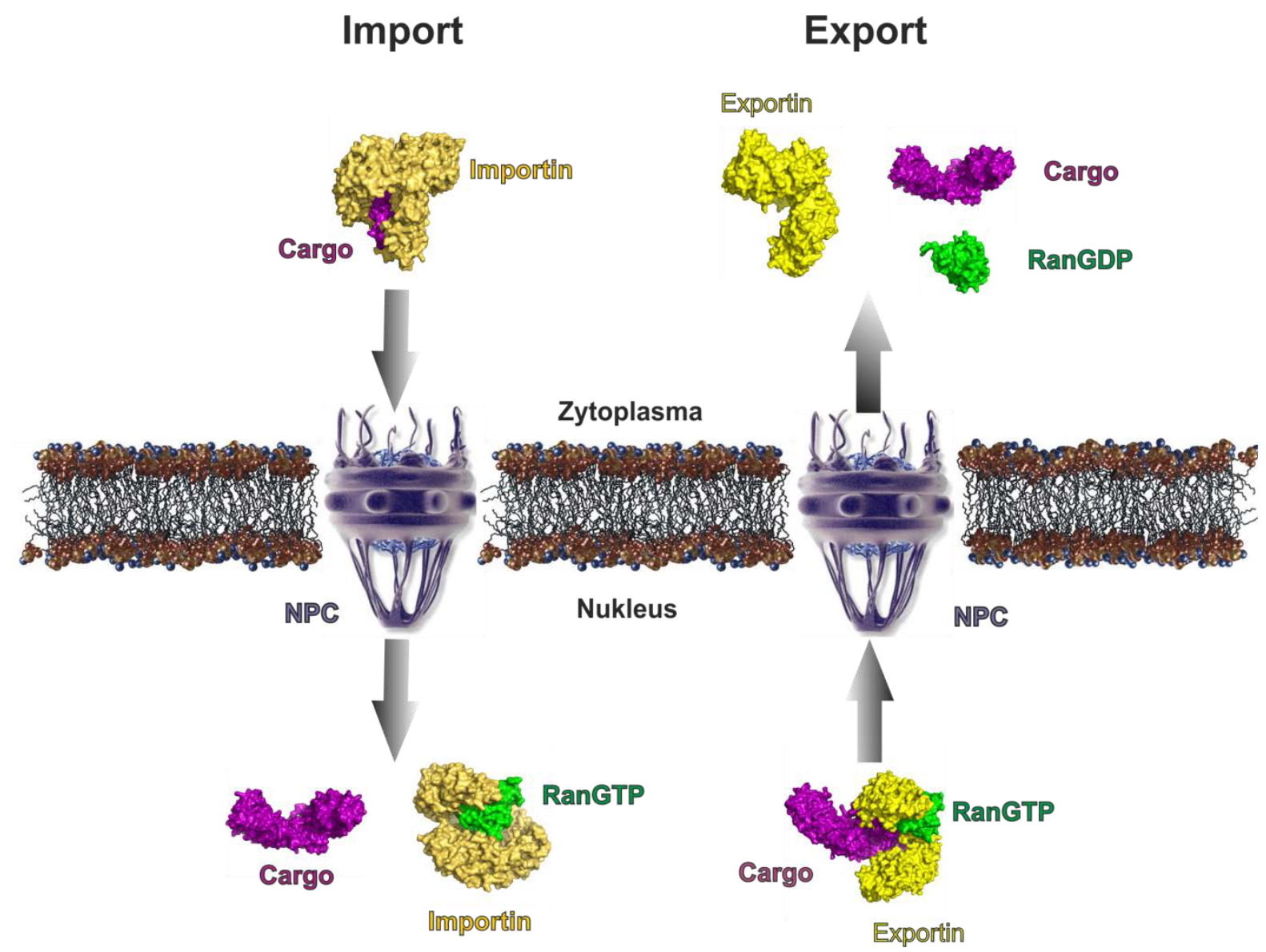

Abb. 4: Schematische Darstellung des Kernimport und Kernexport durch Rezeptoren der Imortin $\beta$ Superfamilie. Auf der linken Seite ist der Kernimport gezeigt. Das Importin (gold) bindet das Substrat (Cargo, magenta) im Zytoplasma. Der Komplex wird durch den NPC transportiert, wo das Cargo durch Interaktion des Rezeptors mit der GTPase Ran (grün) in GTP gebundener Form (RanGTP) frei gesetzt wird. Auf der rechten Seite ist der Kernexport gezeigt. Ein Exportin (gelb) bindet RanGTP und folgend das Cargo. Der ternäre Komplex wird den NPC transportiert und fällt im Zytoplasma durch GTP Hydrolyse auseinander. Die verwendeten Komplexe und Einzelproteine stammen aus der RCSB Protein Datenbank, Cargo PDB ID 1IAL, Importin:RanGTP Komplex PDB ID 2X19, Importin: Cargo Komplex PDB ID 1QGK, RanGDP PDB ID 3GJ0, Exportin:Cargo:RanGTP Komplex PDB ID 1WA5, Exportin PDB ID 1Z3H. Die Lipiddoppelschicht wurde aus malvern.com entnommen. Das NPC wurde aus Modell http://sspatel.googlepages.com; @ 2000-2006 Samir S. Patel entnommen. Für die Oberflächendarstellung der Proteine wurde Pymol verwendet 
In Abb. 4 ist ein einfaches Schema des Kernimports und- exports gezeigt. Im Zytoplasma wird das Cargo über das NLS von Importinen erkannt und gebunden. Dieser entstandene Importkomplex interagiert mit einem NPC und wird in den Zellkern transferiert. Im Zellkern interagiert der Rezeptor des Importkomplexes mit der kleinen GTPase Ran (von

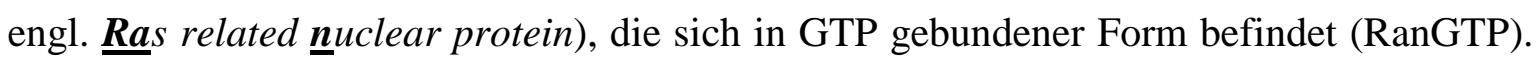
Das Substrat wird freigesetzt und der Rezeptor im Komplex mit RanGTP in das Zytoplasma zurück transportiert. Durch die Hydrolyse des Ran gebundenen GTP wird der Komplex aufgelöst und das Importin steht für einen neuerlichen Transport von Makromolekülen zu Verfügung (Cook et al., 2007; Stewart, 2007). Der Kernexport läuft im Grunde sehr ähnlich ab. Im Unterschied zum Importin ist die Bindung von RanGTP an das Exportin eine Voraussetzung um das Substrat zu binden. Dieser ternäre Komplex Exportin:RanGTP:Substrat ist in der Lage mit dem NPC zu interagieren und diesen zu passieren. Im Zytoplasma führt die Hydrolyse des Ran gebundenen GTP zu GDP zum Auseinanderfallen des Exportkomplex und zur Freisetzung des Transportsubstrates. Der Kerntransport lässt sich somit in vier Schritte gliedern, 1) Bildung des Transportkomplex,

2) Transport durch den Kernporenkomplex, 3) Freisetzung des Substrates und 4) Transportrezeptor Recycling (Stewart, 2007).

\subsection{Die kleine GTPase Ran}

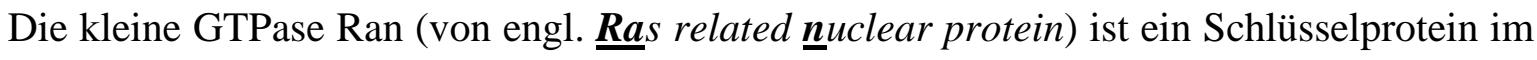
Kerntransport und spielt dort eine tragende Rolle. Es ist ein kleines G-Protein der Ras Superfamilie und besteht aus 216 Aminosäuren mit einem Molekulargewicht von 25 kDa. Als kleines G-Protein ist Ran in der Zelle in zwei nukleotidgebundenen Zuständen zu finden, und zwar in einem Komplex mit GTP oder GDP (Guiochon-Mantel et al., 1994; Joseph, 2006; Melchior et al., 1993; Moore and Blobel, 1993). Das Molekül zeigt dabei eine eher globuläre Struktur (Abb. 5) mit mehreren flexiblen Regionen, der Switch 1 bzw. Switch 2 Region (As 30-47 und 65-80), sowie die eine saure Sequenz (DEDDDL) umfassende C-terminale Erweiterung. Diese Regionen zeigen strukturelle Veränderungen in Abhängigkeit vom jeweils gebundenen Nukleotid (Abb. 5). Ran zeigt im GDP gebundenem Zustand eine relativ offen Konformation, mit der Switch 1 Region in der Nähe des N-Terminus ( $\beta 1)$ positioniert, entfernt vom Nukleotid. Durch die Bindung von GTP kommt es zu einer Konformationsänderung der beiden Switch Regionen, welche darauf hin das GTP aufnehmen (Chook and Blobel, 1999; Partridge and Schwartz, 2009). Die C-terminale Erweiterung des Ran Moleküls befindet sich im GDP gebundenen 
Zustand an die Nukleotidbindedomäne gebunden, ist dagegen GTP gebunden liegt diese Region relativ frei und flexibel vor. Diese Konformationsänderungen erlauben es dem Ran, in seinem aktiven GTP gebundenem Zustand, seine Aufgaben im Kerntarnsport auszuüben.

A

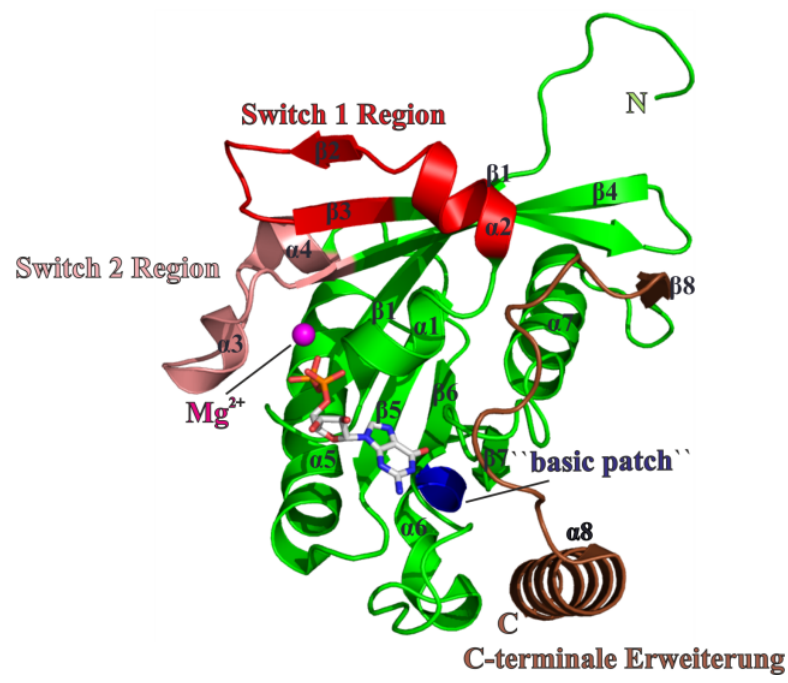

B

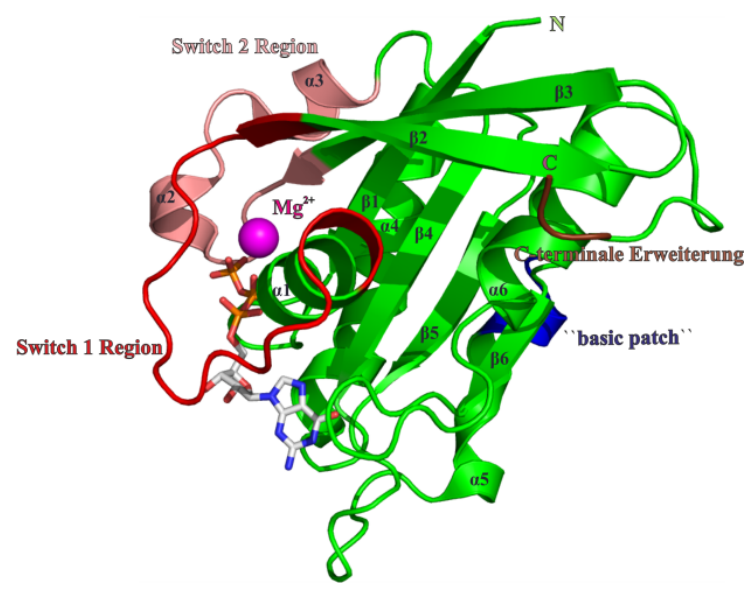

Abb. 5: Strukturelle Organisation der kleinen GTPase Ran. Gezeigt ist die Kristallstruktur der GTPase Ran (grün) in GDP (A) (PDB ID 3GJ0) und in GTP (B) gebundenem Zustand als Cartoon Modell. Die GTP gebundene Struktur ist der Kristallstruktur 3GJX (Monecke et al., 2009) entnommen. Hierbei handelt es sich um die C-Terminal verkürzte GTPase defiziente Mutante der GTPase. Die Switch 1 Region (As 30-47) ist rot gefärbt, die Switch 2 Region (As 65-80) ist in pink gezeigt. Der “basic patch” ist hier blau gezeigt, sowie die C-terminale Erweiterung mit der DEDDDL-Sequenz in braun. Die sekundär Strukturelemente sind Nummeriert, die Nukleotide als Stäbchen dargestellt mit Kohlenstoffatomen in grau, Stickstoff in blau, Sauerstoff in rot und Phosphor in orange. Das Magnesium ist als Sphäre in Magenta gezeigt (Pymol).

\subsubsection{Der Ran Zyklus}

Die kleine GTPase Ran spielt eine zentrale Rolle bei den Kerntransportprozessen (Görlich and Mattaj, 1996; Nigg, 1997; Yoneda, 1997; Yoneda et al., 1999). So führt die Bindung von Ran in GTP gebundenem Zustand zur Freisetzung eines Substrats von Importrezeptoren. Desweiteren bildet dieses Protein einen wesentlichen Teil eines Exportkomplexes (Görlich and Kutay, 1999). So sichert die Zelle während des Kerntransports, dass ein Importin den Zellkern nur nach Abgabe des Cargos wieder verlassen kann, sowie die Rückkehr des Exportins in den Zellkern nach der Hydrolyse des GTP im Ran. Das Ran liegt demnach in zwei Formen vor, in einer GTP-gebunden Form die überwiegend im Karyoplasma vorkommt, so wie in einer GDP-gebunden die nahezu vollständig im Zytoplasma zu finden ist (Izaurralde et al., 1997). Es entsteht so ein steiler 
Konzentrationsgradient von RanGTP mit einer hohen Konzentration im Zellkern und einer niedrigen im Zytoplasma. Dieser Gradient ist der Antrieb für den Kerntransport, sowie die Ursache seiner Direktionalität (Görlich and Mattaj, 1996). Daraus ergibt sich die Frage, wie dieser Gradient aufrecht erhalten wird. Wie andere GTPasen besitzt Ran eine niedrige intrinsische Hydrolyserate und ist so relativ stabil. Aus diesem Grund ist Ran auf weitere Proteine angewiesen um die GTP-Hydrolyse durchzuführen. Das im Zytoplasma auftretende RanGAP1 (von Ran GTPase Activating Protein1) steigert die GTPaseAktivität von Ran und beschleunigt die Hydrolyse des gebundenen GTP zu GDP (Bischoff et al., 1994; Cook et al., 2007; Corbett et al., 1995). Durch die Interaktion der

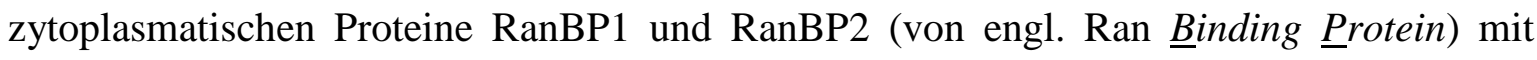
RanGTP wird die Aktivität von RanGAP1 noch einmal gesteigert (Bischoff and Görlich, 1997; Bischoff et al., 1995). So wird die Konzentration von RanGTP im Zytoplasma verringert, während sich die Konzentration von RanGDP erhöht. Den Gegenspieler zu den Proteinen RanGAP1, RanBP1 und RanBP2 bildet der Guanosinnukleotidaustauschfaktor RanGEF (von engl. Ran guanine nucleotide exchange factor), der Regulator für Chromosomenkondensation1 (regulator of chhromosome condensation 1, RCC1). Dieser Faktor befindet sich im Zellkern an die Histone H2A und H2B gebunden (Nemergut et al., 2001) und vermittelt den Austausch von Ran gebundenem GDP zu GTP (Bischoff and Ponstingl, 1991; Renault et al., 2001). Dazu wird das RanGDP durch den Transportfaktor NTF2 (von engl. nuclear transport factor2) in den Zellkern transportiert (ChaillanHuntington et al., 2000; Moore and Blobel, 1994; Ribbeck et al., 1998). Die asymmetrische Verteilung der Faktoren RanGAP1, RanBP (ausschließlich im Zytoplasma) und RanGEF (im Zellkern; Nemergut et al., 2001) erlaubt die Erschaffung und Erhaltung des RanGTP-Gradienten, der die treibende Kraft für den unidirektionalen Kerntransport durch $\beta$-Karyopherine darstellt. In Abbildung 6 ist der Ran-Zyklus während der Interphase des Zellzyklus schematisch dargestellt. Die kleine GTPase Ran spielt jedoch nicht nur eine zentrale Rolle bei den Kerntransportprozessen, sondern auch im Zellzyklus während der Mitose (Clarke and Zhang, 2008; Kalab and Heald, 2008; Yudin and Fainzilber, 2009). 


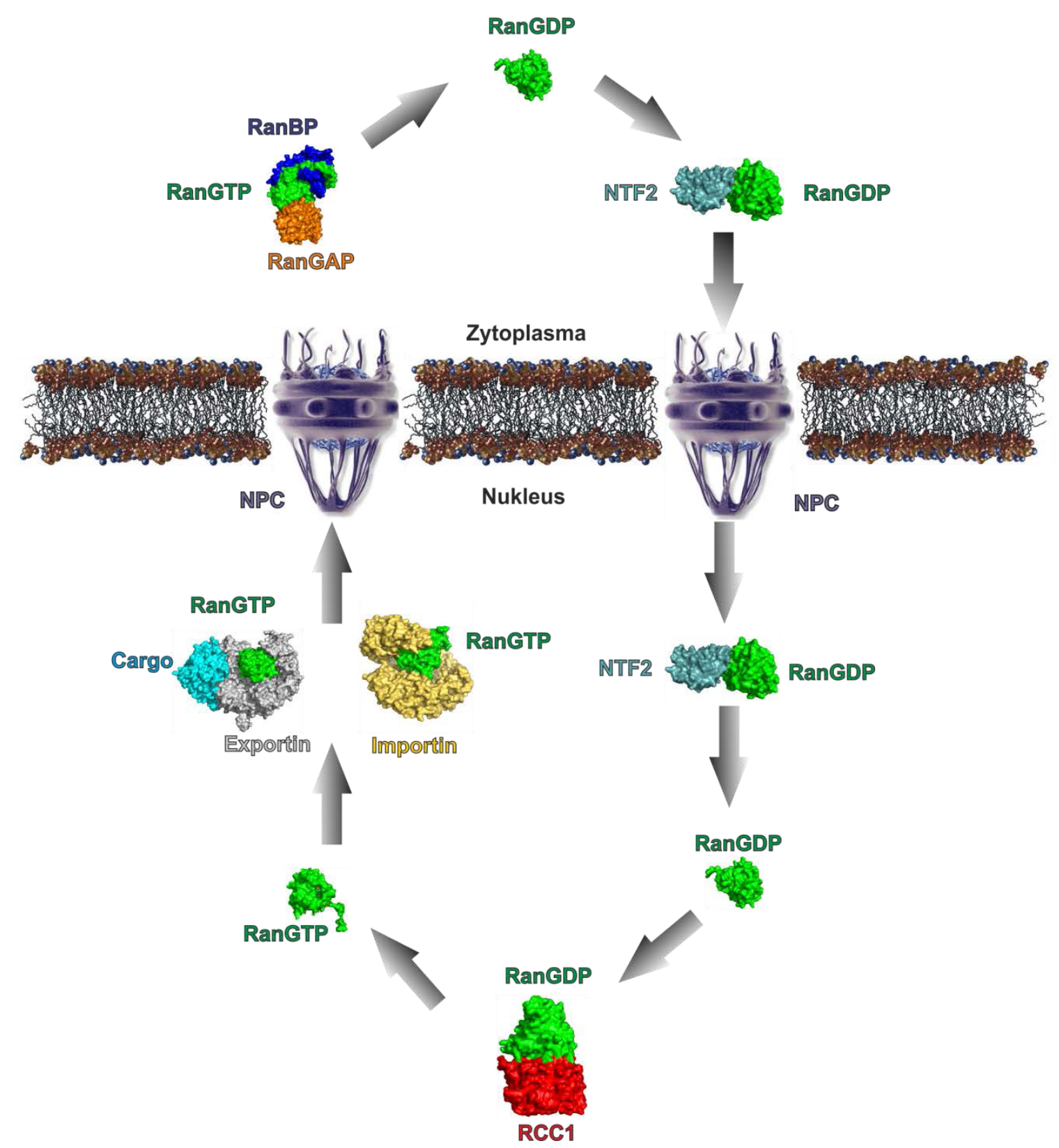

Abb. 6: Schematische Darstellung des Ran Zyklus. Mit Importin (gold) und Exportin (grau) gelangt die GTPase Ran (grün) in seinem GTP gebundenem (RanGTP) in das Zytoplasma. Interaktion mit GTPase aktivierenden Proteinen RanGAP1 (orange), RanBP1 und RanBP2 (RanBP, blau) führt zur GTP Hydrolyse durch Ran. Die RanGTP Konzentration sinkt während die RanGDP Konzentration steigt. Durch Interaktion mit NTF2 (ozeangrün) gelangt RanGDP in den Zellkern. Hier interagiert RanGDP mit RanGEF RCC1 (rot) und das GDP wird gegen GTP ausgetauscht. Ein RanGTP Gradient entsteht über die Kernhülle und wird durch diese Interaktionen aufrecht erhalten. Die verwendeten Komplexe und Einzelproteine stammen aus der RCSB Protein Datenbank, Exportin:Cargo:RanGTP Komplex PDB ID 3GJX, Importin:RanGTP PDB ID 1QGK, RanGTP:RanGAP1:RanBP Komplex PDB ID 1k5D, RanGDP PDB ID 3GJ0, NTF2:RanGDP Komplex PDB ID 1A2K, Rcc1:RanGDP Komplex PDB ID 1I2M, RanGTP PDB ID 1QBK. Das NPC Modell wurde aus http://sspatel.googlepages.com; (C) 2000-2006 Samir S. Patel entnommen. Für die Oberflächendarstellung der Proteine wurde Pymol verwendet 


\subsection{Der Zellzyklus}

Der Zellzyklus ist eine Abfolge von Prozessen in einer eukaryotischen Zelle, zwischen zwei Zellteilungen. Er teilt sich in zwei übergeordnete Phasen, die Mitose oder M-Phase und die Interphase, in der unteranderem der Kerntransport stattfindet (Campbell, N. und Reece, J 6.Auflage, 2003).

\subsubsection{Die Interphase des Zellzyklus}

Die Interphase ist die Zeit, welche zwischen dem Ende einer Mitose und dem Beginn einer Neuen besteht, in der die Zelle wächst und sich auf die nächste Zellteilung vorbereitet. Sie wird aus diesem Grund auch als Wachstumsphase bezeichnet und unterteilt sich wiederum in drei Abschnitte. Diese Abschnitte werden als $\mathrm{G}_{1}$-Phase ( $\mathrm{G}$ von gap), S-Phase und $\mathrm{G}_{2^{-}}$ Phase bezeichnet (Abb. 7). Die Zelle wächst, nimmt Nährstoffe auf und synthetisiert Protein, DNA und RNA und produziert Zellorganellen (Imoto et al., 2011).

Die $\mathrm{G}_{1}$-Phase ist der Zeitraum nach Beendigung der Zellteilung und vor Beginn der SPhase. Es kommt zur Synthese von Proteinen und RNA. Die DNA wird repariert und Zellorganellen ergänzt. DNA wird in dieser Phase nicht repliziert. Die Zelle wächst. In der S-Phase oder auch Synthesephase wird die DNA repliziert und neues Chromatin gebildet. Während der S-Phase wird die genetische Information verdoppelt. in der $G_{2}$-Phase, dem Abschnitt zwischen Ende der S-Phase und Beginn der M-Phase wächst die Zelle weiter, synthetisiert weitere RNA und Proteine, löst Zellkontakte zu Nachbarzellen und rundet sich ab. Die Vorbereitungen zur Zellteilung werden abgeschlossen (Campbell, N. and Reece, J., 2003, 6.Auflage).

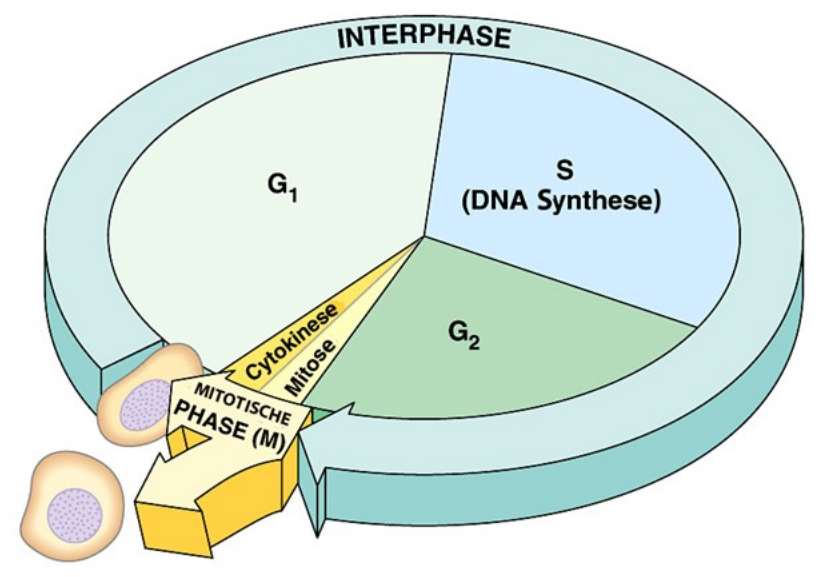

Abb. 7: Der Zellzyklus. Schematische Übersicht über den Zellzyklus. Der Zellzyklus teilt sich in eine Mitotische Phase (M-Phase) und eine Interphase, welche sich wiederum in $\mathrm{G}_{1}$-, S- und $\mathrm{G}_{2}$-Phase unterteilt wird. Die Mitotische Phase ist in die Mitose und die Zytokinese unterteilt (Campbell, N. and Reece, J., 2003, 6.Auflage). 


\subsubsection{Die Mitotische Phase des Zellzyklus}

Die mitotische Phase oder M-Phase ist die Phase der eigentlichen Zellteilung, unterteilt in Mitose und Zytokinese. Die Zytokinese ist der eigentliche Akt der Zellteilung, bei der das Zytoplasma der Zelle aufgeteilt wird (Abb. 7). Die Teilung der Zelle in zwei Tochterzellen erfolgt entlang eines Gebildes aus Actin und Myosin Filamenten. Diese bilden einen kontraktilen Ring in der äquatorialen Ebene der Zelle (Guertin et al., 2002; Nanninga, 2001). Auf der Zelloberfläche entsteht so eine Vertiefung, die Teilungsfurche. Die Kontraktion des Rings aus Actin und Myosin Filamenten führt zu einer Vertiefung der Teilungsfurche und schließlich zur Trennung in zwei Tochterzellen (Guertin et al., 2002; Pollard, 2010). Vor der Teilung der Zelle in zwei Tochterzellen steht die Kernteilung, die Mitose. Die Mitose ist der Prozess der Zellkernteilung. Dieser lässt sich in Stadien einteilen:

Prophase: Die erste Phase der Mitose. Die Zelle tritt aus der Interphase in die Prophase über. Das Chromatin kondensiert und wird in Form einzelner Chromosomen sichtbar. Die Nukleoli des Zellkerns lösen sich auf und verschwinden. Im Zytoplasma wandern die Zentrosomen (Mikrotubuli-Organisationszentrum) an entgegengesetzte Pole der Zelle und bilden den Spindelapparat (Mitosespindel, Spindelpol). Aus diesen wachsen bereits Mikrotubuli (Spindelfasern). Die Mikrotubuli des Zytoskeletts brechen aus einander und die Zelle rundet sich ab (Campbell, N. and Reece, J., 2003, 6.Auflage; Cooper GM. The Cell: A Molecular Approach, 2nd edition, 2000).

Promethaphase: Die zweite Phase der Mitose. Die Kernhülle zerfällt und die Spindelfasern wachsen in das Karyoplasma hinein. Am Zentromer der stärker kondensierten Chromosomen entsteht ein Proteinkomplex, ein Kinetochor (Clarke and Zhang, 2008). Einige der in das Karyoplasma wachsende Mikrotubuli treten in Kontakt mit dem Kinetochor am Zentromer der Chromosomen (Kinetochor-Mikrotubuli), andere Mikrotubuli treten mit den Mikrotubuli der Gegenseite in Wechselwirkung (PolMikrotubuli) (Campbell, N. and Reece, J., 2003, 6.Auflage; Cooper GM. The Cell: A Molecular Approach, 2nd edition, 2000).

Metaphase: Die dritte Phase der Mitose. Durch den Kontakt von Mikrotubuli der beiden Spindelapparate an die Kinetochor Struktur der Chromosomen werden diese in Bewegung versetzt. Die Chromosomen bewegen sich mal zu dem einen, dann wieder zu dem andern Spindelpol, bis sich die Chromosomen in der äquatorialen Ebene ausrichten (Campbell, N. and Reece, J., 2003, 6.Auflage; Cooper GM. The Cell: A Molecular Approach, 2nd edition, 2000). 
Anaphase: Die vierte Phase der Mitose. In dieser Phase kommt es zur Trennung der Chromosomen, welche sich in der äquatorialen Ebene der Zelle angeordnet haben, in die Chromatiden. Die Chromosomen werden durch die Mitosespindel von einander getrennt. Die Mitosespindel ist eine bipolare Struktur aus Mikrotubuli (Kinetochor-Mikrotubuli), welche dem Mikrotubuli-Organisationszentrum (Zentrosom, Spindelpol) entstammen und an das Zentromer der Chromosomen angeheftet sind. Die Trennung in die Chromatiden passiert simultan am Zentromer der Chromosomen, dabei verkürzen sich die KinetochorMikrotubuli. Durch die Verkürzung der Kinetochor-Mikrotubuli werden die Chromatiden zu den Spindelpolen der Zelle gezogen. Die Pole wandern zusätzlich weiter auseinander und gleichzeitig werden die Pol-Mikrotubuli länger. Die Anaphase gewährleistet, dass jede Tochterzelle einen identischen Satz an Chromosomen aufweist (Campbell, N. and Reece, J., 2003, 6.Auflage; Cooper GM. The Cell: A Molecular Approach, 2nd edition, 2000).

Telophase: Die fünfte Phase der Mitose. Sie beginnt ab dem Zeitpunkt, da die Chromosomen getrennt und zu den Spindelpolen gezogen wurden. Um die Pole entstehen aus den Fragmenten der zerfallenen Kernhülle und Teilen des inneren Membransystems neue Kernhüllen (Wandke and Kutay, 2013; Xue and Funabiki, 2014), die Chromosomen beginnen sich zu entwinden und die Spindelpole sich aufzulösen. Dies bildet eine Umkehr der Pro- und Promethaphase und markiert den Abschluss der Mitose. Im Anschluss an die Telophase erfolgt die Zytokinese (Campbell, N. und Reece, J, 6.Auflage; Cooper GM. The Cell: A Molecular Approach. 2nd edition. Sunderland (MA): Sinauer Associates; 2000. The Events of M Phase).

\subsubsection{Die GTPase Ran in der Mitose}

Zusätzlich zu seiner Funktion im Kerntransport während der Interphase des Zellzyklus, spielt die GTPase Ran eine wichtige Rolle während der Mitose. So ist sie am Aufbau der Mitosespindel, der Bildung von Kinetochor-Mikrotubuli, deren Verlängerung, sowie der Anlagerung der Mikrotubuli an das Kinetochor der Chromosomen und der Bildung der Kernhülle in der Telophase der Mitose beteiligt (Clarke and Zhang, 2008). Der Mechanismus, durch welchen die GTPase Ran seine Rolle in der Mitose ausübt ist derselbe wie im Kerntransport. Das Ran in seinem GTP gebundenem Zustand interagiert mit Karyopherinen der Importin $\beta$ Familie. Die Karyopherine agieren im Prozess der Mitose als Inhibitoren der Spindelfaktoren. Dies wird durch die Komplexbildung zwischen den Spindelfaktoren und den Karyopherinen erreicht. Durch die Interaktion zwischen RanGTP und $\beta$-Karyopherin werden Spindelfaktoren am Ort ihres Einsatzes freigegeben (Abb. 8). 
Treibende Kraft hinter den Aktionen des RanGTP in der Mitose ist der RanGTP-Gradient mit einer hohen Konzentration an RanGTP in der Umgebung der Chromosomen. Dieser bleibt auch während der Mitose, ohne Kernhülle erhalten. Erreicht wird dies durch die Lokalisation von RCC1 an den Chromosomen, sowie der Lokalisation von RanGAP1 im Zytoplasma. Das RanGTP, so fern gebunden an Kerntransportrezeptoren, ist jedoch vor der Aktivität von RanGAP1 geschützt. Für die Hydrolyse des GTP in den Transportkomplexen ist die Aktivität von RanBP1 oder RanPB2 notwendig (Askjaer et al., 1999; Floer and Blobel, 1996; Görlich et al., 1996; Koyama, 2010; Maurer et al., 2001). In Säugerzellen während der Mitose ist ein Teil des Proteins RanBP1 mit den Zentrosomen assoziiert (Guarguaglini et al., 2000; Kalab and Heald, 2008), während ein Teil des Proteins RanBP2 im Komplex mit SUMOyliertem RanGAP1 an Spindelmikrotubulie und Kinetochoren zu finden ist (Kalab und Heald, 2008; Clarke und Zhang, 2008). Der RanGTP-Gradient liefert dabei auch eine räumliche Information zum Aufbau der Mitosespindel. Die Komponenten die diesen Gradienten aufrechterhalten sind dieselben, welche auch für den Kerntransport verantwortlich sind.

A

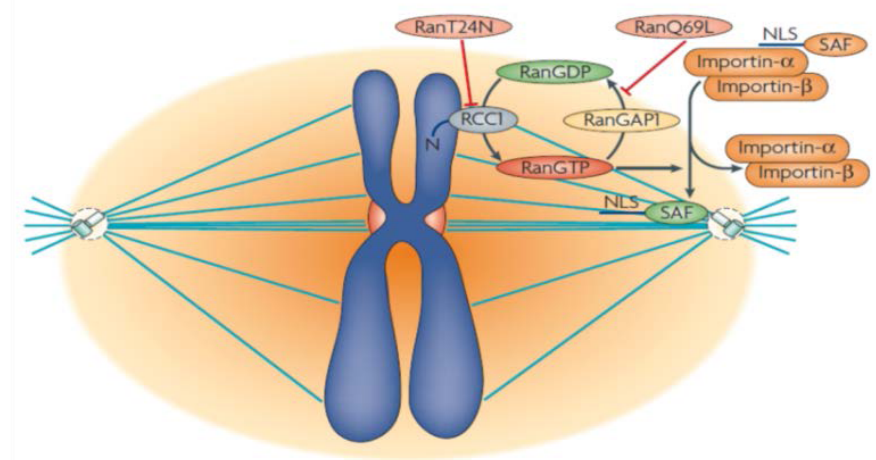

B

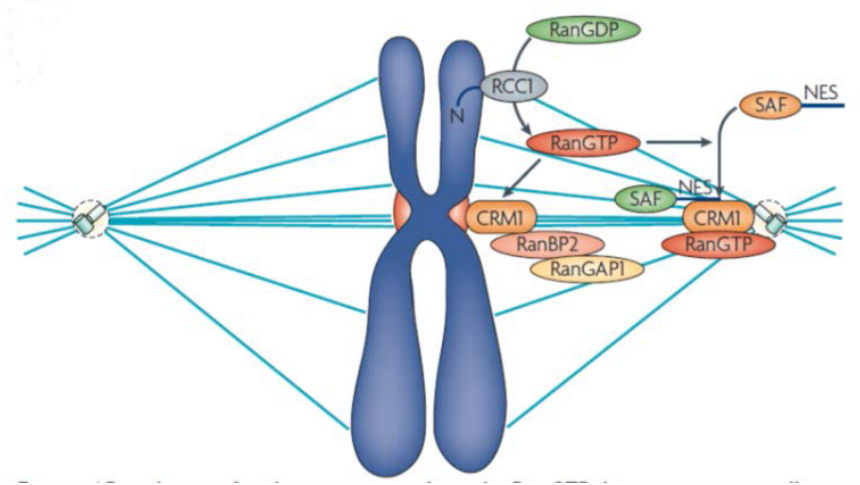

Abb. 8: Der RanGTP Gradient in der Mitose. Beide Teile der Abbildung sind Clarke und Zhang, 2008 entnommen. A) An den Chromosomen entsteht durch RCC1 RanGTP. Dies erzeugt einen wolkenähnlichen RanGTP Gradienten mit hoher Konzentration an RanGTP um die Chromosomen. Mit zunehmendem Abstand von den Chromosomen verringert sich die Konzentration an RanGTP durch GTP Hydrolyse ausgelöst durch RanGAP1. Das RanGTP um die Chromosomen bewirkt die Freisetzung von 
Spindelaufbaufaktoren (SAF) aus den inhibitorischen Komplexen mit Imporin $\alpha$ und Importin $\beta$. B) Zusätzlich zu der Rolle in der Freisetzung von SAFs aus inhibitorischen Komplexen mit Importinen, funktioniert RanGTP auch durch das Exportin Crm1, welches mit Kinetochoren interagiert und die GTPase Aktivierenden Proteine RanGAP1 und RanBP2 rekrutiert. Der RanGAP1:RanBP2 Komplex spielt eine Rolle in der Interaktion des Kinetochor mit Kinetochorfasern, die aus Mikrotubulibündeln bestehen, welche von den Zentrosomen zu dem Kinetochor erstrecken und wichtig in der Chromosomenteilung, während der Anaphase, sind. CRM1 könnte durch Wechselwirkungen mit dem NES dieser Proteine und anderer, die als aktive Komplexe zu den Zentrosomen einberufen werden, wo sowohl Ran, möglicherweise in seiner GTPgebundenen Form und CRM1 lokalisiert sind, funktionieren (Clarke und Zhang, 2008).

Das RanGTP hat eine weitere wichtige Funktion während des Wiederaufbaus der Kernhülle in der Telophase der Mitose. Das Ran an sich ist wesentlich für den Aufbau der Kernhülle um das Chromatin und das Einfügen von Nukleoporinen und des NPC in die sich zusammenfügende Kernhülle. Die Generierung des RanGTP Gradienten um das Chromatin liefert die räumliche Information zum Aufbau der Kernhülle (Clarke und Zhang, 2008). Bestimmte Nukleoporine und Membranproteine liegen im mitotischen Zytosol als Komplex gebunden an Transportrezeptoren in einem funktionsunfähigen Zustand vor. RanGTP veranlasst die Freisetzung der Nukleoporine, Membranproteine von den inhibitorischen Transportrezeptoren und hilft der räumlich begrenzten Formierung der NPCs und der Kernhülle an der Oberfläche des Chromatins (Clarke and Zhang, 2008; Wandke and Kutay, 2013).

Das RanGTP arbeitet in der Mitose, wie im Kerntransport als Regulator dieser Prozesse und operiert zusammen mit Kerntransportrezeptoren. Der RanGTP-Gradient sorgt für die Direktionalität im Kerntransport und liefert die räumliche Information zum Aufbau der Mitosespindel und der Kernhülle am Ende der Mitose.

\subsection{Lysinacetylierung im Kerntransport}

Im Jahr 2009 veröffentlichte eine Gruppe Wissenschaftler unter Prof. Dr. Matthias Mann (Choudhary et al., 2009) eine Arbeit, in welcher sie eine Proteomanalyse mittels hochauflösender Massenspektrometrie einiger Zelllinien durchführten. In dieser Arbeit konnten sie 1750 Proteine mit 3600 Lysin Acetylierungsstellen identifizieren. Unter diesen Proteinen sind 18 Faktoren des Kerntransportes zu finden, welche in Tabelle 1 aufgeführt sind. Die Acetylierung von Lysinseitenketten in Faktoren des Kerntransport war bis zu diesem Zeitpunkt nicht bekannt. 


\begin{tabular}{|c|c|c|}
\hline Kerntransportfaktor & $\begin{array}{l}\text { Anzahl an } \\
\text { Acetylierungsstellen }\end{array}$ & Acetylierte Lysine \\
\hline Exportin-1(Crm1; Xpo1) & 4 & K446, K455, K686, K693 \\
\hline Nucleoprotein TPR & 10 & $\begin{array}{l}\text { K252, К315, К312, K345, K428, } \\
\text { K457, K713, K723, K748, K755 }\end{array}$ \\
\hline $\begin{array}{l}\text { E3 SUMO-protein ligase } \quad \text { RanBP2 } \\
\text { (RanBP2; Nup358) }\end{array}$ & 1 & K115 \\
\hline $\begin{array}{l}\text { GTP-binding nuclear protein Ran } \\
\text { (RanGTP) }\end{array}$ & 6 & K37, К38, К60, K71, К99, K159 \\
\hline Nuclear pore complex protein Nup98 & 1 & K586 \\
\hline Importin subunit beta-1; KPNB1;NTF97 & 4 & K867, K835, K211, K871 \\
\hline Exportin-2(CSE1L;CAS;XPO2) & 3 & K574, K824, K158 \\
\hline Exportin-T;tRNAexportin(XPOT) & 2 & K635, K628 \\
\hline Exportin-5;Ran-binding protein 21 & 1 & K396 \\
\hline Nucleoporin 50 kDa (Nup50) & 3 & K83, K275, K276 \\
\hline Nucleoporin NUP188 homolog & 1 & K38 \\
\hline Nuclear pore complex protein Nup153 & 4 & K384, K954, K718, K1120 \\
\hline $\begin{array}{l}\text { Ran GTPase-activating protein } 1 \\
\text { (RANGAP1) }\end{array}$ & 2 & K524, K528 \\
\hline Ran-binding protein 9 (RanBP9) & 1 & K405 \\
\hline Ran-binding protein 1 (RanBP1) & 2 & K183, K150 \\
\hline Ran-binding protein 3 (RanBP3) & 2 & K21, K23 \\
\hline $\begin{array}{l}\text { Nuclear envelope pore membrane protein } \\
\text { POM } 121\end{array}$ & 1 & K714 \\
\hline $\begin{array}{l}\text { Nuclear pore complex protein Nup205 } \\
\text { (Nup205) }\end{array}$ & 2 & K41, K44 \\
\hline $\begin{array}{l}\text { Nuclear pore complex protein Nup214 } \\
\text { (Nup214) }\end{array}$ & 1 & K143 \\
\hline
\end{tabular}

Unter den 18 identifizierten Kerntransportfaktoren befindet sich die kleine GTPase Ran. Aus Tabelle 1 geht hervor, das diese 6 Stellen aufweist an denen eine Acetylierung stattfindet. Die Abbildung 9 zeigt ein Cartoon-Modell von GDP gebundenem Ran zusammen mit einer Balkendarstellung der GTPase in voller Länge. Die Acetylierungsstellen sind farblich und durch Balldarstellung der Lysine in der Abbildung 9 hervorgehoben. In beiden Darstellungsformen ist $\mathrm{zu}$ erkennen, das drei der Acetylierungsstellen innerhalb der variablen Regionen des Moleküls liegen und die 
restlichen drei Stellen zwischen diesen Regionen. Dabei ist zu erkennen, das diese drei (K60, 99 und 159) jeweils in einem Sekundär Strukturelement (K60 in einem $\beta$-Faltblatt und K99 und 159 in einer $\alpha$-Helix) zu finden sind.
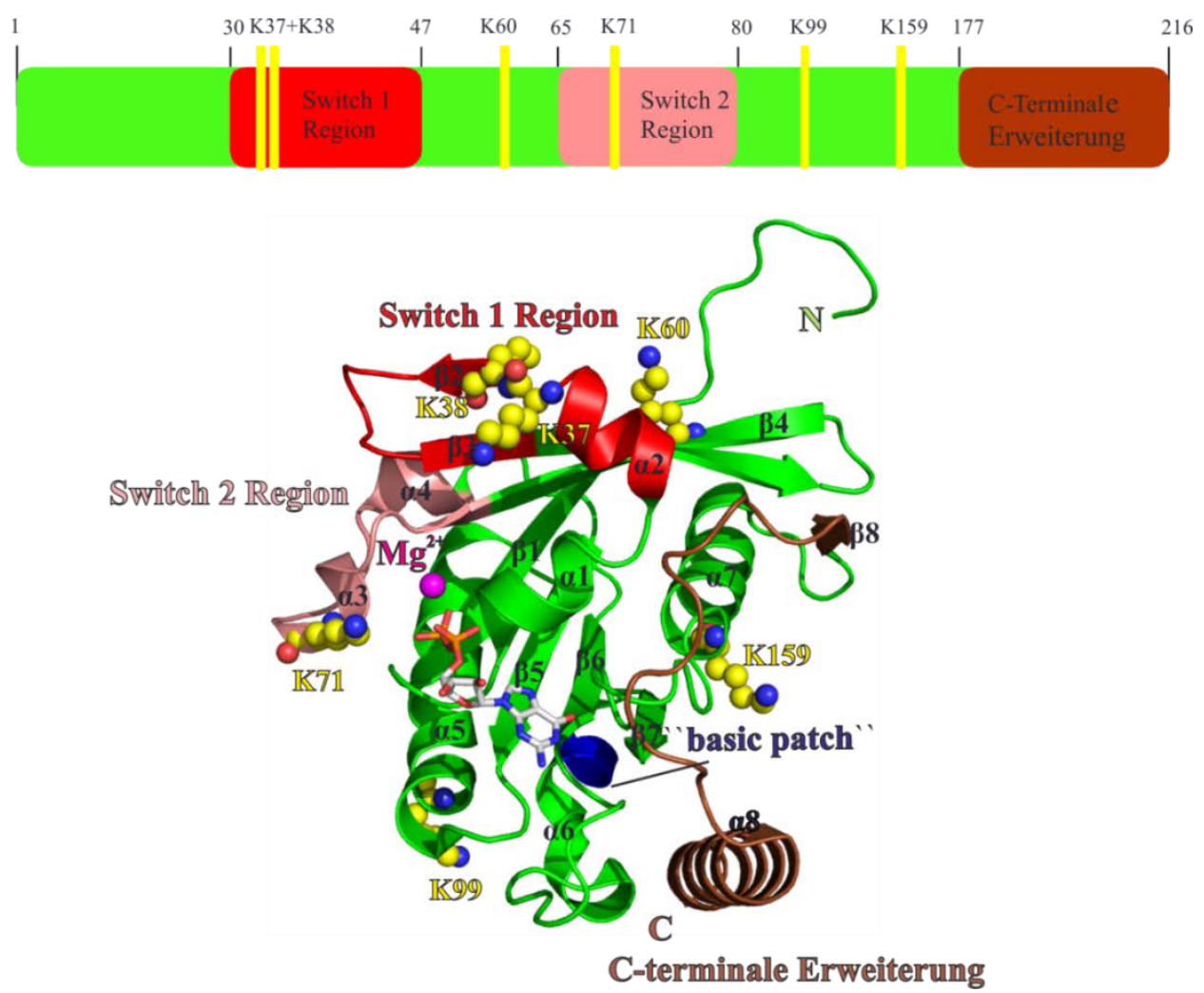

Abb. 9: Kristallstruktur von h.s RanGDP und Balkendarstellung der GTPase in voller Länge mit acetylierbaren Lysinen . Die Kristallstruktur (PDB ID 3GJ0) ist als Cartoon-Modell dargestellt. Die Kristallstruktur, sowie die Balkendarstellung sind grün eingefärbt und die Regionen farblich markiert, mit der Switch 1 Region rot, der Switch 2 Region pink und der C-terminalen Erweiterung in braun. Der basische Bereich ist in der Kristallstruktur blau gefärbt, das Magnesium als Sphere in Magenta gezeigt. Die Sekundärstrukturelemente sind nummeriert und mit $\alpha$ für eine $\alpha$-Helix und $\beta$ für ein $\beta$-Faltblatt bezeichnet. Die Lysine die in Choudhary et al. acetyliert werden sind als Bälle dargestellt mit dem Kohlenstoffatom in gelb und dem Stickstoffatom in blau. Das GDP ist als Stabmodell gezeigt, dabei sind die Kohlenstoffatome grau, Stickstoffatome blau, Sauerstoffatome rot und Phosphatatome orange gefärbt (Pymol).

\subsubsection{Posttranslationale Acetylierung der Aminosäure Lysin}

Die Regulation von zellulären Prozessen, wie dem Kerntransport oder der Mitose, geschieht durch regulatorische Proteine. Die kleine GTPase Ran, mit ihrer GTP gebundenem aktiven und GDP gebundenen inaktiven Form, kann als ein regulatorisches Protein bezeichnet werden. Ein Weg zur Regulation von Proteinen besteht in deren Modifikation durch andere Proteine (z.B. Sumo-Protein oder Ubiquitin), Zucker (Glykosylierung), Methyl-Gruppen oder auch Acetyl-Gruppen. 
Die Modifikation von Proteinen durch Acetylierung an Lysinseitenketten ist eine lange bekannte dynamische, reversible und hoch regulierte chemische Modifikation und zu finden in allen Bereichen des Lebendigen (Choudhary et al., 2009; Cohen and Yao, 2004). Die Acetylierung einer Lysinseitenkette wird durch eine Lysine-Acetyltransferase (KAT) katalysiert. Dabei verwenden diese Acetyl-Coenzym A (Acetyl-CoA) zum Übertragen der Acetylgruppe des Acetyl-CoA auf die $\varepsilon$-Aminogruppe der Lysinseitenkette (Abb. 10). Die Umkehrreaktion, die Deacetylierung einer acetylierten Lysinseitenkette wird durch Deacetylasen (HDAC) katalysiert. Für die Reaktion der Deacetylierung verwenden Deacetylasen $\mathrm{H}_{2} \mathrm{O}$ und hydrolysieren die Bindung der Acetylgruppe an der Aminogruppe der Lysinseitenkette. Bei dieser Reaktion entsteht Acetat als Reaktionsprodukt (Abb. 10). Eine Klasse der Deacetylasen, die Sirtuine verwenden $\mathrm{NAD}^{+}$als Cofaktor für die Reaktion und übertragen das frei werdende Acetat auf ADP-Ribose (Sadoul et al., 2011).
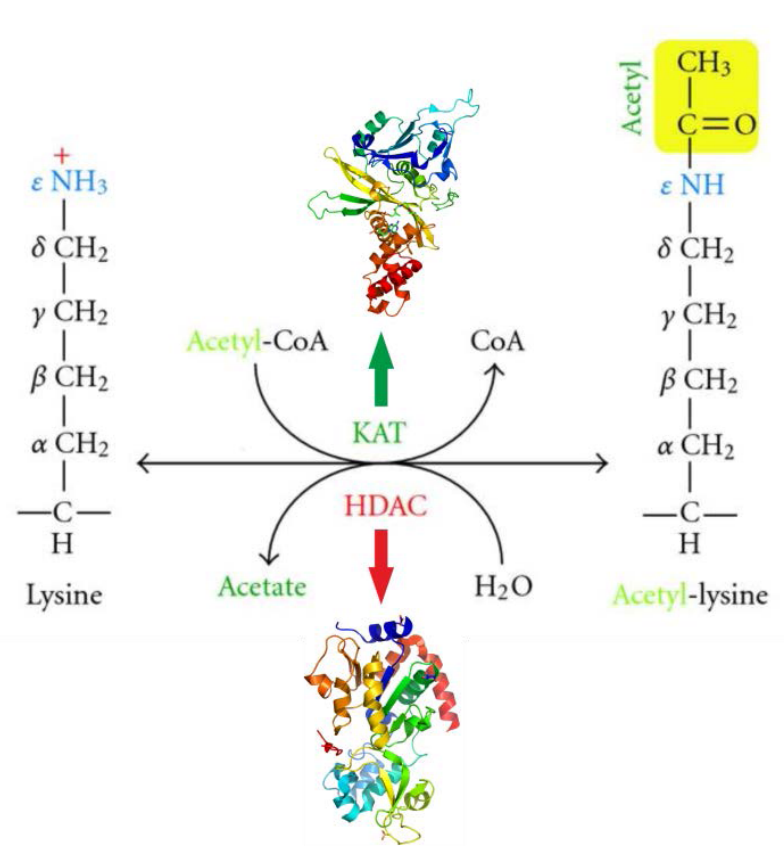

Abb. 10: Schematische Darstellung des Mechanismus zur Übertragung einer Acetylgruppe auf eine Lysinseitenkette. Cartoon Darstellung der Acetylierung und Deacetylierung von Lysinresten. Eine KAT überträgt die AcetylGruppe (gelb) vom Acetyl-CoA auf das Lysin, Deacetylasen hingen entfernen den Acetylrest vom Lysin. Die Klasse der Sirtuine (HDAC) verwendet $\mathrm{NAD}^{+}$für die Hydrolyse der Bindung zwischen der Acetylgruppe und der Aminogruppe, der Rest der Deacetylasen verwendet $\mathrm{H}_{2} \mathrm{O}$. Bei dieser Reaktion entsteht Acetat als Reaktionsprodukt. Sirtuine Übertragen dieses Acetat bei der Deacetylierung auf ADP-Ribose. Die Darstellung entstammt Kim et al., 2010. KAT PDB ID 2P0W, HDAC PDB ID 3GLR, beide sind als Cartoon-Modell dargestellt und in Regenbogen eingefärbt.

Die Acetylierung einer Lysinseitenkette kann mehrere Auswirkungen auf das zu acetylierende Lysin ausüben. Diese kann zu einer Neutralisierung der basischen Ladung des Lysins führen und die Aminosäure vergrößern, was zu einer Änderung der Proteinstruktur und/oder Protein-Protein Interaktion führen kann (Kamieniarz and Schneider, 2009). Die Modifizierung über eine Acetylgruppe kann einen Einfluss auf die Enzymaktivität eines Proteins haben, da die Acetylierung eines Lysins eine leicht andere 
Präferenz für Sekundärstrukturen zeigt als nicht aceyliertes Lysin. Desweitern kann die Acetylierung als Signatur für die Rekrutierung von Proteinen (welche spezifisch das acetylierte Protein erkennen) dienen, sowie neue Bindungsstellen für Protein-Protein Interaktionen ermöglichen (Kamieniarz and Schneider, 2009; Spange et al., 2009).

Eine Acetylierung beeinflusst viele Funktionen von Proteinen, wie deren enzymatische Aktivität, Proteinstabilität, DNA-Bindung, Protein-Protein Interaktion, sowie die Lokalisation von Proteinen. Acetylierte Proteine sind somit Bestandteil vieler zellulärer Prozesse. So beeinflusst die Acetylierung von Lysinresten in Proteinen Prozesse des Zellzyklus, die Regulation der Signal Transduktion, der Regulation und Neugestaltung des Zytoskelettes, sowie der Transkription und Translation. Acetylierte Proteine spielen außerdem eine Rolle bei der Qualitätskontrolle und Reinigung der Zelle von fehlgefalteten, aggregierten oder nicht mehr verwendeten Proteinen. Weiter ist diese Modifikation in der Autophagy und Apoptose zu finden, sowie in Transportprozessen der Zelle (Kamieniarz and Schneider, 2009; Sadoul et al., 2011; Spange et al., 2009). Solche Transportprozesse sind aufgeteilt in zytoplasmatischen Transport über das ER und das Golgi Netzwerk und dem Transport von Makromolekülen über die Kernhülle dem Kerntransport. Die Acetylierung von Lysinresten in Proteinen dient als wichtiges regulatorisches Signal dieser zellulären Prozesse. Obwohl die Rolle der Acetylierung in Histonmodifikationen, besonders Chromatin Remodeling, schon länger bekannt ist, ist über die Acetylierung von Nicht-Histone-Proteinen bislang wenige bekannt.

\subsection{Zielsetzung}

Ziel dieser Arbeit war die strukturelle sowie funktionale Analyse der Acetylierung von Lysinseitenketten der kleinen GTPase Ran. Die Acetylierung dieser kleinen GTPase kann in eine Vielzahl von zellulären Prozessen eingreifen, angefangen vom Kerntransport in der Interphase des Zellzyklus, der Organisation und Aufbau der Mitosspindel, sowie der Verlängerung der Spindelmikrotubuli und deren Anlagerung an die Kinetochore, bis hin zum Neuaufbau der Kernhülle am Ende der Mitose. Die Acetylierung von Lysinresten der kleinen GTPase könnte eine unerwartete regulatorische Ebene für den Kerntransport, sowie die Mitose darstellen. Da die Interaktion der GTPase Ran mit dem Transportrezeptoren ein zentrales Thema im Kerntransport und der Mitose darstellt, liegt der Schwerpunkt dieser Arbeit auf der strukturellen Analyse der Komplexe aus acetyliertem RanGTP mit Crm1 und dem Cargo SPN1, sowie der funktionalen Analyse mit $\operatorname{Imp} \beta$, Crm1 und Imp7. Durch die Struktur des Komplexes aus Crm1:SPN1 und 
acetyliertem RanGTP lässt dieser sich mit der Struktur des bereits gelösten Exportkomplexes Crm1:SPN1:RanGTP, mit Fokus auf die Bindung des RanGTP zum Crm1 vergleichen und Rückschlüsse auf den strukturellen Einfluss einer Acetylierung an bestimmten Stellen der GTPase auf dessen Interaktion zum Crm1 ziehen. Während biochemische Experimente Rückschlüsse auf den funktionalen Einfluss einer Acetylierung der GTPase im Hinblick auf den Kerntransport und der Mitose ermöglichen. 


\section{Material und Methoden}

\subsection{Material}

\subsubsection{Feinchemikalien}

Alle Feinchemikalien und organischen Substanzen werden von den Firmen AppliChem (Darmstadt), BioRad (München), Fluka (Buchs), Merck (Darmstadt), Mettler-Toledo (Steinbach), MWG Biotech (München), Oxoid (Basingstoke, GB), Roth (Karlsruhe), Sigma-Aldrich (Steinheim) oder Bachem (bezogen und besitzen den Reinheitsgrad pro analysis. Dabei wird in der Regel der günstigste Anbieter gewählt.

2.1.2 Geräte

\begin{tabular}{|l|l|}
\hline Äkta Prime & GE Healthcare, Freiburg \\
\hline Äkta Purifier & GE Healthcare, Freiburg \\
\hline Agarose-Gelelektophoresekammer & BioRad, München \\
\hline Binokulare & Leica Mikrosysteme, Wetzlar \\
\hline Brutschrank Mytron & Schütt, Göttingen \\
\hline Fraktionssammler Frac900 & GE Healthcare, Freiburg \\
\hline Feinwaagen & Sartorius, Göttingen \\
\hline FluoroMax-3 Spektrofluorometer & Horiba Scientific, Unterhachingen \\
\hline GelDoc Geldokumentationsgerät & BioRad, München \\
\hline Gelschüttler Promax 1020 & Heidolph, Schwabach \\
\hline Heizbad & IKA, Staufen \\
\hline Heizblock Dri-Block CB-2A & Techne, Minneapolis, USA \\
\hline Innova 4230 Schüttelinkubator & New Brunswick Scientific, Nürtingen \\
\hline Magnetrührer IKAMAG REO & IKA, Staufen \\
\hline Microfluidizer 110 S & Microfluidics, USA \\
\hline Optimax X-Ray Film Processor & Protec, Oberstenfeld \\
\hline PCR-Thermocycler & Biometra, Göttingen \\
\hline PCR-Mastercycler gradient & Eppendorf, Hamburg \\
\hline pH-Meter & Hanna Instruments, Kehl am Rhein \\
\hline
\end{tabular}




\begin{tabular}{|c|c|}
\hline Photometer & Eppendorf, Hamburg \\
\hline Pipettierhilfe Accu-Jet & Brand, Wertheim \\
\hline Rotationsschüttler & Karl Hecht, Staufen \\
\hline Rotor JA-20 / JA-30.50 Ti & Beckman Coulter, Krefeld \\
\hline Rotor JLA 8.1000 & Beckman Coulter, Krefeld \\
\hline Röntgendiffraktometer RU-H3R & Rigaku, Japan \\
\hline Röntgendiffraktometer 007 & Rigaku, Japan \\
\hline $\begin{array}{l}\text { SDS-Elektrophoresekammer Hoefer } \\
\text { miniVE }\end{array}$ & GE Healthcare, Freiburg \\
\hline $\begin{array}{l}\text { Semidry Blotkammer (PerfectBlue Semi- } \\
\text { Dry Elektroblotter) }\end{array}$ & PeqLab, Erlangen \\
\hline Superloops (50 ml, $150 \mathrm{ml})$ & GE Healthcare, Freiburg \\
\hline Sonifier 250 & Branson, USA \\
\hline Taumelrollenmischer RM5 & Schütt, Göttingen \\
\hline Thermomixer comfort & Eppendorf, Hamburg \\
\hline Tischzentrifuge $5417 \mathrm{R}$ & Eppendorf, Hamburg \\
\hline Tischzentrifuge Micro centrifuge II & Sylvania, Ohio, USA \\
\hline Unitron Schüttelinkubatoren & Infors, Einsbach \\
\hline Vakuumkonzentrator 5301 & Eppendorf, Hamburg \\
\hline Vortexer & Schütt, Göttingen \\
\hline Zentrifuge Allegra 21R & Beckman Coulter, Krefeld \\
\hline Zentrifuge Avanti J-20 XPIJA-20 & Beckman Coulter, Krefeld \\
\hline Zentrifuge Avanti J-30 I & Beckman Coulter, Krefeld \\
\hline Zentrifuge Avanti JA-20 & Beckman Coulter, Krefeld \\
\hline
\end{tabular}

\subsubsection{Chromatographiesäulen}

\begin{tabular}{|l|l|}
\hline GST4B/Protino & Machery Nagel, Düren \\
\hline GSTrap FF 5ml & GE Healthcare, Freiburg \\
\hline HiTrapChelating Ni-NTA-Sepharose $5 \mathrm{ml}$ & GE Healthcare, Freiburg \\
\hline
\end{tabular}




\begin{tabular}{|l|l|}
\hline Heparin Sepharose 6 Fast Flow, & GE Healthcare, Freiburg \\
\hline NUCLEOSIL 4000-7 PEI & Machery Nagel, Düren \\
\hline HiPrep 26/10 Desalting & GE Healthcare, Freiburg \\
\hline Superdex200 & GE Healthcare, Freiburg \\
\hline Superdex75 & GE Healthcare, Freiburg \\
\hline Superdex 200 10/300 GL & GE Healthcare, Freiburg \\
\hline Source 30 Q & GE Healthcare, Freiburg \\
\hline XK 16/60 Leer Säule & GE Healthcare, Freiburg \\
\hline XK 26/60 Leer Säule & GE Healthcare, Freiburg \\
\hline
\end{tabular}

\subsubsection{Kit-Systeme}

\begin{tabular}{|l|l|}
\hline $\begin{array}{l}\text { Amersham ECL Prime Western Blotting } \\
\text { Detection Reagent }\end{array}$ & GE Healthcare, Freiburg \\
\hline NucleoSpin Plasmid & Macherey-Nagel, Düren \\
\hline NucleoBond 100 (Midiprep) & Macherey-Nagel, Düren \\
\hline QIAquick Gelextraktionskit & QIAGEN, Hilden \\
\hline QIAquick PCR Reinigungskit & QIAGEN, Hilden \\
\hline QIAGEN Plasmid Mini Kit & QIAGEN, Hilden \\
\hline peqGOLD MicroSpin Cycle-Pure Kit & PeqLab, Erlangen \\
\hline peqGOLD Plasmid Miniprep Kit I & PeqLab, Erlangen \\
\hline
\end{tabular}

\subsubsection{Organismen}

Folgende Escherichia coli Zellstämme wurden benutzt:

\begin{tabular}{|l|}
\hline E. coli BL21(DE3) \\
\hline E. coli BL21(DE3) RIL \\
\hline E. coli BL21(DE3) RP \\
\hline E. coli Rosetta 2 \\
\hline E. coli TG I \\
\hline E. coli M15 (pREP4) \\
\hline E. coli JM109 \\
\hline E. coli SG13009 (pREP4)
\end{tabular}

Stammsammlung der AG Ficner 
E. coli XL10-Gold

E. coli XL1-Blue

\subsubsection{Größenstandards}

\begin{tabular}{|l|l|}
\hline Protein Molecular Weight Marker & Fermentas, St. Leon-Rot \\
\hline PageRuler Prestained Protein Ladder & Thermo Scientific, Rockford \\
\hline PageRuler Unstained Protein Ladder & Thermo Scientific, Rockford \\
\hline DNA-Standard „1kb-ladder” & New England Biolabs, Frankfurt \\
\hline
\end{tabular}

\subsubsection{Enzyme und Inhibitoren}

\begin{tabular}{|l|l|}
\hline BamHI & Fermentas, St. Leon-Rot \\
\hline HindIII & Fermentas, St. Leon-Rot \\
\hline NdeI & Fermentas, St. Leon-Rot \\
\hline XhoI & Fermentas, St. Leon-Rot \\
\hline T4-DNA-Ligase & Fermentas, St. Leon-Rot \\
\hline Thermus aquaticus-Polymerase & Universität Göttingen \\
\hline Pyrococcus furiosus-DNA-Polymerase & New England Biolabs, Frankfurt \\
\hline Phusion-DNA-Polymerase & Finnzymes, Finnland \\
\hline PreScission-Protease & Universität Göttingen \\
\hline Calf Intestine Alkaline Phosphatase (CIAP) & New England Biolabs, Frankfurt \\
\hline Aprotinin & Roth, Karlsruhe \\
\hline Leupeptin & Roth, Karlsruhe \\
\hline Pepstatin & Roth, Karlsruhe \\
\hline PMSF & Roth, Karlsruhe \\
\hline
\end{tabular}

\subsubsection{Plasmide und Vektoren}

\begin{tabular}{|l|l|}
\hline pQE-80-Imp7 & Prof. Dr. D. Doenecke, Göttingen \\
\hline pQE-32-Transportin & $\begin{array}{l}\text { Prof. Dr. R. Kehlenbach, Universität } \\
\text { Göttingen }\end{array}$ \\
\hline pQe-60- Importin $\beta$ & Dr. Achim Dickmanns, Universität Göttingen \\
\hline pQE- -RanQ69L ${ }^{1-180}$ (h.s.) & Dr. D. Görlich \\
\hline pCDF Duet-PylT Ran (h.s.) & Dr. Heinz Neumann, Universität Göttingen \\
\hline
\end{tabular}




\begin{tabular}{|c|c|}
\hline pCDF Duet-PylT RanQ69L ${ }^{1-180}$ & \\
\hline pCDF Duet-PylT RanQ69L ${ }^{1-180}$ K37TAG & \\
\hline pCDF Duet-PylT RanQ69L ${ }^{1-180}$ K38TAG & \\
\hline pCDF Duet-PylT RanQ69L ${ }^{1-180}$ K60TAG & \\
\hline pCDF Duet-PylT RanQ69L ${ }^{1-180}$ K71TAG & \\
\hline pCDF Duet-PylT RanQ69L ${ }^{1-180}$ K99TAG & \\
\hline pCDF Duet-PylT RanQ69L ${ }^{1-180}$ K159TAG & \\
\hline pCDF Duet-PylTRan $_{\mathrm{fl}} \mathrm{K} 37 \mathrm{TAG}$ & \\
\hline pCDF Duet-PylTRan $_{\mathrm{fl}} \mathrm{K} 38 \mathrm{TAG}$ & \\
\hline pCDF Duet-PylTRan $_{\mathrm{fl}} \mathrm{K} 60 \mathrm{TAG}$ & \\
\hline pCDF Duet-PylTRan ${ }_{\mathrm{fl}}$ K71TAG & \\
\hline pCDF Duet-PylTRan $_{\mathrm{fl}}$ K99TAG & \\
\hline pCDF Duet-PylTRan ${ }_{\mathrm{fl}}$ K159TAG & \\
\hline $\begin{array}{l}\text { pCDF Duet-PylT-GST- } \text { RanQ69L }^{1-} \\
{ }^{180} \text { K37TAG }\end{array}$ & \\
\hline $\begin{array}{l}\text { pCDF } \quad \text { Duet-PylT-GST- } \\
{ }^{180} \text { KanQ67AG }\end{array}$ & \\
\hline $\begin{array}{l}\text { pCDF Duet-PylT-GST- } \text { RanQ69L }^{1-} \\
{ }^{180} \text { K60TAG }\end{array}$ & \\
\hline $\begin{array}{l}\text { pCDF Duet-PylT-GST- } \text { RanQ69L }^{1-} \\
{ }^{180} \text { K71TAG }\end{array}$ & \\
\hline $\begin{array}{l}\text { pCDF Duet-PylT-GST- } \text { RanQ69L }^{1-} \\
{ }^{180} \text { K99TAG }\end{array}$ & \\
\hline $\begin{array}{l}\text { pCDF Duet-PylT-GST- } \text { RanQ69L }^{1-} \\
{ }^{180} \text { K159TAG }\end{array}$ & \\
\hline
\end{tabular}

\subsubsection{DNA-Oligonukleotide}

Die DNA-Oligonukleotide wurden HPSF gereinigt von MWG-Biotech (München) bezogen und gemäß den Herstellerangaben gelöst und eingesetzt.

Die Berechnung der Schmelztemperaturen $\mathrm{T}_{\mathrm{m}}$ für die verwendeten DNA-Oligonukleotide erfolgte nach der unten angegebenen Formel.

$\mathrm{T}_{\mathrm{m}}=81,5+0,41(\% \mathrm{GC})-(675 / \mathrm{N})$

mit $\mathrm{N}=$ Anzahl der Nukleotide 


\begin{tabular}{|c|c|}
\hline $\begin{array}{l}\text { pGEXforward: } \\
\text { 5'-GCTGGCAAGCCACGTTTGGT-3' }\end{array}$ & $\begin{array}{l}\text { MWG-Biotech, } \\
\text { Ebersberg }\end{array}$ \\
\hline $\begin{array}{l}\text { pGEXreverse: } \\
\text { 5'-CGTCTCCGGGAGCTGCATGT-3' }\end{array}$ & $\begin{array}{l}\text { MWG-Biotech, } \\
\text { Ebersberg }\end{array}$ \\
\hline $\begin{array}{l}\text { pQEforward: } \\
\text { 5'-CGGATAACAATTTCACACAG-3' }\end{array}$ & QIAGEN, Hilden \\
\hline $\begin{array}{l}\text { pQEreverse: } \\
\text { 5'-GTTCTGAGGTCATTACTGG-3' }\end{array}$ & QIAGEN, Hilden \\
\hline $\begin{array}{l}\text { RanK58TAGf } \\
\text { 5'-CTGGTGAATTTGAGTAGAAGTATGTAGCCACCTTG-3' }\end{array}$ & \\
\hline $\begin{array}{l}\text { RanK58TAGr } \\
\text { 5'-GCTACATACTTCTACTCAAATTCACCAGTCAAATG-3' }\end{array}$ & \\
\hline $\begin{array}{l}\text { RanK59TAGf } \\
\text { 5'-TGAATTTGAGAAGTAGTATGTAGCCACCTTGGGTG-3' }\end{array}$ & \\
\hline $\begin{array}{l}\text { RanK59TAGr } \\
\text { 5'-GCTACATACTACTTCTCAAATTCACCAGTCAAATG-3' }\end{array}$ & \\
\hline $\begin{array}{l}\text { RanK80TAGf } \\
\text { 5'-CAGAGGACCTATTTAGTTCAATGTATGGGACACAG-3' }\end{array}$ & \\
\hline $\begin{array}{l}\text { RanK80TAGr } \\
\text { 5'-CATACATTGAACTAAATAGGTCCTCTGTTGGTGTG-3' }\end{array}$ & \\
\hline $\begin{array}{l}\text { RanK91TAGf } \\
\text { 5'-AGCCGGCCAGGAGTAGGTCGGTGGACTGAGAGATG-3' }\end{array}$ & \\
\hline $\begin{array}{l}\text { RanK91TAGr } \\
\text { 5'-CCACCGAACTACTCCTGGCCGGCTGTGTCCCATAC-3' }\end{array}$ & \\
\hline $\begin{array}{l}\text { RanK119TAGf } \\
\text { 5'-AGAGTTACTTACTAGAATGTGCCTAACTGGCATAG-3' }\end{array}$ & \\
\hline $\begin{array}{l}\text { RanK119TAGr } \\
\text { 5'-TTAGGCACATTCTAGTAAGTAACTCTCGATGTTAC-3' }\end{array}$ & \\
\hline $\begin{array}{l}\text { RanK179TAGf } \\
\text { 5'-TACAACTTTGAATAGCCCTTCCTCTGGCTTGCTAG-3' }\end{array}$ & \\
\hline $\begin{array}{l}\text { RanK179TAGr } \\
\text { 5'-AGAGGAAGGGCTATTCAAAGTTGTAGTTACTTTTG-3' }\end{array}$ & \\
\hline
\end{tabular}




\begin{tabular}{|l|l|}
\hline RanBamTEVf & \\
5'CCAGGATCCAGAAAACCTGTACTTCCAAGGTATGACTGC & \\
\hline $\begin{array}{l}\text { Ran180Xhor } \\
\text { 5'-AGACTCGAGTCAAGGCATGGCAACAAATTC-3' }\end{array}$ & \\
\hline $\begin{array}{l}\text { RanQ69L71TAGf } \\
\text { 5'-GACACAGCCGGCTTAGAGTAGTTCGGTGGACTGAG-3' }\end{array}$ & \\
\hline $\begin{array}{l}\text { RanQ69L71TAGr } \\
\text { 5'-CGAACTACTCTAAGCCGGCTGTGTCCCATACATTG-3' }\end{array}$ & \\
\hline RanQ69Lf & \\
\hline 5'-GACACAGCCGCCTTAGAGAAATTCGGTGGACTGAG-3' & \\
\hline $\begin{array}{l}\text { RanQ69Lr } \\
\text { 5'-CGAATTTCTCTAAGCCGGCTGTGTCCCATACATTG-3' }\end{array}$ & \\
\hline
\end{tabular}

\subsubsection{Sonstige Materialien}

24 Well Kristallisationsschalen sitting drop

Amersham Hyperfilm ECL

Crystal Clear Tape

Glasgeräte

Parafilm

Pipetten (verstellbar), Dispensor

Pipettenspitzen

Reaktionsgefäße $(0.5 \mathrm{ml}, 1.5 \mathrm{ml}, 2.0 \mathrm{ml})$

Reaktionsgefäße (15 ml, $50 \mathrm{ml}$ )

Sterilfilter 0,2 $\mu \mathrm{m} / 0,4 \mu \mathrm{m}$

Vivaspin Konzentratoren (MWCO

$3,10,30,50 \mathrm{kDa})$

Amicom Ultra Konzentratoren (MWCO

3,10,30,50 kDa)

Zentrifugenbecher ( 1 1, $500 \mathrm{ml})$
Hampton Research, USA

GE healthcare

Henkel, Aachen

Merck, Darmstadt

American National Can, USA

Eppendorf, Hamburg

Sarstedt, Nümbrecht

Eppendorf, Hamburg

Sarstedt, Nümbrecht

Vivascience, Hannover

Vivascience, Hannover

Merck Millipore

Beckman Coulter, Krefeld 


\subsection{Methoden}

\subsubsection{Molekularbiologische Methoden}

\subsubsection{Polymerase-Kettenreaktion (PCR)}

Durch die Polymerase-Kettenreaktion (engl. polymerase chain reaction, PCR) ist es möglich spezifisch Desoxyribonukleinsäureketten (DNA) zu amplifizieren. Für diesen Vorgang werden kurze DNA-Oligonukleotide benötigt (20-30 Basen), welche die zu amplifizierende DNA-Sequenz am 3'- und 5'-Ende flankieren und zu dieser komplementär sind, sogenannte Primer. Diese Primer ist notwendig, da das Enzym DNA-Polymerase die Nukleinsäurekette nicht de novo synthetisieren kann. Darüber hinaus werden alle vier Desoxyribonukleosidtriphosphate (dNTPs), die zu amplifizierende Sequenz (Matrize) und eine hitzestabile DNA-Polymerase (z.B. aus Thermus aquaticus) benötigt.

Im Folgenden werden die allgemeinen Reaktionsbedingungen, sowie ein Reaktionsansatz für eine typische PCR angegeben:

\begin{tabular}{|l|l|l|}
\hline Reaktionszyklus & Temperatur & Dauer \\
\hline $\begin{array}{l}\text { 1.Initiale } \\
\text { Denaturierung }\end{array}$ & $94^{\circ} \mathrm{C}$ bis $98^{\circ} \mathrm{C}^{*}$ & $30^{\prime \prime}-2^{\prime}$ \\
\hline 2. Denaturierung & $94^{\circ} \mathrm{C}$ bis $98^{\circ} \mathrm{C}^{*}$ & $10-30^{\prime *}$ \\
\hline $\begin{array}{l}\text { 3.Primer- } \\
\text { Anlagerung }\end{array}$ & $\begin{array}{l}\mathrm{T}_{\mathrm{m}}-5{ }^{\circ} \mathrm{C} \text { unter } \mathrm{T}_{\mathrm{m}} \\
\text { Primer }\end{array}$ & $30^{\prime *}$ \\
\hline 4. Elongation & $68^{\circ} \mathrm{C}$ bis $72^{\circ} \mathrm{C}^{*}$ & $30^{\prime \prime}-4^{\circ *}$ \\
\hline $\begin{array}{l}\text { 5.Terminale } \\
\text { Elongation }\end{array}$ & $72^{\circ} \mathrm{C}^{*}$ & $10^{\prime \prime}$ \\
\hline
\end{tabular}

Die Schritte 2 bis 4 im PCR-Programm werden typischerweise 25 bis 40 mal wieder holt. Die Elogationszeit hängt von der jeweils verwendeten Polymerase, sowie der Länge des zu amplifizierenden Produktes ab. Die Temperatur, bei der die Hybridisierung der DNA-Oligonukleotide stattfindet, hängt von der Schmelztemperatur der jeweiligen Oligonukleotide ab. Dabei wird die Hybridisierungstemperatur in der Regel $5{ }^{\circ} \mathrm{C}$ unter der Schmelztemperatur der Oligonukleotide gewählt. Die optimale Elongationstemperatur für die verwendete Phusion- als auch die Taq- und Pfu- Polymerase liegt bei $72{ }^{\circ} \mathrm{C}$. Die Elongationsdauer pro $1 \mathrm{~kb}$ ist in der Tabelle untern angegeben. 
Die Zeit- und Temperaturoptima variieren je nach verwendeter Polymerase. Die entsprechenden Optima sind im Folgenden aufgeführt:

\begin{tabular}{|l|l|l|l|l|}
\hline Polymerase & Quellorganismus & \multicolumn{3}{|c|}{ Zeit- und Temperaturoptima } \\
\hline & Denaturierung & $\begin{array}{l}\text { Primer- } \\
\text { Anlagerung }\end{array}$ & Elongation \\
\hline Taq & $\begin{array}{l}\text { Thermus } \\
\text { aquaticus }\end{array}$ & $94^{\circ} \mathrm{C} / 30^{\prime \prime}$ & $\mathrm{T}_{\mathrm{m}}-5^{\circ} \mathrm{C} / 30^{\prime \prime}$ & $1 / 1 \mathrm{~kb}$ \\
\hline Pfu & $\begin{array}{l}\text { Pyrococcus } \\
\text { furiosus }\end{array}$ & $94^{\circ} \mathrm{C} / 30^{\prime \prime}$ & $\mathrm{T}_{\mathrm{m}}-5^{\circ} \mathrm{C} / 30^{\prime \prime}$ & $21 / 1 \mathrm{~kb}$ \\
\hline Pfu Turbo & $\begin{array}{l}\text { Pyrococcus } \\
\text { furiosus }\end{array}$ & $94^{\circ} \mathrm{C} / 30^{\prime \prime}$ & $\mathrm{Tm}^{\prime} 5^{\circ} \mathrm{C} / 30^{\prime \prime}$ & $2 " 11 \mathrm{~kb}$ \\
\hline Phusion & $\begin{array}{l}\text { Pyrococcus } \\
\text { furiosus }\end{array}$ & $98^{\circ} \mathrm{C} / 10^{\prime \prime}$ & $\mathrm{T}_{\mathrm{m}}-5^{\circ} \mathrm{C} / 15^{\prime \prime}$ & $30 " / 1 \mathrm{~kb}$ \\
\hline
\end{tabular}

typischer Ansatz für eine PCR:

$5 \mu \mathrm{l}$

je $200 \mu \mathrm{mol}$

$10 \mathrm{pmol}$

$10 \mathrm{pmol}$

$10-100 \mathrm{ng}$

$1-2 \mu \mathrm{l}$

ad $50 \mu \mathrm{l}$ 10x PCR-Puffer

dNTPs

DNA-Oligonukleotide

DNA-Oligonukleotide

DNA-Matritze

DNA-Polymerase

$\mathrm{ddH}_{2} \mathrm{O}$

\subsubsection{Ortsgerichtete Mutagenese}

Die ortsgerichtete Mutagenese (engl. site directed mutagenesis) dient zur Einführung einer zielgerichteten Mutationen in eine gewünschte DNA-Sequenz. Die Mutagenese erfolgt mittels Polymerase-Kettenreaktion, hierbei werden DNA-Oligonukleotide (Primer) benutzt, welche die gewünschte Mutation tragen. Die Primer (25-45 Basen) mit der erwünschten Mutation lagern sich sowohl in 5' als auch in 3' Richtung an die zu mutierende DNA-Sequenz an. Bei dieser Mutagenese amplifiziert die Pfu-TurboPolymerase das gesamte Plasmid, wobei durch Fehlpaarung der Primer die Mutation in das Endprodukt eingefügt wird. Auf diese Weise ist es möglich einzelne Nukleotide oder auch ganze Codons auszutauschen, sowie auch kurze Insertionen oder Deletionen einzuführen. 
Diese Pfu-Polymerasen besitzen zusätzlich zu ihrer Polymeraseaktivität eine Aktivität die zur Fehlerkorrektur dient (proofreading activity, 3'-5'-Exonukleaseaktivität). Das Ursprungsplasmide, die als Matritze für die PCR verwendet werden und aus Bakterienzellen isoliert werden können, liegen durch bestimmte zelluläre Vorgänge methyliert vor. Um das parentale Plasmid zu entfernen wird dieses mit dem Restriktionsenzym DpnI zerschnitten, welches lediglich die methylierte DNA der Ursprungsplasmide verdaut. Die mutierten, amplifizierten Plasmide werden in Bakterienstämmen vermehrt. Anschließend müssen die Vektoren aus einzelnen Kolonien isoliert werden. Solche, die die gewünschte Mutation enthalten, werden durch Sequenzierung (2.2.1.3 DNA-Sequenzierungidentifiziert.

Die Amplifikation wird wie unter 2.2.1.1 Polymerase-Kettenreaktion (PCR)beschrieben durchgeführt. Der PCR-Ansatz wird mit 5 U DpnI versetzt und für eine Stunde bei $37{ }^{\circ} \mathrm{C}$ inkubiert. Es folgt die Transformation von $5 \mu$ des Ansatzes in E. coli XL1-Blue oder DH10-b.

Nachfolgend sind die Reaktionsbedingungen, sowie ein typischer Reaktionsansatz für die PCR angegeben:

\begin{tabular}{|l|l|l|}
\hline Reaktionszyklus & Temperatur & Dauer \\
\hline $\begin{array}{l}\text { 1.Initiale } \\
\text { Denaturierung }\end{array}$ & $96^{\circ} \mathrm{C}$ & $1^{\prime}$ \\
\hline 2. Denaturierung & $96^{\circ} \mathrm{C}$ & $20^{\prime \prime}$ \\
\hline $\begin{array}{l}\text { 3.Primer- } \\
\text { Anlagerung }\end{array}$ & $\begin{array}{l}\mathrm{T}_{\mathrm{m}}-5{ }^{\circ} \mathrm{C} \text { unter } \mathrm{T}_{\mathrm{m}} \\
\text { Primer }\end{array}$ & $30^{\prime \prime}$ \\
\hline 4. Elongation & $72{ }^{\circ} \mathrm{C}^{*}$ & $6^{\prime}-7^{\prime}$ \\
\hline $\begin{array}{l}\text { 5.Terminale } \\
\text { Elongation }\end{array}$ & $72^{\circ} \mathrm{C}^{*}$ & $10^{\prime}$ \\
\hline
\end{tabular}

Die Schritte 2 bis 4 im PCR-Programm werden typischerweise 25 mal wieder holt PCR Ansatz:

$2 \mu \mathrm{l}$

je $200 \mu \mathrm{mol}$

$10 \mathrm{pmol}$

$10 \mathrm{pmol}$

$0,4 \mu \mathrm{l}$

$0,4 \mu \mathrm{l}$ 10x PCR-Puffer

dNTPs

DNA-Oligonukleotide

DNA-Oligonukleotide

DNA-Matritze

DNA-Polymerase 
ad $20 \mu l$

$\mathrm{ddH}_{2} \mathrm{O}$

\subsubsection{DNA-Sequenzierung}

Die Sequenzanalyse einer DNA-Sequenz (DNA-Sequenzierung) erfolgt nach der „didesoxy-Methode“ nach Sanger (1977). Bei dieser Methode kommt es während der Amplifikation der zu sequenzierenden DNA durch PCR zu Kettenabbrüchen, welche durch den zufälligen Einbau fluoreszenzmarkierter ddNTPs (didesoxy-Ribonukleosidtriphosphat) verursacht werden. Diese Kettenabbrüche kommen zustande, da den fluoreszenzmarkierten ddNTPs die 3'-OH-Gruppe fehlt. Laut Statistik ist somit folgend jedes mögliche, auf ddNTP-endende Fragment im Ansatz enthalten. Die unterschiedlichen Fragmente in Länge und fluoreszenzmarkierten ddNTP-Enden, können durch lange Kapillaren getrennt und detektiert werden. Mittels dem BigDye Terminator v1.1 Seq-Mix von Applied Biosystems ist es möglich die komplette Reaktion in einem einzigen Ansatz durchzuführen.

Für einen typischen Sequenzierungsansatz werden pipettiert:

$\begin{array}{ll}200-400 \mathrm{ng} & \mathrm{zu} \quad \text { sequenzierendes DNA-Fragment } \\ & \text { (Template) } \\ 10 \mathrm{pmol} & \text { Sequenzier-Oligonukleotid (Primer) } \\ 1,5 \mu \mathrm{l} & \text { Seq-Mix } \\ 1,5 \mu \mathrm{l} & \text { Seq-Puffer } \\ \text { ad } 10 \mu \mathrm{l} & \mathrm{H}_{2} \mathrm{O}\end{array}$

Das Programm für Sequenzierungsreaktionen sieht dabei wie folgt aus:

\begin{tabular}{|l|l|l|}
\hline Schritte & Temperatur & Dauer \\
\hline 1.Initiale Denaturierung & $94^{\circ} \mathrm{C}$ & $2^{\prime}$ \\
\hline 2. Denaturierung & $94^{\circ} \mathrm{C}$ & $30^{\prime \prime}$ \\
\hline 3.Primer-Hybridisierung & $50^{\circ} \mathrm{C}$ & $30^{\prime \prime}$ \\
\hline 4. Elongation & $60^{\circ} \mathrm{C}$ & $4^{\prime}$ \\
\hline 5. Finale Elongation & $60^{\circ} \mathrm{C}$ & $10^{\prime}$ \\
\hline
\end{tabular}

Die Schritte 2 bis 4 im PCR-Programm werden 25-mal wiederholt.

Die optimale Elongationstemperatur liegt hier bei $60{ }^{\circ} \mathrm{C}$, die Hybridisierungstemperatur ist abhängig von den verwendeten DNA-Oligonukleotiden (vgl. 2.1.9). Nach der Reaktion wird das PCR-Produkt für den Sequenzierungsautomaten, von störenden Größen, wie DNA-Oligonukleotide, Polymerase und restliche ddNTPs zu entfernen. Hierzu werden dem Ansatz unterschiedliche Komponenten hinzu pipettiert: 
$1 \mu l$

$1 \mu \mathrm{l}$

$50 \mu 1$

0,125 M EDTA

3 M Natriumacetat

Ethanol (99 \%)

Der Ansatz wird vorsichtig durchmischt, für 5' inkubiert bei RT und anschließend bei 16000 x g für 15' zentrifugiert. Der Überstand wird vorsichtig abgenommen, das Pellet in $70 \mu \mathrm{l}$ Ethanol $(70 \% \mathrm{v} / \mathrm{v})$ gewaschen und erneut für 5' zentrifugiert. Das Pellet wird getrocknet und schließlich in $15 \mu \mathrm{l}$ Formamid aufgenommen. Die gereinigten DNAFragmente werden in einem Kapillarsequenzierer (2.1.2) analysiert.

\subsubsection{Spaltung von DNA mit Restriktionsendonukleasen}

DNA kann durch Restriktionsendonukleasen gespalten werden. Diese Enzyme stammen aus Prokaryoten, wo sie dem Abbau von Fremd-DNA dienen. Die DNA des Prokaryonten ist durch Methylierung bestimmter Stellen vor dem Abbau durch diese Enzyme geschützt. Eine Restriktionsendonuklease erkennt spezifische Basenabfolgen in doppelsträngiger DNA und hydrolisiert die Phosphodiesterbindung an einer für sie spezifischen Stelle zwischen den Nukleotiden. Die Erkennungssequenz der Nuklease weist dabei meist eine Sequenz mit einer zweifachen Rotationssymmetrie (Palindrom) und einer Länge von 6-8 Basenpaaren auf. Beim schneiden des Doppelstranges entstehen je nach Nuklease überhängende DNA-Enden (sticky ends) oder glatte DNA-Enden (bluntends).

Ein typischer Ansatz enthält:

$0,5-3 \mu g$

DNA

$1 \mathrm{x}$ oder $2 \mathrm{x}$

Restriktionsenzympuffer (10x Tango-Puffer)

$3 \mathrm{U} / 1 \mu \mathrm{g}$ Restriktionsendonuclease für 3' Schnittstelle

$3 \mathrm{U} / 1 \mu \mathrm{g}$ Restriktionsendonuclease für 5' Schnittstelle ad $20-40 \mu \mathrm{l}$ $\mathrm{ddH}_{2} \mathrm{O}$

Das Volumen des Ansatzes richtet sich in erster Linie nach der Konzentration der Plasmidpräparation.

Der Ansatz wird für 60' bis $120^{\prime}$ bei $37^{\circ} \mathrm{C}$ inkubiert. Anschließend wird der Verdau 20' bei $80{ }^{\circ} \mathrm{C}$ gestoppt, oder direkt durch Agarosegelelektophorese (2.2.1.6) analysiert. Gegebenfalls werden diese Proben für weitere Schritte aus dem Agarosegel isoliert. 


\subsubsection{Ligation von DNA-Fragmenten in einen Zielvektor durch DNA-Ligasen}

DNA-Ligasen spielen in der Natur eine entscheidende Rolle bei der DNA-Replikation. Sie katalysieren die Bildung einer Phosphodiesterbindung zwischen nebeneinander liegender Nukleotide. Dabei werden zwei DNA-Einzelstränge zu einem einzigen verknüpft, aufgrund dieser Eigenschaft finden sie Anwendung in der Molekularbiologie. Hier werden sie benutzt, um DNA-Fragmente nach der Hybridisierung der überhängenden Enden von Fragment und Vektor zu verknüpfen. Sie ermöglichen auf diese Weise das Einsetzen von Zielsequenzen in ein geschnittenes Plasmid an genau dafür vorgesehenen Stellen. Ein typischer Ligationsansatz setzt sich wie folgt zusammen:

$\begin{array}{ll}2 \mathrm{U} & \text { T4-DNA-Ligase } \\ 50 \mathrm{ng} & \text { Plasmid } \\ \mathrm{X} \text { ng } & \text { Zielsequenz } \\ 1 \mathrm{x} & \text { T4-DNA-Ligase-Puffer } \\ 1 \mathrm{mM} & \text { ATP } \\ \text { ad } 10 \mu \mathrm{l} & \mathrm{ddH}_{2} \mathrm{O}\end{array}$

Die Zielsequenz wird üblicherweise in 5-fachem molarem Überschuss in Relation zum Vektor eingesetzt. Die Inkubation des Ligationsansatzes erfolgt für 16-24 Stunden bei 16 ${ }^{\circ} \mathrm{C}$ oder für $60^{\prime}$ bei $37{ }^{\circ} \mathrm{C}$. Die Ligationsreaktion wird für $15^{\prime}$ bei $65{ }^{\circ} \mathrm{C}$ gestoppt und anschließend in chemischkompetente E. coli Zellen (XL1 blue oder XL10 gold) transformiert (2.2.2.3). Die Selektion erfolgreicher Ligationen erfolgt durch Plasmidpräparation (2.2.2.4) mit anschließendem Verdau durch Restriktionsendonukleasen (2.2.1.4) und Analyse durch Agarosegelelektrophorese (2.2.1.6). Positive Ligationen werden durch Sequenzierungen (2.2.1.3) verifiziert.

\subsubsection{Agarosegelelektophorese}

\section{1 x TBE-Puffer:}

$89 \mathrm{mM}$ Tris

89 mM Borsäure

2 mM EDTA pH 8,0
10 x Agarosegel-Probenpuffer:

0,5\% (w/v) Bromphenolblau

0,5\% (w/v) Xylencyanol FF

$60 \%(\mathrm{v} / \mathrm{v})$ Glycerin

In dieser Arbeit wurden ausschließlich Gele mit einem Anteil an Agarose von 1\% (w/v) verwendet. Um die zu analysierende Nukleinsäuren aufzutrennen, wurden diese mit 
Probenpuffer vermischt. Die Auftrennung der Nukleinsäuren erfolgte bei einer konstanten Spannung von 8-12 V/cm. Zur Sichtbarmachung der DNA wurde dem Agarosegel in einem Verhältnis von 1:20000 die in DNA interkalierende Substanz Gelred hinzugefügt. Die Detektion der DNA wurde mittels UV-Durchlicht bei $254 \mathrm{~nm}$ oder $365 \mathrm{~nm}$ (bei folgender Gelelution) durchgeführt und mit Hilfe eines Geldokumentationsgerätes (Geldoc, Biorad, München) archiviert.

\subsubsection{DNA-Isolierung aus Agarosegelen}

Für die Isolierung von DNA aus Agarosegelen wurden die Kit-Systeme PeqGOLD Gel Extraction Kit ( PeqLab, Erlangen) oder QIAquick Gel extraction kit (Qiagen, Hilden). Es wurde nach den Angaben des Herstellers vorgegangen.

\subsubsection{Genetische Codierung von Acetyllysin}

Das Konzept der Erweiterung des genetischen Codes kann auch als Amber-Suppressor System bezeichnet werden. Mit diesem Konzept/System kann spezifisch eine nicht essentielle Aminosäure oder unnatürliche Aminosäure in ein Protein eingefügt werden (Kamieniarz and Schneider, 2009; Liu and Schultz, 2010; Neumann et al., 2008, 2009).

In dieser Arbeit wird das Amber-Suppressor System verwendet um Proteine mit acetyliertem Lysin an einer spezifischen Stelle des Proteins zu erhalten. Die Produktion von spezifisch acetyliertem Protein findet in E.coli Zellen statt. Um dies zu ermöglichen wird in die DNA-Sequenz des zu modifizierenden Proteins an der Stelle für das zu acetylierende Lysin das Amber-Stopcodon TAG kloniert, dies erfolgt über ortsgerichtete Mutagenese (2.2.1.2). Im Weiteren werden die für das TAG Stopcoden spezifische tRNA $^{\text {CUA }}$, sowie die Aminoacyl-tRNA Synthetase, zur Beladung der tRNA mit Acetyllysin, benötigt. Hierbei befinden sich die tRNA und das Gen auf einem Plasmid, wohingegen die Synthetase auf einem extra Plasmid lokalisiert ist. Beide Plasmide werden mittels Transformation (2.2.2.3) in E.coli Zellen eingebracht. Das Acetyllysin wird den Zellen im Expressionsmedium zur Verfügung gestellt (Konzentration von Acetyllysin im Medium $10 \mathrm{mM}$ ). Zur Inhibierung von Deacetylasen, welche in E.coli vorhandenen sind, wird Nicotinamid (NAM) in einer Endkonzentration von 20 mM zum Expressionsmedium gegeben. Die Zellen nehmen das Acetyllysin aus dem Medium auf. Über die Synthetase wird die tRNA ${ }^{\mathrm{CUA}}$ mit dem Acetyllysin beladen. Die beladene tRNA kann folgend von 
dem Ribosom der Zelle benutzt werden um an der Stelle des Stopcodons das Acetyllysin in das Protein einzubauen (Abb. 11).

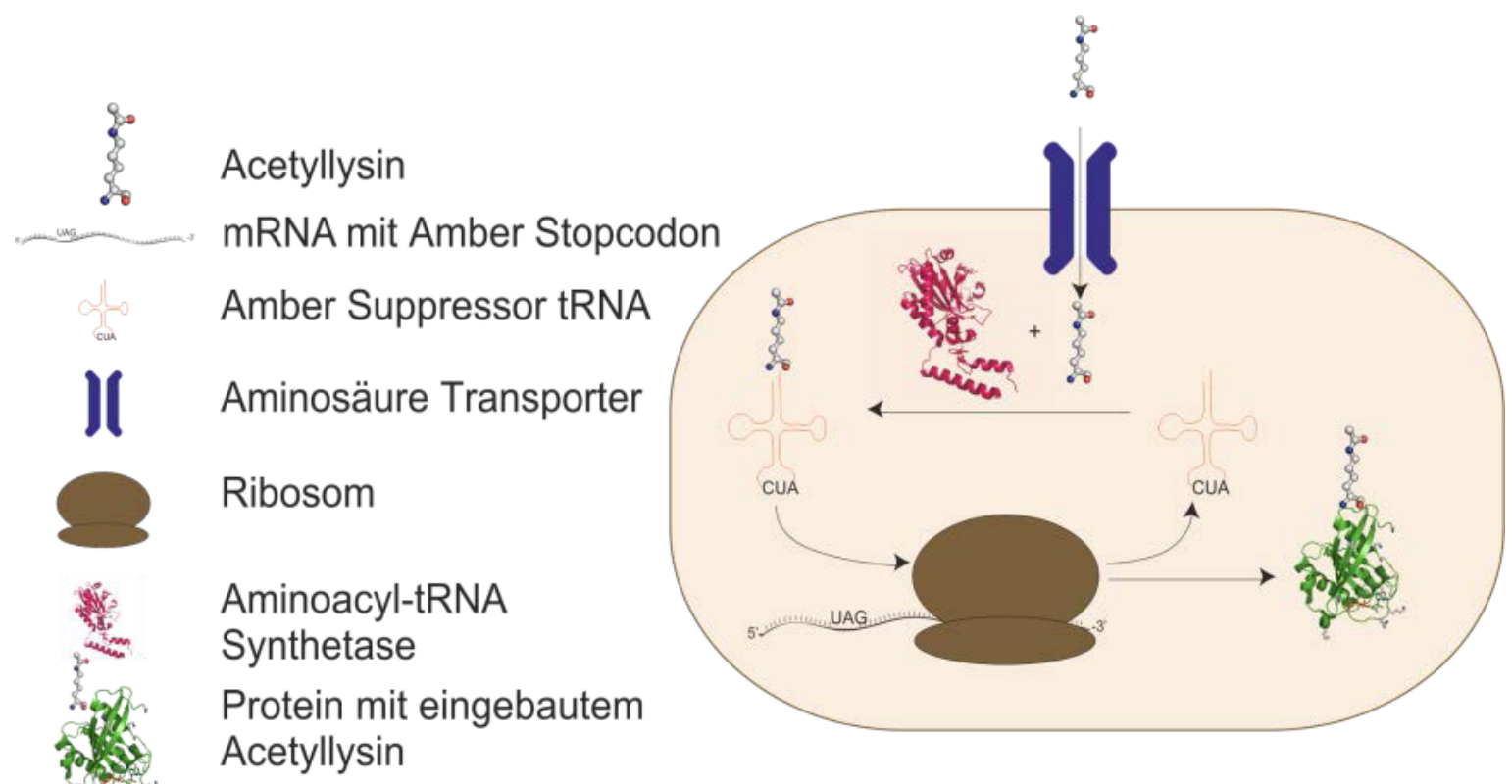

Abb. 11: Schematische Darstellung der Gencode Erweiterung. Gezeigt ist der schematischen Ablauf der Generierung von acetyliertem Protein in einer E.coli Zelle. Die beteiligten Komponenten sind in der Legende auf der linken Seite gezeigt.

\subsubsection{Klonierung der GTPase Ran verkürzt und in voller Länge in acetylierter Form}

Zu Beginn dieser Arbeit wurde der Wildtyp der GTPase Ran auf dem Vektor pCDF Duet von Dr. H. Neumann zur Verfügung gestellt. Dieser Vektor enthielt zusätzlich zum Gen für die GTPase Ran ein Gen für eine tRNA, das PylT Gen (im Folgenden als pCDF Duet PylT bezeichnet).

Um die GTPase Ran in einer verkürzten Variante ( $\operatorname{Ran}^{1-180}$ ) mit der Q69L Mutation zu erzeugen, wurde das Gen neu kloniert. Als Vorlage wurde das Wildtyp Gen im pCDF Duet PylT Vektor verwendet. Das Gen für $\operatorname{Ran}^{1-180}$ wurde über PCR (2.2.1.1) amplifiziert (Abb. 12), sowie anschließend mittels Restriktionsverdau (2.2.1.4) bearbeitet und anschließend durch Ligation (2.2.1.5) in den Expressionsvektor pCDF Duet PylT eingefügt. Als Restriktionsschnittstellen wurden BamHI und XhoI verwendet. Die Q69L Mutation, sowie der Austausch eines Codons für Lysin zum Amber-Stopcodon erfolgte durch ortsgerichtete Mutagenese (2.2.1.2). Die Richtigkeit der Konstrukte wurde mittels DNA-Sequenzierung (2.2.1.3) überprüft.

Zur Anfertigung eines Gens der GTPase Ran mit dem Amber-Stopcodon an Stelle eines Lysin-codons, wurde eine ortsgerichtete Mutagenese (2.2.1.2) durchgeführt. Die 
Richtigkeit der so erhaltenen Konstrukte wurde mittels DNA-Sequenzierung (2.2.1.3) überprüft.

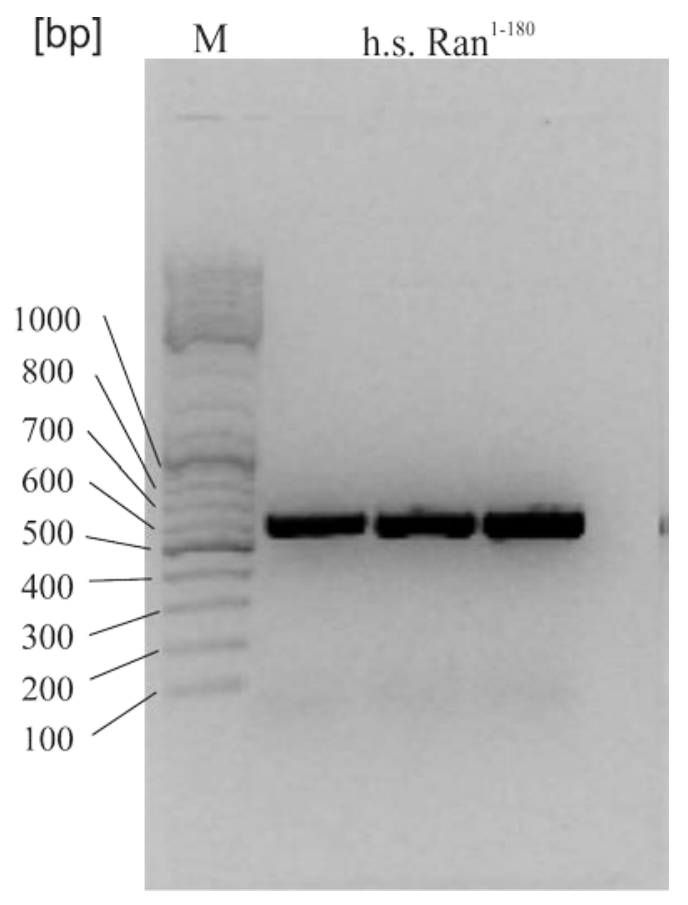
Abb. 12: 1\%iges Agarosegel des PCR-Produktes vom h.s. Ran $^{1-180}$ (577bp). Der Marker (M) ist auf der linken Seite in Basenpaaren (bp) angegeben. Die über das Agarosegel visualisierte PCR-Produkt entspricht der erwarteten Länge

\subsubsection{Klonierung des GTPase aktivierenden Protein RanGAP1}

Das RanGAP1 lag als Konstrukt ohne Affinitätssequenz (Dr. R.Kehlenbach) im pET-11d Plasmid vor. Unter Verwendung des pET-11d Konstruktes als Matrize für eine PCR (2.2.1.1) wurde das RanGAP1 Gen mit Restiktionschnittstellen für BamHI und XhoI amplifiziert (Abb. 13). Das Amplifikat und das Plasmid pGEX-6P1 werden mittels der Restriktionsenzyme BamHI und XhoI (2.2.1.4) geschnitten und über Ligation (2.2.1.5) miteinander verbunden. Durch DNA-Sequenzierung (2.2.1.3) positver Klone nach der Transformation (2.2.2.3) der Ligation konnte die Fehlerfreiheit des Gens von RanGAP1 bestätigt werden. 


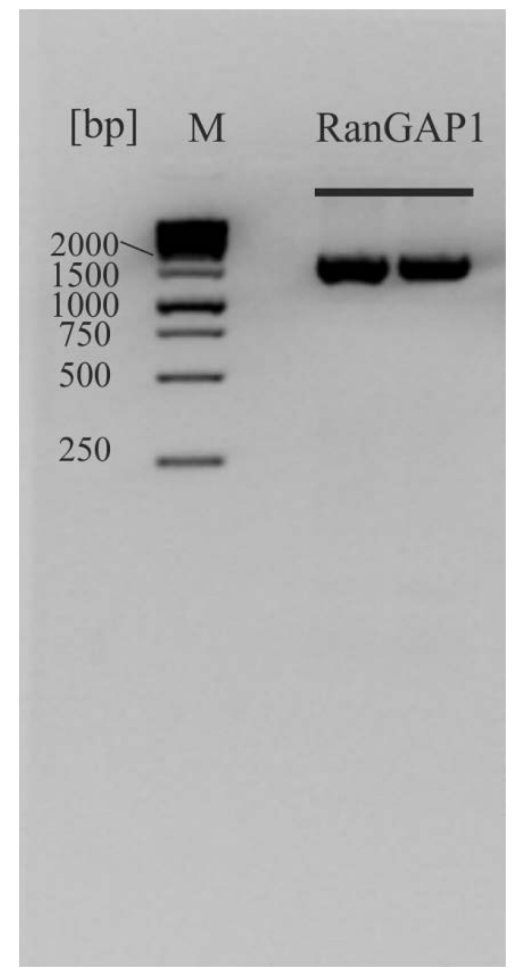

Abb.13: 1\%iges Agarosegel des PCR-Produkts vom RanGAP1 (1767 bp). Der Marker (M) ist auf der linken Seite in Basenpaaren (bp) angegeben. Die über das Agarosegel visualisierte PCR-Produkt entspricht der erwarteten Länge

\subsubsection{Mikrobiologische Methoden}

\subsubsection{Herstellung von Flüssig- und Festmedien}

\section{LB-Medium:}

10 g Trypton/Pepton

5 g Hefeextrakt

$10 \mathrm{~g} \mathrm{NaCl}$

ad $1 \mathrm{l} \mathrm{H}_{2} \mathrm{O}$

\section{YT-Medium:}

16 g Trypton/Pepton

10 g Hefeextrakt

$5 \mathrm{~g} \mathrm{NaCl}$

ad $11 \mathrm{H}_{2} \mathrm{O}$

\section{YT-Agar für Selektionsplatten:}

$8 \mathrm{~g}$ Trypton/Pepton

5 g Hefeextrakt

$2,5 \mathrm{~g} \mathrm{NaCl}$

7,5 g Agar-Agar

ad $500 \mathrm{ml} \mathrm{H}_{2} \mathrm{O}$

Für die Kultivierung von Bakterien werden Flüssig- und Festmedien verwendet, dabei wird bei der Herstellung unter einer Sterilwerkbank gearbeitet. Alle Medien werden nach der Herstellung autoklaviert. Falls Antibiotika verwendet werden, werden diese nach dem Abkühlen des Agars in der erforderlichen Menge zugegeben. Das noch flüssige Agargemisch wird in Petrischalen gegossen und die Platten werden bei $4{ }^{\circ} \mathrm{C}$ und gegebenenfalls dunkel gelagert. Die Flüssigmedien werden zur Vermehrung der in den Zellen enthaltenen DNA sowie zur Proteinexpression verwendet. Je nach Zellstamm und Plasmidsystem werden das entsprechende Medium und die entsprechenden Antibiotika eingesetzt. 


\subsubsection{Herstellung chemisch kompetenter E.coli Zellen}

Für die Herstellung chemisch kompetenter E.coli Zellen wurde eine Kolonie des betreffenden E.coli Stammens in einer Vorkultur über Nacht bei $37{ }^{\circ} \mathrm{C}$ angezogen. Aus dieser Vorkultur wurde eine $500 \mathrm{ml}$ große Hauptkultur aus LB-Medium (2.2.2.1) erstellt und bei $37{ }^{\circ} \mathrm{C}$ unter Schütteln bis zu einer $\mathrm{OD}_{600}$ von 0,6 - 0,8 wachsen gelassen. Im folgenden wurde die Kultur für 30' auf Eis gestellt und anschließend für 10' bei 3000 rpm zentrifugiert. Das Sediment wurde in $125 \mathrm{ml}$ 0,1 $\mathrm{M} \mathrm{MgCl}_{2}$ Lösung aufgenommen, 20' auf Eis inkubiert und anschließend 10' bei 2500 rpm zentrifugiert. Das entstandene Pellet wurde in $250 \mathrm{ml} \mathrm{0,1} \mathrm{M} \mathrm{CaCl}_{2}$ Lösung resuspendiert weitere 15' auf Eis inkubiert und ein letztes mal 10' bei 2500 rpm zentrifugiert. Das nun entstandene Pellet in $5 \mathrm{ml} 0,1 \mathrm{M} \mathrm{CaCl}_{2}$ (85\% (w/v))/Glycerin (15\% (v/v)) aufgenommen und in 50-100 $\mu$ l Aliquots mit flüssigem Stickstoff tiefgefroren. Die chemisch kompetenten E.coli Zellen wurden bei $-80{ }^{\circ} \mathrm{C}$ gelagert.

\subsubsection{Transformation chemisch kompetenter E.coli Zellen}

Ein Aliquot von 50-100 $\mu \mathrm{l}$ des jeweiligen chemisch kompetenten E.coli Stammes wird zusammen mit 50-400 ng Plasmid-DNA zur Transformation eingesetzt. Die zusammengefügten Komponenten werden 30' auf Eis inkubiert. Anschließend werden die Zellen einem Hitzeschock bei $42{ }^{\circ} \mathrm{C}$ für 60" ausgesetzt und darauffolgend 5' auf Eis inkubiert. Nach Zugabe von $900 \mu$ l Medium wird der Transformationsansatz 45' bei $37{ }^{\circ} \mathrm{C}$ unter Schütteln inkubiert. Der Ansatz wird darauf folgend 60" bei 2500 xg zentrifugiert, das Pellet in 100-200 $\mu \mathrm{l}$ resuspendiert und auf Agarplatten mit dem entsprechenden Selektionsantibiotikum ausgestrichen. Die Platte wird bei $37{ }^{\circ} \mathrm{C}$ über Nacht umgedreht inkubiert.

\subsubsection{Plasmidpräparationen}

In dieser Arbeit werden Plasmide ausschließlich mit Hilfe von Plasmidextraktions-Kits (2.1.4) isoliert, nachdem sie in Zellen vom Typ E. coli XL1 Blue vermehrt wurden. Je nach benötigter Plasmidmenge werden entweder Präparationen kleinen, mittleren oder großen Maßstab durchgeführt. Der grundlegende Ablauf dieser Präparationen gliedert sich in den Aufschluss der Zellen mittels alkalischer Lyse, das Abzentrifugieren der Zelltrümmer und chromosomaler DNA, das Binden der Plasmide an Säulenmaterial, dem waschen der gebundenen Plasmide und der Elution von dem Säulenmaterial. Die genaue Durchführung ist in den Protokollen der Hersteller (2.1.4) beschrieben. Aufgereinigte Plasmide werden 
über einen Restriktionsverdau (2.2.1.4) mit anschließender Agarosegelelektrophorese (2.2.1.6) oder alternativ durch Sequenzierung (2.2.1.3) analysiert. Für die Präparation im kleinen Maßstab werden $5 \mathrm{ml}$ Übernacht-Kulturen geerntet und die DNA nach Herstellerangaben präpariert. Im mittleren Maßstab sollen hierzu 500 ml Übernachtkultur verwendet werden. Bei der Präparation von Plasmid-DNA im mittleren Maßstab wurde von dem Protokoll des Herstellers abgewichen. Die von der Säule eluierte DNA wurde mittels 2-Propanol gefällt. Dazu wurde die eluierte DNA mit 2-Propanol versetzt, im Anschluss $15^{\prime}$ auf $-80{ }^{\circ} \mathrm{C}$ inkubiert und 20' bei $5000 \mathrm{xg}$ und $4{ }^{\circ} \mathrm{C}$ abzentrifugiert. Das

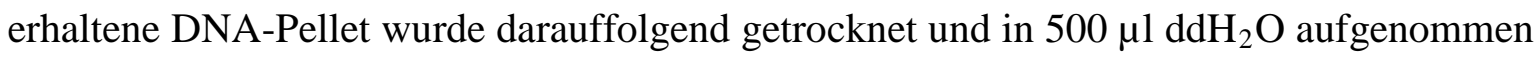
und mit 1,5 ml 70\% (v/v) Ethanol gewaschen. Das daraus resultierende Pellet wurde dann

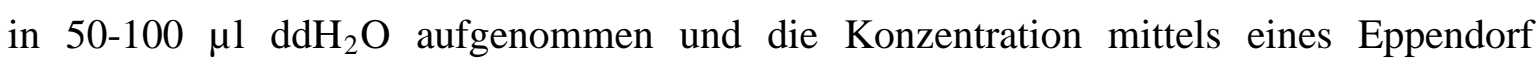
Photometers bei $260 \mathrm{~nm}$ bestimmt. Die DNA wurde bei $-20^{\circ} \mathrm{C}$ gelagert.

\subsubsection{Expression rekombinanter Proteinein E. coli}

Die in dieser Arbeit verwendeten Vektoren für die Expression rekombinanter Proteine tragen einen durch Laktose induzierbaren Promotor (wie der lac-Promotor oder der tacPromotor). Die Verwendung solcher Promotren erlaubte die Induktion der Expression des Proteins über das Laktose-Analogon Isopropyl- $\beta$-D-thiogalactopyranosid (IPTG). Die verwendeten Vektoren wurden mittels Transformation (2.2.2.3) in den entsprechenden $E$. coli Stamm eingebracht und die Zellen in einer Vorkultur aus 2YT- oder LB-Medium, sowie dem entsprechenden Antibiotikum bei $37{ }^{\circ} \mathrm{C}$ über Nacht angezogen. Für die Hauptkultur des jeweiligen rekombinanten Proteins wird Medium mit dem entsprechenden Antibiotikum versetzt und mit der Vorkultur 1:100 bzw. 1:50 angeimpft. Die Hauptkultur wird bis zu einer optischen Dichte $\left(\mathrm{OD}_{600}\right)$ von 0,6 bis 1 bei $37{ }^{\circ} \mathrm{C}$ geschüttelt. Die Expression des Proteins wird durch Zugabe von 0,5 mM IPTG gestartet und mit $30 \mathrm{mM}$ $\mathrm{K}_{2} \mathrm{HPO}_{4}$ abgepuffert. Die Dauer und Temperatur der Expression richtete sich nach dem jeweiligen rekombinanten Protein.

\subsection{Expression von acetyliertem und nicht acetyliertem Ran (Homo sapiens) in} pCDFR Duet PylT

Für die Expression von acetyliertem Ran wurde das Konzept des genetic code expansion verwendet (2.2.1.8). Hierbei wurde mittels ortsgerichteter Mutagenese (2.2.1.2) das amberStopcodon (TAG) im Gen des Ran, an der Stelle für das zu acetylierende Lysin eingesetzt. 
Um das Ran mit acetyliertem Lysin zu exprimieren sind weitere Komponenten in Form der amber tRNA, spezifisch für das amber Stopcodon, sowie einer Aminoacyl-tRNASynthetase, notwendig. Für die Expression von acetyliertem Ran wurden E. coli BL21(DE3) Zellen mit zwei Vektoren transformiert, dabei trug ein Vektor das Zielgen für Ran und die amber tRNA (pCDF Duet PylT), während die Aminoacyl-tRNA-Synthetase auf einem zweiten Vektor lokalisiert war. Für die Hauptkultur wurde ein Liter LB-Medium in einem Verhältnis von 1:50 mit einer Vorkultur inokuliert und bei $37{ }^{\circ} \mathrm{C}$ bis zu einer optischen Dichte von 0,8 wachsen gelassen. Die Expression wird mittels zugabe von IPTG in einer Endkonzentration von 0,5 mM gestartet. Sie erfolgte für $4 \mathrm{~h}$ bei $37^{\circ} \mathrm{C}$.

\subsection{Expression von rekombinantem h.s. Crm1}

Das Protokoll zur Expression, sowie der verwendete Zellstamm und das Crm1 Konstrukt wurden von Dr. T. Monecke zur Verfügung gestellt. Die Expression von Crm1 wurde mit dem E. coli Stamm TG-1 durchgeführt. Sie weicht von einer normalen Expression ab, da hier die Expression nicht durch Zugabe von IPTG gestartet wurde. Um h.s. Crm1 zu exprimieren werden Zellen aus einem Glyzerinstock mittels einer Pipettenspitze in eine Vorkultur aus 2YT-Medium überführt. Die Vorkultur wird für mindestens 5 Stunden bei $37{ }^{\circ} \mathrm{C}$ inkubiert. Die Hauptkultur wurde aus dieser Vorkultur im Verhältnis 1:100 inokuliert und über Nacht bei $37{ }^{\circ} \mathrm{C}$ bis zu einer optischen Dichte von 3-5 wachsen gelassen.

\subsection{Expression von rekombinantem SPN1}

Die Expression von rekombinantem SPN1 wird nach Strasser et al. (2004) durchgeführt

\subsection{Expression von RanGAP1 (Mus musculus)}

Für die Expression von RanGAP1 wurde der E. coli Stamm Rosetta 2 (DE3) verwendet. Das RanGAP1 Konstrukt (2.2.1.10) wird mittels Transformation in den E.coli Rosetta 2 (DE3) eingebracht (2.2.2.3). Die transformierten Zellen werden anschließen auf 2YT-Agar ausgestrichen und über Nacht bei $37{ }^{\circ} \mathrm{C}$ inkubiert. Die Kolonien auf dem 2YT-Agar werden verwendet um eine Vorkultur anzuimpfen. Die Vorkultur wird über Nacht bei $37^{\circ} \mathrm{C}$ angezogen. Für die Expression wird 1L 2YT-Medium mit 2\% Glukose in einem Verhältnis 1:100 mit der Vorkultur inokuliert. Die inokulierte Kultur wird bis zu einer 
$\mathrm{OD}_{600}$ von 0,9-1 bei $37^{\circ} \mathrm{C}$ wachsen gelassen. Die Expression wurde durch Zugabe von 0,5 mM IPTG induziert und für $19 \mathrm{~h}$ bei $16{ }^{\circ} \mathrm{C}$ durchgeführt. Zusätzlich wird der Kultur 30 $\mathrm{mM} \mathrm{K}_{2} \mathrm{HPO}_{4}$, zum puffern der Kultur, bei Zugabe des IPTG, hinzugefügt.

\subsubsection{Zellernte und Aufschluss einer E.coli Expressionskultur}

Um rekombinante Proteine aus Bakterienzellen zu isolieren, müssen die Zellen geerntet und aufgeschlossen werden. Die Ernte erfolgt durch Zentrifugation bei 5000 x g für 30" bei $4{ }^{\circ} \mathrm{C}$. Das hierbei entstehende Bakterien-Pellet wird in 1x PBS (phosphate buffered saline) resuspendiert und erneut bei $4000 \mathrm{x}$ g für $30^{\prime}$ bei $4{ }^{\circ} \mathrm{C}$ zentrifugiert. Der Überstand wird dekantiert und das geerntete Zellpellet entweder direkt aufgeschlossen oder in flüssigem Stickstoff gefroren und bei $-20^{\circ} \mathrm{C}$ gelagert.

Zum Aufschluss wird das Bakterien-Pellet (2.2.2.5) in 3-5 ml Lysepuffer pro Gramm Zellpellet aufgetaut und resuspendiert. Die Zusammensetzung des Lysispuffers richtet sich im Einzelfall nach den Eigenschaften des zu isolierenden Proteins. Der pH-Wert des Puffers richtet sich nach dem isoelektrischen Punkt des Proteins. Salze und Glycerin beeinflussen die Löslichkeit beim Aufschluss. Um proteolytische Enzyme zu inaktivieren, wird dem Ansatz einer Lösung aus Protease-Inhibitoren bestehend aus $80 \mu \mathrm{M}$ Aprotinin, 2 $\mathrm{mM}$ Leupeptin und $1 \mathrm{mM}$ Pepstatin, sowie $125 \mu \mathrm{L} 10 \mathrm{mM}$ PMSF zugegeben. Der Zellaufschluss im pneumatischen Zelldesintegrator (Fluidizer) wird bei 80-90 psi in 5-7 Zyklen durchgeführt. Hierbei wird die Zellsuspension unter dem hohen Druck durch eine Kapillare gepresst. Die dabei entstehenden Scherkräfte lassen die Zellen aufplatzen. Nach dem Aufschluss der Zellen wird die Suspension in Beckmann-Zentrifugenröhrchen überführt und bei $30000 \mathrm{x}$ g für $40^{\prime}$ bei $4{ }^{\circ} \mathrm{C}$ zentrifugiert. Nach der Trennung des Lysates in Zelltrümmer und Überstand werden die Proben aus dem Aufschluss, dem Pellet der Zelltrümmer, sowie dem Überstand über ein SDS-Gel analysiert.

\subsubsection{Proteinbiochemische Methoden}

\subsubsection{Chromatographische Trennmethoden}

Die Reinigung der in dieser Arbeit verwendeten Proteine wurde sowohl bei $20^{\circ} \mathrm{C}$ als auch bei $4^{\circ} \mathrm{C}$ an einem Äkta Prime System durchgeführt. Alle verwendeten Säulen wurden vor dem Äquilibrieren mit Puffer, als auch nach dem Gebrauch mit $\mathrm{ddH}_{2} \mathrm{O}$ gespült. Nach dem Gebrauch der Säulen werden diese in 20 \% igem Ethanol/Wasser (v/v) gelagert. 


\subsection{Affinitätschromatographische Reinigung von Proteinen mit Histidin-} Affinitätssequenz

In dieser Arbeit wurden für die Aufreinigung von Proteinen mit His-Sequenz die HisTrapFF Ni-NTA-Sepharose-Säulen (5 ml, GE Healthcare) benutzt. Als Metallion wird Nickel benutzt, das über vier koordinative Bindungen an NTA gebunden ist. NTA ist seinerseits kovalent an die Sepharose-Trägermatrix gebunden. Die reversible Bindung von Metallion und Histidin-Sequenz am Zielprotein wurde entweder durch einen linearen Gradienten von 0-100\% oder durch einen einzelnen Schritt mit Imidazol gelöst.

Nach dem Laden der Proteinprobe auf die Säule über einen Superloop (50 oder $150 \mathrm{ml}$ ) wurde mit zwei Säulenvolumina HisA gewaschen, um unspezifisch gebundene Proteine zu entfernen. Anschließend wurde über einen aufsteigenden Imidazolgradienten (0-100\% HisB) oder in einem einzigen Schritt (100\% HisB) eluiert. Das Eluat wurde fraktioniert und die Fraktionen mittels SDS-Gel analysiert. Die Proben, welche das Zielprotein enthielten, wurden gepoolt und für weitere Aufreinigungsschritte bei $4{ }^{\circ} \mathrm{C}$ gelagert.

\subsection{Affinitätschromatographische Reinigung von Proteinen mit Glutathion-S- Transferase}

Die Glutathion-S-Transferase (GST) ist ein Enzym, welches in der Lage ist sein Substrat, Glutathion ( $\gamma$-Glutamylcysteinylglycin), hochaffin und spezifisch zu binden. Das macht man sich bei dieser Methode zunutze, indem bei der Expression an das Zielprotein, durch eine Verbindungssequenz getrennt, die Glutathion-S-Transferase angehängt wird. Das so entstandene Fusionsprotein kann nun über eine Säule mit Glutathion-Sepharose (GSHSepharose) von den restlichen Proteinen separiert werden. Dabei bindet die Affinitätssequenz des Fusionsproteins an das mit der Säulenmatrix gekoppelte Glutathion, wodurch das Fusionsprotein immobilisiert wird. Nach einem Waschschritt wird das immobilisierte Zielprotein durch Zugabe von $30 \mathrm{mM}$ reduziertem Glutathion wieder in die mobile Phase überführt und somit von der Säule eluiert. In dieser Arbeit wurden $5 \mathrm{ml}$ GSH-Sepharose (GE Healthcare) und GST4B/Protino (Machery Nagel) Säulen verwendet. Der Überstand des zentrifugierten Aufschlusses wurde über die Säule geleitet. Es folgt ein Waschschritt, um alles nicht gebundene Protein zu entfernen. Die kompetetive Verdrängung, und damit die Elution, erfolgte durch einen Elutionspuffer, wobei das Eluat fraktioniert wurde. 


\subsection{Affinitätschromatographische Reinigung von Proteinen über Heparin-} Sepharose

In der Proteinreinigung wird Heparin-Sepharose benutzt um DNA und RNA bindende Protein zu isolieren und von anderen zu trennen. Bei dem Säulenmaterial handelt es sich um 6\% Agarose mit Heparin als Ligand. Das Heparin imitiert hierbei die polyanionische Struktur von Nukleinsäuren und ist so in der Lage DNA und RNA bindende Proteine zu immobilisieren. Die zu trennende Probe wird, nach dem Äquilibrieren der Säule mit Bindepuffer, durch einen Superloop geladen. Nicht gebundene Proteine werden durch Waschen mit Bindepuffer entfernt und gebundene Proteine durch erhöhte Ionenstärke eluiert. Die Elution erfolgt durch einen steigenden Salzgradienten von 0-100\% Puffer B, hierbei erhöht sich die Ionenstärke in der Elutionslösung. Das Eluat wird fraktioniert, die Fraktionen mittels SDS-Gel analysiert und das Protein für weiter Schritte bei $4{ }^{\circ} \mathrm{C}$ gelagert.

\subsection{Umpuffern von Proteinlösung durch Entsalzungs-Säulen und Dialyse}

Proteinlösungen lassen sich durch Dialyse oder die Verwendung von Entsalzungssäulen in Puffer anderer Zusammensetzung überführen. Mittels der Dialyse durch eine selektivpermeable Membran können Proteine von kleineren Molekülen (z.B. Salzionen) getrennt werden. Die Ionen diffundieren in die umgebende Lösung geringerer Salzkonzentration bis zur Einstellung des Konzentrationsgleichgewichts. Entsalzungssäulen (HiPrep 26/10 Desalting) funktionieren grundsätzlich wie Gelfiltrationssäulen. Die Poren des Säulenmaterials sind kleiner, um das Eindringen von Proteinen in die Gelmatrix zu verhindern. Salzionen und andere niedermolekulare Moleküle (Elutionssubstrate von Affinitätschromatographien) können in diese Poren eindringen und ihre Elution wird dadurch verzögert.

Dieser Schritt der Aufreinigung wird in dieser Arbeit benötigt, um reduziertes Glutathion bzw. Imidazol aus dem Eluat einer Affinitäts-Reinigung zu entfernen und eine erneute Bindung von GST bzw. Hisdidin-Affinitätssequenz an das Säulenmaterial zu ermöglichen (GSH-Sepharose bzw. Ni-NTA-Sepharose). Die verwendete Säule war in diesem Fall eine 53 ml HiPrep Desalting 26/10-Säule (GE Healthcare). Die Proteinkonzentration der zu entsalzenden Probe darf nicht höher als $70 \mathrm{mg} / \mathrm{ml}$ sein und das Volumen $15 \mathrm{ml}$ nicht überschreiten. Die Säule wird zur Verwendung mit dem Puffer äquilibriert in die Proteine überführt werden sollen. Danach wird die Proteinlösung aufgetragen und mit dem 
Äquilibrierungspuffer eluiert und fraktioniert. Der verwendete Puffer richtete ich in diesem Schritt der Aufreinigung nach dem Bindepuffer der jeweiligen Säule.

\subsection{Anionenaustauschchromatographie}

Über Ionenaustauschchromatographie lassen sich Proteine mit unterschiedlichem isoelektrischen Punkt über ihre Oberflächenladung voneinander trennen. In dieser Arbeit wurde das auf einer Polystyrol/Divinylbenzol-Polymermatrix basierende Anionenaustauscher Material Source 30 Q in einem XK16/20 Mantel verwendet, hierbei handelte es sich um einen starken Anionenaustauscher. Um das gewünschte Protein an das Säulenmaterial zu binden wurde ein Puffer gewählt, dessen pH-Wert etwa 1-2 Einheiten über dem pI des Zielproteins lag. Zur Elution des Zielproteins kann entweder ein sinkender $\mathrm{pH}$ - oder ein steigender Anionengradient verwendet werden. Die Probe wurde in dieser Arbeit mittels eines Superloops über das Säulenmaterial geleitet, über einen steigenden Salzgradient/Anionengradient eluiert und in 4 ml Fraktionen aufgefangen.

\subsection{Größenausschlusschromatographie}

In der Größenausschlusschromatographie (auch Gelfiltration genannt) werden Proteine aufgrund ihres Gyrationsradius, ihrer Form und Größe voneinander getrennt. Bei Reinigungen von Proteinen im präparativen Maßstab wurden entweder die HiPrep 26/60 Superdex 200 Säule von GE Healthcare (eignet sich zur Trennung von Proteinen mit einer Molekülmasse von weniger als 200 kDa) oder die HiPrep 26/60 Superdex 75 Säule (eignet sich zur Trennung von Proteinen mit einer Molekülmasse von weniger als $75 \mathrm{kDa}$ ) verwendet. Nach Äquilibrierung der Säule mit dem 1,5 fachem Säulenvolumen an Elutionspuffer wurde die Probe über einen $5 \mathrm{ml}$-Auftragsschleife injiziert. Die Proteinprobe wird von der Säule mit Puffer eluiert, 3-5 ml große Fraktionen wurden aufgefangen und die Fraktionen anschließend im SDS-Polyacrylamidgel analysiert.

In der analytischen Größenausschlusschromatographie wurde die Bildung homogener Proteinkomplexes untersucht. Für diese Interaktionsstudien wurde eine Superdex 200 10/300 Gl verwendet. Hier wurden $500 \mu \mathrm{l}$ der zu analysierenden Proteinlösung auf die Säule aufgetragen. Das Eluat wurde in $500 \mu \mathrm{L}$ großen Fraktionen gesammelt und mittels SDS-Gel anlysiert. 


\subsubsection{Beladung von Ran mit GTP}

Zur Beladung von Ran mit GTP wird dieses mit EDTA (etwa 150-200 facher Überschuss über Ran) und einem 50 bis 100 fachen Überschuss an GTP für 60' bei $25^{\circ} \mathrm{C}$ unter gelegentlichem Schütteln inkubiert. Die Reaktion wird durch Zugabe von Magnesiumchlorid (3 fach über EDTA) und Inkubation für $20^{\prime}$ bei $25^{\circ} \mathrm{C}$ gestoppt. Um überschüssiges GTP abzutrennen wird der Reaktionsansatz über eine Säule entsalzt (2.2.3.1.4). Die das Protein enthaltenden Fraktionen werden vereinigt und bis zu der gewünschten Konzentration von 1-2 mg/ml eingeengt (2.2.3.6). Die Beladung wird mittels HPLC- Anionenaustauschchromatographie (2.2.3.3) überprüft.

\section{Entsalzungs Puffer}

$50 \mathrm{mM}$ Tris/Hcl pH 7.5

$200 \mathrm{mM} \mathrm{NaCl}$

$5 \mathrm{mM} \mathrm{MgCl}_{2}$

$5 \%$ Glyzerin

$1 \mathrm{mM}$ DTT

\subsubsection{Analyse des Nucleotidladestatus über HPLC- Anionenaustauschchromatographie}

\section{Puffer A:}

$10 \mathrm{mM}$ Tris $\mathrm{pH} 8$

\section{Puffer B:}

$10 \mathrm{mM}$ Tris $\mathrm{pH} 8$

$2 \mathrm{M} \mathrm{NaCl}$

Um zu ermitteln wie viel Ran GTP gebunden und wie viel GDP gebunden vorliegt, wird eine Analyse des Guanosinnukleotid Ladestatus von Ran durchgeführt. Mittels HPLCAnionenaustauschchromatographie mit einer Nucleosil 4000-7 PEI (Machery Nagel) Säule lässt sich diese Analyse durchführen.

Das zu analysierende Protein wurde durch Erhitzen auf $96^{\circ} \mathrm{C}$ denaturiert und somit gefällt. Das gefällte Protein wurde mittels Zentrifugation für $10^{\prime}$ bei $25000 \mathrm{x} \mathrm{g}$ und $4{ }^{\circ} \mathrm{C}$ sedimentiert. Der Überstand (enthält Nucleotide) wurde mit $\mathrm{ddH}_{2} \mathrm{O}$ auf $300 \mu \mathrm{l}$ verdünnt und über eine $500 \mu \mathrm{l}$ Auftragsschleife injiziert. Der Lauf fand bei $1 \mathrm{ml} / \mathrm{min}$ statt. Eluiert wurde durch einen linearen Gradienten von 0-100\% Puffer B über 12 Säulenvolumen. Als Standard wurde GTP verwendet. 


\subsubsection{Diskontinuierliche Polyacrylamidgelelektrophorese von Proteinen}

Für die Durchführung eines SDS-Gel wird das Gelelektrophoresesystem der Firma Hoefer/GE Healthcare verwendet. Pro Gel wird eine Glasplatte und eine Aluminiumoxidplatte mit Ethanol gewaschen und staubfrei getrocknet. Auf die Keramikplatte wird jeweils am rechten und linken Rand ein Abstandshalter aufgelegt. Auf den Abstandshalter wird die Glasplatte aufgesetzt. Dieser Aufbau wird in eine Gießkammer für 4 Gele eingesetzt und zwischen jede Glasplatte und der nächsten Keramikplatte eine Plastikscheibe gelegt. Die Kammer wird bis $2 \mathrm{~cm}$ unterhalb des oberen Randes mit Trenngellösung aufgefüllt und mit 100\% (v/v) Isopropanol überschichtet. Nach der Polymerisierung des Trenngels wird das Isopropanol entfernt. Die Kammer wird bis zur oberen Kante mit Sammelgellösung gefüllt und pro Gel wird ein Kamm eingesetzt. Für die Elektrophorese wird ein Gel in eine Gelhalterung eingespannt und in die Laufkammer gesetzt. Das Reservoir der Laufkammer, so wie der Gelhalterung werden mit Laufpuffer gefüllt und der Kamm entfernt. Die zu analysierenden Proben werden 1:1 (v/v) mit 2x Laemmli-Probenpuffer gemischt und in die Geltaschen geladen. Proben aus Expressionen bilden eine Ausnahme. Diese werden pelletiert, das Pellet wird in $100 \mu \mathrm{l}$ x $\mathrm{OD}_{600} \mathrm{H}_{2} \mathrm{O}$ resuspendiert und anschließend mit $100 \mu \mathrm{l}$ x OD $_{600}$ Laemmli-Probenpuffer versetzt. Die Expressionsproben werden 5 ' bei $95{ }^{\circ} \mathrm{C}$ erhitzt und gleiche Volumina auf dem SDS-Gel analysiert.

\section{Trenngel (12,5\%/15 \%):}

12,5/15 \% (w/v) Acrylamid,

0,33/0,4 \% (w/v) Bisacrylamid

0,375 M Tris (HCl) pH 8,8

$0,1 \%(w / v)$ SDS

$0,1 \%(\mathrm{v} / \mathrm{v})$ TEMED

0,05 \% (w/v) Ammoniumpersulfat

\section{SDS-Laufpuffer:}

$\begin{array}{ll}0,025 \mathrm{M} & \text { Tris-HCl } \\ 0,192 \mathrm{M} & \text { Glycin } \\ 0,1 \%(\mathrm{w} / \mathrm{v}) & \text { SDS }\end{array}$

\section{Sammelgel (5 \%):}

$5 \%$ (w/v) Acrylamid

0,13 \% (w/v) Bisacrylamid

125 mM Tris (HCl) pH 6,8

$0,1 \%(w / v)$ SDS

$0,1 \%(\mathrm{v} / \mathrm{v})$ TEMED

0,05 \% (w/v) Ammoniumpersulfat

2x SDS-Probenpuffer (Laemmli-Puffer):

0,0625 M Tris-HCl pH 6,8

0,07 M SDS

$50 \%(\mathrm{v} / \mathrm{v}) \quad$ Glycerin

0,1\% (w/v) Bromphenolblau

$5 \%(\mathrm{v} / \mathrm{v}) \quad \beta$-Mercaptoethanol 


\subsubsection{Visualisierung von Proteinen durch Coomassie Brilliant Blue}

Elektrophoretisch getrennte Proteine können mittels einer Coomassie Brilliant Blue G 250/R250-Lösung sichtbar gemacht werden, wobei die Nachweisgrenze 0,3 $\mu$ g Protein pro Bande beträgt. Dabei wird das Gel nach der Elektrophorese in einem Färbebad 60 Sekunden in der Mikrowelle auf höchster Stufe erhitzt und anschließend 10-20 Minuten geschwenkt. Das Entfärben erfolgt danach in $\mathrm{dH}_{2} \mathrm{O}$, wobei das $\mathrm{Gel}$ jeweils erhitzt wurde.

\section{Färbelösung:}

$\begin{array}{ll}10 \%(\mathrm{v} / \mathrm{v}) & \text { Ethanol } \\ 5 \%(\mathrm{v} / \mathrm{v}) & \text { Essigsäure } \\ 0,015 \%(\mathrm{w} / \mathrm{v}) & \text { Coomassie G250/R250 }\end{array}$

\subsubsection{Einengen von Proteinlösungen durch Zentrifugation}

Eine einfache und schnelle Methode um Proteinlösungen $\mathrm{zu}$ konzentrieren ist die Zentrifugation der Lösung in Gefäßen, welche am Boden eine Membran mit definierter Porengröße besitzen (Konzentratoren). Unter dieser Membran ist ein weiteres Gefäß aufgesetzt, welches den Durchfluß auffängt. Bei einem ideal kugelförmigen Proteinmolekül korreliert die Anzahl der Aminosäuren mit dem Durchmesser in einem definierten Verhältnis. Dadurch können sich Proteinmoleküle, welche kleiner sind als der Durchmesser der Pore, Wasser und gelöste Ionen durch diese in das Auffanggefäß bewegen. Das zu konzentrierende Protein wird hierbei zurückgehalten, wodurch sich seine Konzentration stetig erhöht. Die Zentrifugationen erfolgen dabei, je nach Art und Hersteller der Gefäße bei 3000-4500 x g und $4{ }^{\circ} \mathrm{C}$. Es wird jeweils die Konzentration der Proteinlösung nach der Zentrifugation bestimmt (2.2.4.1)

\subsubsection{Spaltung von Proteinen durch Proteasen}

Die Spaltung von Proteinen durch Proteasen wird im Zuge dieser Arbeit verwendet um Affinitätssequenzen von einem Zielproteinen zu entfernen. Affinitätssequenzen werden bei der Expression an das Zielprotein angehängt, binden an eine bestimmte Säulenmatrix und ermöglichen so das Isolieren eines erwünschten Proteins aus einem Gemisch. Dabei befindet sich zwischen Zielprotein und Affinitätssequenz eine Proteaseschnittstelle mit einer definierten Aminosäureabfolge. Die Spezifität, Geschwindigkeit und optimale 
Temperatur der Spaltungsreaktion, sowie die Sequenz der Proteaseschnittstelle hängen dabei von der jeweiligen Protease ab.

In dieser Arbeit wird zur Abtrennung der Affinitätssequenzen die PreScission-Protease verwendet, um die Glutathion-S-Transferase-Affinitätssequenz vom Zielprotein zu

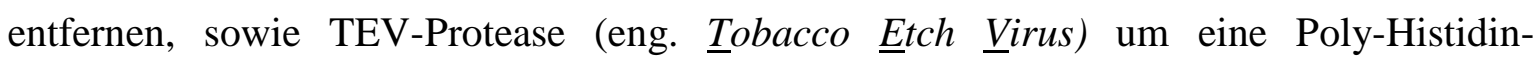
Affinitätssequenz zu entfernen. Für die Spaltungsreaktion wurde ein Protein/ProteaseVerhältnis von 100:1 eingestellt. Es wurde bei $4{ }^{\circ} \mathrm{C}$ auf dem Taumelrollmischer für mindestens 16 h inkubiert. Die Analyse der Spaltung erfolgte durch SDS-Gel (2.2.3.4).

\subsubsection{Detektion von Proteinen über Westernblot}

In dieser Arbeit wird der semidry Western-Blot mit einer PeqLAB-Blotkammer und Sekundärantikörpern mit gekoppelter Meerrettichperoxidase (HRP) verwendet, um acetyliertes Lysin spezifisch nachzuweisen.

Für die Durchführung eines Westernblots wird ein SDS-Gel (2.2.3.4) durchgeführt. Nach Beendigung der SDS-GEL werden die aufgetrennten Proteine auf eine Nitrocellulosemembran übertragen (Blotten). Whatman-Papier (2 x 4 Stücke) und Membran werden in 1x Blotpuffer inkubiert und mit dem SDS-Gel blasenfrei in der Kammer geschichtet (von unten; Whatman-Papier-Membran-Gel- Whatman-Papier). Der Transfer erfolgt für 50 min bei 200 V und 250 mA. Nach dem Transfer wird die Membran mit Ponceau S angefärbt, die Protein- und Markerbanden dokumentiert und die Membran mit dH2O gewaschen. Das geblottete Gel wird mit Coomassie gefärbt. Die Membran wird kurz in PBS gewaschen und anschließen für 30'-120' bei RT mit 3\% BSA in PBS geblockt. Nach dem Blocken der Membran erfolgt die Inkubation mit dem Primär Antikörper (1:3000-1:10000 in 3 \% BSA in PBS) bei $4{ }^{\circ} \mathrm{C}$ über Nacht. Anschließend wird die Membran 3x 10' mit PBS gewaschen und für 60'-120' mit dem Sekundärantikörper (1:10000) bei RT inkubiert. Die Banden werden über ECL sichtbar gemacht. Dabei werden zwei Komponenten, Luminol und Peroxid (Amersham ECL Prime Western Blotting Detection Reagent, GE Life Sience), in einem Verhältnis 1:1 gemischt und auf die Membran gegeben. Die Detektion der Reaktion erfolgt mittels eines Röntgenfilms (Amersham Hyperfilm ECL) und eines Entwicklers (Optimax X-Ray Film Processor, Protec)

\subsubsection{RanGAP Assay}

Der RanGAP Assay (Bischoff et al., 1994) wird durchgeführt um die GTP-Hydrolyse durch Ran und seinen Mutanten zu untersuchen. In dem Assay wird die Hydrolyse des Ran gebunden GTPs mit Hilfe eines Phosphat bindenden Proteins (Pi-Sensor, Life 
technologies) (2.2.4.3), sowie über die Freisetzung von radioaktivem Phosphat aus dem [ $\gamma$ -

$\left.{ }^{32} \mathrm{P}\right]-\mathrm{GTP}$, verfolgt.

\subsection{RanGAP Assay mit radioaktiv markiertem GTP}

Die GTPase Reaktion wird in einem Endvolumen von $50 \mu$ l durchgeführt. Mit Transportpuffer wird das Endvolumen eingestellt. Ran (Radioaktivität ca. 60000-90000 cpm) zusammen mit 5mM GTP (Endkonzentration $1 \mathrm{mM}$ ). Durch Zugabe von $0.5 \mathrm{nM}$ RanGAP wird die Reaktion gestartet Vor der Zugabe von RanGAP, wird eine Probe $(\mathrm{t}=0$ (Hintergrund)) entnommen. Nach der Zugabe von RanGAP wird eine Probe nach unterschiedlichen Zeitpunkten genommen (z.B. 15", 30", 1', 2', 5', 15', 30'). Durch die Zugabe von $1 \mathrm{ml}$ Stoppuffer wird die Reaktion getoppt. Der Reaktionsansatz für 4' bei 13000 rpm zentrifugiert. Das freigesetzte radioaktive Phosphat in $740 \mathrm{ml}$ des Überstandes wird durch Szintillationszählung gemessen.

$\begin{array}{ll}\text { Stoppuffer } & \text { Transportpuffer } \\ 10 \mathrm{mM} \mathrm{NaH}_{2} \mathrm{PO}_{4} & \text { 20mM Hepes, pH 7.3 } \\ 0.1 \mathrm{M} \mathrm{HCl} & 110 \mathrm{mM} \mathrm{KOAc} \\ 10 \%(\mathrm{v} / \mathrm{v}) \text { Ethanol } & 2 \mathrm{mM} \mathrm{Mg}(\mathrm{OAc})_{2} \\ 7 \%(\mathrm{w} / \mathrm{v}) \text { Aktivkohle } & 1 \mathrm{mM} \mathrm{EGTA} \\ & 1 \mathrm{mg} / \mathrm{ml} \mathrm{BSA}\end{array}$

\subsection{RanGAP Assay mit Phosphat Sensor}

Die GTPase Reaktion wird in einem Endvolumen von $150 \mu$ l durchgeführt. Gereinigtes und mit GTP beladenes (2.2.3.2) Ran (Endkonzentration des eingesetzten Ran $5 \mu \mathrm{M}$ ) wird mit Phosphat Sensors (Endkonzentration 1,5 $\mu \mathrm{M}$ - 1,8 $\mu \mathrm{M}$ ) für 5 ' bei $21{ }^{\circ} \mathrm{C}$ inkubiert und für weitere 5' ein Fluoreszenzspektrum aufgenommen. Mit der Zugabe von RanGAP (Endkonzentration 0,5 nM) wird die Reaktion gestartet. Die Reaktion wird für 35' bei 21 ${ }^{\circ} \mathrm{C}$ verfolgt und aufgenommen.

\section{GTPase Reaktionspuffer}

50 mM Tris/HCl pH 7.5

$100 \mathrm{mM} \mathrm{NaCl}$

$10 \mathrm{mM} \mathrm{MgCl}_{2}$

1 mM EDTA 


\subsubsection{Ran Protektions Assay}

Der Ran Protektions Assay (Askjaer et al., 1999; Petosa et al., 2004) wird durchgeführt um die Bindung von Ran und seinen Mutanten an Transportrezeptoren zu untersuchen. In dem Assay wird die Hydrolyse des Ran gebunden GTPs mit Hilfe eines Phosphat bindenden Proteins (Pi-Sensor, Life technologies) (2.2.4.3), sowie über die Freisetzung von radioaktivem Phosphat aus dem $\left[\gamma^{32} \mathrm{P}\right]-\mathrm{GTP}$, verfolgt.

\subsection{Ran Protektions Assay mit radioaktiv markiertem GTP}

Die GTPase Reaktion wird in einem Endvolumen von $50 \mu$ l durchgeführt. Mit Transportpuffer wird das Endvolumen eingestellt. Gereinigtes und mit $\left[\gamma_{-}{ }^{32} \mathrm{P}\right]-\mathrm{GTP}$ beladenes Ran (wie in 2.2.3.2 durchgeführt) wird mit unterschiedlichen Konzentrationen an Transportrezeptoren (Endkonzentration 0 bis $400 \mathrm{nM}$ ) und $5 \mathrm{mM}$ GTP (Endkonzentration $1 \mathrm{mM}$ ) inkubiert. Die erste Probe ohne RanGAP bildet den Hintergrund. Die Reaktion wird Zugabe von RanGAP (Endkonzentration $5 \mathrm{nM}$ ) gestartet und für 10' laufen gelassen. Durch Zugabe von $1 \mathrm{ml}$ Stoppuffer wird die Reaktion getoppt. Der Reaktionsansatz für 4' bei 13000 rpm zentrifugiert. Das freigesetzte radioaktive Phosphat in $740 \mathrm{ml}$ des Überstandes wird durch Szintillationszählung gemessen.

$\begin{array}{ll}\text { Stoppuffer } & \text { Transportpuffer } \\ 10 \mathrm{mM} \mathrm{NaH}_{2} \mathrm{PO}_{4} & 20 \mathrm{mM} \mathrm{Hepes,} \mathrm{pH} \mathrm{7.3} \\ 0.1 \mathrm{M} \mathrm{HCl} & 110 \mathrm{mM} \mathrm{KOAc} \\ 10 \%(\mathrm{v} / \mathrm{v}) \text { Ethanol } & 2 \mathrm{mM} \mathrm{Mg}(\mathrm{OAc})_{2} \\ 7 \%(\mathrm{w} / \mathrm{v}) \text { Aktivkohle } & 1 \mathrm{mM} \mathrm{EGTA} \\ & 1 \mathrm{mg} / \mathrm{ml} \mathrm{BSA}\end{array}$

\subsection{Ran Protektions Assay mit Phosphat Sensor}

Gereinigtes und mit GTP beladenes Ran (2.2.3.2) wird mit unterschiedlichen Konzentrationen an Crm1 (Endkonzentration 0 bis $1500 \mathrm{nM}$ ) und einer konstanten Konzentration an SPN1 (Endkonzentration $3 \mu \mathrm{M}$ ) für $10^{\prime}$ bei $20^{\circ} \mathrm{C}$ in Anwesenheit des PiSensors (Endkonzentration 1,5 $\mu \mathrm{M}$ ) inkubiert und ein Fluoreszenzspektrum als Hintergrundfluoreszens aufgenommen. RanGAP (Endkonzentration $5 \mathrm{nM}$ ) wird dem 
Ansatz beigefügt und die Reaktion für $15^{\prime}$ bei $20^{\circ} \mathrm{C}$ verfolgt und aufgenommen. Die GTPase Reaktion wird in einem Volumen von $150 \mu \mathrm{l}$ durchgeführt. Mit GTPase Reaktionspuffer wird das Endvolumen des Assays eingestellt. Für die Auswertung wird die Hintergrundfluoreszens von der erreichten Maximalfluoreszens abgezogen und die errechnete Fluoreszenzänderung gegen die Crm1 Konzentration aufgetragen. Aus dieser Auftragung kann mittels eines Kurvenangleiches über eine quadratische Funktion die Bindungskonstante, der $\mathrm{K}_{\mathrm{d}}$-Wert, berechnet werden.

$$
F=\frac{B \max }{2} \times \frac{1}{2}\left[\left(\bar{C}_{s}+K_{d}+\bar{C}_{a}\right)-\sqrt{\left(\bar{C}_{s}+K_{d}+p \bar{C}_{a}\right)^{2}-4 \bar{C}_{a} \bar{C}_{s}}\right]
$$

Die Bindungskonstante $\left(\mathrm{K}_{\mathrm{d}}\right)$ wird durch Anpassen der Lösung der quadratischen Funktion an die Daten errechnet, die die Komplexkonzentration unter Annahme einer 1:1 Stöchiometrie beschreibt. Die gemessene Bindungskurve ist die Gesamtfluoreszenz F in Abhängigkeit der freien Ligandenkonzentration $\bar{C}_{s}$, wobei $\bar{C}_{a}$ die freie Proteinkonzentration, $K_{d}$ die Dissoziationskonstante und $B_{\max }$ die maximale Fluoreszenzabnahme ist. Der Kurvenangleich erfolgt mit konstantem $\bar{C}_{a}$ als Anpassungsparameter und liefert die $\mathrm{K}_{\mathrm{d}}$ des untersuchten Gleichgewichtes. Die grafische Darstellung und der Kurvenangleich wurden mit dem Program SigmaPlot durchgeführt.

\section{GTPase Reaktionspuffer}

$50 \mathrm{mM}$ Tris/HCl pH 7.5

$100 \mathrm{mM} \mathrm{NaCl}$

$10 \mathrm{mM} \mathrm{MgCl}_{2}$

1 mM EDTA

\subsubsection{Bindungsstudie des Exportkomplex Crm1:Spn1:acetyliertem RanGTP mittels analytischer Gelfiltration}

Bei Interaktionsstudien über analytische Gelfiltration wird die Bildung eines homogenen Proteinkomplexes untersucht. Um eine gute Trennung des Komplexes von kleineren Subkomplexen oder Einzelkomponenten $\mathrm{zu}$ erreichen, werden die beteiligten Komponenten in unterschiedlichen Verhältnissen zueinander verwendet und anschließend über analytische Gelfiltration aufgetrennt (2.2.3.1.6) mit einer Superdex 200 10/300 GL und einem SDS-Gel analysiert. Alle Ansätze werden vor der Gelfiltration für 10' zentrifugiert. RanGTP wird in Form von RanQ69L ${ }^{1-180}$ eingesetzt. Die Komponenten werden individuelle gereinigt und erst für das Experiment zusammen geführt. 
Für die Assemblierung eines Exportkomplex werden die Proteine Crm1, Spn1 und RanGTP in einem Verhältnis von 1:4:6 eingesetzt, wobei die kleineren Proteine im Überschuss verwendet werden. Crm1 wird RanGTP für 20' aus Eis inkubiert, danach wird Spn1 hinzugegeben. Der Ansatz wird mit Gelfiltrationspuffer 1 langsam auf das entsprechende Endvolumen gebracht.

Für die Assemblierung des Transportkomplexes bestehend aus Importin $\beta$ und RanGTP werden die Proteine $\operatorname{Imp} \beta$ und RanGTP in einem Verhältnis von 1:6 eingesetzt, wobei die kleineren Proteine im Überschuss verwendet werden. $\operatorname{Imp} \beta$ wird mit RanQ69L ${ }^{1-180}$ für 30' auf Eis inkubiert. Die Analyse wird in Gelfiltrationspuffer 2 durchgeführt.

\section{Gelfiltrationspuffer 1 Gelfiltrationspuffer 2}

$50 \mathrm{mM} \mathrm{NaCl}$

$50 \mathrm{mM}$ Tris $\mathrm{pH}$ 7,5

$2 \mathrm{mM} \mathrm{Mg}(\mathrm{OAc})_{2}$

$50 \mu \mathrm{M}$ GTP

5 mM DTT*
$100 \mathrm{mM} \mathrm{NaCl}$

$20 \mathrm{mM}$ Tris $\mathrm{pH} 7,5$

$1 \mathrm{mM} \mathrm{MgCl}_{2}$

$50 \mu \mathrm{M}$ GTP

$1 \mathrm{mM}^{\mathrm{DTT}} *$

\subsubsection{Bindungsstudien über Pulldown-Assays}

Ein Pulldown-Assay dient dem Nachweis einer Interaktion zwischen zwei oder mehreren Proteinen. In einem solchen Experiment wird ein Protein mit Affinitätssequenz an einer entsprechenden Sepharose-Matrix immobilisiert. Proteine, welche als mögliche Interaktionspartner des immobilisierten Proteins in Frage kommen, seinerseits aber nicht mit der Sepharose-Matrix interagieren kann, wird anschließend über die Sepharose-Matrix geleitet. Werden nach ausgiebigem Waschen beide Proteine im Elutionsagens spezifisch von der Sepharose gelöst, so ist eine Interaktion zwischen beiden Proteinen nachgewiesen. Eluiert das zweite Protein allerdings schon beim Waschen, so findet unter den gegebenen Pufferbedingungen keine Interaktion statt. In dieser Arbeit wurden Pulldown-Assays ausschließlich mit GSH-Sepharose durchgeführt. Dabei werden 2 nmol des GSTFusionsproteins auf $50 \mu \mathrm{l}$ GSH-Sepharose in $1 \mathrm{ml}$ Bindungspuffer immobilisiert (60' bei 4 ${ }^{\circ} \mathrm{C}$ Rollen). Der Ansatz wird durch dreimalige Zentrifugation (1.000 xg, $\left.4{ }^{\circ} \mathrm{C}, 1 "\right)$ mit Pufferaustausch zwischen den Zentrifugationsschritten gewaschen. Folgend werden 4 nmol des betreffenden, gereinigten Interaktionspartners in $1 \mathrm{ml}$ Bindungspuffer zugegeben und für $60^{\prime}$ bei $4^{\circ} \mathrm{C}$ unter Rollen inkubiert. Nach dreimaligem Waschen in Bindungspuffer mit 
erfolgt die Elution der immobilisierten Proteinspezies mit Elutionspuffer. Alle entsprechenden Proben werden mittels SDS-Gel analysiert.

\begin{tabular}{ll} 
Bindepuffer & Elutionspuffer \\
\hline $250 \mathrm{mM} \mathrm{NaCl}$ & Bindepuffer \\
$50 \mathrm{mM} \mathrm{HEPES} \mathrm{pH} \mathrm{7,5}^{2}$ & $+30 \mathrm{mM}$ red. Gluthation \\
$5 \mathrm{mM} \mathrm{MgCl}_{2}$ & \\
$50 \mu \mathrm{M} \mathrm{GTP}$ & \\
$10 \%$ Glyzeriun &
\end{tabular}

\subsubsection{Spektroskopische Methoden}

\subsubsection{Konzentrationsbestimmung von Proteinlösungen}

Die Proteinkozentration einer Probe wird nach der Methode von Bradford bestimmt oder über den Absorption vom Trp/Tyr des Proteins bei $280 \mathrm{~nm}$.

Für die Bestimmung der Proteinkonzentration nach Bradford werden $20 \mu \mathrm{l}$ der Proteinlösung zu $980 \mu$ l eines 1:5 verdünnten Bradfordreagenz (Roth, Karlsruhe) gegeben, gut gemischt und 5' bei Raumtemperatur inkubiert. Für den Leerwert werden $20 \mu 1$ des Puffers in dem das Protein gelöst ist mit $980 \mu$ l eines 1:5 verdünnten Bradfordreagenz, gut gemischt und auch 5' bei Raumtemperatur inkubiert. Anschließend wird die Absorption bei 595 nm der Probe gegen den Leerwert gemessen. die Absorption bei 595 nm im Bereich von 0,1 - 0,9 entspricht der Proteinkonzentration in $\mathrm{mg} / \mathrm{ml}$.

Bei der Ermittlung der Proteinkonzentration über die Absorption bei $280 \mathrm{~nm}$ lässt sich die Proteinkonzentration mittels des Lambert-Beerschen Gesetzes errechnen.

$$
c=\frac{A}{\varepsilon \times d}
$$

Hier entsprechen $\quad A=$ Absorption bei $280 \mathrm{~nm}$

$$
\begin{aligned}
& \varepsilon=\text { molarer Extinktionskoeffizient }\left[\mathrm{M}^{-1} \mathrm{~cm}^{-1}\right] \\
& \mathrm{c}=\text { Konzentration }[\mathrm{M}] \\
& \mathrm{d}=\text { Schichtdicke der Küvette }[\mathrm{cm}]
\end{aligned}
$$


Die Konzentration einer Nukleinsäurenlösung kann quantitativ mittels eines Photometers bei $260 \mathrm{~nm}$ gegen einen Leerwert ermittelt werden. Dabei sind folgende Umrechnungswerte heranzuziehen:

$\begin{array}{lll}\text { 1 A 260nm } & = & 50 \mu \mathrm{g} / \mathrm{ml} \text { doppelsträngige DNA } \\ \text { 1 A 260nm } & = & 40 \mu \mathrm{g} / \mathrm{ml} \text { einzelsträngige DNA } \\ \text { 1 A 260nm } & = & 33 \mu \mathrm{g} / \mathrm{ml} \text { Oligonukleotid }\end{array}$

Wie rein eine Nukleisäurelösung ist kann über den Quotient der Extinktionen bei $260 \mathrm{~nm}$ und $280 \mathrm{~nm}$ ermittelt werden. Die aromatischen Aminosäuren von Proteinen absorbieren vor allem im Bereich von $280 \mathrm{~nm}$, wohingegen Nukleinsäuren ein Absorptionsmaximum bei $260 \mathrm{~nm}$ besitzen. Reine DNA liegt dem zu folge bei einem Quotienten von 1,8 bis 2,0 vor. Eine mit Proteinen verunreinigte DNA-Lösungen weist einen kleineren Quotienten der Absorptionen bei $260 \mathrm{~nm} / 280 \mathrm{~nm}$ auf.

\subsubsection{Phosphate Sensor Assay}

In dieser Arbeit wird der Phosphat Sensor in Verbindung mit dem Ran Protektions Assay und dem RanGAP Assay verwendet. Hierbei handelt es sich um ein Phosphat bindendes Protein, welches mit einem MDCC Fluorophor modifiziert wurde. Durch die Bindung von einem Phosphatmolekül an den Sensor kommt es zu einem Fluoreszenzsignal, welches mit dem Spektrofluorimeter Fluoromax III (Jobin Yvon) detektiert werden kann. Der Sensor wird in einer Endkonzentration von $1.5 \mu \mathrm{M}$ bis 1,8 $\mu \mathrm{M}$ aus einer $45 \mu \mathrm{M}$ Stocklösung verwendet. Die Anregung erfolgt bei 425 nM mit der Emission bei 460 nM. Die Messungen mit dem Sensor werden jeweils mit Blenden von 0.5/0.4 nm, einem Messpunkt alle 0,5 " und einer Integrationszeit von 0,5" durchgeführt.

\subsubsection{Reinigungsprotokolle}

\subsubsection{Ran (Homo sapiens) in pCDFR Duet PylT}

\subsection{Acetyliertes und nicht acetyliertes RanQ69L $1-180$}

Nach Expression (2.2.2.5.1) und Lyse (2.2.2.6) werden alle Schritte bei $4{ }^{\circ} \mathrm{C}$ durchgeführt. Erster Schritt in der Reinigung ist die Affiniätschromatographie über Ni-NTA-SepharoseSäulen (2.2.3.1.1). Die Affinitätssequenz wird durch proteolytischen Verdau (2.2.3.7) entfernt und das Protein folgend entsalzt (2.2.3.1.4). Es folgt ein zweiter Schritt über eine Ni-NTA-Sepharose. Das Zielprotein befindet sich im Durchfluss und wird für die 
Gelfiltration (2.2.3.1.6) verwendet. Das fertige Protein wird eingeengt, in Aliquots zu 100 $\mu \mathrm{l}$ mit flüssigem Stickstoff tiefgefroren und bei $-80{ }^{\circ} \mathrm{C}$ gelagert.

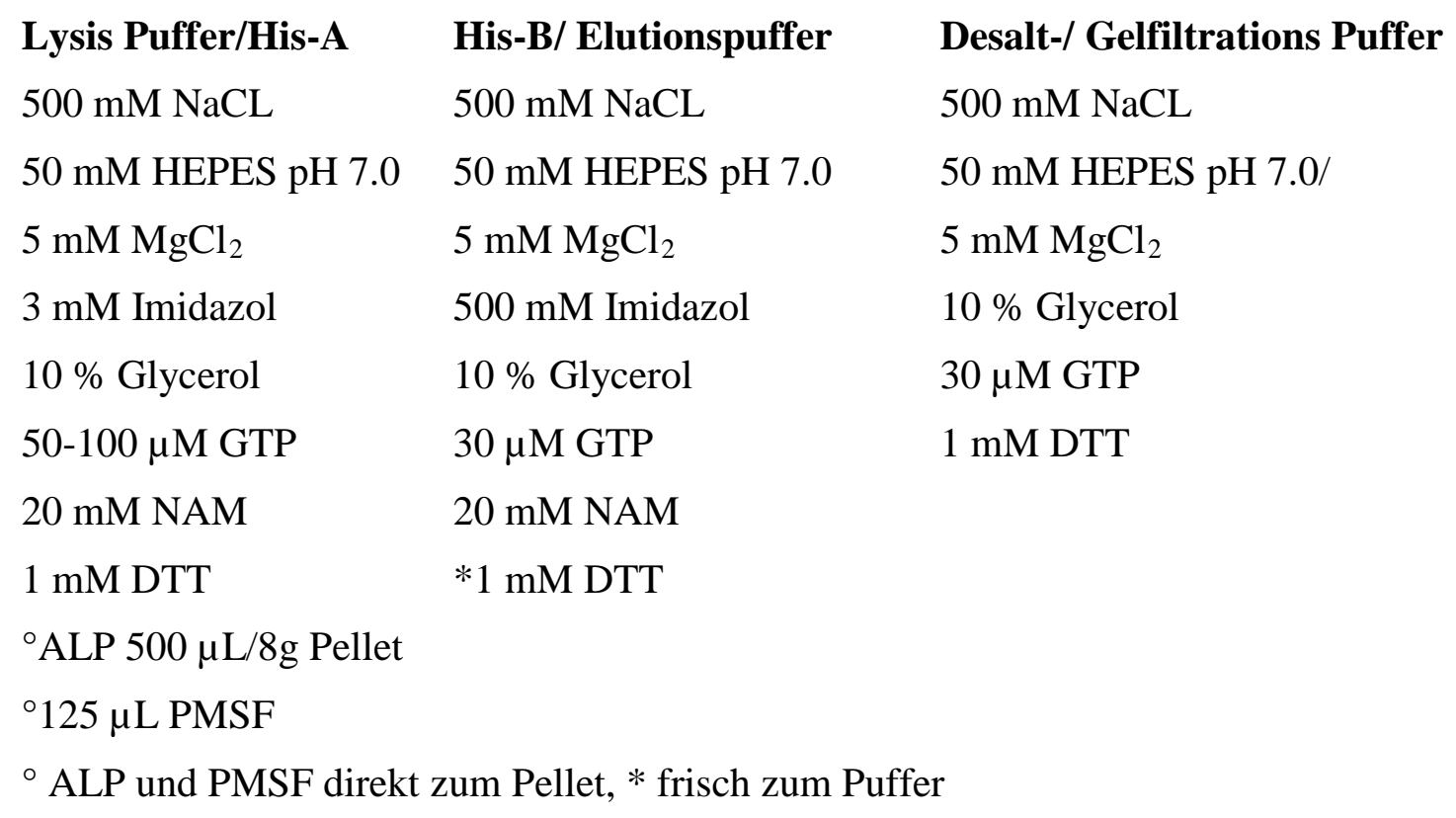

\subsection{Acetyliertem und nicht acetyliertem $\operatorname{Ran}_{\mathrm{fl}}$}

Alle Schritte der Reinigung werden bei $4{ }^{\circ} \mathrm{C}$ durchgeführt. Der Überstand nach der Lyse (2.2.2.6) wird im ersten Schritt der Reinigung über Ni-NTA-Sepharose-Säulen (2.2.3.1.1) geleitet. Das eluierte Protein wird eingeengt (2.2.3.6) und für den Schritt der Gelfiltration (2.2.3.1.6) verwendet. Das gereinigte Protein wird ankonzentriert und in Aliquots zu 100 $\mu$ tiefgefroren. Die Lagerung findet bei $-80^{\circ} \mathrm{C}$ statt.

\begin{tabular}{|c|c|c|}
\hline Lysis Puffer/His-A & His-B/ Elutionspuffer & Gelfiltrations Puffer \\
\hline $500 \mathrm{mM} \mathrm{NaCL}$ & $500 \mathrm{mM} \mathrm{NaCL}$ & $500 \mathrm{mM} \mathrm{NaCL}$ \\
\hline 50 mM HEPES pH 8.0 & 50 mM HEPES pH 8.0 & 50 mM HEPES pH 8.0/ \\
\hline $5 \mathrm{mM} \mathrm{MgCl}_{2}$ & $5 \mathrm{mM} \mathrm{MgCl}_{2}$ & $5 \mathrm{mM} \mathrm{MgCl}_{2}$ \\
\hline 3 mM Imidazol & 500 mM Imidazol & 10 \% Glycerol \\
\hline 10\% Glycerol & 10 \% Glycerol & $1 \mathrm{mM}$ DTT \\
\hline 20 mM NAM & 20 mM NAM & \\
\hline $1 \mathrm{mM}$ DTT & *1 mM DTT & $*$ \\
\hline \multicolumn{3}{|l|}{${ }^{\circ}$ ALP $500 \mu$ L/8g Pellet } \\
\hline${ }^{\circ} 125 \mu \mathrm{L}$ PMSF & & \\
\hline ALP und PMSF & n Pellet, * fr & \\
\hline
\end{tabular}




\subsubsection{Crm1 (Homo sapiens)}

Die Reinigung von Crm1 erfolgt bei $4{ }^{\circ} \mathrm{C}$ in drei Schritten. Im ersten Schritt wird das exprimierte Protein (2.2.2.5.2) nach der Lyse (2.2.2.6) über Affiniätschromatographie mittels Ni-NTA-Sepharose-Säulen (2.2.3.1.1) geleitet und über einen Gradienten von 6 Säulenvolumen eluiert (0-100\% B, 100 \% entsprächen 400 mM Imidazol). Im zweiten Schritt wird das eluierte Protein umgepuffert (2.2.3.1.4) und weiter über einen Anionentauscher (2.2.3.1.5) gereinigt. Die Elution verläuft in einem linearen Gradienten von 15-20 Säulenvolumen (50-500 mM NaCl). Im finalen Schritt erfolgt der Aufreinigung erfolgt die Gelfiltration mit einer Superdex 200 XK26/60 Säule (2.2.3.1.6). Das gereinigte Protein wird ankonzentriert (2.2.3.6) und mit flüssig Stickstoffe in Aliquots zu $100 \mu \mathrm{l}$ tiefgefroren. Die Lagerung erfolgt bei $-80{ }^{\circ} \mathrm{C}$.

\begin{tabular}{|c|c|c|}
\hline$\underline{\text { His-A Puffer }}$ & $\underline{\text { His-B Puffer }}$ & Entzalzungspuffer \\
\hline $500 \mathrm{mM} \mathrm{NaCl}$ & $500 \mathrm{mM} \mathrm{NaCl}$ & $50 \mathrm{mM} \mathrm{NaCl}$ \\
\hline $\begin{array}{l}50 \mathrm{mM} \text { HEPES } \mathrm{pH} \\
7,5\end{array}$ & $\begin{array}{l}50 \mathrm{mM} \text { HEPES } \mathrm{pH} \\
7,5\end{array}$ & $\begin{array}{l}50 \mathrm{mM} \text { HEPES } \mathrm{pH} \\
7,5\end{array}$ \\
\hline $2 \mathrm{mM} \mathrm{MgCl}_{2}$ & $2 \mathrm{mM} \mathrm{MgCl} 2$ & $2 \mathrm{mM} \mathrm{Mg}(\mathrm{OAc})_{2}$ \\
\hline 30 mM Imidazol & 400 mM Imidazol & ${ }^{\circ} 2 \mathrm{mM}^{-} \mathrm{DTT}^{*}$ \\
\hline${ }^{\circ} 2$ mM DTT* & ${ }^{\circ} 2$ mM DTT* & \\
\hline \multicolumn{3}{|l|}{ * frisch zum Puffer } \\
\hline$\underline{\text { Niedrigsalzpuffer }}$ & $\underline{\text { Hochsalzpuffer }}$ & Gelfiltrationspuffer \\
\hline $50 \mathrm{mM} \mathrm{NaCl}$ & $500 \mathrm{mM} \mathrm{NaCl}$ & $50 \mathrm{mM} \mathrm{NaCl}$ \\
\hline $\begin{array}{l}50 \mathrm{mM} \text { HEPES } \mathrm{pH} \\
7,5\end{array}$ & $\begin{array}{l}50 \mathrm{mM} \text { HEPES } \mathrm{pH} \\
7,5\end{array}$ & $\begin{array}{l}50 \mathrm{mM} \text { HEPES } \mathrm{pH} \\
7,5\end{array}$ \\
\hline $2 \mathrm{mM} \mathrm{Mg}(\mathrm{OAc})_{2}$ & $2 \mathrm{mM} \mathrm{Mg}(\mathrm{OAc})_{2}$ & $2 \mathrm{mM} \mathrm{Mg}(\mathrm{OAc})_{2}$ \\
\hline${ }^{\circ} 2$ mM DTT* & ${ }^{\circ} 2$ mM DTT* & ${ }^{\circ} 5$ mM DTT* \\
\hline
\end{tabular}

\subsubsection{Spn1 (Homo sapiens)}

Alle Reinigungsschritte werden bei Raumtemperatur durchgeführt. Die Reinigung von SPN1 wird wie in Strasser et al (2004) beschrieben durchgeführt. Das fertig gereinigte Protein wird eingeengt (2.2.3.6) in Aliquots zu $100 \mu$ l tiefgeforen und bei $-80{ }^{\circ} \mathrm{C}$ gelagert.

Lysis Puffer
$1 \times \mathrm{PBS}$
$2,5 \mathrm{mM} \mathrm{MgCl}_{2}$
2mM EDTA

GSH-A Puffer $100 \mathrm{mM} \mathrm{NaCl}$

20mM Tris pH7,5

2,5 $\mathrm{mM} \mathrm{MgCl}_{2}$

\author{
GSH-B Puffer \\ $100 \mathrm{mM} \mathrm{NaCl}$ \\ 20mM Tris pH7,5 \\ 2,5 $\mathrm{mM} \mathrm{MgCl}_{2}$
}


2 mM DTT*

○ALP $500 \mu \mathrm{L} / 8 g$ Pellet

$2 \mathrm{mM}$ EDTA

*2 mM DTT*

○ ALP zum Pellet, * frisch zum Puffer

\section{Heparin A Puffer}

$20 \mathrm{mM} \mathrm{NaCl}$

20mM Tris $\mathrm{pH} 7,5$

$5 \mathrm{mM} \mathrm{MgCl}_{2}$

2mM EDTA

*2mM DTT*
Heparin B Puffer

$1 \mathrm{M} \mathrm{NaCl}$

20mM Tris pH7,5

$5 \mathrm{mM} \mathrm{MgCl}_{2}$

2mM EDTA

*2 mM DTT*
2mM EDTA

*2 mM DTT*

30mM red. Gluthation

\subsubsection{RanGAP1 (Mus musculus) in pGEX-6P-1}

Die Reinigung von RanGAP1 nach Expression (2.2.2.5.4) und Aufschluss (2.2.2.6) verläuft bei $20^{\circ} \mathrm{C}$. Das Lysat wird über GSH-Sepharose Säulen geleitet (2.2.3.1.2) und das interagierende Protein in einem Schritt mit $30 \mathrm{mM}$ reduziertem Glutathion eluiert. Zur Entfernung der GST-Affinitätssequenz wird dem Eluat nach einengen auf $4 \mathrm{ml}$ (2.2.3.6) Prescission Protease (2.2.3.7) beigefügt. Im letzten Schritt wird das Protein über Gelfiltration (2.2.3.1.6) mit einer Superdex 200 XK26/60 Säule gereinigt. Das gereinigte Protein wird ankonzentriert (2.2.3.6) in Aliquots $\mathrm{zu} 100 \mu \mathrm{l}$ mit flüssig Stickstoff eingefroren und bis zur Verwendung bei $-80^{\circ} \mathrm{C}$ gelagert.

\begin{tabular}{|c|c|c|}
\hline Lysis/GST-A Puffer & $\underline{\text { GST-B Puffer }}$ & Gelfiltrationpuffer \\
\hline 50 mM Tris pH 8 & 50 mM Tris $\mathrm{pH} 8$ & 50 mM Tris pH 7.6 \\
\hline $200 \mathrm{mM} \mathrm{NaCL}$ & $200 \mathrm{mM} \mathrm{NaCL}$ & $200 \mathrm{mM} \mathrm{NaCL}$ \\
\hline 1 mM EDTA & $1 \mathrm{mM}$ EDTA & *1 mM DTT \\
\hline *1 mM DTT & *1 mM DTT & \\
\hline * ALP & *30 mM red. Gluthation & \\
\hline * PMSF & & \\
\hline *add fresh & & \\
\hline
\end{tabular}

\subsubsection{Exportkomplex Crm1:SPN1: RanGTP}

Für die Assemblierung des Exportkomplex bestehend aus Crm1, SPN1, und RanGTP werden die individuell gereinigt verwendet. RanGTP wird in Form von RanQ69L ${ }^{1-180}$ eingesetzt, welches in acetylierter Form benutzt wird. Zur Bildung des Exportkomplex werden die individuellen Proteine Crm1, Spn1 und RanQ69L ${ }^{1-180}$ in einem Verhältnis von 1:4:6 eingesetzt, wobei die kleineren Proteine im Überschuss verwendet werden. 
Crm1 wird mit acetyliertem RanQ69L ${ }^{1-180}$ für 30' aus Eis inkubiert, danach wird SPN1 hinzugegeben. Der Ansatz wird in einen Dialyseschlauch überführt und für 3-4 h bei $4{ }^{\circ} \mathrm{C}$ gerührt. Es erfolgt ein Pufferwechsel und weiteres Inkubieren über Nacht bei $4{ }^{\circ} \mathrm{C}$. Folgend wird der Ansatz dem Dialyseschlauch entnommen und der Komplex weiter über Gelfiltration (2.2.3.1.6) mit einer Superdex 200 XK 26/60 von den überschüssigen Proteinen getrennt. Der erhaltene Komplex wird eingeengt (2.2.3.6), in Aliquots zu 30-60 $\mu \mathrm{l}$ tiefgefroren und bis zur weiteren Verwendung bei $-80^{\circ} \mathrm{C}$ gelagert.

\section{Dialysepuffer}

$50 \mathrm{mM} \mathrm{NaCl}$

$50 \mathrm{mM}$ Tris $\mathrm{pH}$ 7,5

$2 \mathrm{mM} \mathrm{Mg}(\mathrm{OAc})_{2}$

${ }^{\circ} 5$ mM DTT*

\author{
Gelfiltrationspuffer \\ $50 \mathrm{mM} \mathrm{NaCl}$ \\ $50 \mathrm{mM}$ Tris $\mathrm{pH}$ 7,5 \\ $2 \mathrm{mM} \mathrm{Mg}(\mathrm{OAc})_{2}$ \\ ${ }^{\circ} 50 \mu \mathrm{M}$ GTP \\ 5 mM DTT*
}

\subsubsection{Kristallographische Methode}

\subsubsection{Kristallisation von Proteinen}

Zur Kristallisation von Proteinen wird in dieser Arbeit die Methode des sitzenden Tropfen verwendet. Die Kristallisation geschieht dabei in sitting drop Kristallisationsschalen durch Dampfdiffusion. In das Reservoir der Kristallisationsschale werden 500 $\mu \mathrm{l}$ der Kristallisationslösung vorgelegt. In die zentrale Vertiefung der Schalen werden 1-2 $\mu \mathrm{l}$ der Proteinlösung mit einer Konzentration von 5-7 mg/ml pipettiert und im Verhältnis 1:1 mit der Kristallisationslösung gemischt. Nach dem Mischen wird die Schale mit durchsichtigem Klebeband verschlossen und anschließen bei $20^{\circ} \mathrm{C}$ oder $25^{\circ} \mathrm{C}$ gelagert.

\subsubsection{Kryo-Bedingungen}

Die Auswahl des Kryopuffers, mit dem Kristalle für Röntgenbeugungsexperimente vorbereitet werden, kann einen beträchtlichen Einfluss auf das Streuverhalten eines Kristalls nehmen. Dieser Puffer muss in der Lage sein das Entstehen von Wasserkristallen bei $100 \mathrm{~K}$ zu verhindern. Die Kristallisationsbedingungen, in welchen die Kristalle wachsen, eignen sich in manchen Fällen direkt als Kryopuffer. Da dies jedoch häufig nicht der Fall ist, muss meist erst eine geeignete Kryo-Bedingung ermittelt werden. Diese besteht meist aus dem Reservoir mit Zusatz geeigneter Chemikalien, wie zum Beispiel 
Glycerin, Polyethylenglykol, Butandiol oder anderen in verschiedenen Konzentrationen. Um die Kristalle in den Kryopuffer zu überführen werden diese mit einer kleinen Neilonschleife (Loop) der Kristallistionsbedingung entnommen, in diesem direkt mit Kryopuffer benetzt und in flüssig Stickstoff eingefroren. In diesem Zustand kann der Kristall im Loop auf dem Goniometerkopf montiert werden. In dieser Arbeit bestand die Kryo-Bedingung aus dem Reservoir mit 16\% 2,3-Butandiol, 2\% PEG400 und 8\% Glyzerin.

\subsubsection{Röntgenbeugungsexperimente}

Ein Röntgenbeugungsexperiment wird einerseits durchgeführt um zu testen, ob ein erhaltener Kristall aus Protein besteht und ein dementsprechendes Beugungsmuster entsteht, sowie andererseits zur Sammlung von Daten für die Berechnung der Struktur von Proteinen. In beiden Fällen wird ein Einkristall mittels einer kleinen Neilonschleife aus der Kristallisationsbedingung entnommen und im Schnittpunkt zwischen Röntgenstrahl und Rotationsachse des Goniometers auf dem Goniometerkopf montiert. Für Tests von Crm1:Spn1:RanGTP Kristallen wird das Röntgendiffraktometer 007 bzw. Röntgendiffraktometer RU-H3R (Rigaku, Japan) verwendet. Es wird jeweils nur ein Bild aufgenommen, wobei der Kristall 30'-50' belichtet und um $0,25^{\circ}$ gedreht wird. Ein Datensatz eines Kristalls aus Crm1, SPN1 und acetyliertem RanGTP wurde an der Beamline P13 des Deutschen Elektronen-Synchrotron (DESY, Hamburg) bei 100K aufgenommen. Der Kristall mit acetyliertem Lysin 71 wurde bei einer Wellenlänge von 0.824800 Å, einem Kristall-Detektor Abstand von $61.6 \mathrm{~cm}$ mit einem PILATUS 6M Detektor gemessen und dabei für $180^{\circ}$ mit $0.1^{\circ}$ pro Bild gedreht. Der Kristall mit acetyliertem Lysin 99 wurde bei einer Wellenlänge von $0.773180 \AA \AA$ mit einem Kristall-Detektor Abstand von $73,8 \mathrm{~cm}$ gemessen. Der Kristall wurde um insgesamt $223^{\circ}$ mit $0.1^{\circ}$ pro Bild gedreht. Zur Indizierung, Integration und Datenreduktion der erhaltenen Daten werden die Programme XDS, XSCALE (Kabsch, 1993) und XPREP (Sheldrick, 2005) benutzt.

\subsubsection{Lösung des Phasenproblems durch Molekularen Ersatz}

Aus den, nach den Röntgenbeugungsexperimenten (2.2.6.3) erhalten Beugungsdaten lässt sich eine Elektronendichteverteilung errechnen. Hier für wird die Fourier-Transformation verwendet, diese verbindet die experimentellen Beugungsdaten im reziproken Raum mit der Elektronendichte im Realraum. 
$\rho(x y z)=\frac{1}{V} \sum_{h} \sum_{k} \sum_{l} \vec{F}_{\mathrm{hkl}} e^{-2 \pi i(h x+k y+l z)}$

Für die Strukturfaktoren $\vec{F}_{\text {hkl }}$ gilt:

$\vec{F}_{\mathrm{hkl}=}\left|F_{\mathrm{hkl}}\right| e^{i \varphi(h k l)}$.

Aus dieser Beziehung wird ersichtlich, dass die Kenntnis der Phasen $\varphi(h k l)$ der Beugungsdaten für die Berechnung der Elektronendichte unerlässlich ist.

$\rho(x y z)=\frac{1}{V} \sum_{h} \sum_{k} \sum_{l}\left|F_{\mathrm{hkl}}\right| e^{-2 \pi i(h x+k y+l z)+i \varphi(h k l)}$

Während des Sammelns der Beugungsdaten geht die Phaseninformation verloren, dies nennt man das kristallographische Phasenproblem. Dieses Problem lässt sich mit unterschiedlichen Methoden lösen, wie zum Beispiel durch Anomale Dispersion (SAD/MAD), durch isomorphen Ersatz (SIR/MIR) oder molekulare Ersatz (MR, molecular replacement).

In dieser Arbeit wird die Methode des molekularen Ersatzes verwendet, da bereits Moleküle ähnlicher Struktur bekannt sind. Dem zugrunde liegt die Patterson-Methode. Dabei wird sich zu Nutze gemacht eine intermolekulare Vektorkarte berechnen zu können, die Patterson-Karte. Diese wird durch Quadrierung der Strukturfaktoamplituden und dem Nullsetzen aller Phasen erhalten und wird durch die Patterson-Funktion ausgedrückt (Rhodes, 2006).

$\rho(u, v, w)=\frac{1}{V} \sum_{h k l}\left|F_{\mathrm{hkl}}\right|^{2} e^{-2 \pi i(h u+k w+l w)}$

Die über die Patterson-Funktion berechnete Patterson-Karte der unbekannten Struktur lässt sich nun über eine Rotationsfunktion, basierend auf der Maximum-Likelihood-Methode, in Korrelation zur Patterson-Karte des Suchmodelles bringen. Die höchste Korrelation tritt dabei auf, wenn sowohl die unbekannte als auch die bekannte Struktur annähernd gleich orientiert sind. Die Orientierung des Suchmodells kann in Eulerwinkeln angegeben und für die anschließende Translationssuche genutzt werden. Bei dieser wird in einer sog. fast translation function das Suchmodell durch Translation in die korrekte Position in der Einheitszelle verschoben. Auch hier wird nach der höchsten Korrelation der Patterson-Karten von Suchmodell und unbekannter Struktur gesucht. Die korrekte Translation wird in kartesischen Koordinaten angegeben.

Mit den Ergebnissen der Rotations- und der Translationssuche lassen sich nun die Phasen der unbekannten Struktur ermitteln. Diese Methode kam bei der Strukturbestimmung des Komplexes Crm1:SPN1:RanGTP mit acetyliertem RanQ69L ${ }^{1-180}$ zum Einsatz. Hierfür wurde das Programm PHASER verwendet. 


\subsubsection{Modellbau und Strukturverfeinerung}

Für den Bau der Modelle der Strukturen von Crm1:Spn1:RanGTP mit acetyliertem RanQ69L ${ }^{1-180}$ wurde Phenix AutoBuild und COOT (Emsley \& Cowtan, 2004) verwendet und mit Phenix- Softwarepaket verfeinert. Nach dem Vergleichen der Modelle mit der $2 \mathrm{~F}_{\text {obs }}-\mathrm{F}_{\text {calc }}$ Elektronendichtekarte werden zunächst die Bereiche der Modelle an die Elektronendichtekarte angepasst, so wie Bereiche verändert, welche eine gemeinsame Dichte belegen und sich daher überlagern. Diese neuen Modelle werden benutzt um die Strukturen weiter zu verfeinern. In der Strukturverfeinerung werden van-der-Waals Abstände, polare und ionische Wechselwirkungen und die Temperaturfaktoren der einzelnen Atome (B-Faktoren) berücksichtigt, als auch die beobachteten den berechneten Strukturfaktoren angeglichen. Durch Vergleich der beobachteten und der aus dem Modell berechneten Strukturfaktoramplituden lässt sich die Qualität der Angleichung abschätzen (R-Faktor). $\mathrm{R}_{\text {cryst }}$ der kristallographische R-Faktor bezeichnet den aus diesem Vergleich errechneten Fehler und ist definiert als:

$$
R_{\text {Cryst }}=\frac{\sum|| F_{\text {obs }}|-| F_{\text {calc }}||}{\sum\left|F_{\text {obs }}\right|}
$$

Dabei entspricht $\mathrm{F}_{\text {calc }}$ den berechneten und $\mathrm{F}_{\mathrm{obs}}$ den beobachteten Strukturfaktoramplituden. Der freie R-Faktor $\mathrm{R}_{\text {free, }}$, welcher auf dieselbe Weise berechnet wird, aber von nicht in die Verfeinerung mit einbezogenen Reflexen (5\% der Reflexe entnommen dem Datensatz) Gebrauch macht, wird als weitere Kontrolle hinzugezogen. Dieser sogenannte Testsatz wird einzig zur Kreuzvalidierung eingesetzt, um die Konvergenz der Strukturverfeinerung zu kontrollieren. Ferner wird die verfeinerte Elektronendichtekarte mit der ursprünglichen Dichte, welche aus der Phaseninformation des molekularen Ersatzes berechnet wurde, verglichen und die resultierende $F_{\text {obs }}-F_{\text {calc }}$ Elektronendichtekarte zum Abgleich während des Modellbaus verwendet. 


\section{Ergebnisse}

\subsection{Die GTPase Ran verkürzt und in voller Länge in acetylierter Form}

Um die kleine GTPase Ran mit acetyliertem Lysin funktional und strukturell zu untersuchen, war es erforderlich diese in verschiedenen Formen sowohl für biochemische als auch für kristallographische-Experimente in verschiedenen Längen (Abb. 14) mit den entsprechenden Mutationen zu klonieren, exprimieren und zu reinigen. Für biochemische Experimente wurde die GTPase in ihrer vollen Länge gewählt und für Kristallisationsexperimente eine verkürzte Form, welcher die Reste 181- 216 fehlten, sowie einer zusätzlichen Glutamin (Gln, Q) zu Leucin (Leu, L) Mutation an Position 69, welche die GTP Hydrolyse sehr stark verringert.

Die Klonierung der GTPase ist in Material und Methoden 2.2.1.9 Klonierung der GTPase Ran verkürzt und in voller Länge in acetylierter Form beschrieben. Für die funktionale und strukturelle Untersuchung wurden die in Tabelle 2 aufgelisteten Konstrukte verwendet. Das entsprechende Vorgehen zur Expression und Reinigung der GTPase ist beispielhaft in den nächsten 2 Unterkapiteln für die zwei Längen je an einem Beispiel dargestellt.

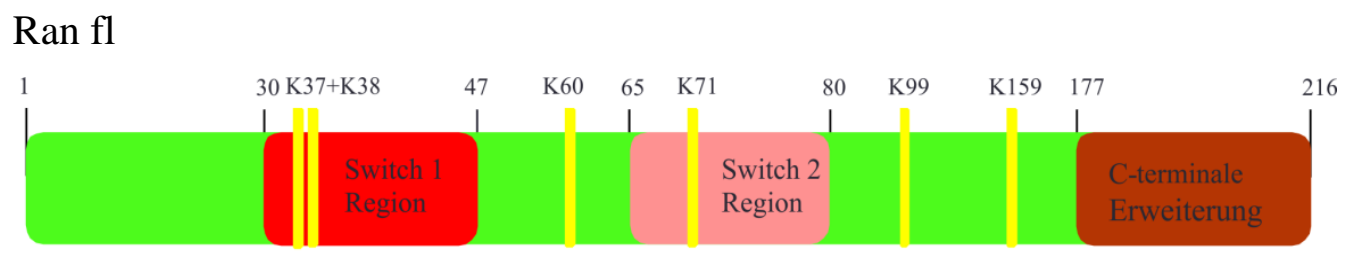

RanQ69L ${ }^{1-180}$

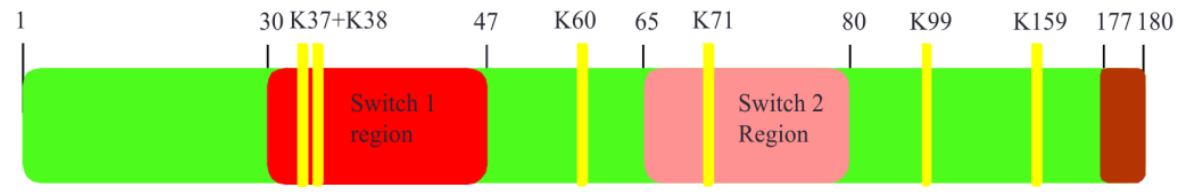

Abb. 14: Schematische Darstellung der verwendeten h.s.Ran Konstrukte.

Es sind die beiden Grundkostruckte dargestellt, die in der Arbeit verwendet wurden. Die einzelnen Mutanten werden nicht dargestellt, dass sie sich von den Grundkostruckten in Länge und genereller Zusammensetzung nicht unterscheiden. In rot ist die erste variable Region (Switch 1 Region AS 30 bis 47), in pink ist die zweite variable Region, AS 65 bis 80) dargestellt. Die C-Terminale Verlängerung (AS 177- 216) mit der DDDEDL-Sequenz ist in braun dargestellt. Die gelben Balken zeigen die Choudhary et al., (2009) festgestellten acetylierbaren Lysine an. 
Tabelle 2: In der Arbeit verwendete Konstrukte der kleinen GTPase Ran

$\begin{array}{cc}\text { RanQ69L } & \text { 1-180 } \\ \text { WT } & \text { Ranstrukt }_{\mathbf{f l}} \text { Konstruk } \\ \text { K37TAG } & \text { WT } \\ \text { K38TAG } & \text { K37TAG } \\ \text { K60TAG } & \text { K38TAG } \\ \text { K71TAG } & \text { K60TAG } \\ \text { K99TAG } & \text { K71TAG } \\ \text { K159TAG } & \text { K99TAG }\end{array}$

3.1.1 Expression und Reinigung von acetyliertem und nicht acetyliertem RanQ69L ${ }^{1-}$ 180

Das durch Sequenzierung (2.2.1.3) überprüfte und korrekte RanQ69L ${ }^{1-180}$ Konstrukt mit dem jeweiligen Amber-Stopcodon (an der jeweils in Tabellen 2 angegebenen Position) wird zusammen mit einem Plasmid transformiert, welches die notwendige AminoacyltRNA-Synthetase trägt (pBK-AckRS3) und benötigt wird um die tRNA mit Acetyllysin zu beladen. Für die Expression des acetylierten, sowie des nicht acetylierten RanQ69L ${ }^{1-180}$ wurden E.coli BL21 (DE3) Zellen verwendet und die Expression nach 2.2.2.5.1 in Material und Methoden durchgeführt.

Durch die Verwendung eines pCDF Duet Plasmids als Expressionsvektor lies sich RanQ69L $^{1-180}$ als Hexa-His-Fusionsprotein exprimieren. Die Hexa-His-Sequenz ist hier am N-Terminus des Proteins lokalisiert. Dies erlaubte die Reinigung von RanQ69L ${ }^{1-180}$ in acetylierter, wie nicht acetylierter Form über diese Hexa-His-Sequenz unter Verwendung von $\mathrm{Ni}^{2+}$-NTA Sepharose Säulen (2.2.3.1.1) bei $4{ }^{\circ} \mathrm{C}$. Die Abbildung 15 zeigt die SDSGele zu den einzelnen Schritten der Reinigung von RanQ69L ${ }^{1-180}$, beispielhaft am RanQ69L ${ }^{1-180}$ K71Ac. In Abb.15A ist das SDS-Gel zum ersten Schritt der Reinigung dargestellt. Hier zeigt sich das nach diesem ersten Schritt der Reinigung über $\mathrm{Ni}^{2+}$-NTA Sepharose das Protein noch stark verunreinigt eluiert (letzten 3 Reihen Abb. 15A). Das eluierte Fusionsprotein ist durch einen schwarzen Pfeil markiert und bei einem apparenten Molekulargewicht von etwa $25 \mathrm{kDa}$ zu beobachten. Das verwendete Konstrukt enthielt eine Schnittstelle für die TEV-Protease (eng. Tabacco Etch Virus), diese ermöglicht das Abtrennen der Hexa-His-Sequenz vom eigentlichen Protein. In einem Zwischenschritt der Reinigung von RanQ69L ${ }^{1-180}$ in seiner acetylierten, so wie nicht acetylierter Form, wird dem von der $\mathrm{Ni}^{2+}$-NTA Sepharose eluiertem Protein die TEV-Protease im Verhältnis 1:100 zur Gesamtproteinmenge Ran zugegeben und über Nacht bei $4^{\circ} \mathrm{C}$ inkubiert. Die Probe 
wird nachfolgend entsalzt (2.2.3.1.4) um das Imidazol $\mathrm{zu}$ entfernen, mit welchem RanQ69L ${ }^{1-180}$ von der Säule eluiert wurde. Dieser Zwischenschritt diente der Vorbereitung zu einer zweiten $\mathrm{Ni}^{2+}$-NTA Sepharose Lauf, bei dem Verunreinigungen und die nicht gespaltenen Proteine sowie die TEV-Protease an das Säulenmaterial binden, das von dem Hexa-Histidin-Tag befreite RanGTP aber nicht. Dieser zweite Schritt der Reinigung ist in Abb. 15B an Hand des SDS-Gel dargestellt. Dabei ist in der ersten Spalte die Probe nach der Inkubation mit der TEV-Protease aufgetragen, in der Folgenden die Probe nach dem Entsalzen. In diesen beiden Spalten ist zu beobachten, das aufgrund der Aktivität der Protease das RanQ69L ${ }^{1-180}$ bei etwa $20 \mathrm{kDa}$ zu beobachten ist, was dem erwarteten Molekulargewicht von RanQ69L ${ }^{1-180}$ entspricht. Das RanQ69L ${ }^{1-180}$ ohne die Histidinsequenz (His-Tag) interagiert nicht mit der $\mathrm{Ni}^{2+}$-NTA Sepharose Säule und eluiert im Durchfluss der $\mathrm{Ni}^{2+}$-NTA Sepharose Säule (Abb. 15B Durchfluss). Im Vergleich mit den Proben nach dem TEV-Verdau und der Entsalzung sind weniger Verunreinigungen im Durchfluss zu beobachten. Es zeigt sich das höher molekulare Verunreinigungen mit der $\mathrm{Ni}^{2+}$-NTA Sepharose Säule interagieren und dadurch von dem RanQ69L ${ }^{1-180}$ abgetrennt werden, desgleichen gilt für die TEV-Protease, sowie nicht verdautem His-RanQ69L ${ }^{1-180}$, welches noch den His-Tag trägt. Das sich im Durchfluss befindende RanQ69L ${ }^{1-180}$ wird vereinigt, ankonzentriert (2.2.3.6) und für einen weiteren Schritt der Reinigung, der Gelfiltration (2.2.3.1.6) verwendet. Die Probe wird über eine Superdex 75 XK26/60 geleitet. Abbildung 15C zeigt das SDS-Gel zur Gelfiltration. Zusätzlich zu den Proben der Gelfiltration wurde eine Probe des vereinigten Proteins nach der zweiten $\mathrm{Ni}^{2+}$-NTA Sepharose Säule aufgetragen. Die zwei Spuren nach dem Marker in Abb. 15C (bezeichnet mit Max1) sind Fraktionen aus dem ersten Maximum, das in der Gelfiltration entsteht. Die hinteren sechs Spuren auf dem SDS-Gel (bezeichnet mit Max2) sind Fraktionen, die aus einem zweiten Maximum der Gelfiltration von RanQ69L ${ }^{1-180}$ resultieren. Wie zu erkennen ist enthalten die vereinigten Fraktionen aus der zweiten $\mathrm{Ni}^{2+}$-NTA Sepharose Säule (Abb. 15C, Pool) noch einige Verunreinigungen. Das erste Maximum enthält, wie das SDS-Gel zeigt (Abb. 15C, Max1) die höher molekularen Verunreinigungen, die nach der zweiten $\mathrm{Ni}^{2+}$-NTA Sepharose Säule noch vorhanden sind. In den Fraktionen des zweiten Maximum (Abb. 15C, Max2) ist das RanQ69L ${ }^{1-180}$ zu erkennen. RanQ69L ${ }^{1-180}$ eluiert in monomere Form und ohne weitere Verunreinigungen. Durch Kommunikation und Erfahrung innerhalb des Labors kann die zweite Bande in Höhe von etwa 45 kDa als Dimer des RanQ69L ${ }^{1-180}$ identifiziert werden. 
A)

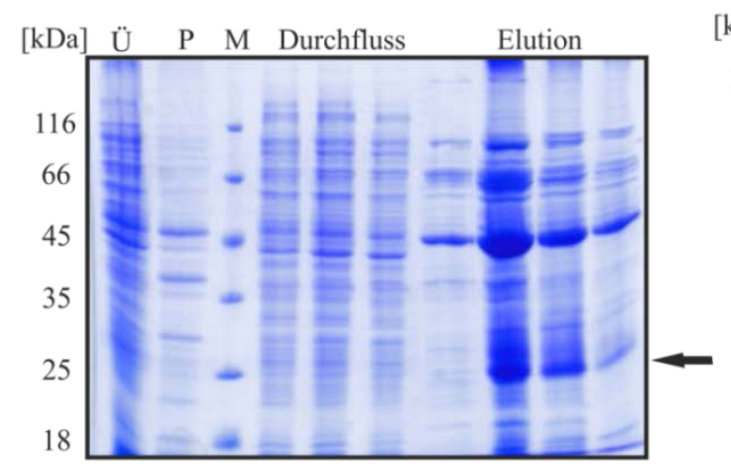

C)

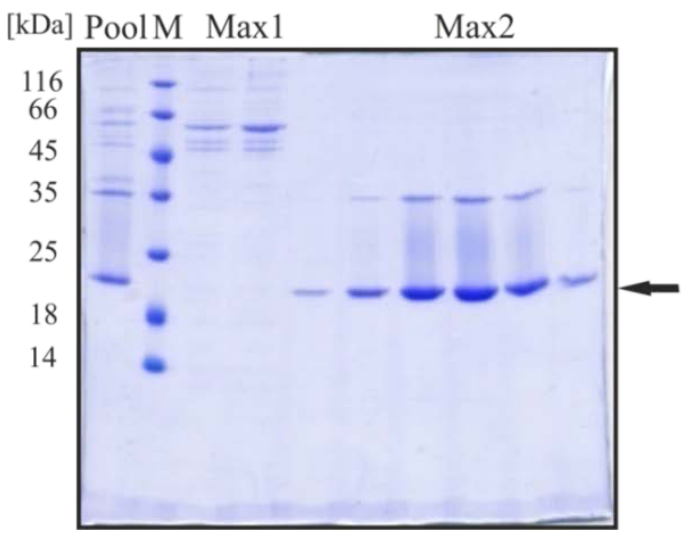

B)

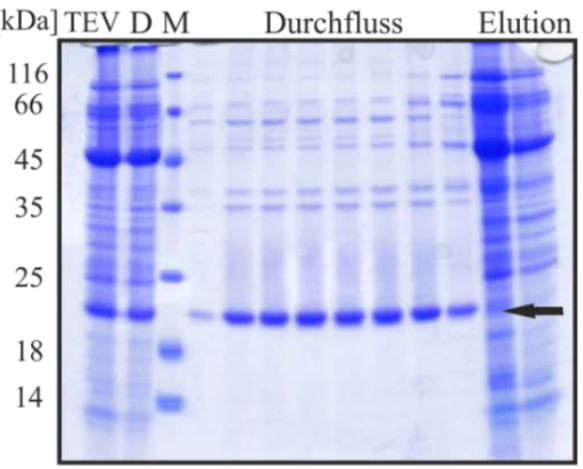

Abb. 15: Reinigung von RanQ69L ${ }^{1-180}$ in acetylierter, wie nicht acetylierter Form am Beispiel von RanQ69L $^{1-180}$ K171Ac. $M=$ Marker, $\mathrm{P}=$ Pellet, Ü= Überstand, $\mathrm{D}=$ Entsalzung, Max1= Maximum1, Max2= Maximum 2. Der schwarze Pfeil markiert RanQ69L ${ }^{1-180}$. Die SDS-GEL sind repräsentativ für die Reinigung aller Acetyllysinmutanten, so wie des Wildtyps A) Affinitätschromatographie über $\mathrm{Ni}^{2+}$-NTA Sepharose. B) Zweite Affinitätschromatographie über $\mathrm{Ni}^{2+}$-NTA Sepharose. TEV bezeichnet das Vereinigte Protein versetzt mit TEV-Protease C) Gelfiltration Superdex 75 XK 26/60. Pool bezeichnet das vereinigte Protein nach der zweiten Affinitätschromatographie

Diese Aufreinigung, wie auch die in Abb.15 gezeigten Ergebnisse der SDS PAGE sind für sämtliche Acetyllysinmutanten, sowie der nicht acetylierten Form von RanQ69L ${ }^{1-180}$ repräsentativ. Das Protein ist nach der Reinigung rein genug für die Verwendung in biochemischen, wie kristallografischen Experimenten. Nach der Gelfiltration wurden 1-2 mg/L acetyliertes RanQ69L ${ }^{1-180}$, sowie etwa $10 \mathrm{mg} / \mathrm{L}$ nicht acetyliertes RanQ69L ${ }^{1-180}$ erhalten. 


\subsubsection{Expression und Reinigung von acetyliertem und nicht acetyliertem Vollängen} Ran

Wie für die Produktion von acetyliertem RanQ69L ${ }^{1-180}$, so wird auch acetyliertes $\operatorname{Ran}_{\mathrm{fl}}$ mittels des Amber-Supressor Systems exprimiert (2.2.1.8). Das entsprechende Konstrukt wird zusammen mit dem pBK-AcKRS3 Plasmid transformiert und die Expression wie in 2.2.2.5.1 durchgeführt.

Mit der Verwendung des pCDF Duet Vektors, als Expressionssystem für $\operatorname{Ran}_{\mathrm{fl}}$ Mutanten und Wildtyp, ist es möglich das $\operatorname{Ran}_{\mathrm{fl}}$ mit einer Hexa-Histidinsequenz am N-terminus zu erzeugen. Abbildung 16 zeigt die Reinigung von $\operatorname{Ran}_{\mathrm{fl}}$ Mutanten und Wildtyp am Beispiel von $\operatorname{Ran}_{\mathrm{fl}}$ K71Ac. Die Poly-Histidinsequenz am $\operatorname{Ran}_{\mathrm{fl}}$ ermöglicht es das Protein in einem ersten Schritt, analog der verkürzten Variante mit Q69L Mutation, über Affinitätschromatographie mit $\mathrm{Ni}^{2+}$-NTA Sepharose zu reinigen. Die Abb. 16A zeigt das SDS-Gel zum ersten Schritt der Reinigung über die Affinitätschromatographie. In den Elutionsfraktionen ist das zuvor immobilisierte $\operatorname{Ran}_{\mathrm{fl}}$ deutliche bei ca. $27 \mathrm{kDa} \mathrm{zu}$ beobachten. In der ersten Spur (erste Fraktion der Elution) ist dieses schon hoch konzentriert, jedoch auch stark verunreinigt. Diese sowie die darauffolgende Fraktion werden vereinigt und für die Gelfiltration auf ca. $4 \mathrm{ml}$ ankonzentriert.

Der nächste Schritt in der Reinigung von $\operatorname{Ran}_{\mathrm{fl}}$ ist eine Gelfiltration mit Superdex 75 XK26/60 Säule, um Verunreinigungen mit höherem, so wie niedrigerem Molekulargewicht abzutrennen. Abb. 16B zeigt das SDS-Gel, welches aus dieser Gelfiltration resultiert. Die mit Max1 bezeichneten Spuren rechtes des Markers enthalten einzelne Proben aus dem ersten Maximum der Gelfiltration, die Spuren die mit Max2 beschriftet sind die eines zweiten Maximum. Das zweite Maximum hat ein höheres Retentionsvolumen als das mit Max1 bezeichnete Maximum. Max1 (Abb. 16B) weist Proteine höher Molekulargewichte, dementsprechend Proteine mit größerem Gyrationsradius auf, als dies bei $\operatorname{Ran}_{\mathrm{fl}}$ der Fall ist. In Abb. 16B ist zu erkennen, dass das $\operatorname{Ran}_{\mathrm{fl}}$ im zweiten Maximum eluiert. Wie bei der $\mathrm{Ni}^{2+}$-NTA Sepharose läuft das Ran ${ }_{\mathrm{fl}}$ bei einem apparenten Molekulargewicht von $27 \mathrm{kDa}$. Es eluiert in seiner monomeren Form von der Säule. Im Vergleich mit Abb. 16A weißt das Max2 in Abb. 16B deutlich geringere Verunreinigungen auf. Die in Max2 sichtbare zweite Bande entspricht wie in der Reinigung des verkürzten Konstrukts dem Dimer, welches nur auf dem SDS-Gel entsteht. Um zu überprüfen, ob die aufgereinigten Proteine acetyliert sind wurde eine Westernblot Analyse durchgeführt (Abb. 16C). Durch die Verwendung eines spezifischen Antikörpers gegen Acetyllysin ist es möglich Proteine mit acetyliertem Lysin zu identifizieren. In Abb. 16C sind alle Mutanten nach der $\mathrm{Ni}^{2+}$-NTA Sepharose (mit 
$\mathrm{H}$ bezeichnet) und der Gelfiltration (mit S bezeichnet), wie auch der Wildtyp aufgetragen.

Die Mutanten wurden der Reihe nach von K37 (Lysin 37 in der Primärsequenz) bis K159 (Lysin 159 in der Primärsequenz) auf das SDS-Gel aufgetragen. Die mit K bezeichnete Spur enthält eine Positivkontrolle also ein Protein bei dem bekannt ist, dass es acetyliert vorliegt. In der letzten Spur mit WT bezeichnet wurde der Wildtyp $\operatorname{Ran}_{\mathrm{fl}}$ auf das Gel aufgetragen. Es zeigt sich das alle aufgereinigten Mutanten acetyliert sind. Das $\operatorname{Ran}_{\mathrm{fl}}$ ist in dieser Form rein genug für die Verwendung in kristallographischen, sowie biochemischen Experimenten.

A)

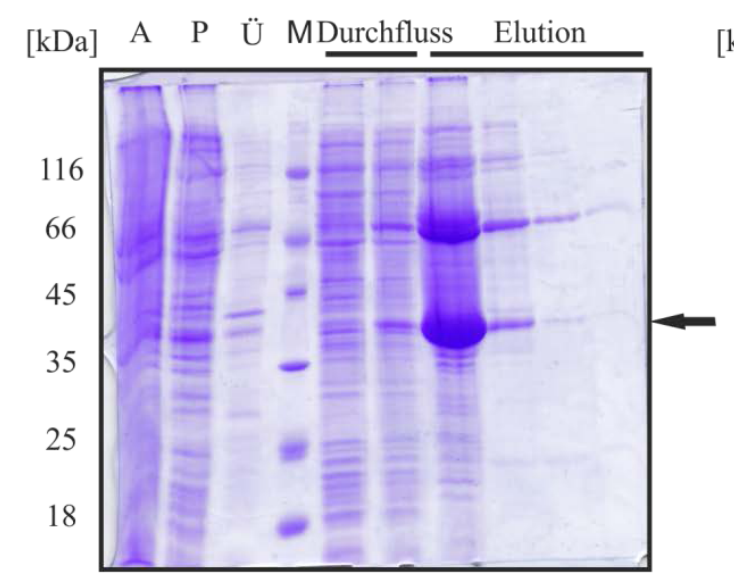

C)

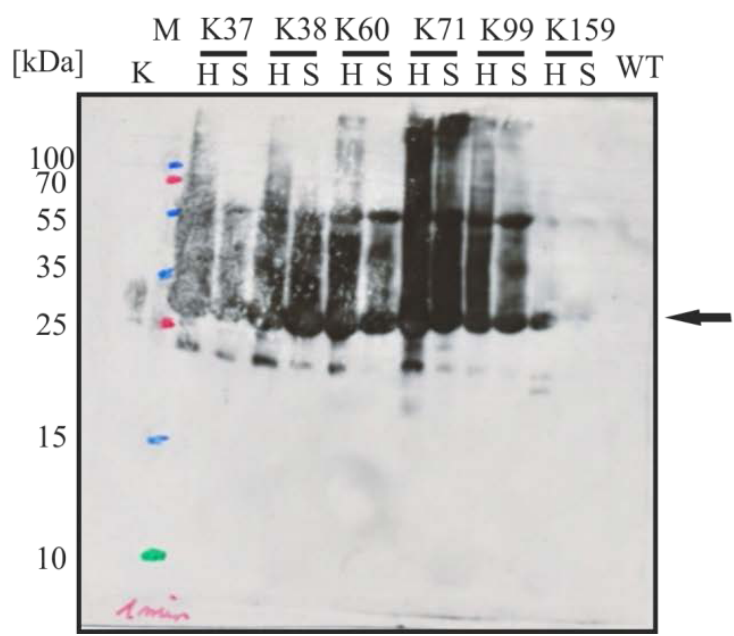

B)

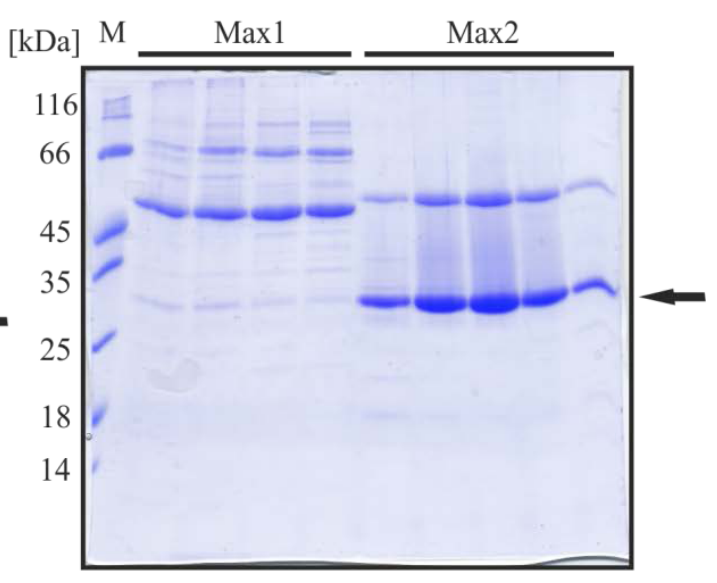

Abb. 16: Reinigung von $\operatorname{Ran}_{\mathrm{fl}}$ in acetylier Form und als Wildtyp am Beispiel von $\operatorname{Ran}_{\mathrm{fl}} \mathrm{K} 71 \mathrm{Ac}$. Die SDS-GEL sind repräsentativ für die Reinigung aller Mutanten, so wie des Wildtyps in ihrer vollen Länge. M= Marker,. Ein schwarzer Pfeil markiert das $\operatorname{Ran}_{\mathrm{fl}}$. A) SDS-Gel der Affinitätschromatographie über NiNTA Sepharose. In den ersten drei Spuren des SDS-Gels sind Proben vom Aufschluss der Zellen aufgetragen ( $\mathrm{A}=$ Aufschluss nach Fluidizer, $\mathrm{P}$ das Pellet und Ü der Überstand nach Zentrifugation). In den ersten zwei Spuren nach dem Marker sind zwei Fraktionen aus dem Durchfluss der Ni2+-NTA Sepharose zu sehen, darauf folgt in den Spuren Proben der Elution. Im Durchfluss der Ni2+-NTA Sepharose ist etwas $\operatorname{Ran}_{\mathrm{fl}} \mathrm{zu}$ erkennen. Mit der Hexa-Histidin-Sequenz eluiert Ran $_{\mathrm{fl}}$ bei einem apparenten Molekulargewicht 
von 27 kDa. B) SDS-Gel der Gelfiltration Superdex 75 XK 26/60. Max1= Maximum1, Max2= Maximum 2 C) Westernblot Aufgetragen alle gereinigten Mutanten von $\operatorname{Ran}_{\mathrm{fl}}$, so wie Wildtyp. K bezeichnet die verwendete Kontrolle, $\mathrm{H}$ die Probe der His-Trap und S die Probe nach der Gelfiltration. WT bezeichnet das Wildtyp Ran

Die für eine Untersuchung der Acetylierung gereinigten und zu Verfügung stehenden Mutanten sind in Tabelle 3 wiedergegeben. Ein Pluszeichen bezeichnet eine gereinigtes Protein und ein Minuszeichen, dass das Protein nicht gereinigt wurde.

Tabelle 3: Auflistung der in der Arbeit gereinigten kleinen GTPase Ran.

$\begin{array}{lccc} & \operatorname{Ran}_{\mathrm{fl}} & \mathrm{RanQ69L}^{1-180} & \mathrm{GST}^{1} \\ \mathrm{~K} 37 \mathrm{Ac} & + & + & + \\ \mathrm{K} 38 \mathrm{Ac} & + & + & - \\ \mathrm{K} 60 \mathrm{Ac} & + & + & + \\ \mathrm{K} 71 \mathrm{Ac} & + & + & - \\ \mathrm{K} 99 \mathrm{Ac} & + & + & - \\ \text { K159Ac } & + & + & 1-180\end{array}$

\subsection{Reinigung von Crm1}

Für die Untersuchung der Funktion von acetyliertem Ran sind weitere Proteine wichtig. Eines dieser Proteine ist der Kerntransportfaktor Crm1. Die Expression von Crm1 weicht von der üblichen Methodik ab, so wird für die Expression ein Glycerin-Stock verwendet. Des Weiteren handelt es sich um eine nicht induzierte Expression. Die Zellen werden in eine Vorkultur überführt für mindestens vier Stunden bei $37^{\circ} \mathrm{C}$ inkubiert und anschließend auf $1 \mathrm{~L}$ verdünnt. Die Hauptkultur schüttelt über Nacht bei $37^{\circ} \mathrm{C}$ bis zu einer optischen Dichte von 3-5. Crm1 lässt sich in 3 Schritten Reinigen. In Abbildung 17 sind die SDSGele zum jeweiligen Schritt der Reinigung gezeigt.

Bei der Reinigung von h.s. Crm1 handelt es sich um ein bereits etabliertes Protokoll (Thomas Monecke, MSB), das bei $4{ }^{\circ} \mathrm{C}$ durchgeführt wird. Der erste Schritt der Reinigung nach dem Aufschließen der Zellen (Abb. 17A) besteht in der Durchführung einer Affinitätschromatographie über Ni-NTA-Sepharose. 
A)

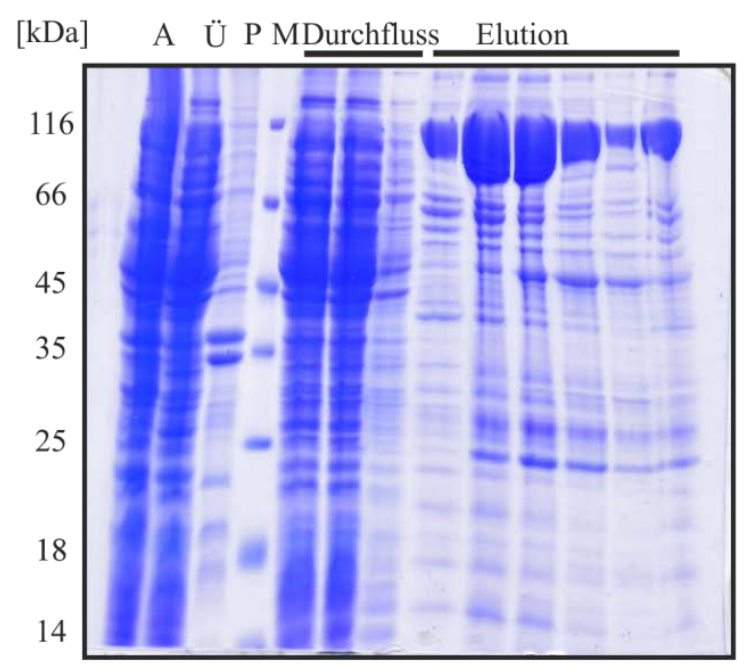

C)

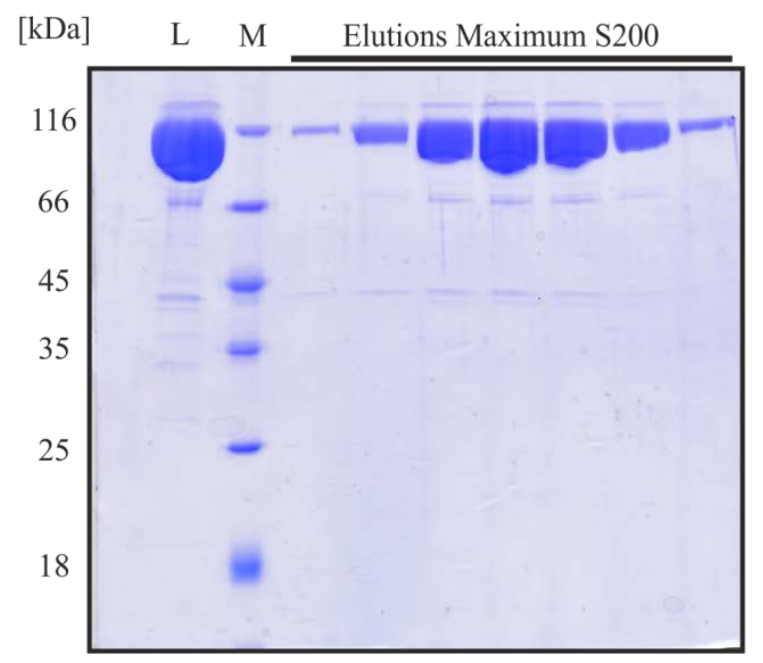

B)

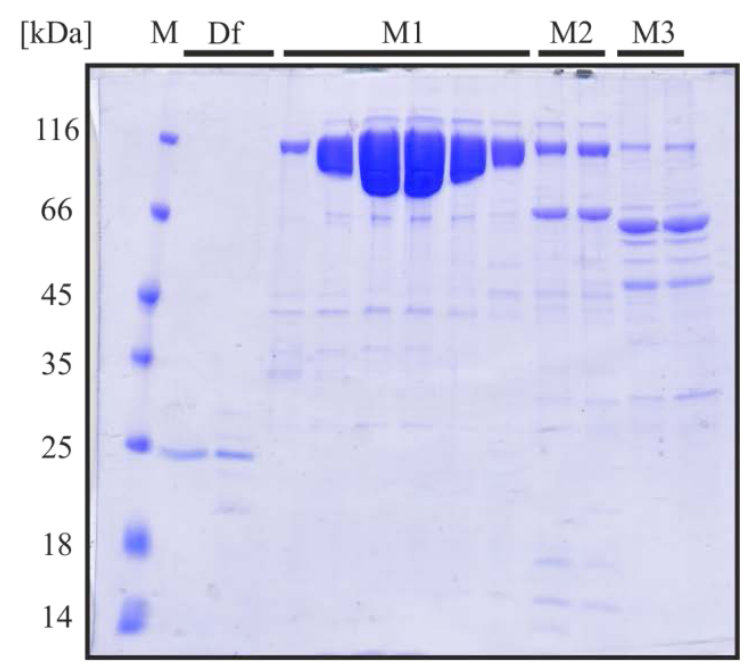

Abb.17: Reinigung von h.s.Crm1.

M= Marker, P= Pellet, Ü= Überstand, D= Entsalzung, M1= Maximum1, M2= Maximum 2, M3 Maximum 3, $\mathrm{Df}=$ Durchfluss, $\mathrm{L}=$ Pool der Anionenaustauschchromatographie A) Affinitätschromatographie über $\mathrm{Ni}^{2+}-$ NTA Sepharose. B) Zweite Affinitätschromatographie über Anionenaustauschchromatographie. C) Gelfiltration Superdex 200 XK 26/60.

Auf der SDS-Gel zu der Affinitätschromatographie in Abb. 17A wurde in den ersten drei Spuren (bezeichnet mit A, Ü und P für Auufschluss, Überstand und $\underline{P} e l l e t)$ Proben nach dem Aufschluss der Zellen der Expression aufgetragen. Rechts des Markers folgen Proben der Ni-NTA-Sepharose, drei aus den Durchflussfraktionen und die restlichen sechs aus den Elutionsfraktionen. Weder in den Proben nach dem Aufschluss noch im Durchfluss der NiNTA-Sepharose Säule ist Crm1, welches bei einem apparenten Molekulargewicht von ca. 116 kDa eluiert zu erkennen. In den Fraktionen der Elution ist einen starke Bande bei 116 kDa zu beobachten, sowie noch deutlich erkennbare Verunreinigungen. Diese Fraktionen 
werden vereint und durch einen Entsalzungsschritt für die weitere Reinigung vorbereitet. Um die vorhandenen Verunreinigungen, sowie Abbauprodukte des h.s. Crm1 abzutrennen wird eine Anionenaustauschchromatographie nach dem Entsalzungsschritt als zweiten Schritt der Reinigung durchgeführt. Abb. 17B zeigt das zur Anionenaustauschchromatographie gehörige SDS-Gel. Von links nach rechts wurden Proben von verschiedenen Fraktion der Anionenaustauschchromatographie aufgetragen, Df sind zwei Proben aus dem Durchfluss, M1-M3 Proben aus dem sich durch den Elutionsgradienten ergebenden Elutionsprofil. Das SDS-Gel zeigt das nur geringe Mengen der sich in der Probe befindenden Proteine nicht mit dem Anionentauschermaterial interagieren, gebunden werden, und durch die Säule fließen. Während des Gradienten kann h.s. Crm1 schon zu einem großen Teil von den Verunreinigungen und den Abbauprodukten getrennt werden, dies zeigt sich beim Betrachten der Spuren unter M1, M2 und M3. Dabei eluiert das Crm1 früher (Abb. 17B, M1 ca 116 kDa), als der Großteil der Verunreinigungen und Abbauprodukte (Abb. 17B, M2 und 3). Es sind jedoch noch leichte Banden zusätzlich zum Crm1 in M1 zu beobachten. Die zu M1 gehörenden Faktionen werden vereinigt und für eine Gelfiltration Superdex 200 26/60 eingeengt. Die Gelfiltration (2.2.3.1.6) bildet den dritten und abschließenden Schritt der Reinigung von h.s. Crm1 (Abb. 17C) um das h.s Crm1 von Aggregaten zu trennen. Während der Gelfiltration wurde nur ein Maximum beobachtet, Abb. 17C zeigt das SDS-Gel zu dem Lauf. Aufgetragen wurden eine Probe vor der Gelfiltration (L), sowie alle Fraktionen des erhaltenen Maximums. Es zeigt sich in diesem Maximum das h.s. Crm1 in seiner monomeren Form eluierte. Auf dem SDS-Gel sind nur noch ganz leichte Verunreinigungen zu erkennen. In dieser Form ist das h.s.Crm1 rein genug für die Verwendung in kristallografischen und biochemischen Experimenten, sowie der Verwendung zur Bildung eines Komplexes mit RanGTP.

\subsection{Reinigung von h.s. SPN1}

Ein weiteres Protein, welches für die Analyse von acetyliertem RanGTP verwendet wird ist Homo sapiens Surportin 1 (h.s. SPN1). Die Reinigung von h.s. SPN1 beruht auf einem bereits etablierten Protokoll (Strasser et al., 2004), das Reinigungsprotokoll wird von Dr T. Monecke zur Verfügung gestellt. Das Protein wird hierbei in Rosetta 2 (DE3) expremiert (2.2.2.5.3) und in drei Schritten aus den Expressionszellen aufgereinigt (2.2.5.3). In der Abbildung 18 sind die SDS-Gele zur Reinigung des h.s. Spn1 gezeigt. 
$\mathbf{A}$

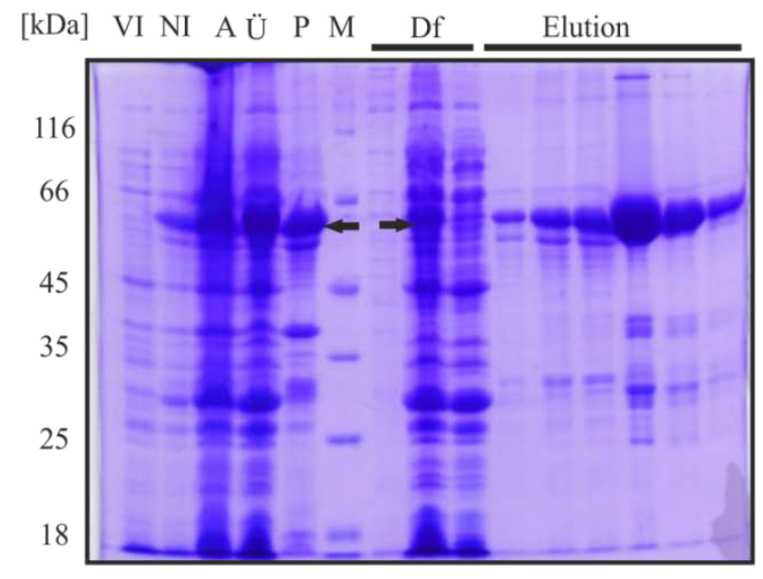

C

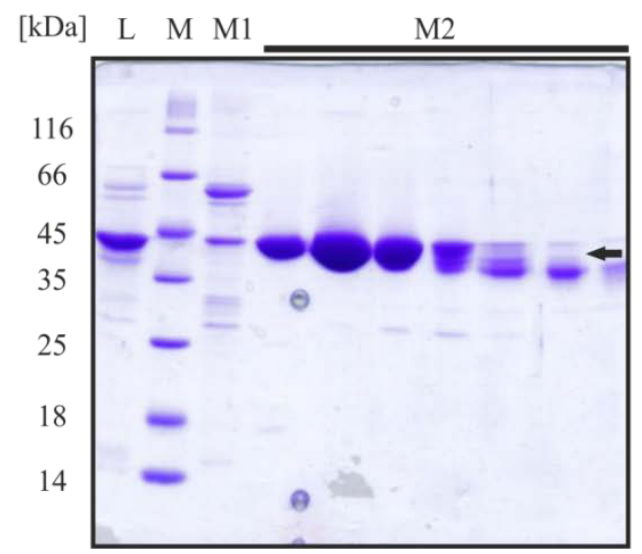

\section{B}

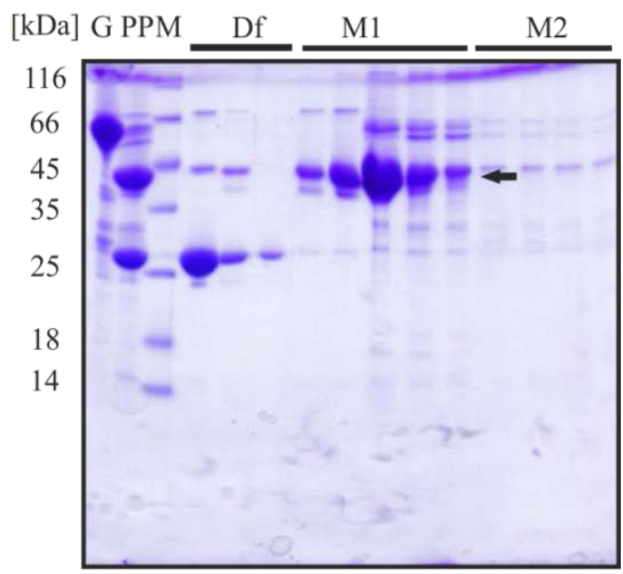

Abb. 18: Reinigung von h.s.SPN1.

A) SDS-Gel zur GSH-Sepharose. VI= Vor Induktion, NI= Nach Induktion, A= Aufschluss, Ü= Überstand, $\mathrm{P}=$ Pellet, Df= Durchfluss B) SDS-Gel der Heparin Sepharose. G= vereinigtes Protein nach der GSHSepqhros, PP= bezeichnet das Vereinigte Protein versetzt mit Prescission Protease, M1= Maximum1, M2= Maximum 2. C) SDS-Gel der Gelfiltration Superdex 75 26/60. M1= Maximum1, M2= Maximum 2, L= Pool der Heparin Sepharose

Durch die Verwendung des Plasmids pGEX-6-P1 als Expressionsplasmid war es möglich h.s.SPN1 als GST-Fusionsprotein zu exprimieren und die Aufreinigung mit einer GSHSepharose zu beginnen. In Abb. 18A ist das SDS-Gel zur GSH-Sepharose gezeigt. Auf das Gel aufgetragen wurden Proben der Expression vor der Induktion mit IPTG (VI) und nach der Induktion (NI), sowie Proben vom Aufschluss der Zellen (Aufschluss A, Überstand Ü und Pellet P). Des Weitern folgen nach dem Marker Proben aus dem Durchfluss (Df) und der Elution der GSH-Sepharose. Wie das SDS-Gel zur GSH-Sepharose Reinigung zeigt (Abb. 18A) ist nach der Induktion der Expression eine deutliche Bande für das Fusionsprotein in der Probe nach Induktion, bei einem apparenten Molekulargewicht von etwa $64 \mathrm{kDa}$ zu erkennen und zeigt somit eine deutliche Expression des h.s.Spn1. In den 
Proben Aufschluss der Expressionszellen ist deutliche das lösliche Fusions-Protein im Überstand nach der Zentrifugation zu erkennen. Jedoch war auch eine beträchtliche Menge des h.s. Spn1 Fusionsprotein im Pellet der Zentrifugation enthalten. Die Fraktionen des Durchfluss (Df Abb. 18A) zeigen, das ein Teil des h.s.Spn1 Fusions-Proteins entspricht nicht mit der GSH-Sepharose interagiert und somit die verwendete Säule passiert. Das durch GST immobilisierte Fusionsprotein wird mittels reduziertem Glutathion eluiert (Abb. 18A Elution). Die Fraktionen der Elution zeigen ein mit wenigen anderen Proteinen verunreinigtes Fusionsprotein und nur kleine Mengen an GST (27 kDa). Die Elutionsfraktionen werden vereinigt und für weitere Schritte verwendet. Das GST-h.s.Spn1 ist mittels eines schwarzen Pfeils markiert.

Das pGEX-6P-1 Plasmid weist eine Protease Schnittstelle für die PreScission Protease auf, was es möglich macht die GST-Affinitätssequenz von dem h.s.SPN1 zu entfernen. Das aus der Affinitätschromatographie erhaltene und vereinigte Protein wird mit der PreScission Protease versetzt und über Nacht bei $4{ }^{\circ} \mathrm{C}$ inkubiert (2.2.3.7). Der Verdau wir über ein SDS-Gel (Abb. 18B, Spuren G und PP) analysiert. Es ist zu erkennen das der Verdau von GST-h.s.SPN1 nicht ganz vollständig erfolgte. In der Spur PP ist neben einer Bande bei ca. 42 kDa (h.s.SPN1) und 27 kDa (GST) auch eine Bande bei 64 kDa (GST-h.s.SPN1) zu beobachten.

Der zweite Schritt der Reinigung besteht in einer Affinitätschromatogtraphie mittels Heparin-Sepharose. Da es sich bei h.s. SPN1 um ein RNA-bindendes Protein handelt lässt es sich über die Heparin-Sepharose von RNA, sowie GST und der PreScission Protease trennen. Die Analyse über das SDS-Gel (Abb. 18B) zeigt, das in diesem Schritt das GST nicht mit dem Säulenmaterial interagiert und somit im Durchfluss (Df) eluiert. Während der Elution über einen $\mathrm{NaCl}$ Gradienten entstehen zwei Maxima M1 und M2, wobei das h.s.SPN1 in M1 eluiert, wie Abb. 18B zeigt, zusammen mit nicht verdautem h.s.SPN1 und einigen Verunreinigungen. Das Maximum M2 enthält wie sich in Abb. 18B zeigt geringe Mengen an h.s.SPN1 in gleicher Signalstärke wie die vorhandenen Verunreinigungen in diesen Fraktionen. Die Fraktionen aus M1 werden vereinigt und für eine Gelfiltration (2.2.3.1.6) ankonzentriert.

Die Gelfiltration mit einer Superdex 75 XK26/60 Säule ist der dritte und letzte Schritt der Reinigung von h.s.Spn1. In der Abb. 18C ist das SDS-Gel zu diesem Schritt der Reinigung dargestellt. Sie zeigt in der ersten Spur des SDS-Gels die Probe vor der Gelfiltration, sowie die zwei während der Gelfiltration entstehenden Maxima M1 und M2. Dabei ist zu erkennen (Abb. 18C) das in M1 das nicht verdaute GST-h.s.Spn1 (64 kDa), sowie 
scheinbar oligomeres h.s.Spn1 ohne Affinitätssequenz und einige der Verunreinigungen. In M2 hingegen ist das eluiert h.s.Spn1 bei seinem erwarteten Elutionsvolumen. Auf dem SDS-Gel wurden die Fraktionen der Elution M2 von links nach rechts entsprechend dem Volumen ihrer Elution aufgetragen, die früheren links nach rechts weitergehend. Es zeigt sich, dass das monomere h.s.SPN1 ohne weitere Verunreinigungen in den ersten drei Fraktionen von M2 zu finden ist. In den weiteren Fraktionen sind zunehmend Abbauprodukte und Verkürzungen des h.s.SPN1 zu beobachten. Die ersten drei Fraktionen von M2 werden demnach vereinigt und für weitere Experimente verwendet.

\subsection{Klonierung und Reinigung von RanGAP1}

Um RanGTP in funktionaler hinsichtlich zu analysieren wird RanGAP1 benötigt, da dieses die GTPase Aktivität von Ran in GTP gebundenem zustand erhöht (Bos et al., 2007). Das RanGAP1 lag als Konstrukt ohne Affinitätssequenz (Dr. R. Kehlenbach) im pET-11d Plasmid vor. Da die Expression von RanGAP1 aus dem pET-11d Plasmid zur Lokalisation des RanGAP1 in Zell Einschlusskörperchen führt, wurde dieses neu kloniert (2.2.1.10). Durch die Sequenzierung positiver Klone nach der Transformation (2.2.2.3) konnte die Fehlerfreiheit des Gens von RanGAP1 bestätigt werden.

Für die Expression von RanGAP1, wurde das Konsturkt pGEX-6P1-RanGAP1 in Rosetta 2 (DE3) transformiert (2.2.2.3) und exprimiert. In Abb. 19A ist ein SDS-Gel zur Expression von RanGAP1 in Rosetta 2 (DE3) gezeigt. Durch die Verwendung des pGEX 6P1 Plasmids als Expressionsvektor wurde die RanGAP1 als GST-Fusionsprotein exprimiert. Auf dem SDS-Gel sind jeweils eine Probe von vor der Induktion der Expression (VI), sowie eine Probe nach der Expression bei der Ernte der Expressionszellen (NI) aufgetragen. Es ist zu erkennen, das nach der Induktion der Expression durch IPTG eine Bande bei etwa 68 kDa-70 kDa deutlicher auftritt, wenn man beide Spuren vergleicht. Wenn auch diese Bande für das Fusionsprotein bei geringerem apparenten Molekulargewicht läuft (Molekulargewicht von GST-RanGAP1 liegt bei $90 \mathrm{kDa}$ ) als zu erwarten ist, so kann doch angenommen werden, dass die Expression erfolgreich war (Abb. 19A, der Pfeil markiert das GST-RanGAP1). Da das RanGAP1 von sich aus schon viele negativ geladene Aminosäuren mitbringt, kommt dieses abnormale Laufverhalten zu Stande. 
A

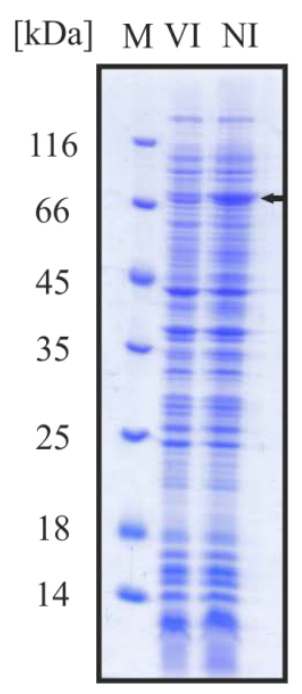

B

[kDa] VI NI A Ü PM Df Elution

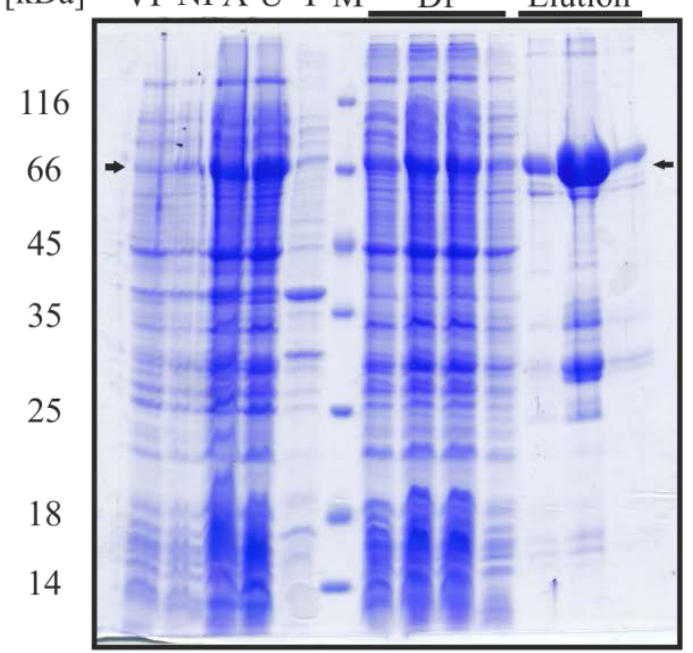

C

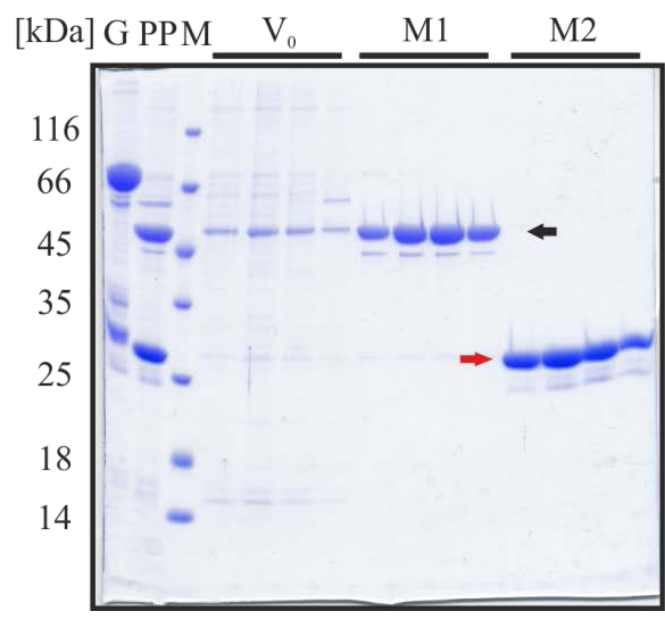

Abb. 19: Expression und Reinigung von RanGAP1.

A) 12,5\% SDS-Gel der Expression von RanGAP1 in Rosetta 2 (DE3). VI= Vor Induktion, NI= Nach Induktion. Ein schwarzer Pfeil markiert das GST-RanGAP1. B) $12,5 \%$ SDS-Gel der Affinitätschromatographie über GSH-Sepharose. VI= Vor Induktion, NI= Nach Induktion, A= Aufschluss, $\ddot{U}=$ Überstand, P= Pellet, Df= Durchfluss. GST-RanGAP1 wird durch einen schwarzen Pfeil markiert. C) 12,5\% SDS-Gel der Gelfiltration. G= vereinigtes Protein nach der GSH-Sepharose, PP= bezeichnet das Vereinigte Protein versetzt mit Prescission Protease, M1= Maximum1, M2 $=$ Maximum 2, $\mathrm{V}_{0}$ bezeichnet das Ausschlußvolumen der Gelfiltrationssäule. Ein schwarzer Pfeil markiert RanGAP1, ein roter Pfeil markiert das GST

Die GST-Affinitätssequenz am RanGAP1 ermöglicht die Aufreinigung von RanGAP1 über diese Affinitätssequenz. Die Abb. 19B zeigt das SDS-Gel zur Affinitätschromatographie, dem ersten Schritt der Reinigung von RanGAP1. Auf das Gel wurden neben den Proben der Affinitätschromatographie auch Proben der Expression, sowie des Zellaufschluss aufgetragen. Es ist zu erkennen, das wie in Abb. 19A das GST- 
RanGAP1 (68-70 kDa) von den Zellen expremiert wurde. Nach dem Aufschließen der Zellen mit einem Fluidizer ist das exprimierte Protein im Ausfschluss zu erkennen (markiert durch einen schwarzen Pfeil, bei 68-70 kDa). Die Proben vom Überstand und dem Pellet nach der Zentrifugation lassen erkennen, das ein sehr großer Teil des exprimierten Proteins löslich in den Zellen und nur ein geringer Teil in Einschlußköpern zu finden ist (Abb. 19B). Die Proben des Durchfluss (Df) auf dem SDS-Gel zeigen etwas GST-RanGAP1, welches nicht mit der Säule interagiert. An das Säulenmaterial gebundenes Protein wird mit reduziertem Glutathion (Abb. 19B) eluiert. Das SDS-Gel mit den Proben dieser Elution (Abb. 19B, Elution) zeigt deutlich ein Bande bei 68-70 kDa, die auch in den nach Induktionsproben und im Überstand nach dem Aufschluss der Zellen zu erkennen ist, mit deutlichen Verunreinigungen. Diese Proben der Elution werden für einen weiteren Schritt in der Reinigung vereinigt.

Zur Abspaltung der GST-Affinitätssequenz vom RanGAP1 wird das Protein der vereinigten Elutionsfraktionen über Nacht bei $4{ }^{\circ} \mathrm{C}$ mit der PreScission-Protease inkubiert (2.2.3.7). Eine Analyse über ein SDS-Gel (Abb. 19C) zeigt, das nach der Inkubation mit der PreScission-Protease eine weitere Bande bei 50 kDa auftritt. Das GST-RanGAP1 wurde nicht ganz vollständig gespalten, da die Bande bei 68-70 kDa noch schwach zu erkennen ist.

Um das abgespaltene GST, sowie das nicht Verdaute GST-RanGAP1, die PreScissionProtease und andere Verunreinigungen vom RanGAP1 abzutrennen wird eine Gelfiltration (2.2.3.1.6) mit einer Superdex 200 XK26/60 Säule durchgeführt. In Abb. 19C ist die Analyse der Gelfiltration über ein SDS-Gel gezeigt. Während der Gelfiltration entstehen drei Maxima, das erste mit $\mathrm{V}_{0}$ bezeichnet eluiert bei dem Ausschlussvolumen der Gelfiltrationssäule um etwa $100 \mathrm{ml}$. Auf dem SDS-Gel (Abb. 19C) ist zu erkennen, das im Ausschlußvolumen der Säule RanGAP1 (50 kDa) zusammen mit einem großen Teil der Verunreinigungen eluiert. Die verbleibenden zwei Maxima sind auf dem SDS-Gel mit M1 und M2 bezeichnet, M1 bezieht sich auf das Maximum welchen nach $\mathrm{V}_{0}$ folgt und vor M2 auftritt, M2 bezieht sich dem entsprechend auf das zuletzt auftretende Maximum. Wie die Analyse über das SDS-Gel (Abb. 19C) zeigt eluiert das RanGAP1 in M1 (markiert durch einen schwarzen Pfeil), während das abgespaltene GST in M2 zu finden ist. Es ist zu erkennen, dass das RanGAP1 zu ca. 90\% sauber und klar getrennt vom GST von der Gelfiltrationssäule eluiert. In dieser Form ist das RanGAP1 rein genug für biochemische Experimente und kann verwendet werden. 


\subsection{Strukturelle und funktionale Analyse des Exportkomplex Crm1:Spn1:RanGTP mit acetyliertem RanGTP}

Mit RanGTP in seiner acetylierten Form, sowie den Proteinen Crm1, Spn1 und RanGAP1 zur Hand lässt sich der Einfluss einer Acetylgruppe am RanGTP auf dessen Interaktion mit dem Kerntransport Faktor h.s. Crm1 analysieren.

\subsubsection{Bindungsstudie über Analytische Gelfiltration}

Ein Komplex aus den Proteinen h.s.Crm1, h.s.Spn1 und RanQ69L ${ }^{1-180}$ in GTP gebundener Form (Exportkomplex) konnte bereits erfolgreich kristallisiert und die Struktur dieses Komplexes gelöst werden (Monecke et al., 2009).

Der Einfluss der Acetylgruppe der verschiedenen Acetyllysin Mutanten von Ran in Bezug auf die Bindung an Crm1 wurde mittels analytischer Gelfiltration untersucht (Abb. 20). Für dieses Experiment wurde Ran in der verkürzten Variante (AS 1-180) mit der Q69L Mutation wendet. Hierbei wird RanQ69L ${ }^{1-180}$ in acetylierter Form, sowie ohne Acetylgruppe, zusammen mit Crm1 und Spn1 inkubiert und die Bildung des Exportkomplex über eine analytische Superdex 200 10/300 GL Gelfiltrationssäule und SDS-Gel analysiert (Abb. 20, 2.2.3.10). Neben den einzelnen Komplexansätzen mit den RanQ69L ${ }^{1-180}$ Acetyllysin Mutanten K37, K38, K60 , K71, K99 und K159, wurde auch der Komplex mit nicht acetyliertem RanQ69L ${ }^{1-180}$, sowie Crm1 alleine in der Abb. 20A in Form einer Überlagerung der Chromatogramme der einzelnen Ansätzen dargestellt. Die Komplexierung der drei Proteine kann dabei über eine Verschiebung des gemeinsamen Absorptionsmaximums in Richtung des Ausschlußvolumens hinsichtlich des Crm1 verifiziert werden (Abb. 20A). Dies zeigt sich bei dem Vergleich von Crm1 als einzelnes Protein mit dem Komplex aus Crm1:Spn1:RanQ69L ${ }^{1-180}$. Die Proben aus den jeweiligen Absorptionsmaxima zeigen alle eine Proteinbanden bei jeweils $120 \mathrm{kDa}, 42 \mathrm{kDa}$ und 21 kDa, entsprechend der verwendeten Proteine Crm1 (125 kDa) Spn1 (42 kDa) und $\operatorname{RanQ69L}^{1-180}(21 \mathrm{kDa})$. 
A)

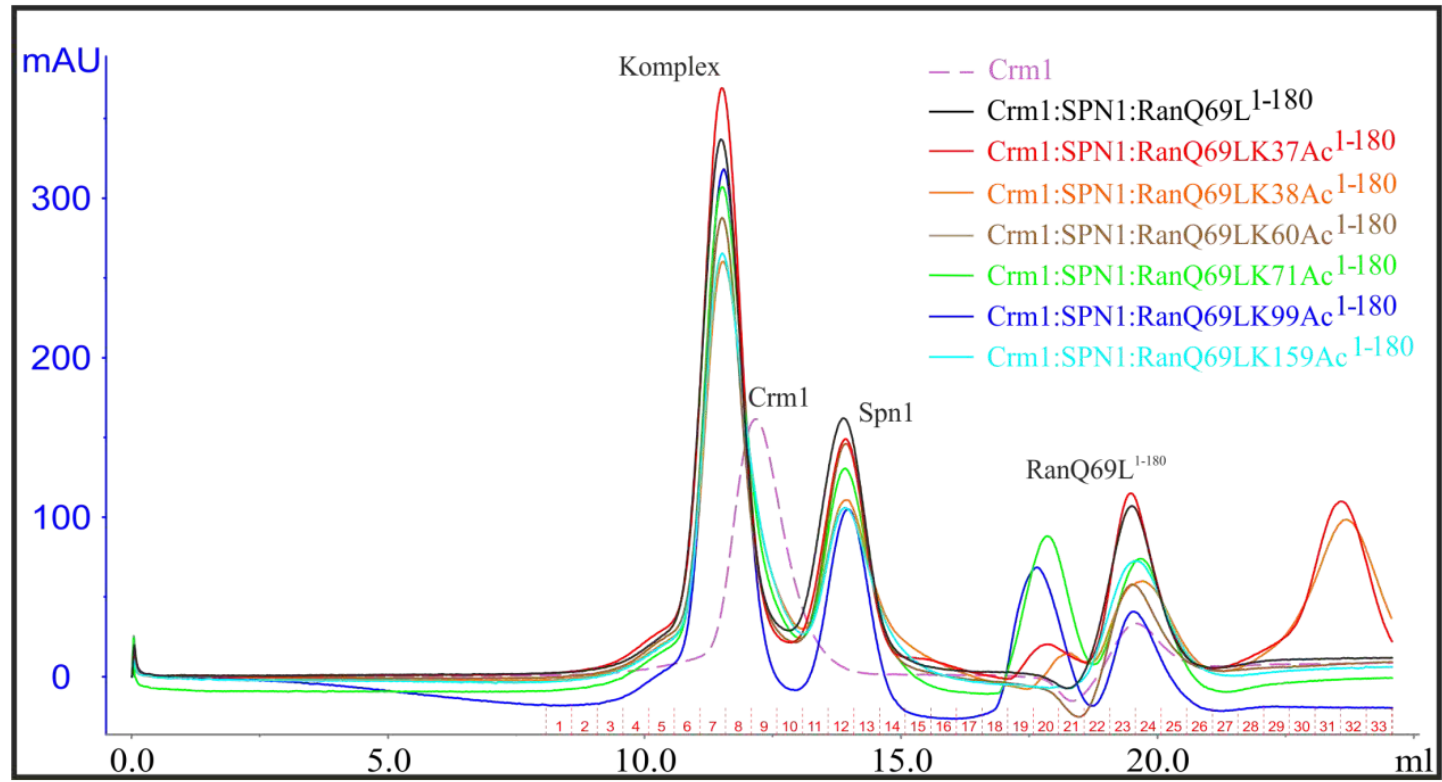

B)
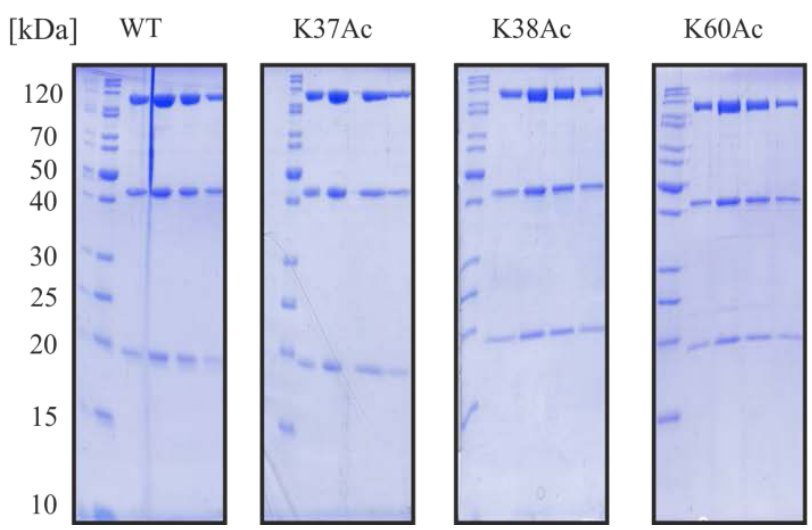

K71Ac

K99Ac

K159Ac
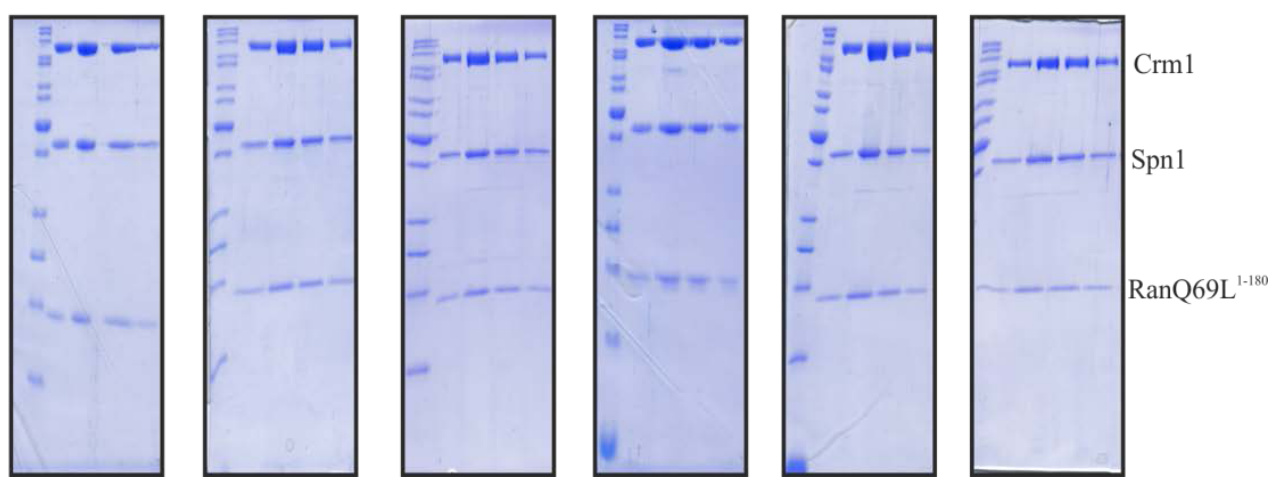

Abb. 20: Bindungsstudie der Komplexbildung mittels analytischer Gelfiltration über Superdex 200

10/300GL. A) Überlagerung der Chromatogramme resultierend aus den einzelnen Komplexen mit unterschiedlichen RanQ69L ${ }^{1-180}$ Acetyllysin Mutanten. Die farbigen Linien repräsentieren die Absorption bei $280 \mathrm{nM}$ des jeweiligen Exportkomplex mit den Acetyllysin Mutanten des RanQ69L ${ }^{1-180}$ oder des Crm1 im einzelnen und sind in der Abbildung angegeben. B) SDS-Gele der einzelnen Läufe. Hier ist ein 15\% SDSGel nach Coomassie-Färbung gezeigt.

Die Verschiebung des gemeinsamen Absorptionsmaximums in Richtung des Ausschlußvolumens im Vergleich zum Crm1 alleine, sowie das Vorhandensein der Proteinbanden für Crm1, Spn1 und RanQ69L ${ }^{1-180}$ in diesem Absorptionsmaximum zeigen das vorhanden sein eines stabilen Komplexes mit allen verwendeten RanQ69L ${ }^{1-180}$ Acetyllysinmutanten. In diesem Experiment wurde kein Unterschied im Laufverhalten zwischen dem Komplex mit RanQ69L ${ }^{1-180}$ ohne Acetylgruppe und den Komplexen mit den RanQ69L ${ }^{1-180}$ Acetyllysin Mutanten gezeigt. 

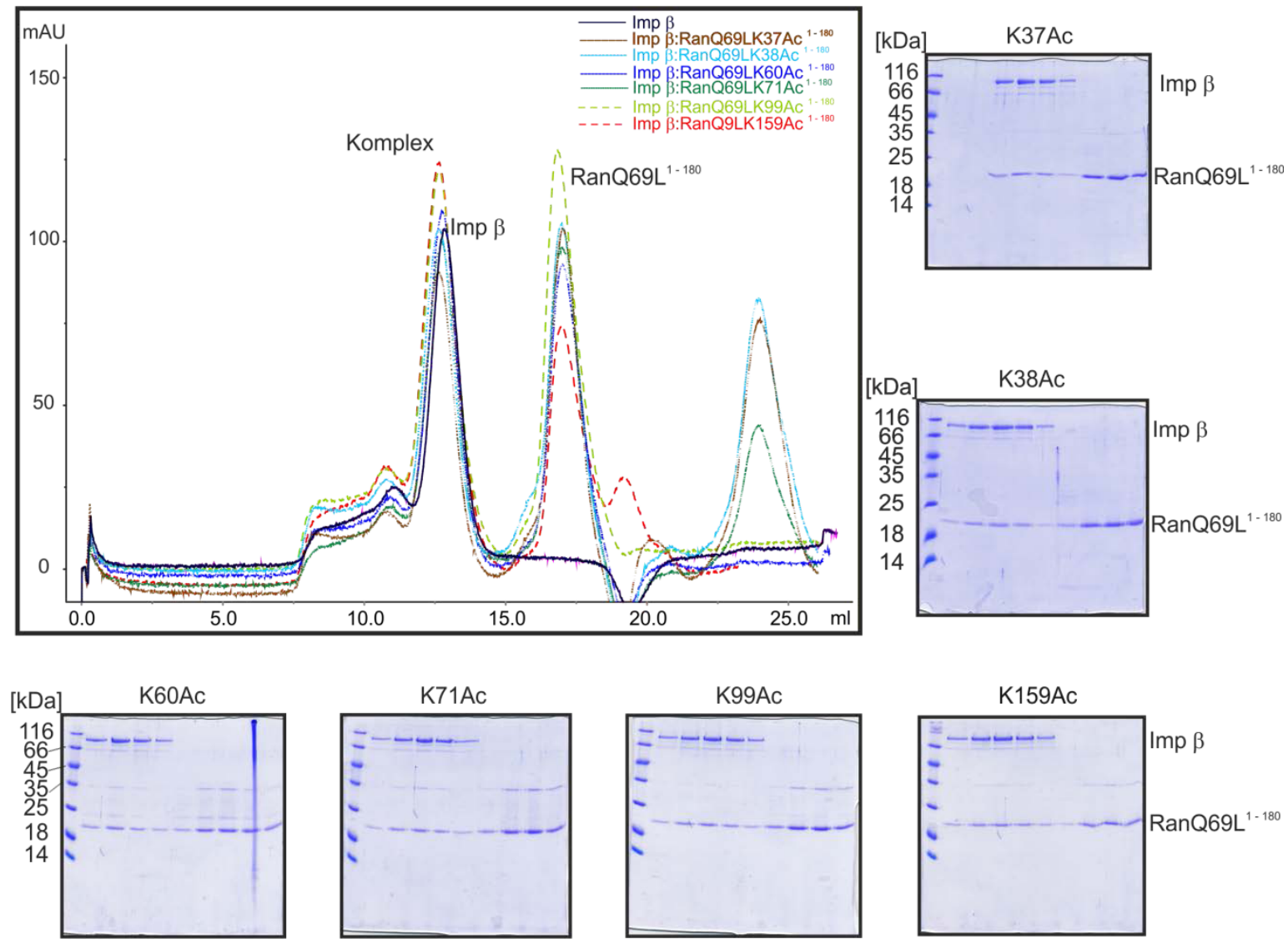

Abb. 21: Bindungsstudie der Komplexbildung mittels analytischer Gelfiltration über Superdex 20010/300GL. Überlagerung der Chromatogramme resultierend aus den einzelnen Komplexen mit unterschiedlichen RanQ69L ${ }^{1-180}$ Acetyllysin Mutanten. Die farbigen Linien repräsentieren die Absorption bei $280 \mathrm{nM}$ des jeweiligen Komplex mit den Acetyllysinmutanten des RanQ69L ${ }^{1-180}$ oder des Imp $\beta$ im Einzelnen und sind in der Abbildung angegeben. Die 15\% SDS-Gele nach Coomassie-Färbung sind am Rand des Chromatogramm gezeigt. Die jeweilige Mutante ist über dem SDS-Gel angegeben.

Analog dem h.s.Crm1, lies sich auch der Einfluss der Actylgruppe der Acetyllysin Mutanten von Ran in Bezug auf die Bindung an den Importrezeptor h.s.Importin $\beta$ mittels analytischer Gelfiltration untersuchen (Abb. 21). Für dieses Experiment wurde Ran in der verkürzten Variante (AS 1-180) mit der Q69L Mutation wendet. RanQ69L ${ }^{1-180}$ in acetylierter Form wurde zusammen mit $\operatorname{Imp} \beta$ inkubiert und die Bildung des Importkomplex über eine analytische Superdex 200 10/300 GL Gelfiltrationssäule und SDS-Gel analysiert (Abb. 21, 2.2.3.11). Zusätzlich zu den einzelnen Komplexansätzen mit den RanQ69L ${ }^{1-180}$ Acetyllysin Mutanten K37, K38, K60, K71, K99 und K159, wurde auch das $\operatorname{Imp} \beta$ alleine in der Abb. 21 in Form einer Überlagerung der Chromatogramme der einzelnen Ansätze dargestellt. Die Komplexbildung der beiden Proteine kann dabei über eine Verschiebung des gemeinsamen Absorptionsmaximums in Richtung des Ausschlußvolumens hinsichtlich des h.s.Imp $\beta$ verifiziert werden (Abb. 21, 
Chromatogramm). Dies zeigt sich bei dem Vergleich von $\operatorname{Imp} \beta$ mit dem Komplex aus Imp $\beta$ :RanQ69L ${ }^{1-180}$. Die Verschiebung des Absorptionsmaximums der Komplexe gegenüber dem $\operatorname{Imp} \beta$ alleine ist sehr marginal und beträgt maximal 0,2 ml. Die Proben aus den jeweiligen Absorptionsmaxima (die ersten vier Spuren nach dem Marker des jeweiligen SDS-Gel) zeigen alle eine Proteinbanden bei jeweils 100 kDa und 21 kDa. Auf den restlichen Spuren der SDS-Gele wurden jeweils Proben der Maxima um etwa 16-17 ml des Retentionsvolumens aufgetragen. Diese Proben zeigen auf dem SDS-Gel jeweils eine Bande bei ca. $21 \mathrm{kDa}$ und teilweise auch bei $42 \mathrm{kDa}$. Die Signale entsprechen den verwendeten Proteine $\operatorname{Imp} \beta$ (97 kDa) und RanQ69L ${ }^{1-180}$ (21 kDa, dimer $\left.42 \mathrm{kDa}\right)$.

Die Verschiebung des gemeinsamen Absorptionsmaximums um 0,2 ml in Richtung des Ausschlußvolumens, sowie das Auftreten einer Proteinbande für $\operatorname{Imp} \beta$ und RanQ69L ${ }^{1-180}$ in diesem Absorptionsmaximum zeigen das vorhanden sein eines stabilen Komplexes zwischen den Acetyllysin Mutanten von RanQ69L ${ }^{1-180}$ und h.s.Imp $\beta$.

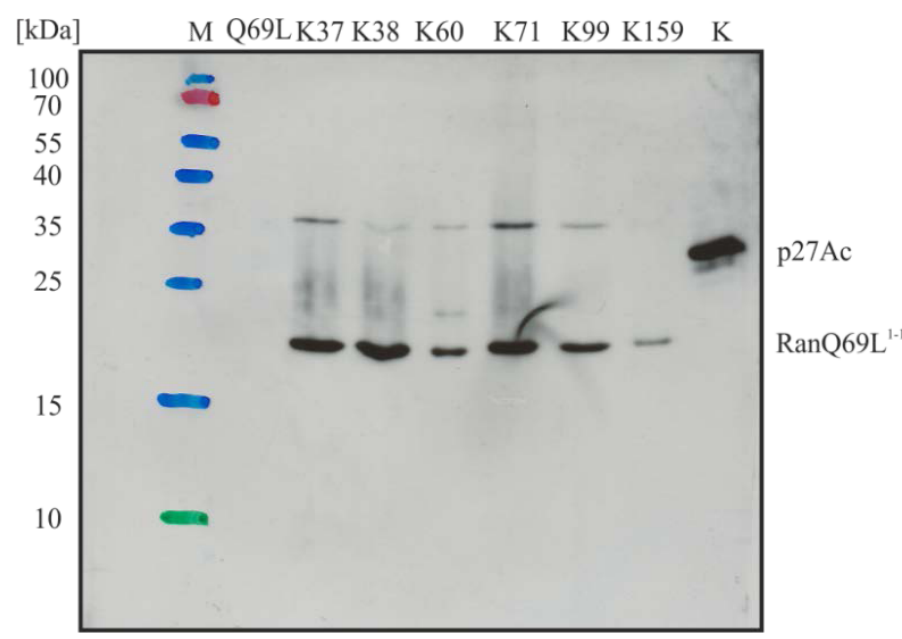

Abb. 22: Westernblot aller gereinigten Acetyllysin Mutanten von RanQ69L ${ }^{\text {1-180 }}$ Die eingesetzten Proteine wurden mittels eines Antikörpers gegen Acetyllysin detektiert und mittels ECL sichtbar gemacht. Die Markerproteine (M) sind auf der linken Seite mit ihren Molekulargewichten [kDa] benannt. Alls positiv Kontrolle (K) diente das acetylierte Protein p27.

Um sicher zu gehen, dass die eingesetzten RanQ69L ${ }^{1-180}$ Acetyllysine Mutanten mit einer Acetylgruppe versehen waren, wurde ein Westernblot unter Verwendung eines Primärantikörpers gegen Acetyllysin durchgeführt (2.2.3.8). In Abbildung 22 ist dieser Westernblot dargestellt. Auf das SDS-Gel für den Westernblot wurden jeweils die einzelnen aufgereinigten Mutanten aufgetragen. Hier ist für die einfache Q69L Mutante von $\operatorname{Ran}^{1-180}$ kein Signal für einer Acetylgruppe zu erkennen, für die in den weiteren Spuren aufgetragenen Acetyllysin Mutanten zeigen jeweils ein positives Signal für acetyliertes Lysin. Bei dem p27 (Abb. 22) handelt es sich um eine Positivkontrolle, also um ein Protein, welches ein acetyliertes Lysin aufweist. Das Auftreten von Signalen bei 
Einsatz eines Antikörpers gegen Acetyllysin zeigt an, das die eingesetzte RanQ69L ${ }^{1-180}$ Acetyllysin Mutanten acetyliert vorlagen.

Durch diese Experimente lässt sich jedoch keine Aussage über die Bindungsstärke von RanGTP an Crm1 im Beisein von SPN1, sowie von RanGTP an $\operatorname{Imp} \beta$ treffen. Es konnte jedoch gezeigt werden, dass stabile Transportkomplexe mit den RanQ69L ${ }^{1-180}$ Acetyllysin Mutanten entstehen und diese keine Veränderung im Laufverhalten auf einer Gelfiltrationssäule zeigen.

\subsubsection{Bindungsstudie von acetyliertem RanQ69L ${ }^{1-180}$ K37Ac und K71Ac mit Transportrezeptoren über einen Pulldown-Assay}

Da zu erkennen war das alle acetylierten Ran Mutanten sowohl mit dem Exportrezeptor Crm1 in Anwesenheit von SPN1 als auch mit dem Importrezeptor Importin $\beta$ (Imp $\beta$ ) interagieren (siehe 3.5.1) wurde die Bindung der RanQ69L ${ }^{1-180}$ K37Ac (Switch 1 Region) und K71Ac (Switch 2 Region) Mutanten an weiteren Transportrezeptoren untersucht (Transportin und Importin 7). Eine Interaktion von zwei oder mehr Proteinen miteinander lässt sich nicht nur über analytische Gelfiltration untersuchen. Protein-Protein Interaktionen lassen sich auch über einen Pulldown-Assay nachweisen. Um dies für die acetylierten Mutanten zu tun wurde GSH-Sepharose für den Pulldown verwendet.

In Abbildung 23 ist ein Pulldown-Assay mit immobilisiertem RanQ69L ${ }^{1-180}$ K37Ac und K71Ac gezeigt. In beiden Experimenten wurden die immobilisierten RanQ69L ${ }^{1-180}$ Mutanten mit Importrezeptoren inkubiert. Im Pulldown-Assay mit immobilisierten RanQ69L ${ }^{1-180}$ K37Ac wurden neben den Importrezeptoren Importin $\beta(\operatorname{Imp} \beta)$, Importin7 (Imp7) und Transportin auch der Exportrezeptor Crm1 und das Exportsubstrat SPN1 verwendet. Durch die Verwendung des Amber-suppressor Systems entstehen während der Expression der Mutanten kurze Fragmente. Die Verwendung des GST-tag hindert die Abtrennung dieser Fragmente von dem vollen Konstrukt. Diese Fragmente sollten für eine Interaktion mit Transportrezeptoren nicht ausreichen. Um dies zu überprüfen wurde auch das Fragment über GST immobilisiert und mit den Rezeptoren inkubiert. Gewonnen wurden die Fragmente durch die Expression der Actyllysin Mutanten von Ran, ohne die Synthetase und Acetyllysin mit anschließender Reinigung. Die Reinigung der Fragmente erfolgt in zwei Schritten über Affinitätschromatographie und Gelfiltration (Abb. A3). 
A
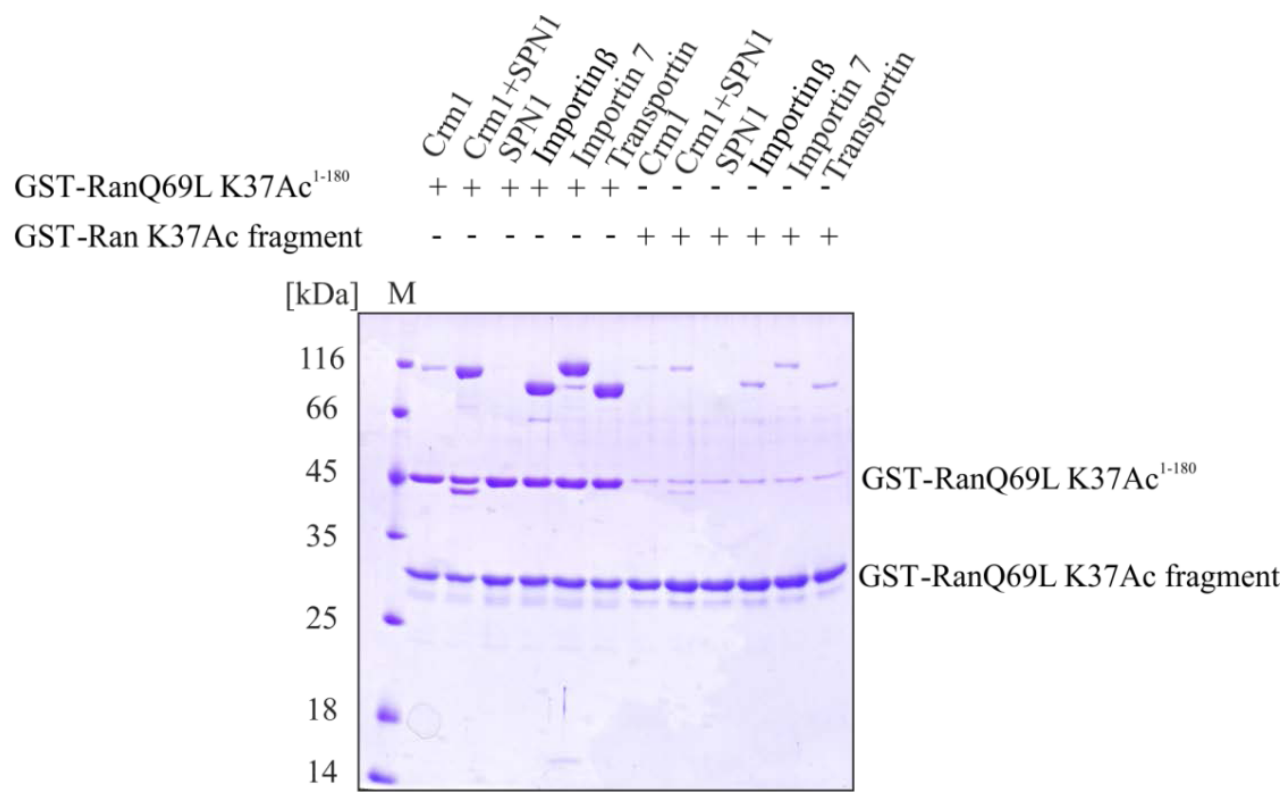

B

GST-RanQ69L K71 Ac $c^{1-180}$

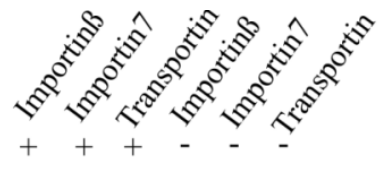

GST-Ran K71Ac fragment

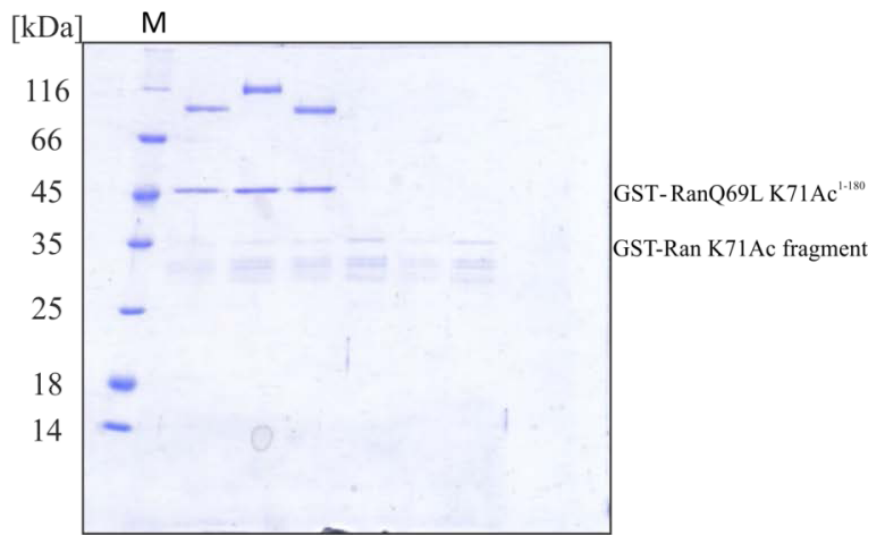

Abb. 23: Bindugsstudie von RanQ69L ${ }^{1-180}$ K37Ac und K71Ac mit Importrezeporen über einen

Pulldown-Assay. Gezeigt sind die SDS-Gele nach erfolgter Coomassie-Färbung. Aufgetragen wurden Probe der Elution des Pulldown-Assay mit immobilisiertem RanQ69L ${ }^{1-180}$ K37Ac (A), sowie mit immobilisiertem RanQ69L ${ }^{1-180}$ K71Ac (B). Der Marker (M) ist auf der rechten Seite in kDa angegeben. Ein + bezieht sich auf die Anwesenheit von immobilisierte RanQ69L ${ }^{1-180}$ oder Fragment mit Transportrezeptor, während ein - auf die Abwesenheit von immobilisierte RanQ69L ${ }^{1-180}$ oder Fragment hindeutet. Das Fragment entsteht durch das Einfügen des TAG Stopcodons zur Erstellung der acetylierten RanQ69L ${ }^{1-180}$ Mutanten.

Zur Analyse des Pulldown Assay wurde die Elution auf ein SDS-Gel aufgetragen. Es zeigt sich das Crm1 alleine schon mit der RanQ69L ${ }^{1-180}$ K37Ac Mutante interagiert (Abb. 23A), diese durch die Anwesenheit des Transportsubstrat (SPN1) noch gesteigert wird. Zu 
erkennen ist dies an den drei eluierten Banden. SPN1 alleine zeigt keine Interaktion mit RanQ69L ${ }^{1-180}$ K37Ac. Auch die Importrezeptoren $\operatorname{Imp} \beta$, Imp7 (Imp7) und Transportin interagieren mit RanQ69L ${ }^{1-180}$ K37Ac. In allen Elutionen ist das Ran-Fragment zu erkennen. In der Kontrolle mit immobilisiertem Ran-Fragment sind auch schwache Signale der Rezeptoren zu beobachten, die durch das Vorhandensein von gesamt Konstrukt GSTRanQ69L ${ }^{1-180}$ K37Ac erklärt werden können (schwache Signale auf Gel) (Abb. 23A). Eine starke Interaktion zwischen dem RanQ69L ${ }^{1-180}$ K37Ac Fragment und den Importrezeptoren ist nicht zu beobachten.

Auf das SDS-Gel (Abb. 23B) des Pulldowns mit immobilisierten RanQ69L ${ }^{1-180}$ K71Ac sind Proben der Elution aufgetragen. Das SDS-Gel zeigt, dass eine Interaktion zwischen dem immobilisierten RanQ69L ${ }^{1-180}$ K71Ac und den Importrezeptoren Importin $\beta$, Importin7 und Transportin stattfindet. Zwischen dem RanQ69L ${ }^{1-180}$ K71Ac Fragment und den Importrezeptoren ist keine Interaktion erkennbar.

Die Fragmente beider Mutanten RanQ69L ${ }^{1-180}$ K37Ac und K71Ac zeigen keine Interaktionen mit Transportrezeptoren, bei den gesamt Konstrukten in voller Länge ist eine Interaktion zu beobachten. Die Acetylierung von Ran an den Lysinen in den variablen Regionen GTPase (K37, K38 und K71), sowie der Lysine in den Bereichen zwischen den variablen Regionen (K60, K99 und K159), zeigen keine Auffälligkeiten betreffend der Bindung der GTPase an die Transportrezeptoren (h.s.Crm1, Imp $\beta, \operatorname{Imp} 7$ und Transportin).

\subsubsection{Analyse der GTPase-Aktivität der RanGTP Acetyllysin Mutanten}

Bei Ran handelt es sich im Großen und Ganzen um einen molekularen Schalter. In der Zelle wechselt Ran zwischen dem GTP gebunden aktiven Zustand ("on state") und dem GDP gebunden passiven Zustand ("off state"). Der Wechsel von RanGTP zu RanGDP wird durch RanGAP1 katalysiert (GTP-Hydrolyse). RanGAP1 ist ein direkter Interaktionspartner der GTPase Ran und Teil des Ran Zyklus.

Zur Untersuchung des Einflusses der Acetylierung auf die Funktion von Ran wurden verschiedenen Methoden und Ansätze verwendet.

1. Der Einflusses einer Acetylgruppe auf die GTP-Hydrolyse durch Ran kann in einem GAP-Assay untersucht werden,

2. sowie indirekt durch Bindung an Transportrezeptoren, mittels Ran Protections Assay

Die GTP-Hydrolyse wurde dabei mit unterschiedlichen Methoden nachgewiesen.

1. Über die Messung von freigesetztem radioaktiven Phosphat des $\left[\gamma^{32}{ }^{32}\right]-G T P$ und 
2. mittels einer nicht radioaktiven indirekten Methode, eines Phosphat Sensors (siehe 2.2.4.3)

Für diese Experimente wurde das Ran in voller Länge verwendet, da die verkürzte Form mit der Q69L Mutation den GTP gebundenen Zustand des Ran stabilisiert und die Hydrolyse durch RanGAP1 nicht induziert wird (Bischoff et al., 1994; Seewald et al., 2002). Um die beiden experimentellen Ansätze durchführen zu können ist es wichtig, dass sich das Ran im GTP gebundenem Zustand befindet. Um dies zu ermöglichen wurde eine Beladung von Ran mit GTP, wie in Abschnitt 2.2.3.2 beschrieben durchgeführt. Abbildung 24 zeigt die Analyse der Beladung mit GTP. Durch diese Methode der Beladung der GTPase mit GTP konnte, wie in Abb.24 zu erkennen konnte das Ran WT, sowie die Acetyllysin Mutanten, zu 60-70 \% mit GTP beladen werden. Der jeweilige andere Teil (30-40\%) befand sich danach in GDP gebundener Form. Grundlage der Berechnung der Beladung ist die Fläche unterhalb des GDP, sowie des GTP Maximums.

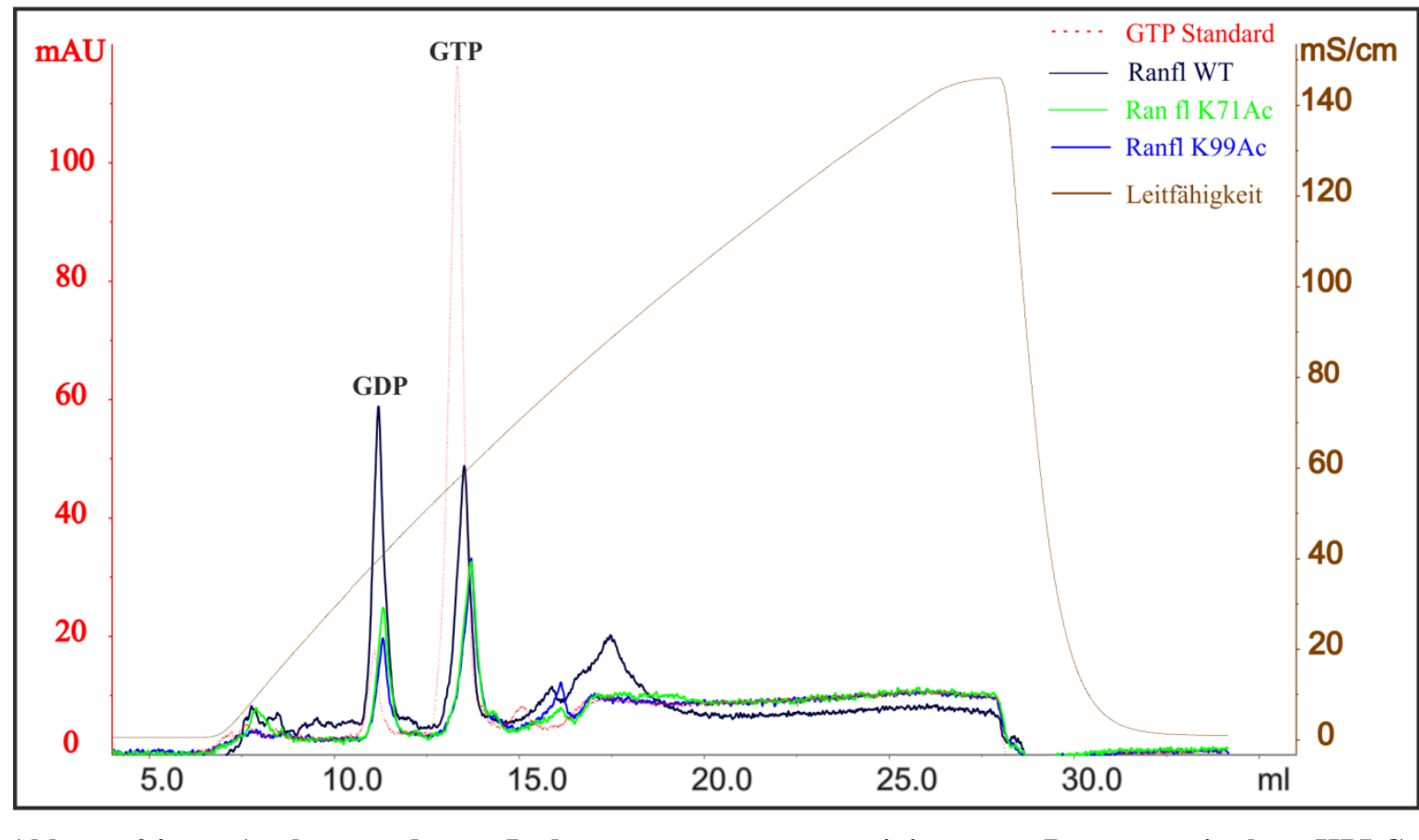

Abb. 24: Analyse des Ladestatus von gereinigtem $\operatorname{Ran}_{\mathrm{fl}}$ mittel HPLCAnionenaustauschchromatographie über Nucleosil 4000-7 PEI . Gezeigt ist die Überlagerung der Chromatogramme der einzelnen Analysen. Auf der X-Achse ist das Retentionsvolumen in [ml] und auf der Y-Achse die Absorption bei $260 \mathrm{~nm}$ [mAU] und die Leitfähigkeit [mS/cm] aufgetragen. Die Absorption bei $260 \mathrm{~nm}$ des GTP Standard ist rot, sowie die Analyse an den Beispielen von $\operatorname{Ran}_{\mathrm{fl}}$ WT in schwarz, $\operatorname{Ran}_{\mathrm{fl}}$ $\mathrm{K} 71 \mathrm{Ac}$ in grün und $\operatorname{Ran}_{\mathrm{fl}}$ K99Ac in blau. 


\subsubsection{Funktionale Analyse der GTPase Ran, der GAP-Assay}

Im GAP-Assay kann die GTPase-Aktivität der RanGTP Mutanten betrachtet werden. Dabei wird die Hydrolyseaktivität des RanGTP durch die Zugabe von RanGAP1 gesteigert. Die Hydrolyse des GTP wird auf zwei Wegen untersucht:

Einmal durch das freigesetzte radioaktive Phosphat des $\left[\gamma_{-}{ }^{32} \mathrm{P}\right]$-GTP und in einem erneuten Experiment mit normalem GTP durch ein Phosphat bindendes Protein (Phosphatsensor). Durch die Bindung des bei der Hydrolyse frei werdenden Phosphats an den Sensor entsteht ein Fluoreszenzsignal das beobachtet werden kann. Um das Ran mit dem radioaktiven GTP zu beladen, wurde das Ran zunächst mit EDTA, sowie anschließend mit $\mathrm{MG}^{2+}$ und $\left[\gamma-{ }^{32} \mathrm{P}\right]-$ GTP inkubiert um GDP zu entfernen und GTP zu binden. Überschüssiges $\left[\gamma_{-}-{ }^{32} \mathrm{P}\right]-$ GTP wurde über PD10 Entsalzungssäulen entfernt und der Beladungsgrad bestimmt. Die gewonnenen Daten beider Experimente lassen sich in Form einer Auftragung der relativen $\left[\gamma-{ }^{32} \mathrm{P}\right]-\mathrm{GTP}$ Hydrolyse (Abb. 25A), sowie des relativen Fluoreszenzsignals (Abb. 25B) gegen die Zeit darstellen.
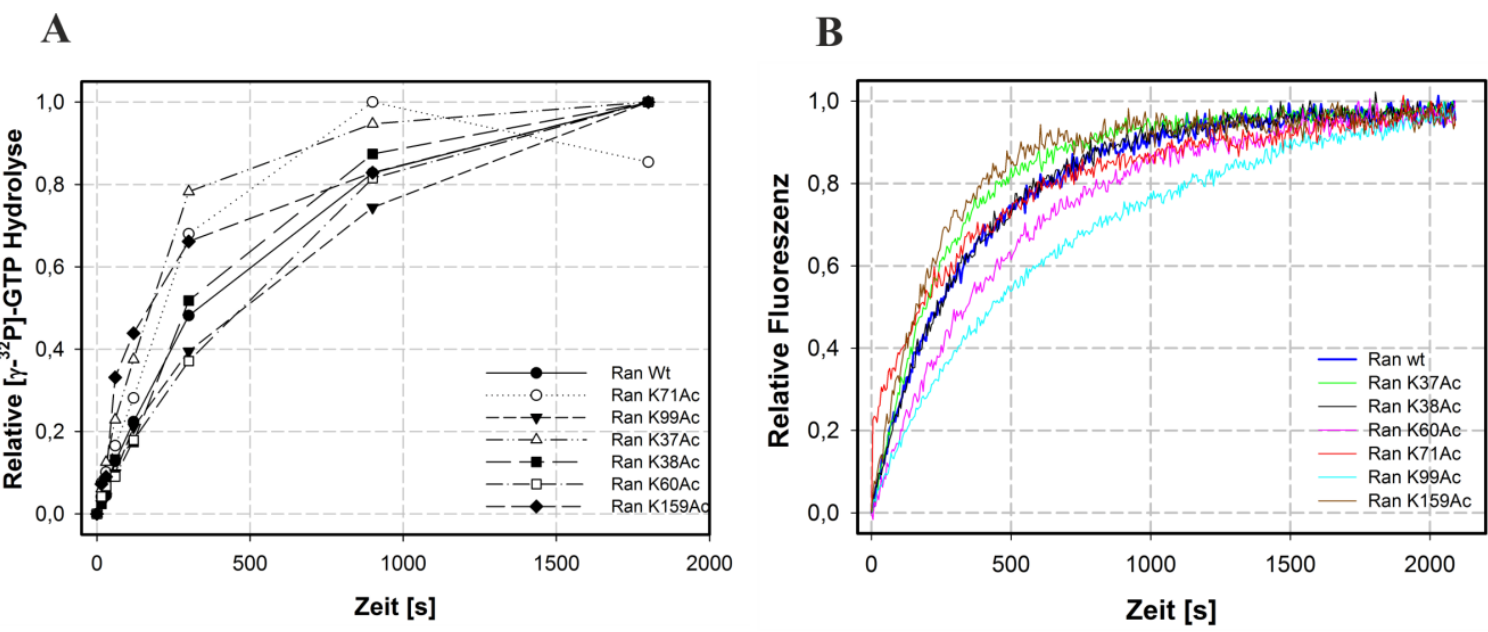

Abb. 25: GAP-Assay von RanGTP Acetyllysin Mutanten mittels radioaktiv markiertem GTP und

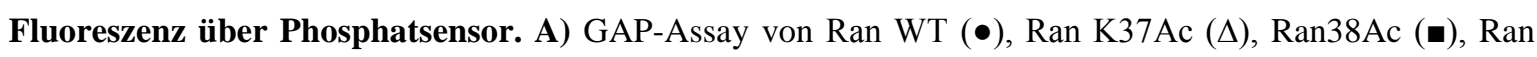
K60Ac (口), K71Ac (०), Ran K99Ac ( $)$, Ran K159Ac (•) mittels radioaktiv markiertem GTP. Aufgetragen ist die Relative $\left[\gamma_{-}{ }^{32} \mathrm{P}\right]-\mathrm{GTP}$ Hydrolyse gegen die Laufzeit [s]. B) GAP-Assay mittels Phosphatsensor von RanGTP Wildtyp (blau) Ran K37Ac (grün), Ran K38Ac (schwarz), Ran K60Ac (pink), K71Ac (rot) und Ran K99Ac (türkis), Ran K159Ac (braun). Aufgetragen die relative Fluoreszenz gegen die Zeit $[\mathrm{s}]$.

Aus der Auftragung der Daten des GAP-Assay mit radioaktivem GTP (Abb. 25A) ergibt sich eine Tendenz der Mutanten K37Ac, K71Ac und K159Ac für beschleunigte Hydrolyse des GTP in den ersten Sekunden der Reaktion. Die Mutante K71Ac erreicht nach 900s seine maximale Hydrolyseaktivität. Die Mutanten K99Ac benötigt länger um das GTP zu 
hydrolysieren, dies zeigt sich an dem flacheren Verlauf der Kurve (Abb. 25A). Die GTPHydrolyse ist demnach langsamer als beim Wildtyp. Der GAP-Assay unter Verwendung des Phosphatsensors zeigt ähnliche Resultate, wie mit radioaktivmarkiertem GTP. So zeigen in diesem Experiment die Mutanten K37Ac und K159Ac ebenfalls eine gesteigerte Hydrolyseaktivität in den ersten Sekunden der Reaktion und erreichen das Maximum etwas schneller als der Wildtyp. Die Mutanten K60Ac und K99Ac dagegen zeigen eine niedrigere Hydrolyseaktivität in den ersten Sekunden der Reaktion. Dabei benötigt die Mutante K99Ac länger um auf die Werte des Wildtyp zugelangen.

Aus beiden Experimenten geht hervor, dass die Mutanten K37Ac und K159Ac bei der GTP-Hydrolyse schneller sind, wohingegen die Mutante K99Ac eher langsamer ist, als dies bei Wildtyp RanGTP zu beobachten ist.

\subsubsection{Funktionale Analyse von acetyliertem RanGTP im Komplex mit} Transportrezeptoren mittels radioaktiv markiertem GTP

Zur weiteren Untersuchung des Einflusses der Acetylierung auf die Funktion von Ran wurde ein abgewandelter experimenteller Ansatz des GAP-Assay verwendet. In diesem wurde die Hydrolyse von GTP durch Ran, das sich im Komplex mit verschiedenen Transportrezeptoren (h.s.Crm1, Importin $\beta$ und Importin7) befindet, untersucht (RanProtections Assay, 2.2.3.10). Die Hydrolyse des GTP durch Ran wurde mittels radioaktiv markiertem GTP ([ $\left.\left.\gamma^{3}{ }^{32} \mathrm{P}\right]-\mathrm{GTP}\right)$ beobachtet. In diesem Experiment mit radioaktivem GTP als Nachweismethode werden die Mutanten mit steigenden Konzentrationen an Transportrezeptoren (im Fall von h.s.Crm1 in Anwesenheit eines Kernexportsignal (NES)) inkubiert. Durch Zugabe von RanGAP1 wird die Hydrolyse gestartet. Die Hydrolyse von GTP wird durch das freigesetzte radioaktive Phosphat gemessen.

Die Daten, welche in diesem Experiment erhalten werden lassen sich in Form einer Auftragung der Prozentualen GTP-Hydrolyse gegen eine steigende Konzentration an Transportrezeptor (0-400 nM) darstellen (Abb. 26). Neben Importin $\beta$ und Importin 7 als Importrezeptoren wurde auch Crm1 Die Experimente mit h.s.Crm1 (Abb. 26A) zeigen einen signifikanten Unterschied einiger Mutanten gegenüber dem Wildtyp. So zeigt der Wildtyp bei 400 nM h.s.Crm1 eine noch vorhandene Hydrolyseaktivität, von dem ursprünglich vorhandenen markierten RanGTP werden noch 33 \% hydrolysiert. Die Mutante K37Ac zeigt keinen signifikanten Unterschied im Vergleich zum Wildtyp. Die Mutanten K71Ac und K38Ac zeigen trotz h.s.Crm1+NES noch Hydrolyse von GTP. Im Gegensatz zum Wildtyp werden hier bis zu 80 \% des GTP (bei 400 nM Crm1) 
hydrolysiert. Auch die Mutante K60Ac zeigt eine erhöhte Hydrolyseaktivität (60 \% hydolysiertes GTP bei 400 nM h.s.Crm1). Diese Mutanten binden somit weniger stark an das h.s.Crm1. Die Mutanten K99Ac und K159Ac zeigen hingegen eine niedrigere Hydrolyseaktivität als der Wildtyp (36 \% und $23 \%$ hydrolysiertes GTP bei $40 \mathrm{nM}$, sowie $10 \%$ bei $400 \mathrm{nM}$ ) die Mutante K159Ac zeigt bei $400 \mathrm{nM}$ einen Ausreißer mit $30 \%$ hydrolysiertem GTP. Der generelle Verlauf der Mutante K159Ac (0, 40 und $120 \mathrm{nM}$ h.s.Crm1) weist Ähnlichkeit zur Mutante K99Ac auf. Beide Mutanten lassen eine stärkere Bindung an das h.s.Crm1 erkennen, als das Wildtyp Ran. Das Experiment mit dem Importrezeport $\operatorname{Imp} \beta$ zeigt generell keinen Unterschied zwischen den Mutanten und dem Wildtyp RanGTP. Es ist zu erkennen, dass schon bei der niedrigen Konzentration von 40 nM keine GTP-Hydrolyse mehr stattfindet (Abb. 26B).
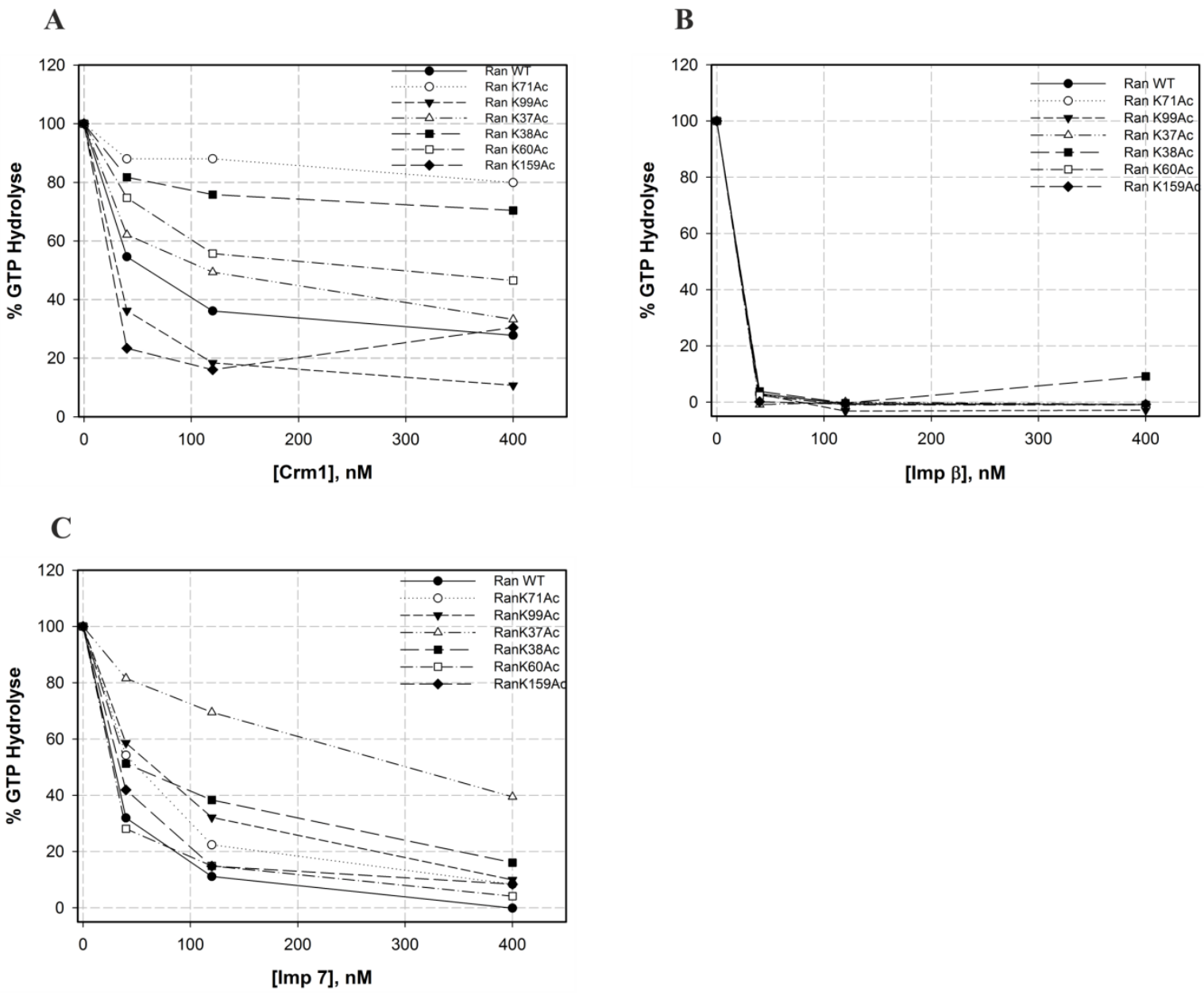

Abb. 26: Ran Protektion mittels radioaktiv markiertem RanGTP. Titration einer steigenden Konzentration (0-400 nM) der Transportrezeptoren Crm1 (A), Importin $\beta$ (B) und Importin7 (C) gegen [ $\gamma$ -

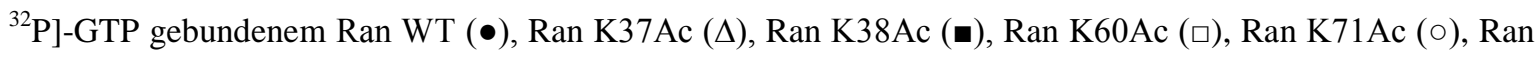
K99Ac ( $\boldsymbol{\nabla})$ und Ran K159Ac $(\bullet)$ ) . Auftragung der GTP Hydrolyse [\%] gegen die Rezeptor Konzentration 
Die Gegenwart von Imp7 im Ran-Protections Assay (Abb. 26C) lässt Unterschiede zwischen dem Wildtyp und den Mutanten erkennen. So zeigt der Wildtyp bei $400 \mathrm{nM}$ Imp7 keine GTP-Hydrolyse mehr. Einen signifikanten Unterschied zeigt die Mutante K37Ac, welche bei 400 nM Imp7 noch eine GTP-Hydrolyse von 40 \% zeigt. Die Mutante zeigt für jeden Messpunkt eine signifikant höhere Hydrolyseaktivität, als dies für den Wildtyp der Fall ist. Die Mutante K38Ac zeigt in dieser Hinsicht ein ähnliches Verhalten wie die Mutante K37Ac, weicht dabei jedoch weniger stark vom Wildtyp ab. So zeigt die Mutante K38Ac bei 400 nM noch eine Hydrolyseaktivität mit $20 \%$ hydrolysiertem GTP. Diese Mutanten binden somit weniger stark an das Imp7. Auch die anderen Mutanten zeigen noch eine geringfügig höhere Hydrolyseaktivität, verglichen mit dem Wildtyp. Die Acetylierung von RanGTP zeigt einen Einfluss auf Komplexe mit h.s.Crm1 und Imp7, keinen Einfluss jedoch auf eine Interaktion mit $\operatorname{Imp} \beta$.

\subsubsection{Funktionale Analyse von acetyliertem RanGTP im Komplex mit} Transportrezeptoren mittels Phosphatsensor

Neben radioaktiv markierten GTP ([ $\left.\left.\gamma^{32} \mathrm{P}\right]-\mathrm{GTP}\right)$ als Nachwiesmethode für die Hydrolyse von GTP durch Ran im Ran Protections Assay (2.2.3.10.2), lässt sich diese Analyse der Acetyllysin Mutanten auch mit einer indirekten Methode durchführen, mittels eines Phosphat Sensors (2.2.4.3). Für diesen Assay wurde das Ran in seiner vollen Länge und ohne die Q69L Mutation verwendet. Mit Ran in GTP gebundener Form (3.5.3 Abb. 24) konnte der Ran Protections Assay durchgeführt werden. Wie auch in dem Assay mit radioaktiv markiertem GTP als Nachweismethode wurden die Mutanten mit steigender Konzentration h.s.Crm1 in Anwesenheit von SPN1 inkubiert. Dabei wurde Ran in einer Gesamtkonzentration eingesetzt, in der die Konzentration von GTP gebundenem Ran 1.5 $\mu \mathrm{M}$ entsprach. Die Titration erfolgte mit steigender h.s.Crm1 Konzentration bis zu einer Konzentration von $1.5 \mu \mathrm{M}$ unter der Annahme einer 1:1 Stöchiometrie zwischen RanGTP und h.s.Crm1. Die aus diesem Assay erhaltenen Daten lassen sich in Form einer prozentualen GTP-Hydrolyse (Abb. 27A), sowie in Form der Bildung des Exportkomplex mit steigender h.s.Crm1 Konzentration mit Kurvenangleich darstellen (Abb. 27B) am Beispiel des Ran K71Ac. 

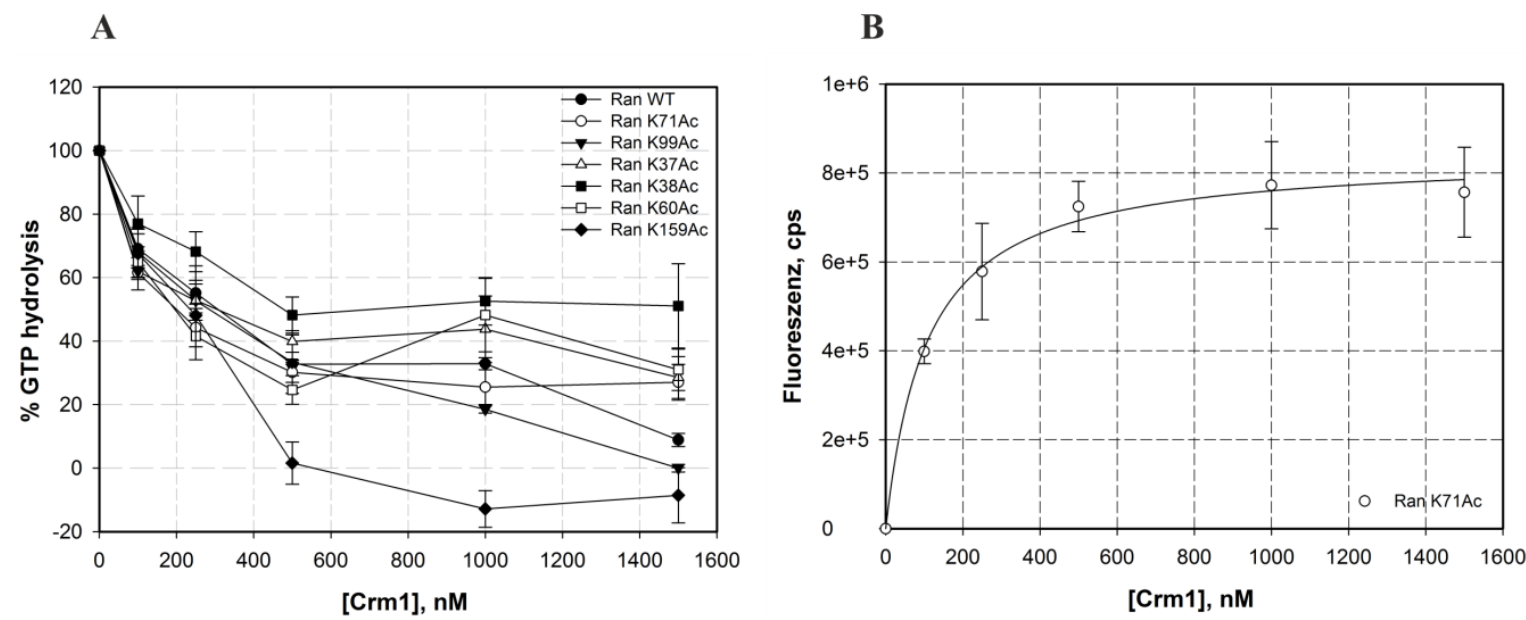

Abb. 27: Funktionale Analyse der RanGTP Acetyllysin Mutanten K71 und K99 mittels Ran Protection Assay. Titration einer bestehende Konzentration (1.5 $\mu$ M, GTP gebundenes Ran) an Ran WT $(\bullet)$,Ran K37Ac $(\Delta)$,Ran K Ran38Ac (•),Ran K60Ac (口), K71Ac (०) und Ran K99Ac ( $\mathbf{\nabla})$, Ran K159Ac ( $)$ gegen eine steigende Konzentration Crm1 (0-1500 nM). A) Auftragung der GTP Hydrolyse [\%] gegen die steigende h.s.Crm1 Konzentration. Aufgetragen wurden die Mittelwerte mit Standardabweichung. B) Komplexbildung von RanGTP mit Crm1 in Anwesenheit von SPN1. Aufgetragen ist die Fluoreszenzzunahme (cps) gegen die Crm1 Konzentration [nM] mit Kurvenangleich am Beispiel der Mutante RanK71Ac.

Die Bindung von RanGTP an h.s.Crm1 schützt das RanGTP vor der Aktivität des RanGAP1. Wie die Abbildung 27A zeigt, weist das Wildtyp RanGTP (1,5 $\mu \mathrm{M})$ bei gleicher Konzentration h.s.Crm1 eine GTP-Hydrolyse von 9 \% auf. In dieser Darstellung (Abb. 27A) lassen sich unterschiedliche Bindungseigenschaften erkennen. So zeigt die Mutante K99Ac noch einen sehr ähnlichen Verlauf wie der Wildtyp, zeigt jedoch bei gleicher Konzentration keine Hydrolyse. Die Mutante K38Ac zeigt den deutlichsten Unterschied im Kurvenverlauf. Bei 500 nM h.s.Crm1 zeigt die Mutante noch eine GTPHydrolyse von 48 \% was sich nicht mehr signifikant ändert. Die Mutanten K37Ac, K71Ac und K60Ac weisen einen ähnlichen Verlauf auf und enden bei gleicher Konzentration an h.s.Crm1 auf 29 \% bzw. 27 \% und 30 \% hydrolysiertem GTP. Im Gegensatz dazu zeigt sich bei der Mutante K159Ac schon bei einer Konzentration von 500 nM h.s.Crm1 keine Hydrolyse mehr.

Aus dem Kurvenangleich der aufgetragenen Daten (Abb.27 B, Beispiel Ran K71Ac) lässt sich der $\mathrm{K}_{\mathrm{d}}$-Wert der Beziehung RanGTP:Crm1 (RanGTP WT und Acetyllysinmutanten) in Abhängigkeit von h.s.SPN1 ermitteln. Die aus dem Kurvenangleich ermittelten $\mathrm{K}_{\mathrm{d}^{-}}$ Werte mit Standardabweichung sind in Tabelle 4 dargestellt. Daraus ergibt sich in diesem Experiment ein $\mathrm{K}_{\mathrm{d}}$-Wert von 260,9 $\mathrm{nM}$ für die Bindung von Wildtyp RanGTP an h.s.Crm1. Die Mutanten zeigen in diesem Experiment unterschiedliche Bindungsstärken. So lassen sich, in Bezug auf den Wildtyp, für die Mutanten K37Ac (125,6 nM), K38Ac 
(138,9 nM), K60Ac (73,3 nM) und K71Ac (106,6 nM) niedrigere Dissoziationskonstanten ermitteln, wohingegen sich für die beiden Mutanten K99Ac (290,2 nM) und K159Ac (321,4 nM) höhere $K_{d}$-Wert ergaben.

Somit binden die Mutanten K37Ac, K38Ac, K60Ac K71Ac stärker an Crm1, zeigt jedoch auch bei höheren Konzentrationen von Cm1 noch Hydrolyseaktivität. Die Mutante K99Ac dagegen verhält sich ähnlich dem WT und zeigt keinen signifikanten Unterschied, während die Mutante K159Ac einen signifikant höheren $\mathrm{K}_{\mathrm{d}}$-Wert zeigt.

Tabelle 4: $K_{d}$-Werte für die Interaktion der RanGTP Mutanten und Wildtyp an h.s.Crm1 in Anwesenheit von h.s.SPN1

DurchKurvenangleich erhaltene $\mathrm{K}_{\mathrm{d}}$-Werte für RanGTPBindung an Crm1 in Anwesenheit von Spn1

\begin{tabular}{ccc}
\hline RanGTP & $\begin{array}{c}\mathrm{K}_{\mathrm{d}}-\text { Werte } \\
{[\mathrm{nM}]}\end{array}$ & $\begin{array}{c}\text { Standartabweichungdes } \\
\text { Kuvenangleiches[nM] }\end{array}$ \\
\hline WT & 260,9 & $\pm 89,6$ \\
K37Ac & 125,6 & $\pm 37,0$ \\
K38Ac & 138,9 & $\pm 51,8$ \\
K60Ac & 73,3 & $\pm 51,7$ \\
K71Ac & 106,6 & $\pm 13,1$ \\
K99Ac & 292,2 & $\pm 87,7$ \\
K159Ac & 321,4 & $\pm 105,3$
\end{tabular}

3.5.4 Präparation und Kristallisation des Exportkomplexes mit acetyliertem RanQ69L ${ }^{1-180}$ an K71 und K99

Mit der Erkenntnis, dass sich ein stabiler Exportkomplex mit den RanQ69L ${ }^{1-180}$ Acetyllysin Mutanten formt, wurden zunächst die RanQ69L ${ }^{1-180}$ Acetyllysin Mutanten K71 und K99 für die Präparation und die Kristallisation eines Exportkomplexes verwendet. Die Präparation der Exportkomplex mit den RanQ69L ${ }^{1-180}$ Acetyllysin Mutanten K71 und K99 wurde auf Grundlage bereits Publizierter Daten (Monecke et al., 2009) und wie in Abschnitt (2.2.5.5) beschrieben durchgeführt. Die einzelnen Komponenten des Exportkomplex wurden in einem 1:4:6 Verhältnis eingesetzt, wobei das h.s.SPN1 in vier fachen und die RanQ69L ${ }^{1-180}$ Acetyllysin Mutanten in 6-fachen Überschuss zum h.s.Crm1 eingesetzt wurden. Nach einer Dialyse des Komplexansatzes, wird eine Superdex 200 XK26/60 Gelfiltrationssäule verwendet um das überschüssige h.s.Spn1 und RanQ69L ${ }^{1-180}$ abzutrennen (Abb. 28). 


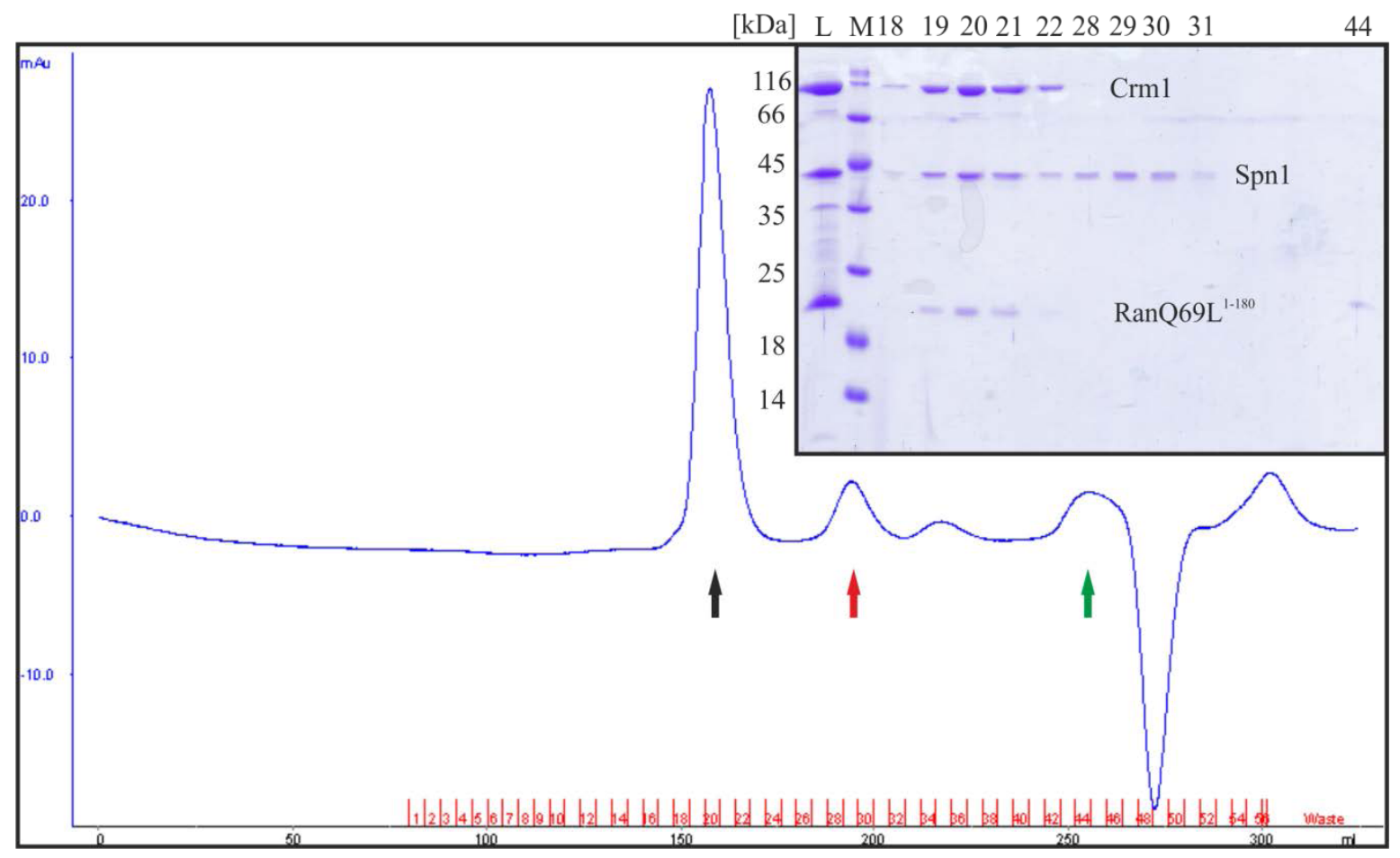

Abb. 28: Präparation des Exportkomplexes mittels Größenauschlußchromatographie. Dargestellt ist das Elutionsprofil der Gelfiltration. Die Absorption bei $280 \mathrm{~nm}$ ist als blaue Linie dargestellt. Auf der XAchse ist das Retentionsvolumen in [ml] und auf der Y-Achse die UV-Absorption [mAU] aufgetragen. Der schwarze Pfeil markiert den Komplex, der rote das überschüssige SPN1 und der grüne das überschüssige RanQ69L ${ }^{1-180}$. Die zu analysierenden Fraktionen sind in rot dargestellt und mit Nummern versehen. In der rechten oberen Ecke des Elutionsprofils ist die Analyse über SDS-Gel dargestellt. Die Zahlen korrespondieren mit den Fraktionen im Elutionsprofil. Die Molekulargewichte der Markerproteine (M) sind angegeben, sowie die Ausgangsprobe vor der Gelfiltration (L).

Der Gelfiltrationslauf wurde über ein SDS-Gel analysiert. Dabei zeigt sich, dass ein homogener Komplex bestehend aus allen drei Proteinen in den mittleren Fraktionen des gemeinsamen Absorptionsmaximums eluiert. In den folgenden Absorptionsmaxima eluierte jeweils nach ihrem Molekulargewicht das Spn1 und die RanQ69L ${ }^{1-180}$ Acetyllysinmutanten. Die mittleren Fraktionen des gemeinsamen Absorptionsmaximum werden vereinigt, auf eine Konzentration von 5-6 $\mathrm{mg} / \mathrm{ml}$ eingeengt und für Kristallisationsversuche verwendet.

Die Kristallisation des Exportkomplexes mit acetylierten RanQ69L ${ }^{1-180}$ Acetyllysin Mutanten K71 und K99 erfolgte im sitzenden Tropfen (2.2.6.1). Da dieser Komplex mit der RanQ69L ${ }^{1-180}$ Mutante bereits kristallisiert wurde (Monecke et al., 2009) konnte dessen Kristallisationsbedingung als Ausgangspunkt für eine Screening der Komplexe mit den Mutanten K71 und K99 gewählt werden. Von der Ausgangsbedingung (11\% (w/v) PEG1000 und 100 mM Tris pH 8.05) wurde zunächst ein Screen mit einer PEG1000 
Konzentration von 10-21\% bei $20^{\circ} \mathrm{C}$ erstellet. Der Komplex mit der K71 Mutante wurde dabei einmal direkt nach der Präparation, sowie nach dem Einfrieren und wieder Auftauen pipettiert (Abb. 29).

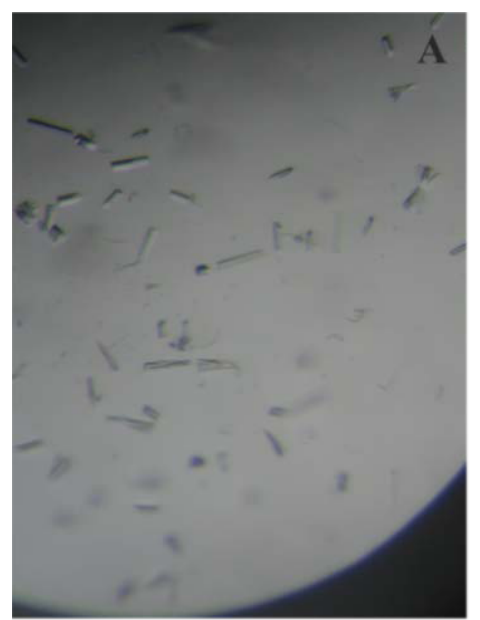

Crm1:SPN1:RanQ69LK71Ac ${ }^{1-180}$ $13 \%$ PEG1000,

$0.1 \mathrm{M}$ Tris $\mathrm{pH} 8.05$

$4.9 \mathrm{mg} / \mathrm{mL}$ Protein, frisch

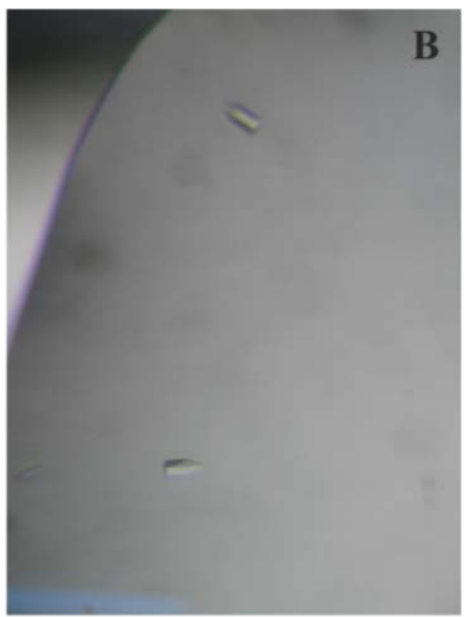

Crm1:SPN1:RanQ69LK71Ac ${ }^{1-180}$ $13 \%$ PEG1000,

$0.1 \mathrm{M}$ Tris $\mathrm{pH} 8.05$

$4.9 \mathrm{mg} / \mathrm{mL}$ Protein, eingeforen

Abb. 29: Kristallisation des Exportkomplex mit RanQ69L ${ }^{1-180}$ Acetyllysin Mutanten K71 und K99. A) Kleine stäbchenförmige Kristalle, entstanden aus nicht eingefrorenem Komplex B) Kleine rechteckige Kristalle, entstanden aus eingefrorenem Komplex. Die Kristallisationsbedingung sind unter den Bildern angegeben.

Die größeren Kristalle und weniger Präzipitat zeigten sich bei einer Konzentration zwischen 12 \% bis 15 \% PEG1000 nach einfrieren des präparierten Komplexes. In den folgenden Kristallisationsexperimenten wurde diese Methode als Standard verwendet (Abb. 29B).

Für gute Röntgenbeugungsexperimente mussten die Kristalle allerdings ein größeres Volumen aufweisen. Um dies zu erreichen wurde die Kristallisationsbedingung um Phenol als Additiv, in unterschiedlichen Konzentrationen erweitert (Abb. 30 A-C), so wie die Kristallisation bei unterschiedlichen Temperatoren (4, 10, 20 und $\left.25^{\circ} \mathrm{C}\right)$ durchgeführt. Die Verwendung von Phenol als Additiv in den Kristallisationsbedingungen führt vermehrt zum Wachstum von Kristallen mit ca. 150-300 x 20-40 x 20-40 $\mu$ m sowohl bei $20{ }^{\circ} \mathrm{C}$ wie auch bei $25^{\circ} \mathrm{C}$ (Abb. 30). Zwischen der Inkubation der Platten bei $20^{\circ} \mathrm{C}$ und $25^{\circ} \mathrm{C}$ (Abb. 30) konnte kein signifikanter Unterschied in der Kristallmorphologie festgestellt werden.

Die Kristalle, die unter dem Einfluss von Phenol (bei $20^{\circ} \mathrm{C}$ sowie bei $25^{\circ} \mathrm{C}$ ) entstanden, erreichten eine Größe, die es erlaubten diese für Beugungsexperimente zu verwenden. 


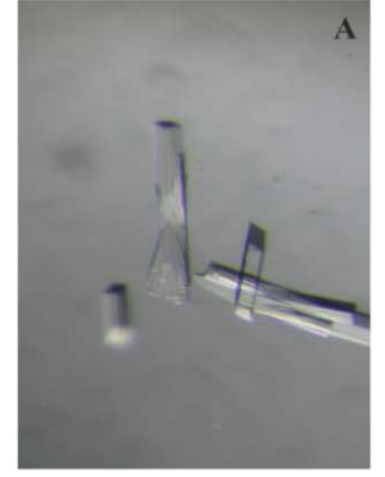

Crm1:SPN1:RanQ69LK71 Ac $\mathrm{Ac}^{1-1 / 80}$ $13 \%$ PEG 1000

$1 \mathrm{mM}$ Phenol

$0,1 \mathrm{M}$ Tris $\mathrm{pH} 8.05$

$20{ }^{\circ} \mathrm{C}$

$5.4 \mathrm{mg} / \mathrm{ml}$ Protein

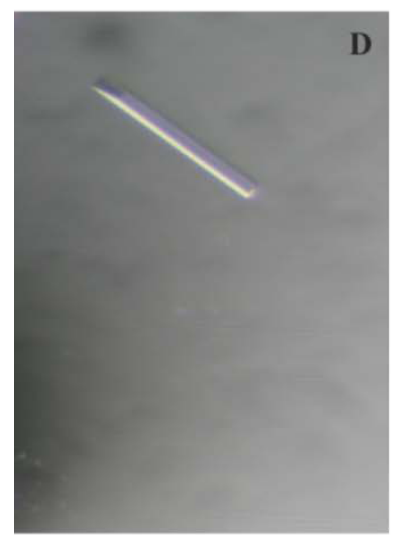

Crm1:SPN1:RanQ69LK71 Ac ${ }^{1-180}$

$12 \%$ PEG 1000

$1 \mathrm{mM}$ Phenol

$0,1 \mathrm{M}$ Tris $\mathrm{pH} 8.05$

$25^{\circ} \mathrm{C}$

$5.4 \mathrm{mg} / \mathrm{ml}$ Protein

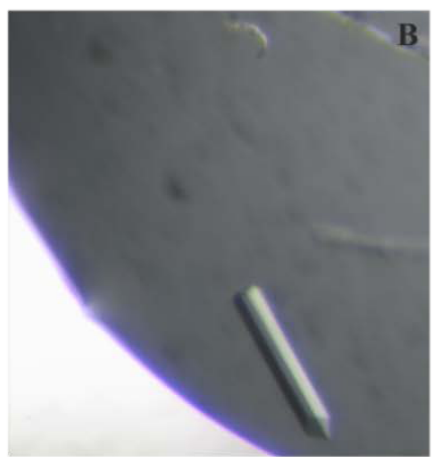

Crm1:SPN1:RanQ69LK71 Ac ${ }^{1-1 / 40}$

$12 \%$ PEG 1000

$2 \mathrm{mM}$ Phenol

$0,1 \mathrm{M}$ Tris $\mathrm{pH} 8.05$

$20^{\circ} \mathrm{C}$

$5.4 \mathrm{mg} / \mathrm{ml}$ Protein

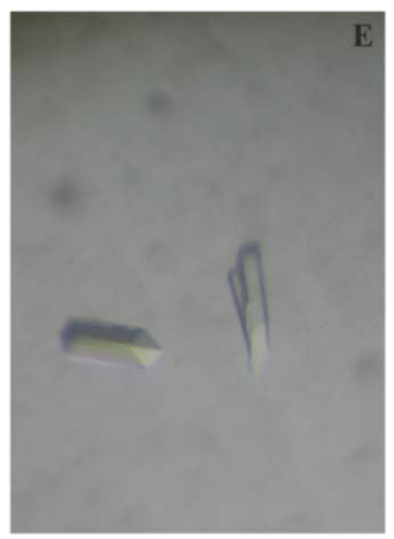

Crm1:SPN1:RanQ69LK71Ac Ac $^{1-180}$

$15 \%$ PEG 1000

$1 \mathrm{mM}$ Phenol

$0,1 \mathrm{M}$ Tris $\mathrm{pH} 8.05$

$25^{\circ} \mathrm{C}$

$5.4 \mathrm{mg} / \mathrm{ml}$ Protein

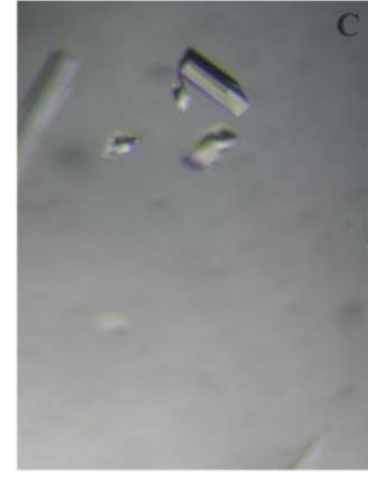

Crm1:SPN1:RanQ69LK71Ac ${ }^{1-180}$ $12 \%$ PEG 1000

$2,5 \mathrm{mM}$ Phenol

$0,1 \mathrm{M}$ Tris $\mathrm{pH} 8.05$

$20{ }^{\circ} \mathrm{C}$

$5.4 \mathrm{mg} / \mathrm{ml}$ Protein

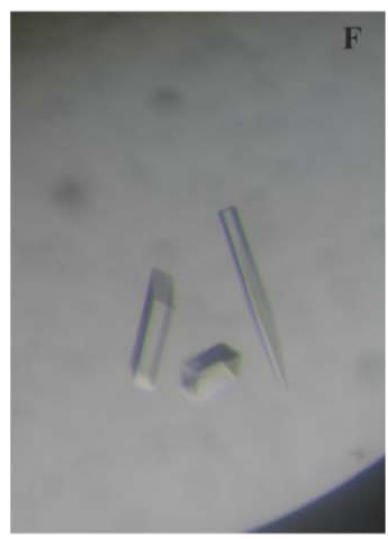

Crm1:SPN1:RanQ69LK71Ac Ac $^{1-18}$

$16 \%$ PEG 1000

$1 \mathrm{mM}$ Phenol

$0,1 \mathrm{M}$ Tris $\mathrm{pH} 8.05$

$25^{\circ} \mathrm{C}$

$5.4 \mathrm{mg} / \mathrm{ml}$ Protein

Abb. 30: Kristallisation des Exportkomplex mit RanQ69L ${ }^{1-180}$ Acetyllysin Mutanten K71 und K99.

A-C) Stabförmige und rechteckige Einkristalle, gewachsen in Bedingungen mit Phenolkonzentrationen bis 2,5 mM bei $20^{\circ} \mathrm{C}$. D-F) Stabförmige und rechteckige Einkristalle gewachsen in Bedingungen mit 12-16\% PEG 1000 bei $25^{\circ} \mathrm{C}$. Diese Bilde sind repräsentativ für Kristalle des Exportkomplex mit der RanQ69L ${ }^{1-180}$ Acetyllysinmutante K99.

Um zu überprüfen, ob die erhaltenen Kristalle aus den präparierten Komplexen bestehen und das für die Präparation verwendete RanQ69L ${ }^{1-180}$ in den Kristallen eine Acetylgruppe am jeweiligen Lysin trägt wurden einige Kristalle aus den Kristallisationsbedingungen aufgelöst. Neben den aufgelösten Kristallen wurden auch Proben aus den Kristallisationstropfen und auch der jeweilige präparierte Komplex auf ein SDS-Gel geladen. Mit diesem Gel wurde anschließend ein Westernblot (2.2.3.8) mit einem Antikörper gegen Acetyllysin durchgeführt (Abb. 31). Die Abbildung 31 zeigt das SDSGel (Abb. 31A), sowie den dazu gehörigen Blot (Abb. 31B). Zusätzlich wurde auf dem 
SDS-Gel (Abb. 31A) Komplex mit normalem RanQ69L ${ }^{1-180}$, sowie normales RanQ69L ${ }^{1-}$ 180 alleine und die acetylierte Mutante K99 als Kontrollen aufgetragen. Der Blot (Abb. 31B) zeigt ein Signal für acetyliertes RanQ69L ${ }^{1-180}$ in den Spuren in denen der Komplex (2 und 5), die Proben der Tropfen (4 und 7), sowie die aufgelösten Kristalle (3 und 6), welche auf das SDS-Gel aufgetragen wurden. In den Spuren in welchen der Komplex mit normalem RanQ69L ${ }^{1-180}$ (1) und das RanQ69L ${ }^{1-180}$ (8) ist kein Signal zu beobachten. Das ein Signal in Spur 9 zu erkennen ist indiziert die Funktionsfähigkeit des Antikörpers. Der Westernblot zeigt demnach, dass der Komplex mit den jeweiligen RanQ69L ${ }^{1-180}$ Mutanten K71 und K99 acetyliert präpariert wurde und die Kristalle aus dem Komplex mit jeweiligem acetyliertem RanQ69L ${ }^{1-180}$ bestanden.

A

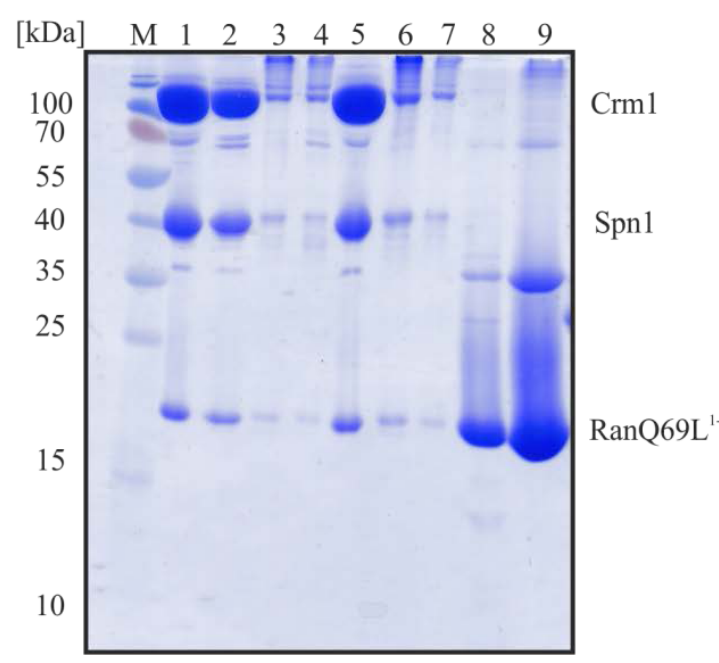

Abb. 31: Kontrolle gelöster Kristalle
B

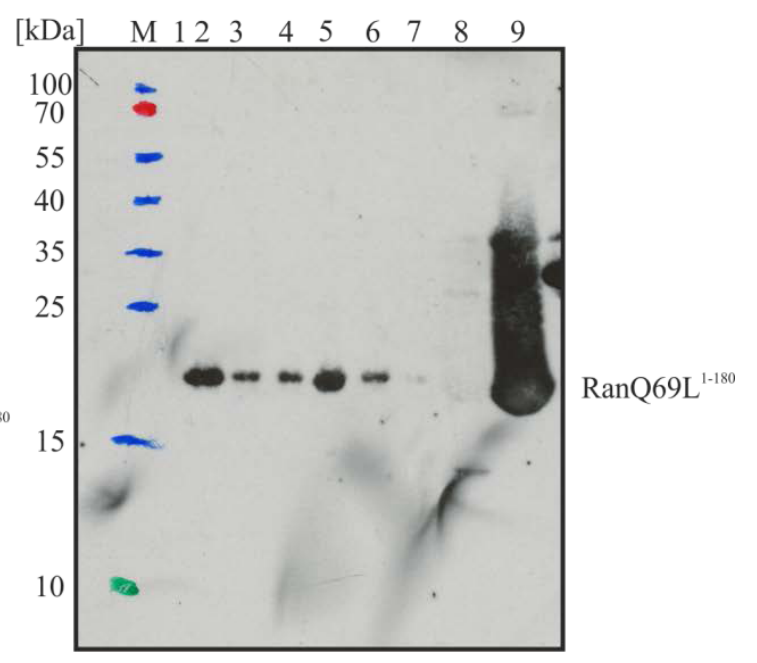

A) SDS-Gel der aufgelösten Kristalle, sowie Proben der Komplexe vor der Kristallisation und der Tropfen nach entnahme der Kristalle. Exportkomplex ohne RanQ69L ${ }^{1-180}$ Acetyllysin Mutante, sowie RanQ69L ${ }^{1-180}$ und RanQ69L ${ }^{1-180}$ K99Ac als Kontrollen für Westernblot. B) Westernblot des SDS-Gel. Die eingesetzten Proben wurden mittels eines Antikörpers gegen Acetyllysin auf Acetylierung kontrolliert und mittels ECL sichtbar gemacht. M= Markerproteine,1= Crm1:SPN1:RanQ69L ${ }^{1-180}$ Komplex , 2= Crm1:SPN1:RanQ69L ${ }^{1-}$ ${ }^{180} \mathrm{~K} 71 \mathrm{Ac}$ Komplex 3= Crm1:SPN1:RanQ69L ${ }^{1-180} \mathrm{~K} 71 \mathrm{Ac}$ Komplex crystals, 4= Crm1:SPN1:RanQ69L ${ }^{1-}$ ${ }^{180}$ K71Ac Komplex Tropfen, 5= Crm1:SPN1:RanQ69L ${ }^{1-180}$ K99Ac Komplex, 6= Crm1:SPN1:RanQ69L ${ }^{1-}$ ${ }^{180}$ K99Ac Komplex Kristalle , 7= Crm1:SPN1:RanQ69L ${ }^{1-180}$ K99Ac Komplex Tropfen , 8= RanQ69L $^{1-180}$, 9= RanQ69L ${ }^{1-180}$ K99Ac .

\subsubsection{Röntgenbeugungsexperiment und Datenprozessierung (P. Neumann)}

Die Kristalle, erhalten in 3.5.4, werden für die Bestimmung der drei dimensionalen Strukturen der Exportkomplexe mit den RanGTP Acetyllysin Mutanten K71 und K99 herangezogen. Ein nativer Datensatz des jeweiligen Exportkomplexes mit den Mutanten 
K71 und K99 wurde am Elektronensynchrotron DESY (Hamburg) bei $100 \mathrm{~K}$ aufgenommen. Diese Experimente wurden von Dr. Piotr Neumann (MSB) durchgeführt. Die Kristalle werden zu diesem Experiment mittels einer Nylonschleife (Loop) aus der Kristallisationsbedingung in Kryopuffer überführt. Der Kryopuffer richtete sich nach der Kristallisationsbedingung mit Zusatz von 16\% 2,3-Butandiol, 2\% PEG400 und 8\% Glyzerin (2.2.6.2-2.2.6.3). Die aus dem Röntgenbeugungsexperiment erhaltenen Daten wurden mit den Programmen XDS und XSCALE bearbeitet und zu einem Datensatz zusammengeführt. Aus diesem ergibt sich die in Tabelle 5 dargestellte Datenstatistik. So lässt sich für beide Kristalle die monokline Raumgruppe $\mathrm{P} 2{ }_{1}$ mit einer Auflösung der Reflexe bis ca. $2.7 \AA$ (Crm1:SPN1:RanQ69LK71Ac ${ }^{1-180}$ ) und ca. $2.4 \AA$ (Crm1:SPN1:RanQ69LK99Ac1-180) ermitteln. Die Phasen zur Berechnung der Strukturfaktoren und eine erste Elektronendichtekarte lassen sich über den Molekularen Ersatz bestimmen.

\begin{tabular}{|c|c|c|}
\hline $\begin{array}{l}\text { Tabelle 5: Statistik der D } \\
\text { RanGTP Mutanten K71 und }\end{array}$ & ammlung der Kristalle der Ex & rtkomplexe mit den aceylierten \\
\hline Kristall: Crm1:SPN1:RanQ69 & & \\
\hline Kristallisationbedingung: 14\% & 1000, 1.5 mM Phenol, 0.1 M Tris p & H $8.05,20^{\circ} \mathrm{C}$ \\
\hline & Crm1:SPN1:RanQ69LK71Ac ${ }^{1-180}$ & Crm1:SPN1:RanQ69LK99Ac ${ }^{1-180}$ \\
\hline Datasammlung & & \\
\hline Raumgruppe & $\mathrm{P} 2_{1}$ & $\mathrm{P} 2_{1}$ \\
\hline Zelldimensionen & & \\
\hline $\mathrm{a}, \mathrm{b}, \mathrm{c}[\AA]$ & $71.9,227.4,161.8$ & $72.25,224.43,162$ \\
\hline$\alpha, \beta, \gamma\left[{ }^{\circ}\right]$ & $90.000,100.723,90.000$ & 90.000100 .75290 .000 \\
\hline Wellenlänge [ $[\AA]$ & 0.824800 & 0.773180 \\
\hline 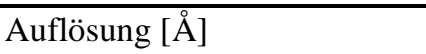 & $50-2.7(2.7)$ & $50.0-2.4(2.4)$ \\
\hline Beobachtete Reflexe & 444699 (39770) & 723983 (44698) \\
\hline Vollständigkeit [\%] & $98.3(97.1)$ & $94.0(72.6)$ \\
\hline $\mathrm{R}_{\text {merge }}[\%]$ & $12.0(69.2)$ & $10.9(55.6)$ \\
\hline Signal/Rauschverhältnis $(\mathrm{I} / \sigma)$ & 10.30 & 12.90 \\
\hline Redundanz & 3,2 & 4.1 \\
\hline $\begin{array}{l}\text { Die Werte in Klammern zeige } \\
R_{\text {merge }}=\frac{\sum_{h k l} \sum_{i} \mid I_{i}(h k l)-\left\langle I_{i}(h k l)\right\rangle}{\sum_{h k l} \sum_{i}\left(I_{i}(h k l)\right\rangle}\end{array}$ & $\begin{array}{l}\text { pezifischen Werte in der äußeren } S \\
\text { ei die Summe i über alle Einzelm }\end{array}$ & $\begin{array}{l}\text { ale } \\
\text { sungen des Reflexes hkl berechnet }\end{array}$ \\
\hline ist. & & \\
\hline
\end{tabular}




\subsubsection{Strukturelle Analyse des Exportkomplex mit RanGTP Acetyllysinmutanten}

Aus den berechneten Strukturfaktoren und Elektronendichtekarte lässt sich ein Modell des Exportkomplexes erstellen. Über das Programm AutoBuild konnten die Aminosäuren in einem ersten Schritt in die Elektronendichtekarte eingepasst werden. Dabei werden die Aminosäuren durch das Programm, nach der Proteinsequenz in die Elektronendichte eingepasst. Die Ausführung von Autobuild und der Strukturverfeinerung wurden von Dr. Piotr Neumann unternommen. Die Verfeinerungsstatistiken sind in Tabelle 6 aufgeführt.

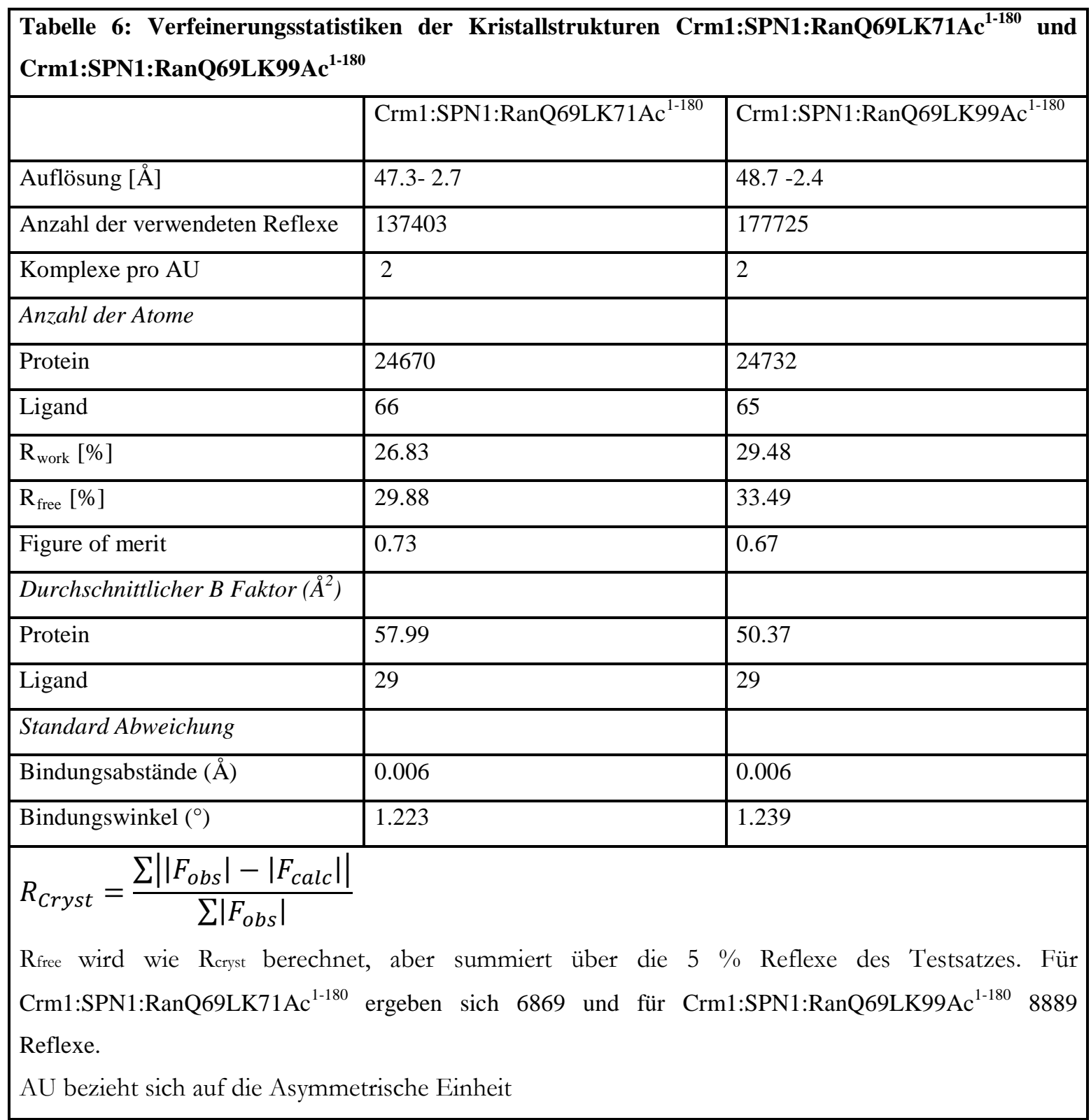


3.5.6.1 Beschreibung des allgemeinen strukturellen Aufbaus des Exportkomplexe mit den RanQ69L ${ }^{1-180}$ Mutanten K71Ac und K99Ac

Die Kristallstruktur der Exportkomplexe mit den acetylierten RanQ69L ${ }^{1-180}$ Mutanten K71Ac und K99Ac sind in Abbildung $32 \mathrm{zu}$ sehen. Sie zeigen einen ähnlichen strukturellen Aufbau wie die bereits gelöste Kristallstruktur des Crm1 Exportkomplex (Monecke et al., 2009, PDB ID 3GJX). Das h.s. Crm1 nimmt hierbei eine ringähnliche, aus HEAT-repeats aufgebaute, Form an und umfasst die Aminosäuren 12-1055. Das Transportsubstrat h.s. SPN1 ist an der Außenseite des ringförmigen h.s. Crm1 lokalisiert. Die Struktur von SPN1 umfasst die Aminosäuren 1-360 und bleibt zu der bereits in Monecke et al. (2009) gelösten Struktur grundlegend unverändert. Das RanQ69L ${ }^{1-180}$ GTP ist im Inneren des h.s. Crm1 Moleküls lokalisiert und wird von diesem umschlossen. Das kristallisierte Molekül RanQ69L umfasste die Aminosäuren 9-179. Diese Beobachtung ist für beide Komplexe zu machen (Abb. 32).

A

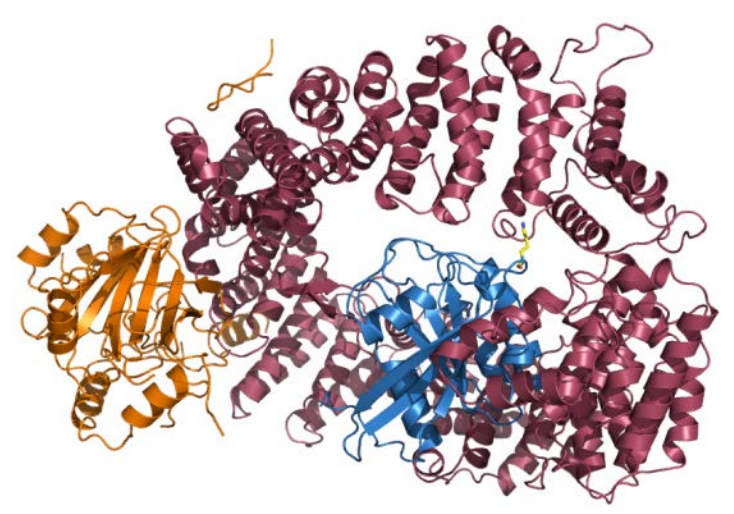

B

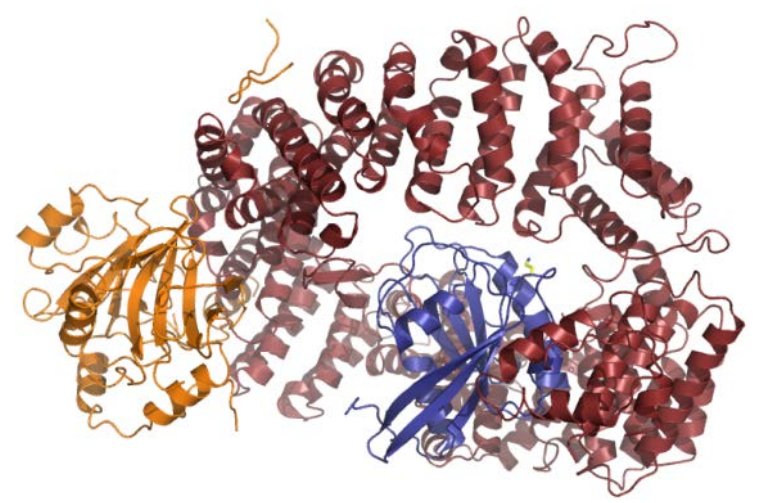

Abb. 32: Kristallstrukturen der Exportkomplexe mit acetylierten RanQ69L ${ }^{1-180}$ Acetyllysinmutanten. Gesamtansicht beider Strukturen, dargestellt als Cartoon Modelle. Das h.s.Crm1 ist himbeerfarben und das h.s.SPN1 in orange dargestellt. A) Zeigt den Komplex aus Crm1:SPN1 mit RanQ69LK71Ac ${ }^{1-180}$. Das Ran in diesem Komplex ist himmelblau eingefärbt B) Zeigt den Komplex aus Crm1:SPN1 mit RanQ69LK99Ac1${ }^{180}$. Das Ran ist in dunkelblau dargestellt (Pymol).

\subsubsection{Betrachtung der acetylierten Lysine 71 und 99}

Die Untersuchung der Strukturmodelle der Exportkomplexe nach Berechnung der Elektronendichtekarte zeigte einige Auffälligkeiten. In Abbildung 33 sind die acetylierten Lysine 71 (Abb. 33A) und 99 (Abb. 33B) zusammen mit der ermittelten Elektronendichtekarte gezeigt. Dargestellt sind die Lysine beider RanQ69L ${ }^{1-180}$ Moleküle der asymmetrischen Einheit als Stäbchenmodell zentriert auf das jeweilige Lysin, sowohl vom Komplex mit der K71Ac Mutante als auch von der K99Ac Mutante. Im Kristallkomplex mit der RanQ69L ${ }^{1-180}$ Mutante K71Ac zeigen sich zwei unterschiedliche 
A
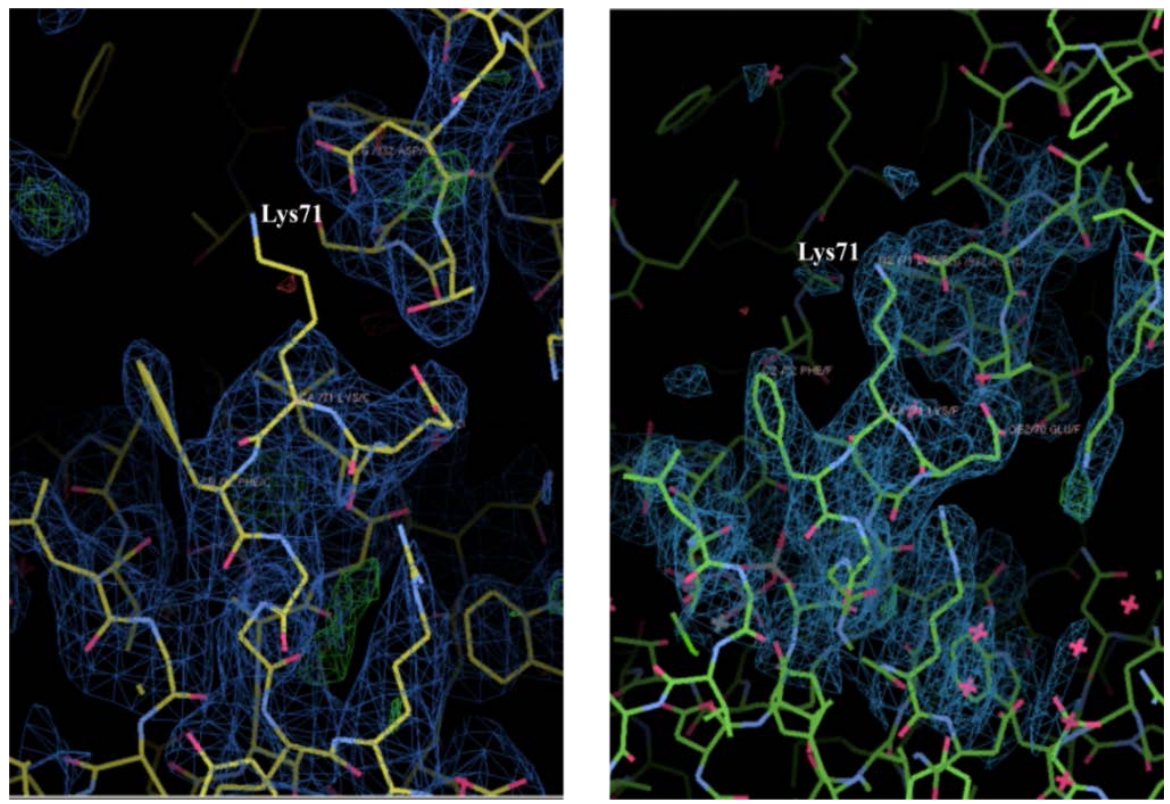

B
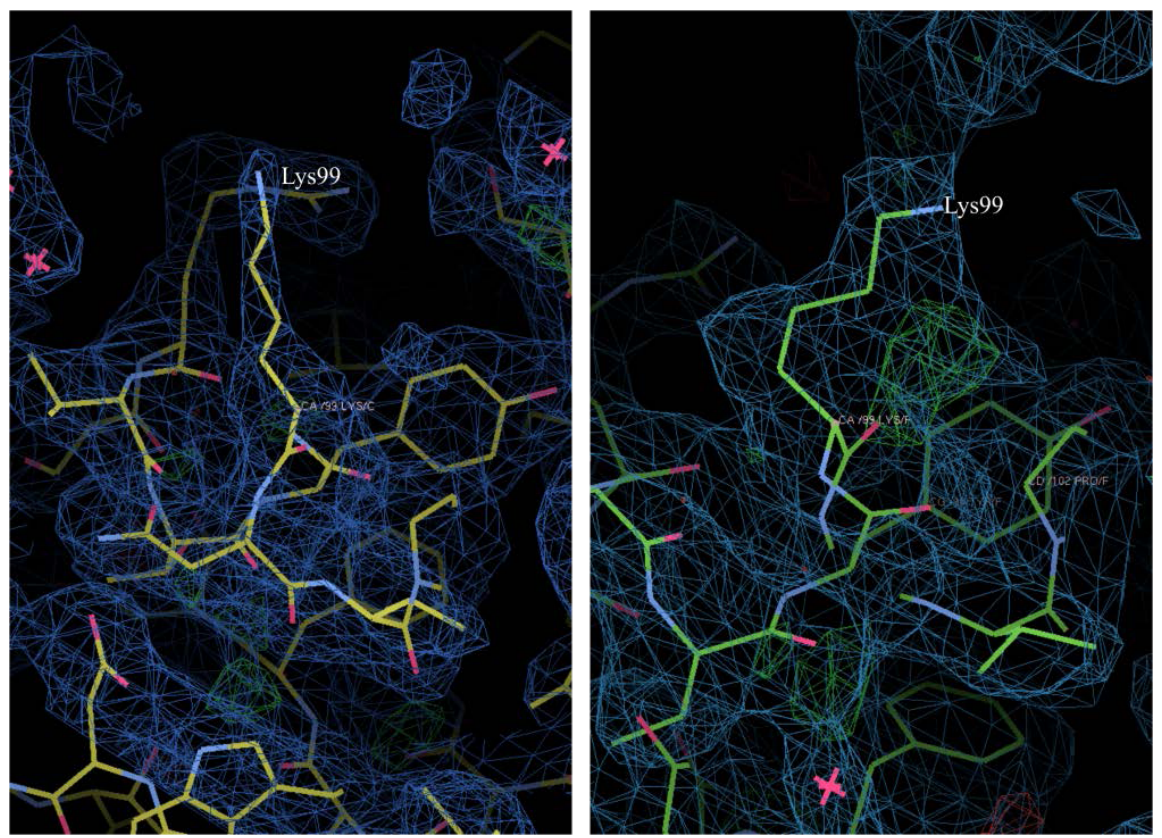

Abb. 33: Elektronendichtedarstellung der Lysine 71 und 99. Die Elektronendichte ist als blaues Gitternetz $(1.0 \sigma)$ und die Aminosäuren als Stabmodell dargestellt. A) fokussiert auf das Lysin 71 des RanQ69L ${ }^{1-180}$ K71Ac aus dem Exportkomplex. Gezeigt sind die beide Moleküle des RanGTP der asymmetrischen Einheit, jeweils in einem Bild auf der linken und rechten Seite der Abbildung. Die Kohlenstoffatome sind gelb (linkes Bild) und grün (rechtes Bild) dargestellt. Die Atome des Stickstoff sind blau, die des Sauerstoff rot eingefärbt. B) fokussiert auf das Lysin 99 des RanQ69L ${ }^{1-180}$ K99Ac aus dem Exportkomplex. Wie in A) sind beide Moleküle des RanGTP der asymmetrischen Einheit in je einem Bild links und rechts in der Abbildung gezeigt. Die Kohlenstoff, Stickstoff und Sauerstoffatome sind wie in A) eingefärbt. 
Formen für das K71Ac des RanQ69L ${ }^{1-180}$. So ist die Elektronendichte für das Lysin 71 in einer der beiden Ketten nicht zu erkennen (Abb. 33A, links), wohingegen in der zweiten Kette Elektronendichte für das Lysin 71 zu erkennen ist (Abb. 33A, rechst). Dabei weist

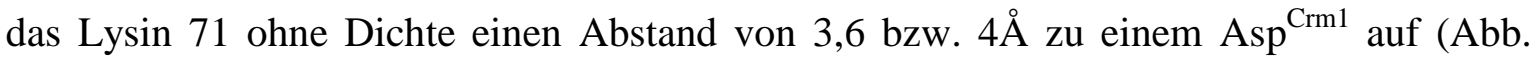
33A, links) und geht somit keine Interaktion mit dem Asp von Crm1 ein. Das Lysin 71 des zweiten Moleküls der asymmetrischen Einheit weist einen Abstand von 3.3Å zum Asp ${ }^{\mathrm{Crm} 1}$ auf und geht daher maximal eine leichte elektrostatische Interaktion mit dem Asp $^{\mathrm{Crm} 1}$ ein (Abb. 33A, rechst). Der kristallisierte Exportkomplex mit der RanQ69L ${ }^{1-180}$ Mutante K99Ac lässt in den RanQ69L ${ }^{1-180}$ Molekülen der beiden Komplexe der asymmetrischen Einheit Elektronendichte für das Lysin erkennen. Dieses Lysin ist dem Solvent zugewannt und in beiden Molekülen der asymmetrischen Einheit unterschiedlich orientiert. Ein Kontakt mit einer Aminosäure des h.s. Crm1 oder h.s.Spn1 kommt nicht zustande. Elektronendichte für eine Acetylgruppe an den Lysinen 71, wie 99 ist nicht erkennbar. Die Acetylgruppe an den Lysinen ist in allen Molekülen des RanGTP nicht definiert und daher nicht gebaut.

\subsubsection{Struktureller Einfluss ein Acetylgruppe auf das RanGTP im Komplex mit h.s.Crm1}

Wie im vorherigen Abschnitt (3.5.4, Abb. 31) bereits gezeigt, sind an den kristallisierten Komplexen Acetylgruppen vorhanden. Im vorangegangenen Abschnitt (3.5.6.2, Abb. 33) sind die gebauten Lysine (an der Position 71 und 99) innerhalb der ermittelten Elektronendichtekarte dargestellt. Um zu ermitteln, ob die Acetylierung des RanGTP an den Lysinen 71 oder 99 eine Effekt auf die Struktur des Exportkomplexes im Ganzen zeigt, wurde eine Überlagerung mit der von der Monecke et al. (2009) gelösten Struktur (PDB ID 3GJX) durchgeführt. Für die Überlagerung wurde das Programm Pymol verwendet. In Abbildung 34 ist die Überlagerung der Modelle mit der Struktur 3GJX dargestellt.

Der Abgleich zwischen den sich ergebenden Modellen für den Exportkomplex mit den jeweils einzeln acetylierten RanQ69L ${ }^{1-180}$ GTP Mutanten K71Ac und K99Ac und dem bereits gelösten Komplex (PDB ID 3GJX) zeigt keinen signifikanten Unterschied im strukturellen Aufbau zwischen den Modellen und dem Komplex 3GJX (Abb. 34).

In näherer Betrachtung der RanQ69L ${ }^{1-180}$ GTP Mutanten K71Ac und K99Ac, wurden diese der jeweiligen Modellstruktur der Komplexe entnommen (Abb. 35). Der Abgleich mit dem RanQ69L $^{1-180}$ GTP aus der Struktur 3GJX, zeigt keinen signifikanten Unterschied zwischen Den Acetyllysin Mutanten und der normalen Q69L Mutante. 
A
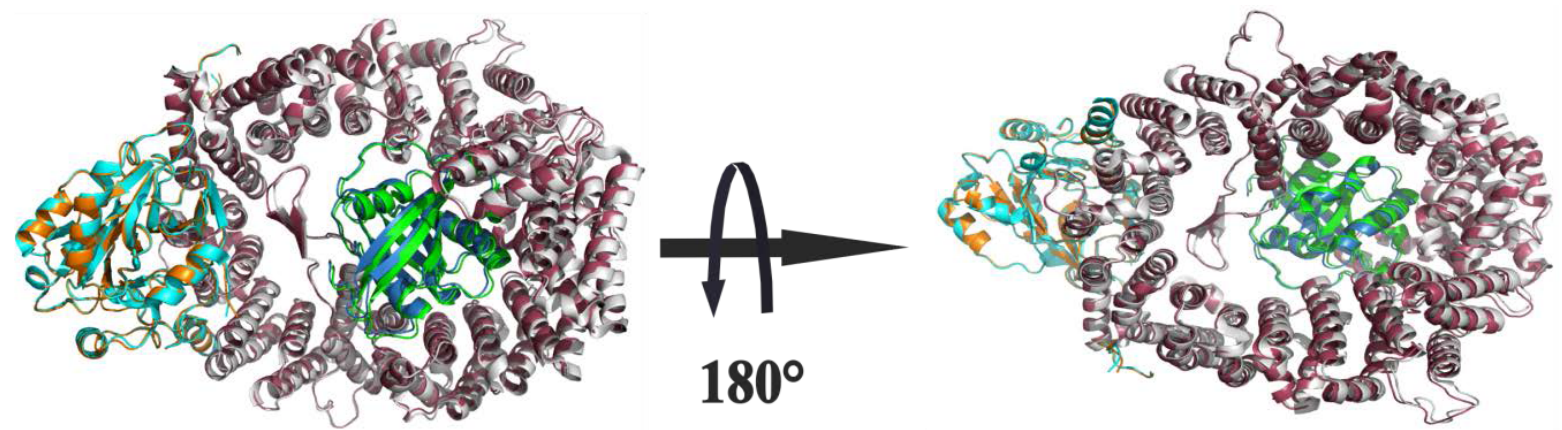

B
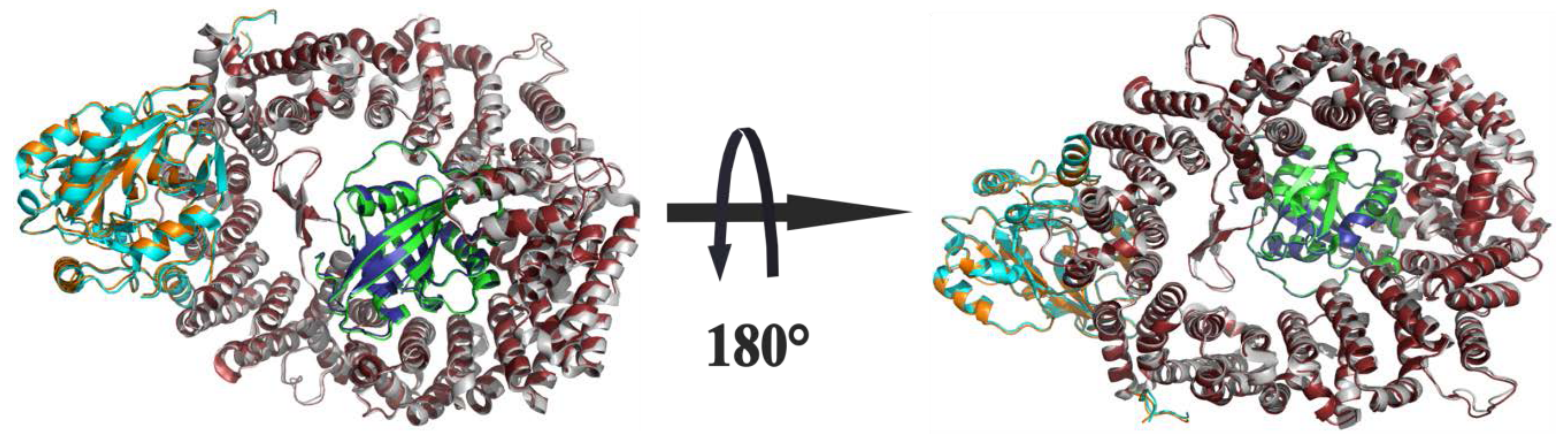

Abb. 34: Vergleich der Kristallstrukturen der Exportkomplexe mit acetyliertem RanQ69L ${ }^{1}{ }^{180 .}$ Dargestellt ist eine Gesamtansicht des Abgleiches der Exportkomplexe mit acetyliertem RanQ69L ${ }^{1-180}$ und dem Exportkomplex 3GJX, sowie die Ansicht um $180^{\circ}$ gedreht. Das Crm1 von 3GJX ist in Grau eingefärbt, wohingegen das SPN1 in Cyan und das RanQ69L ${ }^{1-180}$ in Grün dargestellt. A) zeigt den Abgleich vom Exportkomplex Modell mit RanQ69L ${ }^{1-180}$ K71Ac (Himmelblau eingefärbt) zu Exportkomplex 3GJX. B) hingegen zeigt den Abgleich vom Exportkomplex Modellmit RanQ69L ${ }^{1-180}$ K99Ac (Dunkelblau) zu Exportkomplex 3GJX. Alle Modelle sind als Cartoon Modell dargestellt (Pymol).

Durch eine Betrachtung der Kontaktfläche zwischen den ermittelten Modellen und der Struktur 3GJX lässt sich jedoch ein Unterschied zwischen den Modellen und der Struktur 3GJX feststellen. In Abbildung 36 ist dieser Unterschied dargestellt. Zwischen dem h.s. Crm1 und der RanQ69L ${ }^{1-180}$ Acetyllysin Mutante K71Ac kommt es zu einer polaren Interaktion zwischen dem Asp91des Ran und dem Arg887 des Crm1. Mit einem Abstande von $2.5 \AA$ bilden diese beiden Aminosäuren eine Salzbrücke zwischen der RanQ69L ${ }^{1-180}$ Acetyllysin Mutante K71 und h.s.Crm1 (Abb.36A). Dieselben Aminosäuren sind auch bei einem Kontakt im Modell mit der RanQ69L ${ }^{1-180}$ Acetyllysin Mutante K99Ac zu beobachten (Abb. 36B). In der PDB Struktur 3GJX ist dieser Kontakt nicht zu beobachten (Abb. 36C), das Arg887 des Crm1 ist in dieser Struktur so orientiert, das ein Kontakt zwischen dem Arg887 ${ }^{\mathrm{Crm} 1}$ und dem Asp91 ${ }^{\text {Ran }}$ nicht zustande kommt. 
A
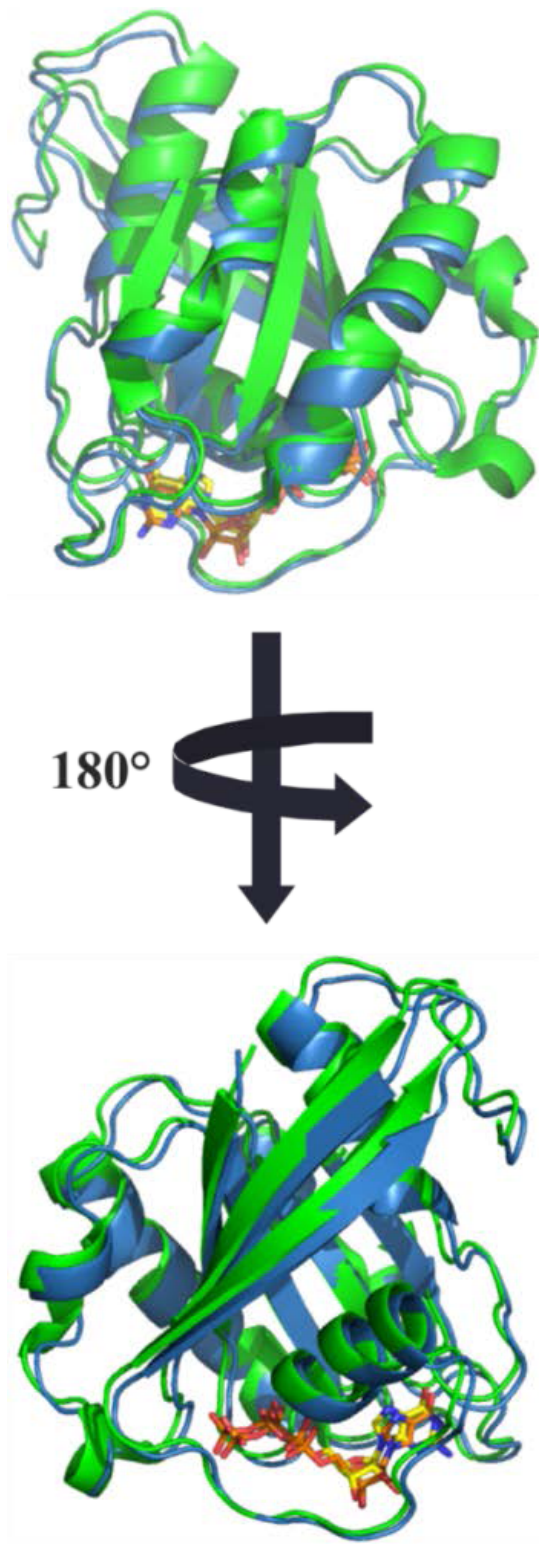

B
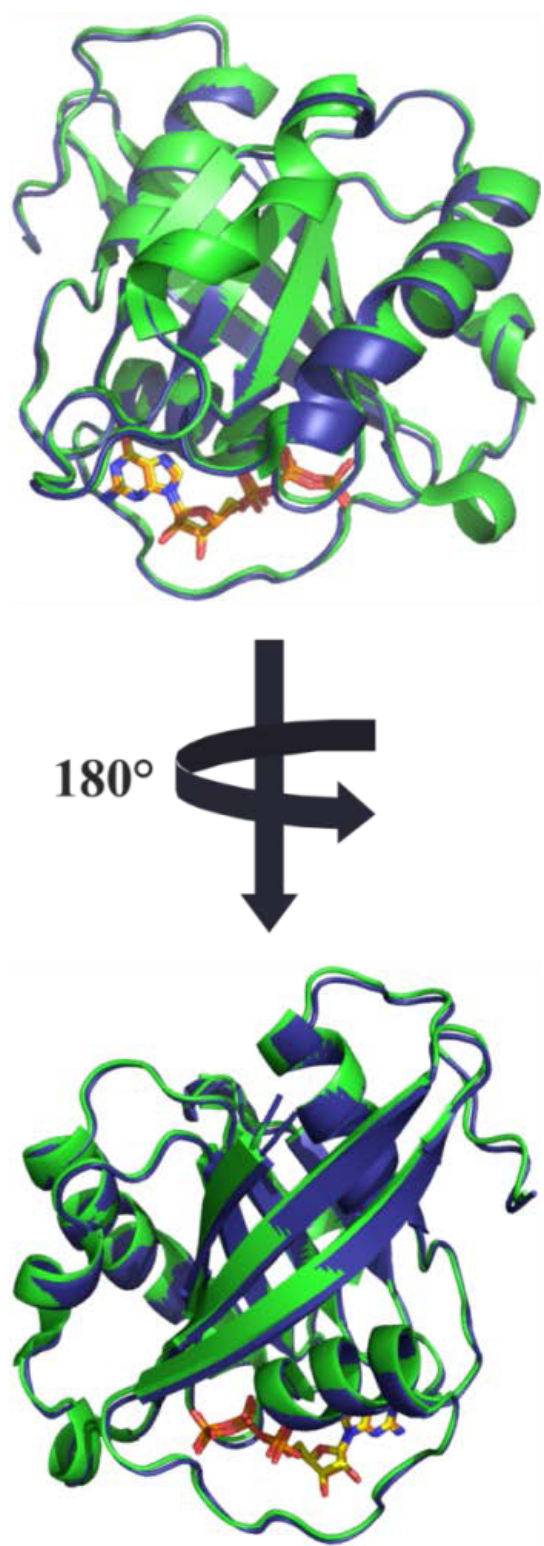

Abb. 35: Vergleich der Kristallstrukturen von acetyliertem RanQ69L ${ }^{1-180}$ GTP mit dem RanQ69L ${ }^{1-180}$ GTP der Struktur 3GJX. Beide acetylieten RanQ69L ${ }^{1-180}$ GTP strukturen, sind aus den jeweiligen Modellen der Exportkomplexe entnommen, sowie das RanQ69L ${ }^{1-180}$ GTP aus der Struktur 3GJX entnommen wurde. Die RanQ69L ${ }^{1-180}$ sind als Cartoon Modelle gezeigt. Das GTP Molekül als Stabmodell dargestellt, wobei Kohlenstoffatome gelb, Sauerstoffatome rot, Stickstoffatome blau und Phosphoratome orange eingefärbt sind. A) zeigt den Abgleich von RanQ69L ${ }^{1-180}$ GTP Model K71Ac (Himmelblau) mit dem RanQ69L ${ }^{1-180}$ GTP von 3GJX mit einer Rotation um $180^{\circ}$. B) zeigt den Abgleich von RanQ69L ${ }^{1-180}$ GTP Modell K99Ac (Dunkelblau) mit dem RanQ69L ${ }^{1-180}$ GTP von 3GJX mit einer Drehung um 180(Pymol). 
A

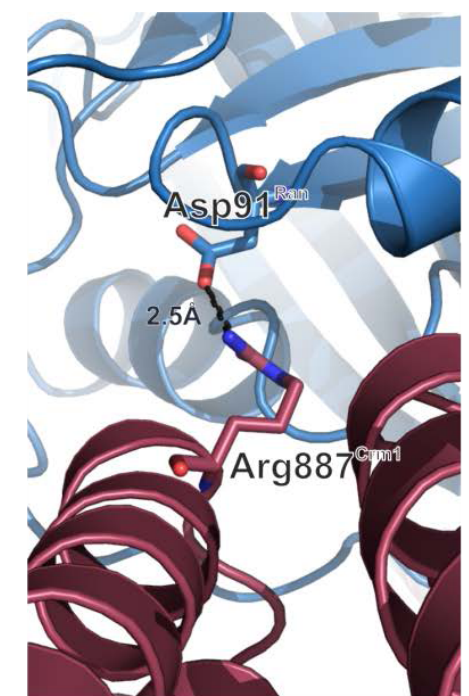

Model Crm1:SPN1:RanQ69LK71Ac Ac $^{1-180}$
B

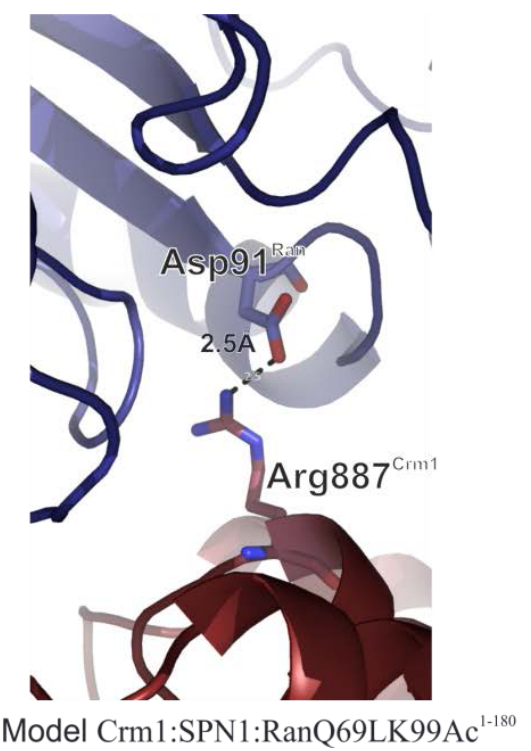

C

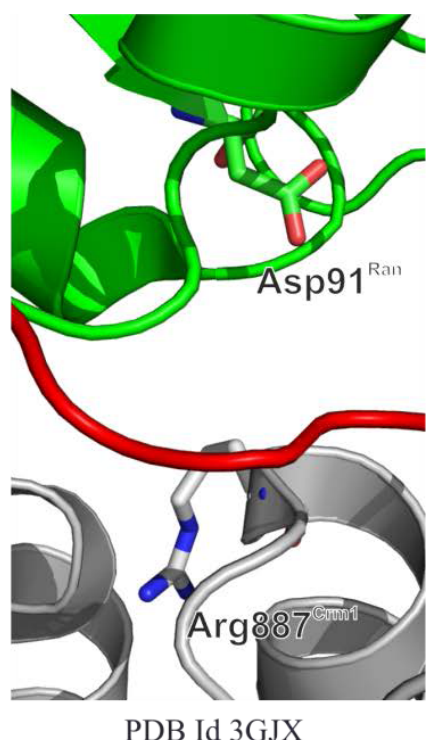

Abb. 36: Detailaufnahme einer Interaktion zwischen h.s.Crm1 RanQ69L ${ }^{1-180}$ GTP. Die beteiligten Aminosäuren sind im Stäbchenmodell dargestellt und entsprechend benannt. Die Stickstoffatome sind blau eingefärbt, die Sauerstoffatome rot und die Kohlenstoffatome richten sich nach dem zu ihnen gehörigen Protein. Die Interaktionen sind durch gepunktete Linie (schwarz) dargestellt. A) zeigt eine Interaktion zwischen RanQ69L ${ }^{1-180}$ K71Ac (Himmelblau) und h.s.Crm1 (Himbeerrot). Arg887 ${ }^{\mathrm{Crm} 1}$ bildet eine Salzbrücke mit dem Asp91 RanGTP. B) Salzbrücke zwischen h.s.Crm1 und RanQ69L ${ }^{1-180}$ K99Ac. Beteiligt an dieser Salzbrücke sind das Arg887 ${ }^{\mathrm{Crm} 1}$ und das Asp91 ${ }^{\text {Ran }}$. C) zeigt den Interaktionsbereich, welcher in A und B zu sehen ist, in der PDB Struktur 3GJX zwischen Crm1 und RanQ691 ${ }^{1-180}$ (Pymol). 


\section{Diskussion}

Die generelle Zielsetzung dieser Arbeit lag im Verständnis der Acetylierung der kleine GTPase Ran (Homo sapiens) und seiner Auswirkung auf den Kerntransport. In dieser Hinsicht sollte acetyliertes Ran strukturell und funktional analysiert werden. Die kleine GTPase wurde dabei einzeln, sowie in Verbindung mit Transportrezeptoren untersucht. 2009 konnte gezeigt werden, das Ran chemisch durch anbringen einer Acetylgruppe an der Aminosäure Lysin modifiziert wird (Choudhary et al., 2009). Diese Konstellation war bis zu diesem Zeitpunkt relativ unbekannt. Neben der kleinen GTPase Ran wurden in den verwendeten nicht synchronisierte humanen Zelllinien MV4-11, Jurkat und A549, weitere Proteine des Kerntransportes mit einem acetylierten Lysin identifiziert (Tabelle 1). Aus diesem Experiment ergaben sich keine prozentualen Verteilung für die einzelnen Acetylierungsstellen der kleinen GTPase Ran (supplementary material Choudhary et al., 2009)

In dieser Arbeit konnten die Mutanten RanQ69L ${ }^{1-180}$ K71Ac und K99Ac zusammen mit dem Exportrezeptor h.s.Crm1 und h.s.SPN1 kristallisiert und die Struktur gelöst werden (Berechnung der Strukturfaktoren durch Dr. Piotr Neumann). Des Weiteren konnte die Bindung der acetylierten kleinen GTPase Ran (der Mutanten K37, K38; K60, K71, K99 und K159) an den Importrezeptor Importin $\beta$ und den Exportrezeptor h.s.Crm1 gezeigt werden. Für die Zielsetzung dieser Arbeit war es daher erforderlich die GTPase Ran mit acetyliertem Lysin zu exprimieren und aufzureinigen (3.1). Die Analyse wurde mit zwei Versionen der GTPase Ran durchgeführt, mit dem Protein in seiner vollen Länge $\left(\operatorname{Ran}_{\mathrm{fl}}\right)$, sowie in einem C-Terminal verkürzten, mit der Q69L Mutation versehenen Konstrukt (RanQ69L ${ }^{1-180}$ ). Durch das Einfügen der Q69L Mutation (Bischoff et al., 1994; Hughes et al., 1998; Klebe et al., 1995) in die GTPase und die C-terminale Verkürzung auf 180 Aminosäuren wird dessen GTPase-Aktivität unterdrückt. Beide Varianten der GTPase (volle Länge und Verkürzung) wurden für unterschiedliche Zwecke verwendet. Das verkürzte Konstrukt wurde für Kristallisationsexperimente und Bindungsstudien über Gelfitration und Pulldown Assay verwendet, während das volle länge Konstrukt ohne Q69L Mutation in den biochemischen Experimenten Verwendung fand.

\subsection{Expression und Reinigung beteiligter Komponenten}

Grundvoraussetzung für die Analyse der acetylierten kleinen GTPase Ran, sowohl in struktureller wie auch in funktionaler Hinsicht, war die Expression und Reinigung der für 
diese Aufgabe notwendigen Komponenten. Bei diesen Komponenten handelte es sich um die acetylierten Konstrukte $\operatorname{Ran}_{\mathrm{fl}}$ und RanQ69L ${ }^{1-180}$, sowie den Exportrezeptor h.s.Crm1, h.s.SPN1 als Transportsubstrat (Cargo) und RanGAP1. Das h.s.Crm1 zusammen mit dem h.s.SPN1 wurde für Kristallisationsexperimente mit acetyliertem RanQ69L ${ }^{1-180}$ und mit acetyliertem $\operatorname{Ran}_{\mathrm{fl}}$ für die funktionale Analyse verwendet. Das RanGAP1 fand Verwendung für die funktionale Analyse von acetyliertem $\operatorname{Ran}_{\mathrm{fl}}$ (3.5.3).

Um die Auswirkung einer Acetylierung der kleinen GTPase Ran zu untersuchen, wurde diese in acetyliertem Zustand benötigt. Zur Generierung von acetylierten Proteinen stehen verschiedene Strategien zur Verfügung. Eine elegante Strategie, welche in dieser Arbeit verwendet wurde, besteht in der genetischen Codierung von Acetyllysin über das AmberStopcodon (Neumann et al., 2008, 2009). Diese Strategie erlaubt es, auf genetischem Weg, das Acetyllysin auch in zentralen Bereichen des Zielproteins einzubauen und bietet eine nahezu 100 \%ige Produktion an acetyliertem Protein (interne Kommunikation mit Prof. Heinz Neumann). Weitere Strategien bestehen in der Verwendung von Lysin (K)Acetyltransferasen (KAT), die in der Lage sind Oberflächen Lysine mit einer Acetylgruppe zu versehen. Eine weitere Strategie, welche von vielen verfolgt wird, besteht im Imitieren des acetylierten Lysin durch Ersatz mit Glutamin (Kamieniarz and Schneider, 2009). Diese beiden Strategien haben ihre Fallstricke. So ist oft die Lysin-Acetyltransferase für die Modifikation nicht bekannt, die Reaktion oft nicht vollständig und nicht spezifisch für ein einzelnes Lysin eines Proteins. Für die Untersuchung von Acetylierungen an spezifischen Lysinen eines Proteins oder Kombinationen der Lysine sind KATs daher nicht geeignet. Das einfügen von Glutamin als Ersatz für Acetyllysin ist ebenfalls nicht perfekt, da das Glutamin eine etwas andere Struktur aufweist als das Acetyllysin. Diese Einschränkungen lassen sich durch native chemische Ligation überwinden. Ein chemisch synthetisiertes Peptid mit dem Acetyllysin wird hier mit dem zu untersuchenden Protein ligiert. Mit dieser Strategie ist es jedoch schwierig Modifikationen (z.B. eine Acetylierung) in zentralen Teilen eines Proteins einzuführen, des weitern ist die chemische Synthese nicht ganz einfach durchzuführen (Kamieniarz and Schneider, 2009; Neumann et al., 2008).

Die Strategie der genetischen Codierung (2.2.1.8) funktioniert über die Expression des zu untersuchenden Proteins in E.coli Zellen. Ein neben Effekt der genetischen Codierung von Acetyllysin, dem Einfügen des Amber-Stopcodon statt der Lysincodons AAA und AAG, besteht im vorzeitigen Abbruch der Transkription der GTPase Ran an der Stelle des Acetyllysin. So entstehen neben dem acetylierten Fusionsprotein entsprechende Fragmente, je nach Lage des Stopcodons mit unterschiedlichem Molekulargewicht. Ein 
weiteres Problem stellt die Existenz einer Deacetylase in E.coli da. Dieses Problem lässt sich durch das Hinzufügen von Nicotinamid zum Expressionsmedium lösen. Das Nicotinamid ist in diesem Fall ein Inhibitor der in E.coli anzutreffenden Deacetylase.

Für die Expressionen und Reinigung der beteiligten Proteine in dieser Arbeit wurden 2 Affinitätssysteme verwendet. Die Konstrukte der GTPase Ran wurden mit einer HexaHistidin Sequenz für den Gebrauch in der Kristallisation und den biochemischen Assays verwendet, während für die Pulldown Assays die GTPase mit der GST-Affinitätssequenz versehen war (Abb. A2). Eine Histidin-Affinitätssequenz wurde auch für die Reinigung des Exportrezeptors h.s.Crm1 verwendet, während das h.s.SPN1, sowie das RanGAP1 mit einer GST-Affinitätssequenz exprimiert und gereinigt wurden.

\subsubsection{Die acetylierte GTPase Ran}

Die Expression der acetylierten GTPase Ran wurde in E.coli BL21(DE3) Zellen durchgeführt. Damit die GTPase mit Acetyllysin exprimiert werden konnte war das Vorhanden sein von Acetyllysin eine Voraussetzung. Dies wurde mit dem Expessionsmedium den Zellen zur Verfügung gestellt. Die Expression der acetylierten GTPase Ran weicht dabei etwas von der Expression der nicht acetylierten GTPase ab. So wird die Expression der acetylierten GTPase bei $37^{\circ} \mathrm{C}$ für 3,5-4 h durchgeführt. Die optimale Expressionsbedingung für die GTPase in gesamter Länge lag bei $18{ }^{\circ} \mathrm{C}$ über Nacht (Dissertation Wohlwend, 2007), während die Expression der verkürzten Variante normalerweise bei $20{ }^{\circ} \mathrm{C}$ über Nacht durchgeführt wurde. Da die Aminoacyl-tRNA Synthetase (2.2.1.8) ihre größte Aktivität jedoch bei $37^{\circ} \mathrm{C}$ besitzt (interne Kommunikation mit Prof. Heinz Neumann) wurde diese Bedingung gewählt. Der Vektor in welchen das Gen für die GTPase in voller Länge und die Verkürzung kloniert wurden (pCDFDuet PylT) wies eine Hexa-Histidin-Sequenz auf, die es möglich machte die GTPase aus einem Zelllysat zu isolieren (3.1). Im Aufschluss nach der Lyse der Expressionszellen lies sich im Überstand keine GTPase erkennen. Die Verwendung des Amder-Stopcodons führt zu einer Verringerung der Ausbeute der Expression auf 10 bis 25\% der Ursprünglichen Ausbeute. Lies sich aus einem Liter Expressionskultur $10 \mathrm{mg}$ der GTPase gewinnen konnte mit der genetischen Codierung von Acetyllysin noch 1 - 2,5 mg acetylierter GTPase gewonnen werden. Soweit verhält es sich für beide Konstrukte gleich. Die Verkürzung der kleinen GTPase wurde über drei Chromatographie-Schritte (3.1.1 Abb. 15) bis zur Homogenität gereinigt werden. In diesem Zustand war das RanQ69L ${ }^{1-180}$ rein genug für die Verwendung in der Kristallisation und Bindungsstudien über Gelfiltration. Die zweite Bande, welche die 
auf dem SDS-Gel auftritt entspricht einem RanQ69L ${ }^{1-180}$-Dimer, diese tritt jedoch nur auf dem SDS-Gel auf und lässt sich nicht auf der Gelfitrationssäule nachweisen (Daten nicht gezeigt). Diese trat auch bei Reinigung von $\operatorname{Ran}_{\mathrm{fl}}$ auf. Wie das RanQ69L ${ }^{1-180}$ wurde dieses mit einer Hexa-Histidin-Sequenz exprimiert. Diese ermöglichte die Isolation des $\operatorname{Ran}_{\mathrm{fl}}$ analog dem RanQ69L ${ }^{1-180}$. Das $\operatorname{Ran}_{\mathrm{fl}}$ wurde jedoch in zwei Chromatographie-Schritten (3.1.2 Abb. 16) nahezu bis zur Homogenität gereinigt. Das Ran $_{\mathrm{fl}}$ war in diesem Zustand für die Verwendung in den RanGAP und Ran Protektions Assays rein genug. Mittels eines Westernblot gegen Acetyllysin konnte gezeigt werden, dass nach der Reinigung beide Konstrukte acetyliert vorlagen RanQ69L ${ }^{1-180}$ acetyliert vorlag (Abb. 16C und Abb. 22). Die während der Expression der entstehenden Abbruchfragmente durch das TAG, sind in der Reinigung von beiden Konstrukten nicht zu erkennen.

Für die Verwendung in Pulldown Assays wurde das RanQ69L ${ }^{1-180}$ K37Ac und K71Ac mit GST verwendet. Die Reinigung ist im Anhang dieser Arbeit gezeigt und lehnt sich an die Reinigung von $\operatorname{Ran}_{\mathrm{fl}}$ an. Ist in den Reinigungen der GTPase vorher kein Fragment vom Abbruch durch das TAG erkennen, lies sich dies durch die Verwendung von GST auf dem SDS-Gel erkennen. Trotz des Größenunterschiedes zum Gesamtkonstrukt lies sich das Fragment nicht abtrennen. Dementsprechend wurde das Fragment in den Pulldown Assays als Kontrolle verwendet.

\subsubsection{Expression und Reinigung zur Analyse benötigter Proteine}

Damit Ran sowohl strukturell als auch funktional analysiert werden konnte wurden zusätzliche Proteine benötigt. Zwei dieser Proteine sind der Exportrezeptor h.s.Crm1 sowie das h.s.SPN1. Die Reinigung des h.s.SPN1 wurde wie in Strasser et al., 2004 beschrieben durchgeführt. Von dem etablierten Protokoll wurde in der Arbeit nicht abgewichen.

Bei der Expression des h.s.Crm1 (2.2.2.5.2) handelte es sich um eine nicht induzierte Expression des Proteins. Das Protokoll zur Expression und Reinigung (2.2.5.2) wurde bereits vor dieser Arbeit in der Arbeitsgruppe etabliert und unverändert verwendet (Dr. T. Monecke). Nach Ablauf der drei Reinigungsschritte konnte das h.s.Crm1 soweit aufgereinigt werden, dass es für die Verwendung in den Experimenten rein genug war (Abb. 17).

Für die funktionale Analyse der GTPase Ran in seiner vollen Länge ist das RanGAP1 ein wichtiger Bestandteil. Da in der Arbeitsgruppe zum Zeitpunkt dieser Arbeit kein Konstrukt des RanGAP1 vorhanden war wurde dieses neu Kloniert (3.4). Dies ermöglichte die Reinigung des RanGAP1 über die GST-Affinitätssequenz. In Expressionstests konnte 
festgestellt (Daten nicht gezeigt) werden, dass eine Expression in Rosetta 2 (DE3) ein gutes Ergebnis lieferte (Abb. 19A). Das RanGAP1 konnte in zwei ChromatographieSchritten über die GST-Affinitässequenz gereinigt werde (Abb. 19B und C). Nach dem Aufschluss der Expressionszellen war das RanGAP1 fast vollständig im Überstand zu finden. Wie zu erwarten wurde der überwiegende Teil des exprimierten Proteins über das GST an die Säule gebunden. Nur wenig interagierte nicht mit der Säule. Das RanGAP1 konnte mit wenigen Verunreinigungen eluiert werden. Durch eine Gelfiltration als zweiten Schritt in der Reinigung konnte das RanGAP1 nach dem Einsatz der Prescission Protease nahezu bis zur Homogenität gereinigt werden (Abb. 19C). Während der Gelfiltration traten drei Maxima auf, die auf dem SDS-Gel wiedergegeben sind. Dabei ist zu erkennen, dass ein Teil des im ersten Schritt eluierten RanGAP1 aggregierte und somit im Ausschlussvolumen $\left(\mathrm{V}_{0}\right)$ der Gelfiltrationssäule auftaucht. Wie sich zeigte konnte das RanGAP1 vom GST getrennt werden, das im hintersten Maximum auf der Säule auftrat. Mit dem RanGAP1 selber tritt ein leichtes Signal bei etwa $45 \mathrm{kDa}$ auf, bei dem es sich mit hoher Wahrscheinlichkeit um ein Abbauprodukt des RanGAP1 handelte. Das Auftreten eines solchen Abbauproduktes ließe sich wahrscheinlich durch einen Wechsel der Temperatur während der Reinigung von Raumtemperatur auf $4^{\circ} \mathrm{C}$ minimierend, sowie durch den Einsatz von Proteaseinhibitoren während der Reinigung des RanGAP1. Nach der Gelfiltration war das RanGAP1 sauber genug für die Verwendung im RanGAP und Ran Protektions Assay.

\subsection{Biochemische und strukturelle Bedeutung der Acetylierung der}

\section{GTPase Ran}

Die Analyse des acetylierten Ran hinsichtlich der Auswirkung der Acetylierung auf das Verhalten der GTPase gestaltete sich vielfältig. Da eine Acetylierung der Aminosäure Lysin die positive Ladung der Aminosäure maskiert, diese vergrößert, sowie einen Einfluss auf die Sekundärstruktur eines Proteins nehmen kann (Kamieniarz and Schneider, 2009; Spange et al., 2009). Aufgrund dieser Eigenschaften bestand die Möglichkeit, dass eine Acetylierung die Bindung zwischen dem Ran und einem interagierenden Protein nicht mehr ermöglicht. Infolge der zentralen Rolle der kleinen GTPase Ran im Kerntransport wurde diese im Zusammenhang mit den beiden meist studierten Rezeptoren des Kerntransports, dem Crm1 und dem h.s.Imp $\beta$, untersucht. Aus der Struktur des Crm1 mit RanGTP und SPN1 (Abb. 37A, PDB ID 3GJX) geht hervor, das zwei er der in Choudhary et al., 2009 gefunden Lysine des RanGTP (K37 und K71) an einer elektrostatischen 
Interaktion von RanGTP mit Asp436 ${ }^{\mathrm{Crm} 1}$ und Asp932 ${ }^{\mathrm{Crm} 1}$ (in der Struktur wurde RanQ69L ${ }^{1-180}$ verwendet) direkt beteiligt sind. Dieser Umstand legte nahe, dass eine Acetylierung der Lysine K37 und/oder K71 des Ran einen direkten Einfluss auf die Bindung von RanGTP zum Crm1 ausübt. Im Fall des Imp $\beta$ (Abb. 37B, PDB ID 1IBR) ist eine solche Beziehung zum K159 Ran bekannt (Vetter et al., 1999a), sowie eine Interktion des K37 Ran mit $E 615^{\operatorname{Imp} \beta}$ und D616 ${ }^{\operatorname{Imp} \beta}$ (Lee et al., 2005). Daher wurde zunächst die Bindung der Acetyllysin Mutanten an die Transportrezeptoren h.s.Crm1 und Imp $\beta$ durch Gelfiltration (3.5.1) und die von der Mutante $K 37^{\text {Ran }}$ und $71^{\text {Ran }}$ im speziellen durch Pulldown Assay (3.5.2) analysiert. Dabei war festzustellen, dass trotz einer einzelnen Acetylierung am Ran ein Komplex (Crm1:SPN1:RanGTP und Imp $\beta$ :RanGTP) zustande kommt (Abb. 20 und 21). Somit war kein generell sichtbarer Einfluss der Acetylierung der in Choudhary et al., (2009) festgestellten Lysine auf die Bindung des RanGTP an die Transportrezeptoren h.s.Crm1 und h.s.Imp $\beta$ erkennbar. Für bei Transportrezeptoren Crm1 und Imp $\beta$ besteht im Zusammenhang mit der Mutante K37Ac ${ }^{\text {Ran }}$ jedoch eine Besonderheit. Eine K37D/K152A Mutante des Ran unterbindet die Crm1:RanGTP:Substrat Komplexbildung (Matsuura and Stewart, 2004) und ist weniger Effizient einen Imp $\beta$ :IBB Komplex aufzulösen (Lee et al., 2005). Dementsprechend besteht wahrscheinlich ein Einfluss der Acetylierung an der Position 37 des Ran auf die Bildung des Crm1:SPN1:RanGTP Komplex, ist jedoch nicht ausreichend um die Komplexaufbau zu verhindern. Wie bei dem Crm1 besteht der Einfluss der Acetylierung am Ran auch auf das $\operatorname{Imp} \beta$, wirkt sich jedoch nicht auf die Bindung an sich aus, sondern vielmehr auf das auflösen von Importkomplexen.

Bindungsstudien über analytische Gelfiltration und Pulldown Assay bieten nur einen begrenzten Einblick in die Interaktion einzelner oder mehrerer Proteine. Die Aussagen, die solche Experimente liefern, begrenzen sich meist darauf ob Proteine unter den gegebenen Faktoren interagieren oder nicht. Da Komplexe zustande kamen, sollte die Beziehung der Acetylierung der GTPase Ran in Verbindung mit h.s.Crm1 zusätzlich strukturell, sowie auch funktional (anhand der GTP Hydrolyse) untersucht werden.

Die Funktion der kleinen GTPase Ran beschränkt sich nicht alleine auf eine Interaktion mit den Transportrezeptoren des Kerntransportes. Wie der Name impliziert handelt es sich um ein GTP hydrolysierendes Protein. Diese Tatsache eröffnet eine weitere Möglichkeit acetyliertes Ran zu untersuchen. Da Ran eine relativ geringe intrinsische Hydrolyserate aufweist (Klebe et al., 1995; Seewald et al., 2003) wurde für die Analyse der GTPaseAktivität das Protein RanGAP1 verwendet (3.5.3). 

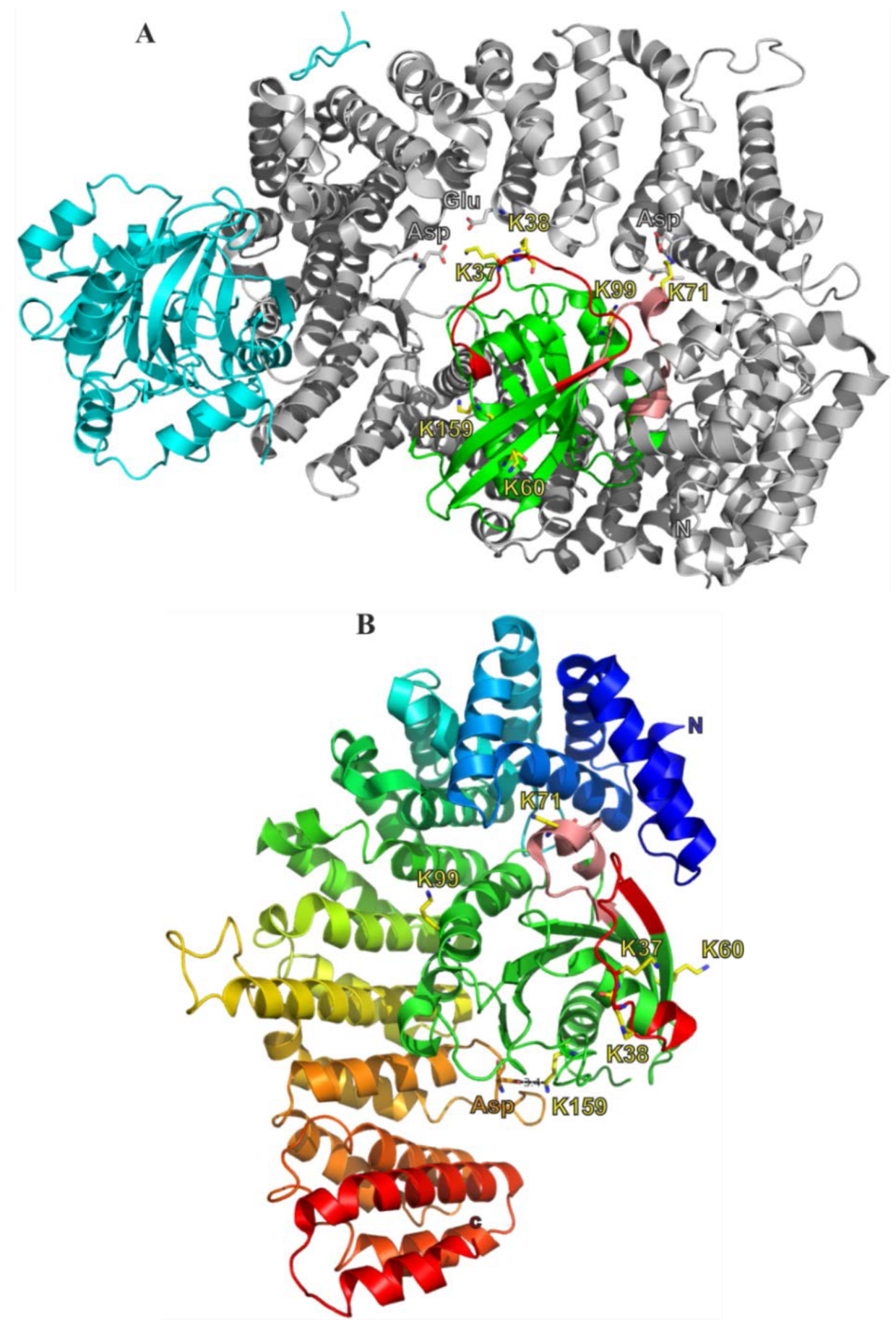

Abb. 37: Kristallstrukturen des Exportrezeptors Crm1 und des Importrezeptors Imp $\beta$ im Komplex mit RanGTP. A) Kristallstruktur des Exportkomplex Crm1:SPN1:RanGTP (PDB Id 3GJX). Die Struktur ist als Cartoon-Modell dargestellt mit dem Crm1 in Grau, dem SPN1 in Türkis. und dem RanGTP in Grün. Die flexiblen Bereiche des Ran sind farblich markiert, mit der Switch 1 Region rot und der Switch 2 Region pink. Lysine nach Choudhary et al sind als Stabmodell dargestellt, die Kohlenstoffatome sind dabei gelb und die Stickstoffatome blau eingefärbt. B) Kristallstruktur von Imp $\beta$ im Komplex mit RanGTP (PDB Id 1IBR) das Imp $\beta$ ist als Cartoon-Modell dargestellt und in Regenbogen eingefärbt, vom N-Terminus blau zum CTerminus rot. Das RanGTP ist wie in A) dargestellt. Die jeweiligen Lysine sind bezeichnet sowie die mutmaßlichen mit diesen interagierenden Aminosäuren (Pymol). 
Die Hydrolyse des Ran gebundenen GTP konnte dabei sowohl über radioaktiv markiertes GTP, als auch über ein Phosphat bindendes Protein beobachte werden. Dabei wurde das Ran alleine (RanGAP Assay), sowie zusammen mit Transportrezeptoren (Ran Protektion Assay) betrachtet.

Wie durch die RanGAP Assay und den Ran Protektions Assay gezeigt binden die Mutanten weiterhin an das RanGAP. In der Struktur bestehend aus RanGTP, RanGAP1 und RanBP1 ist zu erkennen, dass das Lysin $71^{\text {Ran }}$ in direktem Kontakt zum RanGAP1 steht (Abb. 39 unten links (Seewald et al., 2002)). Ein Einfluss der Acetyltgruppe am K71 Ran ist somit zu erwarten gewesen. Das eine Acetylierung den anderen Positionen (Choudhary et al., 2009) einen Einfluss auf die RanGAP vermittelte GTP-Hydrolyse zeigen, konnte so nicht erwartet werden. Die Acetylierung an einer oder mehrerer dieser Postionen könnte einen allosterischen Effekt auf Ran ausüben und so kleinere Änderungen an der Struktur der GTPase bewirken, welche zu dem in 3.5.3.1 (Abb. 25) gezeigten Ergebnis führt. Durch solche strukturellen Veränderungen könnten katalytisch wichtige Aminosäuren, wie z.B. Q69 ${ }^{\text {Ran }}$ (Bischoff et al., 1994; Seewald et al., 2002, 2003) in ihrer Position verändert werden und so die GTP-Hydrolyse beeinflussen. Da für diesen Assay nur eine RanGAP1 Konzentration verwendet wurde war es leider nicht möglich kinetische Konstanten, wie den $\mathrm{K}_{\mathrm{m}}$-Wert oder die Maximalgeschwindigkeit $\mathrm{V}_{\max }$ der GTP Hydrolyse zu bestimmen. Aber auch so tragen die Beobachtungen aus beiden Experimenten zu einem Erkenntnisgewinn bei (Abb. 25). So lässt sich in beiden Assays erkennen, dass die Mutanten K99Ac ${ }^{\text {Ran }}$ und K60Ac ${ }^{\text {Ran }}$ eine signifikant niedrigere GTP Hydrolyse zeigen und länger brauchen um das Ende der Reaktion zu erreichen. Im radioaktiven Assay konnte beobachtet werden das die Mutanten K37Ac ${ }^{\text {Ran }}$, K159Ac ${ }^{\text {Ran }}$ und K71Ac $^{\text {Ran }}$ jeweils eine signifikant höhere Hydrolyse erkennen lassen. Diese Beobachtung konnte unter Verwendung des Phosphatsensors für die Mutanten $\mathrm{K}_{73 \mathrm{Ac}^{\text {Ran }}}$ und K71Ac $^{\text {Ran }}$ nicht angestellt werden. Da weder die Konzentration noch der eigentliche Ladestatus des heißen RanGTP zum Zeitpunkt des Experimentes bestimmt werden konnte, lässt sich diese Abweichung von Phosphatsensor erklären. Eingesetzt wurde das Ran nach der vorher bestimmten Radioaktivität. Es kann jedoch aus beiden Experimenten die Aussage mit genommen werden, das die Acetylierung von Ran an den Lysinen 38, 60, 99 und 159 einen leichten regulatorischen Effekt auf die RanGAP vermittelte Hydrolyse des GTP ausüben, in dem sie diese beschleunigen oder verlangsamen.

Die Ergebnisse der Ran Protektions Assays zeigen, wie die Bindungsstudien über Gelfiltration und Pulldown Assay, das acetyliertes Ran weiterhin im Standes ist mit den 
Rezeptoren des Kerntransport zu interagieren. Bei den Ran Protektions Assays mit Radioaktiven GTP wurden die Transportrezeptoren $\operatorname{Imp} \beta$, Imp7 und Crm1 zusammen mit dem GTP gebundenem acetyliertem Ran verwendet. Die Verwendung von radioaktiv markiertem GTP birgt die bereits genannte Schwierigkeit, den genauen Ladestatus sowie die Konzentration an eingesetztem Ran während der Experimentes nicht zu kennen. Da die Beladung der GTPase mit $\left[\gamma_{-}{ }^{32} \mathrm{P}\right]-G T P$ recht unterschiedlich ausfallen kann lassen sich Unterschiede in der Radioaktivität nicht vermeiden und lediglich durch verdünnen ausgleichen. Dadurch entstehen jedoch Ungenauigkeiten, welche sich in den Ergebnissen auftauchen können. Dennoch lassen sich daraus einige Erkenntnisse gewinnen. Bereits mit einer geringen Konzentration $\operatorname{Imp} \beta$ lässt sich keine GTP- Hydrolyse bei dem Wildtyp Ran, sowie den Mutanten zu beobachten. So ist kein signifikanter Unterschied ersichtlich. Das Ausbleiben der GTP-Hydrolyse bei Anwesenheit des $\operatorname{Imp} \beta$ entspricht dem bereits bekannte Sachverhalt, das die Bindung der kleinen GTPase Ran an Transportrezeptoren das RanGTP resistent gegen die RanGAP1 vermittelte GTP-Hydrolyse wird (Askjaer et al., 1999; Floer and Blobel, 1996; Görlich et al., 1996; Maurer et al., 2001). Dieser Aspekt zeigt das die Acetylierung von Ran keinen Einfluss auf ein Zusammenspiel mit $\operatorname{Imp} \beta$ ausübt (Abb. 26B). Zumindest für die Mutanten K37Ac ${ }^{\text {Ran }}$ und K159Ac ${ }^{\text {Ran }}$ wäre ein Effekt zu erwarten gewesen, da beide Positionen an einer Interaktion mit dem $\operatorname{Imp} \beta$ beteiligt sind (Lee et al., 2005; Vetter et al., 1999) Für die Rezeptoren Imp7 und Crm1 verhält sich dieses etwas anders. In Verbindung mit Imp7 zeigen die Mutante K37Ac ${ }^{\text {Ran }}$ und K38Ac $^{\text {Ran }}$ den deutlichsten Einfluss mit einer Signifikant höheren Hydrolyse Aktivität. Diese beiden Lysine liegen in der Switch 1 Region der kleinen GTPase. Ob diese beiden Aminosäuren an einer Bindung zum Imp 7 beteiligt sind kann weder ausgeschlossen noch bestätigt werden, da von diesem Komplex keine Struktur existiert. Im Fall von h.s.Crm1 ist das Ergebnis interessanter. Da die Mutanten K71Ac und K38Ac höhere Hydrolyse, während die Mutanten K99Ac und 159Ac eine signifikant niedrigere Hydrolyse erkennen lassen. Der Ran Protektions Assay über den Phosphat Sensor wurde einzig mit dem h.s.Crm1 in einer dreier Serie durchgeführt (3.5.3.3). Es zeigen sich nicht viele ähnliche Ergebnisse zum radioaktiven Assay. Die Unterschiede zum Wildtyp treten hier weniger deutlich hervor (Abb. 27A). In diesem Experiment lässt sich allerdings beobachten, dass die Mutante K71Ac bei einer 1:1 Konzentration von Crm1 zu RanGTP eine höhere Hydrolyseaktivität zeigt. Zeigt die Mutanten K37Ac zuvor keinen großen Unterschied zum Wildtyp, so ist ein ähnlich ausgeprägtes Verhalten wie bei K38Ac mit einer höheren Hydrolyse zu beobachten. K38Ac zeigt sich wie im radioaktiven Assay. Das die Mutante 
K159Ac ${ }^{\text {Ran }}$ zeigt schon bei $500 \mathrm{nM}$ keine Hydrolyse mehr, dies impliziert eine starke Interaktion mit h.s.Crm1. Bei einer Konzentration von 500 nM Crm1 sollte noch Hydrolyse stattfinden, da diese Konzentration nur 1/3 der Konzentration an eingesetztem RanGTP entspricht. Freies RanGTP sollte demnach vorhanden sein. Aus dem Kurvenangleich lässt sich ein $\mathrm{K}_{\mathrm{d}}$-Wert für die Bindung von RanGTP an h.s.Crm1 ermitteln (Tabelle 4) und demzufolge die Mutanten K37Ac, K38Ac, K60Ac und K71Ac eine höhere und die Mutanten K99Ac und K159Ac eine niedrigere Affinität erkennen lassen. Aus der Literatur ist bekannt, das die Kombination aus Crm1:RanGTP mit SPN1 einen $\mathrm{K}_{\mathrm{d}}$-Wert von $16 \mathrm{nM} \pm 3 \mathrm{nM}$ besitzt (Petosa et al., 2004). Der ermittelte $\mathrm{K}_{\mathrm{d}}$-Wert von $260 \mathrm{nM}$ für die Interaktion zwischen Crm1 und RanGTP Wildtyp übersteigt diesen um ein Vielfaches. Die in Tabelle 4 dargestellten $\mathrm{K}_{\mathrm{d}}$-Werte liegen ausnahmslos über den von Petosa et al. (2004) ermittelten Werten. Zum einen kann dieser Umstand durch die Verwendung des Phosphat Sensor erklärt werden, welcher das Phosphat mit einem $K_{d}$-Wert von $100 \mathrm{nM}$ bindet. Darüber hinaus wurden nur 6 Datenpunkten für den Kurvenangleich verwendet. Desweiteren ist die Ermittlung der GTP-Hydrolyse bei Petosa et al. (2004) etwas direkter, da hier direkt das frei werdende Phosphat gemessen wird, als dies mit dem Phosphatsensor der Fall ist. In diesem Zusammenhang bietet die Isotherme Titrationskalorimetrie eine genauere Möglichkeit zur Ermittlung der Bindungskonstanten. Nichts desto trotz scheinen, auf den ersten Blick, die Beobachtungen aus den Ran Protektions Assays (3.5.3.2 und 3.5.3.3) nicht mit den Erkenntnissen aus den $K_{d}$-Werten vereinbar zu sein. Die Mutanten die bei höheren Crm1 Konzentrationen noch Hydrolyse zeigen, sollten logisch betrachtet niedrigere Affinität zum Crm1 zeigen als der Wildtyp. Wohingegen Mutanten, welche eine geringer Hydrolyseaktivität zeigen, mit niedrigerer Affinität an das Crm1 binden sollten. In vorangegangenen Studien konnte gezeigt werden, das RanGTP gebunden an Crm1:NESCargo und $\operatorname{Imp} \beta$ resistent gegen RanGAP stimulierte GTP-Hydrolyse ist (Askjaer et al., 1999; Floer and Blobel, 1996; Görlich et al., 1996; Koyama, 2010; Maurer et al., 2001). Da bereits beobachtet werden konnte, das acetyliertes Ran weiterhin in der Lage ist an die Rezeptoren Crm1 und $\operatorname{Imp} \beta$ zu binden lässt vermuten, dass der Einfluss einer einzelnen Acetylierung der GTPase nicht in der Bindung der GTPase an Crm1 bzw. Imp7 zu suchen ist. Die Acetylierung der GTPase scheint in diesem Fall dem RanGAP1 die Möglichkeit zu eröffnen mit dem RanGTP zu interagieren während dieses an den Transportrezeptor gebunden ist (3.5.3.2 und 3.5.3.3). Der Umsatz von GTP zu GDP führt beim Ran zu strukturellen Änderungen und letztendlich zum Auseinanderfallen des Komplexes. Am Auflösen von Transportkomplexen sind in der Zelle normalerweise die Proteine RanBP1, 
sowie die RBD's (engl. Ran binding domain) von RanBP2 beteiligt (Kehlenbach et al., 1999, 2001; Koyama, 2010), in dem sie kleine Veränderungen am Ran induzieren, welche die Freisetzung von Substrat vermittelt. Diese ermöglichen dem RanGAP1 mit RanGTP zu interagieren und die GTP Hydrolyse zu begünstigen. Eine Acetylierung der GTPase Ran scheint demnach eine weitere Möglichkeit zur Regulation von Transportprozessen darzustellen, in dem es dem RanGAP1 erlaubt mit RanGTP zu interagieren während sich dieses noch im Kontakt mit einem Transportrezeptor befindet. Im radioaktiven Assay konnte diese Beobachtung für das $\operatorname{Imp} \beta$ zwar nicht gemacht werden, jedoch begünstigt NLS-Substrat die Trennung des Importkomplex (Kehlenbach et al., 2001). Da sich jedoch nicht einmal ein leichter Unterschied feststellen lässt scheint die Acetylierung von Ran keinen Einfluss auf dessen Interaktion mit $\operatorname{Imp} \beta$ zu haben.

Der Einfluss der Acetylierung auf Eigenschaften der Aminosäure Lysin hinsichtlich Ladung, Größe der Aminosäure und Präferenz für Sekundärstrukturelemente kann Auswirkungen auf die Struktur der GTPase im einzelnen, sowie im Kontakt mit anderen Proteinen zeigen. Das Verhalten der Acetyllysin Mutanten der kleinen GTPase Ran im Ran Protektions Assay, sowie in den Bindungsstudie, kann ein Resultat struktureller Veränderungen der GTPase und seiner Interaktion mit den Transportrezeptoren (z.B. Crm1) sein. Der Umstand, dass ein Exportkomplex Crm1:RanGTP zusammen mit dem Protein SPN1, bereits zu einem früheren Zeitpunkt assembliert und kristallisiert wurde (Monecke et al., 2009), vereinfachte die Kristallisation des Exportkomplex mit acetyliertem RanGTP. Während der Arbeit gelang es den Exportkomplex mit den Ran Mutanten K71Ac und K99Ac zu assemblieren und zu kristallisieren. Beide Mutanten der kleinen GTPase zeigen einen Effekt in den Protektions Assays. Ein Westernblot mit einem Antikörper gegen Acetyllysin (3.5.4, Abb. 31) von aufgelösten Kristallen sowie Tropfen der Kristallisationsansätze bestätigte, dass das RanGTP innerhalb der Kristalle noch acetyliert vorlag. Eine genauere Betrachtung der Elektronendichte hinsichtlich der acetylierten Lysine zeigte Auffälligkeiten bei beiden Mutanten. Obwohl die Acetylierung der kleinen GTPase Ran durch Westernblot (3.5.4, Abb. 31) bestätigt wird, ist keine Elektronendichte für eine Acetylgruppe am K71Ac ${ }^{\text {Ran }}$, sowie am K99 ${ }^{\text {Ran }}$ in beiden Molekülen der asymmetrischen Einheit definiert. Aus diesem Grund konnte die Acetylgruppe an den Lysinen 71 und 99 nicht gebaut werden. Die Ursache der nicht definierten Acetylgruppe an den Lysinen kann in der Beweglichkeit der Acetylgruppe am Lysin liegen. Es besteht jedoch auch die Möglichkeit, dass die Acetylgruppe im Lauf der Kristallisation verloren gegangen ist oder die erreichte Auflösung der Beugungsdaten nicht 
ausreicht um Elektronendichte für die Acetylgruppe $\mathrm{zu}$ berechnen. Von diesen Möglichkeiten erscheint der Verlust der Acetylgruppe nicht als sehr wahrscheinlich, wenn auch möglich. Der Westernblot (3.5.4, Abb. 31) zeigt, das die Kristalle acetyliertes RanGTP enthielten, jedoch nicht ob in den Kristallen auch nicht acetyliertes RanGTP vorhanden war und in welchem Verhältnis dieses zum acetylierten RanGTP lag. Daher können die Kristalle beide Formen enthalten haben und dazu führen, dass Acetylgruppe nicht an jedem RanGTP auftritt und definiert werden kann. Die beiden anderen Möglichkeiten erscheinen wahrscheinlicher, da die Beweglichkeit der freien Acetylgruppe am Lysin eine genaue Lokalisation der Acetylgruppe im Raum erschwert, oder die

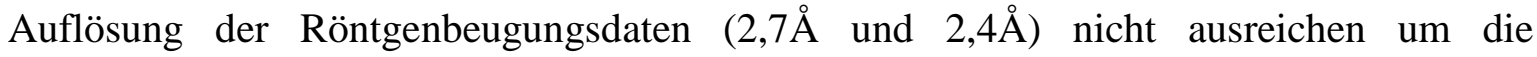
Acetylgruppe zu sehen. Eine Kombination dieser beiden Möglichkeiten könnte die beste Erklärung für die nicht definierte Acetylgruppe an den Lysinen in den Komplexen bieten. Eine weitere Auffälligkeit bei der Betrachtung der Elektronendichte bezieht sich auf die Mutante $\mathrm{K}_{71 \mathrm{Ac}}{ }^{\mathrm{Ran}}$. So ist bei einem Molekül der asymmetrischen Einheit keine Elektronendichte für das $\mathrm{K} 71^{\text {Ran }} \mathrm{zu}$ erkennen, während das zweite Molekül hier eine deutlich erkennbare Dichte aufweist. Die Abwesenheit von Elektronendichte für das Lysin kann durch die Unterbrechung einer Interaktion zwischen dem K71 ${ }^{\text {Ran }}$ und Asp932 ${ }^{\text {Crm1 }}$ aufgrund der Acetylgruppe am K71 Ran erklärt werden. Durch eine Trennung der Interaktion zwischen dem $\mathrm{K} 71^{\mathrm{Ran}}$ und Asp932 ${ }^{\mathrm{Crm} 1}$ liegt das $\mathrm{K} 71^{\text {Ran }}$ frei und flexibel vor. Die Beweglichkeit der nun frei vorliegenden Aminosäure Lysin bietet eine Erklärung für diesen Umstand. Die gewonnen Freiheit des $K 71^{\text {Ran }}$ könnte dazu führen, dass das katalytisch aktive Glutamin (Gln69, Q69) frei wird. Das Glutamin ist im Komplex mit $\operatorname{Imp} \beta$ so fixiert, das es nicht mit einem katalytischen Wasser koordiniert werden kann (Seewald et al., 2002). Wird das Glutamin frei und das RanGTP zugänglich für RanGAP könnte das GTP hydrolysiert werden. Für die Mutante K99Ac ist die Elektronendichte für das K99Ac in beiden Molekülen der asymmetrischen Einheit zu erkennen. Das Lysin 99 von Ran weist dabei keine Interaktion mit dem Crm1 auf und liegt somit von vornherein frei. Durch diese Konstellation unterbricht eine Acetylierung des Lysins keine Interaktion zum Crm1. Die Vergrößerung der Aminosäure durch eine Acetylgruppe (Kim et al., 2006; Spange et al., 2009) eröffnet jedoch die Möglichkeit einer Interaktion mit dem Crm1 über die Acetylgruppe. Infolgedessen könnte es zu einer stärkeren Interaktion zwischen dem RanGTP und dem Crm1 kommen. Da für das K99 Elektronendichte in beiden Molekülen beobachte werden kann scheint es daher unwahrscheinlich, dass das freie K71 Ran aufgrund seiner gewonnenen Beweglichkeit keine Elektronendichte zeigt. 
Ein Abgleich der beiden erhaltenen Strukturmodelle mit der Struktur 3GJX (Monecke et al., 2009) zeigt keine signifikante Abweichung der erhaltenen Strukturen von 3GJX. Auch wenn das Crm1 der Struktur 3GJX aus der Maus (Mus musculus) stammt, so besteht eine sehr hohe Sequenzhomologie zwischen diesem und dem in der Arbeit verwendeten h.s.Crm1. Eine isolierte Betrachtung des RanQ69L ${ }^{1-180}$ K71Ac und K99Ac mit Überlagerung zum RanQ69L ${ }^{1-180}$ aus 3GJX zeigt keinen signifikanten Unterschied der acetylierten Mutanten zu der bereits bestehenden Struktur aus 3GJX (3.5.6.3, Abb. 35). Jedoch konnte in diesem Zusammenhang eine Interaktion zwischen dem Arg887 ${ }^{\mathrm{Crm} 1}$ und dem Asp91 ${ }^{\text {Ran }}$ in beiden Komplexen mit den Mutanten beobachtet werden (Abb. 36), die in der Struktur 3GJX nicht zu erkennen ist. Es besteht Möglichkeit, dass trotz der hohen Sequenzhomologie dieser Umstand auf einen Unterschied zwischen Crm1 aus Maus und humanem Crm1 hervorgeht. Ein Weiterer Unterschied liegt in der Switch 2 Region des Ran, während in 3GJX das K71 in einem Teil einer zweigeteilten Helix zu finden ist, lässt sich das K71 ${ }^{\text {Ran }}$ in beiden Modellen (K71Ac Mutante und K99Ac Mutante) in einer Schleife finden (Abb. 38). Für das Modell mit der Mutante K71 acetyliert, lässt sich diese Beobachtung erwarten da ein acetyliertes Lysin eine leicht andere Sekundärstrukturpräferenz zeigt (Kamieniarz and Schneider, 2009; Kim et al., 2006; Spange et al., 2009). Im Modell mit der Mutante K99 acetyliert ist dies weniger zu erwarten gewesen, da diese in einem Bereich hinter der Switch 2 Region und der zwei geteilten Helix liegt. Wie in Monecke et al. (2009) für den Crm1:SPN1:RanGTP Komplex beschrieben umschließt das h.s.Crm1 das acetylierten RanGTP, das somit in dem Rezeptor eingebettet und von dem SPN1 getrennt vorliegt. Die Modelle sind jedoch mit Vorsicht zu betrachten, da die Aminosäuren lediglich in einem ersten Schritt über ein Program (Phenix Autobuild) in die Elektronendichte eingepasst wurde und die Dichte an einigen Stellen unterschiedliche Orientierungsmöglichkeiten für die Aminosäuren ermöglicht.

Aufgrund der Lage der Lysine 37, 38 und 71 in den variablen Regionen der kleinen GTPase Ran konnte einen Einfluss auf die Interaktion mit Crm1 und Imp $\beta$ erwartet werden. Wie aus den durchgeführten Bindungsstudien über Gelfiltration und Pulldown Assay ersichtlich wurde kann gesagt werden, dass eine einzelne Acetylierung keinen Einfluss auf eine generelle Interaktion von RanGTP mit den Transportrezeptoren Imp $\beta$ und Crm1 ausübt (3.5.1 und 3.5.2). Die Mutanten zeigen jedoch eine Aktivität in Anwesenheit hoher Konzentrationen von Crm1 und Imp7, welche grundsätzlich einen inhibierenden Effekt auf die RanGAP induzierte GTP Hydrolyse ausüben (Askjaer et al., 1999; Floer and Blobel, 1996; Görlich et al., 1996; Koyama, 2010; Maurer et al., 2001). Diese Aktivität 
wird vermeintlich durch die Acetylierung der Lysine in den Switch Regionen des Ran überwunden. In diesem Zusammenhang sind die Ermittelten $\mathrm{K}_{\mathrm{D}}$-Werte mit großer Vorsicht zu betrachten, zudem diese stark von den bereits bekannten abweichen. Ohne die Interaktion mit Transportrezeptoren lässt sich eine, durch Acetylierung, modulierbare.
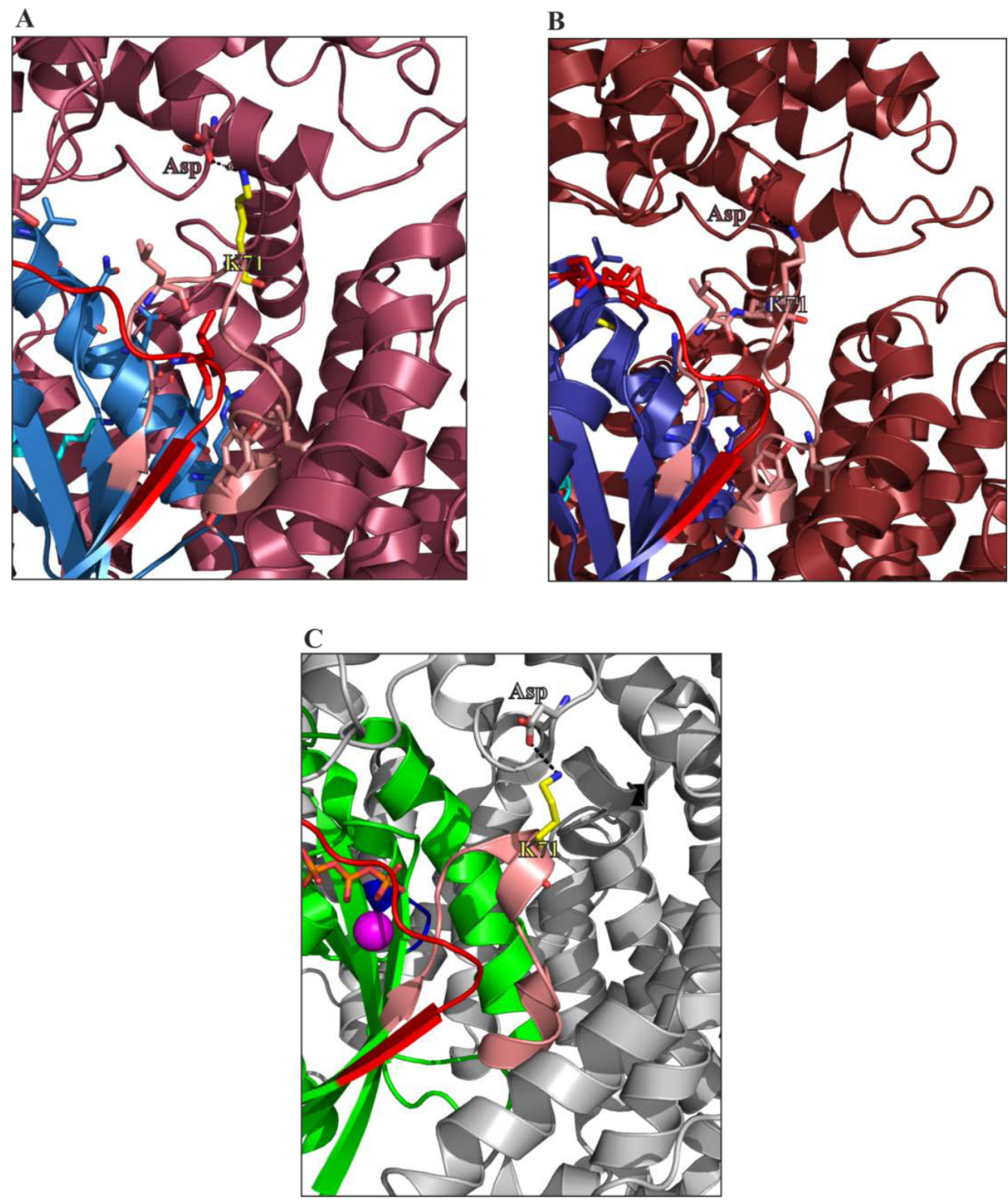

Abb. 38: Detailaufnahme der Switch 2 Region von RanGTP im Komplex mit Crm1. Gezeigt ist die Switch 2 Region (Pink) der Exportkomplex Modelle K71 (A) K99 (B) und der Struktur 3GJX (C). Der Fokus liegt auf der Switch 2 Region des RanGTP mit dem Lysin 71 als Stabmodel mit den Kohlenstoffatomen in gelb (A und C) und pink (B). Das Ran in grün, sowie das Crm1 in Himbeerfarben (A und B) und grau (C). Die Switch 1 Region des RanGTP ist in rot dargestellt. Stickstoffatome sind blau und Sauerstoffatome rot eingefärbt (Pymol). 
Hydrolyseaktivität erkennen. Für Strukturelle Aussagen hinsichtlich der Auswirkungen einer Acetylierung von Ran standen die Strukturen das Exportkomplex Crm1:SPN1:RanGTP jeweils mit den Mutanten RanQ69L ${ }^{1-180}$ K71Ac und K99Ac zur Verfügung (3.5.6). Ein Abgleich der erhaltenen Strukturen mit der Struktur PDB ID 3GJX (Monecke et al., 2009) lässt erkennen das die Acetylierung des RanGTP oberflächlich keine strukturellen Änderungen in der Tertiärstruktur des RanGTP aufweist

In der Arbeit wurden die beiden Kerntransporter Crm1 und $\operatorname{Imp} \beta$, sowie das RanGAP1 in Verbindung mit der actylierten kleinen GTPase Ran untersuch. Es ist jedoch nicht auszuschließen, dass die Acetylierung der kleinen GTPase Ran Interaktionen mit anderen Proteinen beeinflusst. Einer der wichtigsten Interaktionspartner der kleinen GTPase ist sein zweites direktes Regulationsprotein RCC1 (Abb. 39 unten Mitte). Die beiden Lysine $71^{\text {Ran }}$ und $99^{\text {Ran }}$ stehen in direktem Kontakt zum RCC1. Das Lysin $99^{\text {Ran }}$ ragt dabei in den zentralen Bereich des RCC1. Beide Aminosäuren tragen zur engen Bindung des Ran an das RCC1 bei, wobei das K71 ${ }^{\text {Ran }}$ als eine der wichtigsten Interaktionen angesehen wird (Renault et al., 2001). Dabei interagiert das Lysin 99 mit zwei Aminosäuren (Asp128 ${ }^{\text {RCC1 }}$ und Asn181 ${ }^{\text {Rcc1 }}$ ), sowie das Lysin 71 mit einer weiteren Aminosäure (His304 ${ }^{\mathrm{Rcc} 1}$ ). Eine Mutation dieser Aminosäuren aus RCC1 zu Alanin führt zu einem signifikanten Effekt auf den $\mathrm{k}_{\mathrm{cat}}$ des RCC1 (Renault et al., 2001). Die Acetylierung der Lysine 71 und 99 würde dieser Mutation entsprechen und die Verbindung zu den Aminosäuren des RCC1 unterbrechen, was einen Effekt auf die katalytische Aktivität des RCC1 nehmen würde. Es ist auch nicht auszuschließen, dass eine Acetylierung der anderen Lysine einen allosterischen Effekt auf das RCC1 zeigt und strukturelle Veränderungen induziert. Diese Veränderungen könnten bewirken, dass die katalytische wichtige Bereiche bzw. Aminosäure anders platziert werden. Die Acetylierung könnte demnach eine weitere Möglichkeit der Regulation bieten.

Mit Transportrezeptoren der Importin $\beta$-Superfamilie gelangt die kleine GTPase Ran vom Zellkern in das Zytoplasma, durch NTF 2 (Abb. 39 unten rechts) erreicht die GTPase wieder den Zellkern. Das Lys71 ${ }^{\text {Ran }}$ ist an der Interaktion zwischen Ran und NTF2 beteiligt und bildet eine Salzbrücke zu zwei Aspartaten Seitenketten des NTF2 (Stewart et al., 1998a). Eine Unterbrechung dieser Salzbrück ist ausreichend um die Interaktion zwischen Ran und NTF2 zu unterbinden und den Import von Ran in den Zellkern sensibel zu stören(Kent et al., 1999; Ribbeck et al., 1998; Stewart et al., 1998a). Durch Acetylierung von Ran am K71 wird die Ladung der Aminosäure Lysin maskiert und die Interaktion mit den Aspartaten würde damit unterbrochen. Die Bindung von Ran an das NTF2 würde 
ausbleiben und das Ran im GDP gebundenem Zustand würde sich, wie in der Literatur beschrieben (Kent et al., 1999; Ribbeck et al., 1998), im Zytoplasma ansammeln. Des

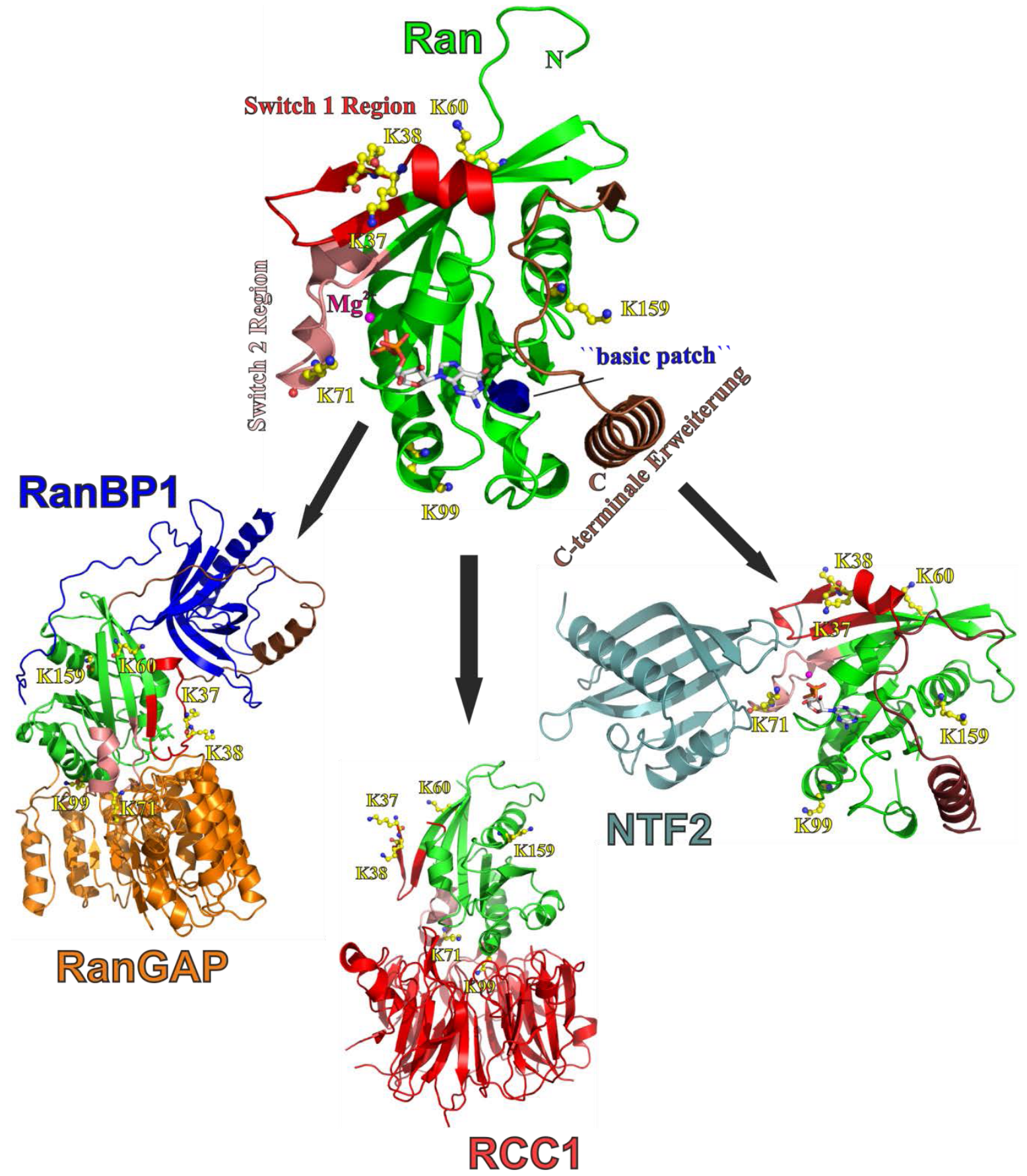

Abb. 39: Übersicht der Komplexe im Wechsel zwischen GTP und GDP gebundenem Zustand der kleinen GTPase Ran. Die Komplexe sind alle als Cartoon-Modell gezeigt. Dargestellt ist das GDP gebundene Ran (grün, oben Mitte als Cartoon-Modell, PDB ID 3GJ0) einzeln, sowie im Komplex mit RanGAP1 und RanBP1 (unten links, RanGAP orange und RanBP1 blau, PDB ID 1k5D), mit RCC1(rot unten Mitte, PDB ID 1I2M) und seinem Transportfaktor NTF2 (unten rechts ozeangrün PDB ID1A2K). Lysine sind als Kugel-Stab-Modell dargestellt, nach Atomen eingefärbt mit Kohlenstoffatomen in gelb, Stickstoffatomen in blau und in der Abbildung beschriftet. Das GDP ist als Stab-Modell dargestellt mit den Kohlenstoffatomen in grau, den Stickstoffatomen in blau, den Sauerstoffatomen in rot und den Phosphoratomen in orange (Pymol). 
Weiteren würde der inhibierende Effekt der Bindung von RanGDP an NTF 2 wegfallen und das RanGDP im Zytoplasma zugänglich für andere Guanosinukleotid Austauschfaktoren (Renault et al., 2001; Stewart et al., 1998a). Ein Einfluss der anderen Acetylierungsstellen (Choudhary et al., 2009) lässt sich im Zusammenhang mit NTF2 schlecht einschätzen.

Zeigen auch die Multisubstrat Transporter $\operatorname{Imp} \beta$ und $\mathrm{Crm} 1$ keine oder nur geringe Beeinflussung durch eine Acetylierung der kleinen GTPase Ran, so kann dies für andere Transportrezeptoren nicht für ausgeschlossen gelten. In Abbildung 40 sind einige bekannte Strukturen von Import- sowie Exportrezeptoren dargestellt, angefangen bei dem Cse1p oben links. In dieser Struktur bildet das K37 ${ }^{\text {Ran }}$ eine Interaktion zum Cse1p, während das K99 $^{\text {Ran }}$ einen Bestandteil der Interaktion von RanGTP mit Imp $\alpha$ (Kap60p) darstellt (Matsuura and Stewart, 2004). Die Acetylierung von Ran an der Position 37 könnte demnach die Interaktion zum Cse1p stören und zu einem ähnlichen Ergebnis (mit Substrat) führen wie es in Matsuura and Stewart (2004) gezeigt wird. Hier wird die Bildung des Cse1ß:Kap60p:RanGTP Exportkomplex durch eine K37D/K152A Mutation unterbunden. Die Acetylierung von Ran an der Position 99 könnte in diesem Zusammenhang eine Auswirkung auf die Bindung von RanGTP zum Impa, im Komplex mit Cse1p haben. Die Acetylierung könnte so die Stabilität des Exportkomplexes beeinflussen. Eine weiterer Rezeptor, welcher mit Ran Interagiert ist Exportin 5 (Abb. 40 oben rechts, Exp5). Von den Lysinen aus Choudhary et al. (2009) interagiert das K159 ${ }^{\text {Ran }}$ mit einem Glutamat des Exp5 (Okada et al., 2009). Das K159 Ran ist auch an einer Interaktion von Ran an ein Aspartat des Transportrezeptor Transportin (Abb. 40 unten rechts (Chook and Gunter, 1999)) beteiligt. Die Acetylierung des K159 Ran könnte dazu beitragen die Interaktion der kleinen GTPase mit den Transportrezeptoren Exp5 und Transportin zu schwächen. Die Acetylierung der GTPase an den Lysinen der Positionen 37 und 71 zeigt in diesem Zusammenhang keinen Einfluss auf die Interaktion mit Transportin (3.5.2 Abb. 23). Weiter in der Abbildung gezeigt ist ein Komplex aus RanGTP und Importin 13 (Abb 40 Imp 13 unten links). Von den 6 Acetylierungsstellen der kleinen GTPase Ran befinden sich die Lysine 39 und 40 (Hefe Zählweise, in der Abbildung sind die Lysine nach der Zählweise für humanes Ran mit K37 und K38 angegeben) im Kontakt mit dem Imp 13 (Bono et al., 2010). Im Komplex mit dem Karyopherin Kap121p (nicht dargestellt) sind dagegen die Lysine 38 und 159 der GTPase Ran an einer Interaktion beteiligt (Kobayashi and Matsuura, 2013). 
In wie weit die Acetylierung der nicht mit Transportrezeptoren Interagierenden Lysine einen Effekt auf die Beziehung von RanGTP zu den Transportrezeptoren zeigen lässt sich schwer sagen. Jedoch besteht die Möglichkeit, dass die Acetylierung der freien Lysine einen allosterischen Effekt auf die GTPase ausüben. Dieser Effekt könnte im Umkehrschluss zu kleinen Veränderungen der GTPase Struktur führen, welche die Interaktion der GTPase mit den Transportrezeptoren beeinflusst. Eine solche

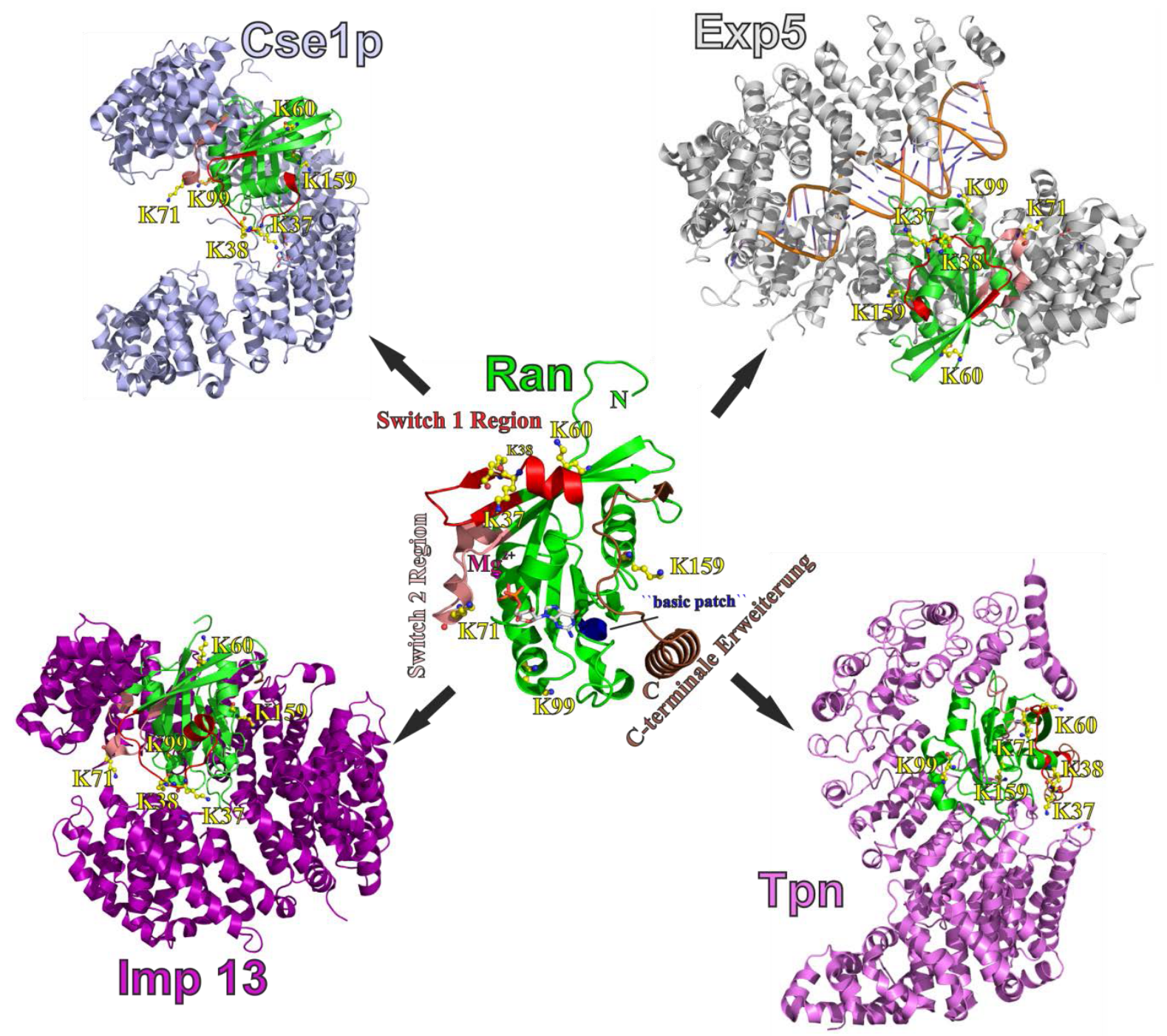

Abb. 40: Übersicht über Transportrezeptoren im Komplex mit der kleinen GTPase Ran. Die Komplexe aus Transportrezeptor und Ran sind alle als Cartoon-Modell gezeigt In der Mitte der Abbildung ist GDP gebundenes Ran (grün, Cartoon-Modell) dargestellt. Um das Ran herum angeordnet sind oben links der Exportrezeptor Cse1p (graublau, PDB ID 1WA5, das Importin Alpha ist nicht mit dargestellt), oben rechts der Exportrezeptor Exportin 5 (Exp5 in grau, PDB ID 3A6P, die pre-miRNA ist als Cartoon-Modell dargestellt), unten links das Importin 13 (Imp 13 in lila, PDB ID 2X19) und unten rechts der Importrezeptor Transportin (Tpn in violett, PDB ID 1QBK). ). Lysine sind als Kugel-Stab-Modell dargestellt und nach Atomen eingefärbt mit Kohlenstoffatomen in gelb und Stickstoffatomen in blau. Die Lysine sind in der Abbildung beschriftet. Das GDP ist als Stab-Modell dargestellt mit den Kohlenstoffatomen in grau, den Stickstoffatomen in blau, den Sauerstoffatomen in rot und den Phosphoratomen in orange (Pymol). 
Beeinflussung könnte dazu führen das ein Exportkomplex nicht mehr zustande kommt oder ein Importkomplex nicht mehr aufgelöst wird, wie für die Ran Mutante K37D/L152A beschrieben(Lee et al., 2005; Matsuura and Stewart, 2004).

\subsection{Einordnung der Acetylierung der GTPase Ran in einen biologischen Kontext}

Wie am Beginn der Diskussion erwähnt und in der Einleitung beschrieben ist die GTPase Ran ein Schlüsselelement der eukaryotischen Zelle. Ran bildet einen zentralen Bestandteil des Kerntransport, da es bei der Bildung von Exportkomplexen sowie dem Trennen von Importrezeptor und Substrat im Importprozess beteiligt ist (Lee et al., 2005; Matsuura and Stewart, 2004). Importrezeptoren kehren mit dem RanGTP in das Zytoplasma zurück. Die asymmetrische Verteilung von Ran im GTP gebundenem Zustand führt zu einem Konzentrationsgradienten über die Kernhülle, der für die Direktionalität des Kerntransport entscheidend ist. Für die Aufrechterhaltung des Konzentrationsgradienten ist die Interaktion von Ran mit unterschiedlichen Partnern wichtig (1.3.1 Abb. 6 und Abb. 39-40). An jedem dieser Punkte kann theoretisch eine Acetylierung der GTPase Ran eine Rolle spielen. Auch in der Mitose spielen RanGTP und sein Konzentrationsgradient eine wichtige Rolle, hier jedoch ohne Kernhülle. Das RanGTP übernimmt auch hier einige Aufgaben durch Interaktionen mit Proteinen, die auch am Kerntransport beteiligt sind. Zusammen mit Crm1 rekrutiert Ran die Proteine RanGAP und RanBP2 an das Kinetochor, bildet mit Crm1 und Spindelfaktoren (SAF) inhibitorische Komplexe und veranlasst die Freisetzung von SAF aus inhibitorischen Komplexen mit Importin. Der RanGTP-Gradient liefert dazu die richtungsgebenden sowie die räumlichen Informationen für den Aufbau der Mitosespindel und der Kernhülle zum Ende der Zellteilung (Bird et al., 2013; Clarke and Zhang, 2008; Kalab and Heald, 2008; Yudin and Fainzilber, 2009). In Abbildung 42 ist eine Übersicht der Beteiligung der kleinen GTPase Ran in der Zelle im Zusammenhang von Kerntransport und Mitose schematisch dargestellt.

Die Interaktion zwischen Transportrezeptor und RanGTP führt nicht nur zur Bildung von Exportkomplexen, Freisetzung von Importsubstrat oder Bildung von inhibitorischen Komplexen während der Mitose, sondern inhibiert auch die durch RanGAP induzierte GTP-Hydrolyse (Askjaer et al., 1999; Floer and Blobel, 1996; Görlich et al., 1996; Koyama, 2010; Maurer et al., 2001). Der Einfluss der Acetylierung auf Crm1:Cargo:RanGTP Komplex, mit GTP-Hydrolyse bei Anwesenheit von Crm1 (3.5.3 und 4.2) bietet der Zelle die Möglichkeit SAF anstellen freizusetzen an denen sich kein 
RanBP1 oder 2 befindet. Die Acetylierung der kleinen GTPase Ran an bestimmten Lysinen scheint demnach eine weitere Möglichkeit zur Regulation von Transportprozessen darzustellen, in dem es dem RanGAP1 erlaubt mit RanGTP zu interagieren während sich dieses noch im Kontakt mit einem Transportrezeptor (Crm1, Imp $\beta$, Imp7) befindet. Die Möglichkeit Cargo bzw. SAF auch ohne RanBP1 oder 2 freisetzen zu können scheint aufgrund der Abwesenheit einer Kernhüllen in der Mitose und damit begleitend der weniger strikten Lokalisation von RanBP1 und 2 (an Zentrosomen, Kinetochor und Mikrotubuli der Spindel (Guarguaglini et al., 2000; Joseph et al., 2004; Kalab and Heald, 2008) für die Mitose von größerer Wichtigkeit zu sein als dies für den Kerntransport der Fall ist.

In 4.2 wurde bereits erwähnt, dass die Acetylierung der GTPase Ran die Hydrolyse von GTP, induziert durch RanGAP1, beeinflusst. Wie aus anderen Studien bereits bekannt (Cohen and Yao, 2004; Inuzuka et al., 2012; Polevoda and Sherman, 2002; Sadoul et al., 2011; Spange et al., 2009) beeinflusst eine Acetylierung Proteinfunktionen, wie die enzymatische Aktivität. So scheint durch Acetylierung die GTP-Hydrolyse gesteigert bzw. verlangsamt zu werden, je nach vorgenommener Acetylierung. Diese beiden Richtungen der Aktivität stellen eine Möglichkeit zur Regulation und Modulation des RanGTP Gradienten dar, in dem die GTP-Hydrolyse gesteigert wird verringert sich die Konzentration an RanGTP. Dies verschiebt den Gradienten zugunsten von RanGDP und verlangsamt im Umkehrschluss die Prozesse des Kerntransport und der Mitose, da weniger RanGTP zu Verfügung steht um die notwenigen Aufgaben für den gewohnten Ablauf dieser Prozesse aus zu führen. Eine Verlangsamung der GTP-Hydrolyse durch Acetylierung führt im Gegenzug zu einer Verschiebung des RanGTP Gradienten zu Gunsten von RanGTP. Dies führt dazu, das freigesetztes RanGTP aus Komplexen mit Transportrezeptoren nicht gleich in RanGDP überführt wird und so für weitere ProteinProtein Interaktionen im Zytoplasma zur Verfügung steht. Dabei intergiert freies RanGTP im Zytoplasma nicht mit dem NTF2, welches das RanGTP in den Zellkern transferiert. Ist zudem das Lysin $71^{\text {Ran }}$ acetyliert könnte dies zu einer Ansammlung von RanGDP im Zytoplasma führen, das durch andere Austauschfaktoren in RanGTP umgesetzt wird (Kent et al., 1999; Renault et al., 2001; Ribbeck et al., 1998; Stewart et al., 1998a, 1998b). Da der RanGTP Gradient sowohl für den Kerntransport als auch für die Mitose die treibende Kraft darstellt, scheint die Acetylierung der GTPase weniger auf einen bestimmten Prozess als vielmehr auf die zentrale Schnittstelle zwischen beiden Prozessen gerichtet zu sein. Eine gerichtete Acetylierung der GTPase Ran scheint nach den Ergebnissen dieser Arbeit auf 
eine Regulation bzw. Modulation der Aktivität der kleinen GTPase und seiner Interaktion mit anderen Proteinen abzuzielen und dadurch eine weitere regulatorische Ebene für Zelluläre Prozesse wie den Kerntransport oder die Mitose zu schaffen. Abseits eines regulatorischen bzw. modulatorischen Effektes einer Acetylierung auf die kleine GTPase Ran könnte eine Acetylierung an einem oder mehrerer Lysine die subzelluläre Lokalisation der kleinen GTPase beeinflussen, wie dies bereits für Prrp, RECQL4 P/CAF und c-Abl berichte wurde (di Bari et al., 2006; Blanco-García et al., 2009; Dietschy et al., 2009; Sasaki et al., 2012). So könnte je nach acetylierter Position die kleine GTPase Ran im Zellkern oder dem Zytoplasma gehalten werden. Daraus ergeben sich viele Möglichkeiten der Beeinflussung der kleine GTPase Ran durch eine kleine Modifikation der Aminosäure Lysin.

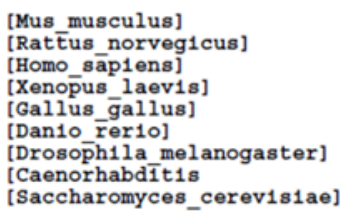

[Saccharomyces_cerev1s1ae]

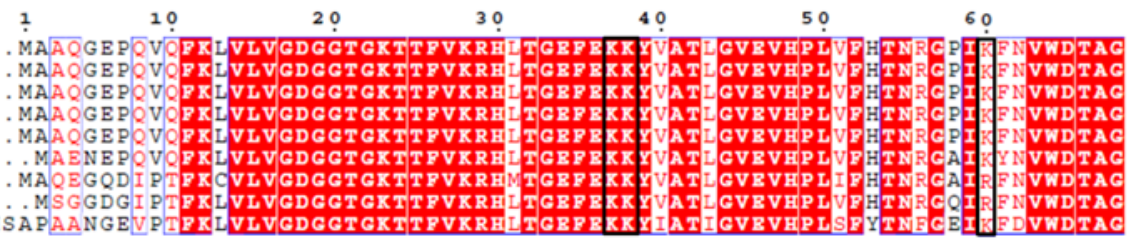

APAANGEI
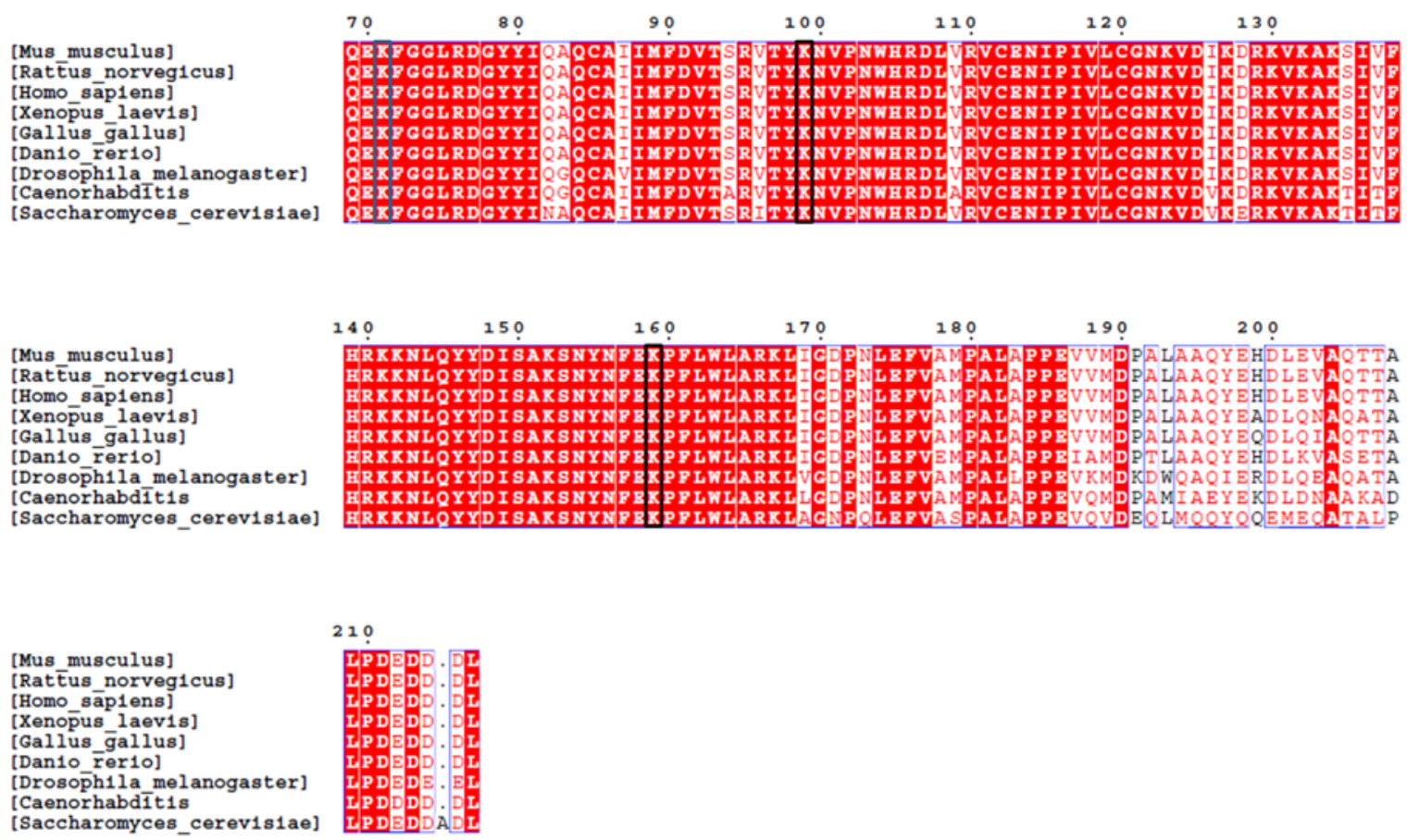

Abb. 41. Sequenzvergleich der GTPase Ran aus unterschiedlichen Organismen. Sequenzvergleich des humanen Ran (Homo sapiens) mit den Orthologen aus Maus (Mus musculus), Wanderratte (Rattus norvegicus), Krallenfrosch (Xenopus laevis), Huhn (Gallus gallus), Zebrafisch (Danio rerio), Fruchtfliege (Drosophila melanogaster), Fadenwurm (Caenorhabditis elegans) und Bäckerhefe (Saccharomyces cerevisiae). Konservierte Reste sind blau umrandet, wobei ähnliche und teilweise konservierte Reste rot sind und Reste, die in allen homologen Proteinen vorkommen rot hinterlegt sind. Die in Choudhary et al., 2009 festgestellten acetylierbaren Lysine sind mit einem schwarzen Kasten markiert. 
Wie Eingangs bereits beschrieben handelt es sich bei der kleine GTPase Ran um eine zentrales Protein im Kerntransport und der Mitose (1.4). Ein Sequenzvergleich der humanen GTPase mit Orthologen aus anderen Spezies lässt eine hohe Sequenzhomologie zwischen dem human Ran und seinen Orthologen erkennen (Abb. 41). Dies lässt die Schlussfolgerung zu, dass ähnliche Effekte auch in anderen Spezies auftreten und nicht nur auf Säugetiere begrenzt sind.
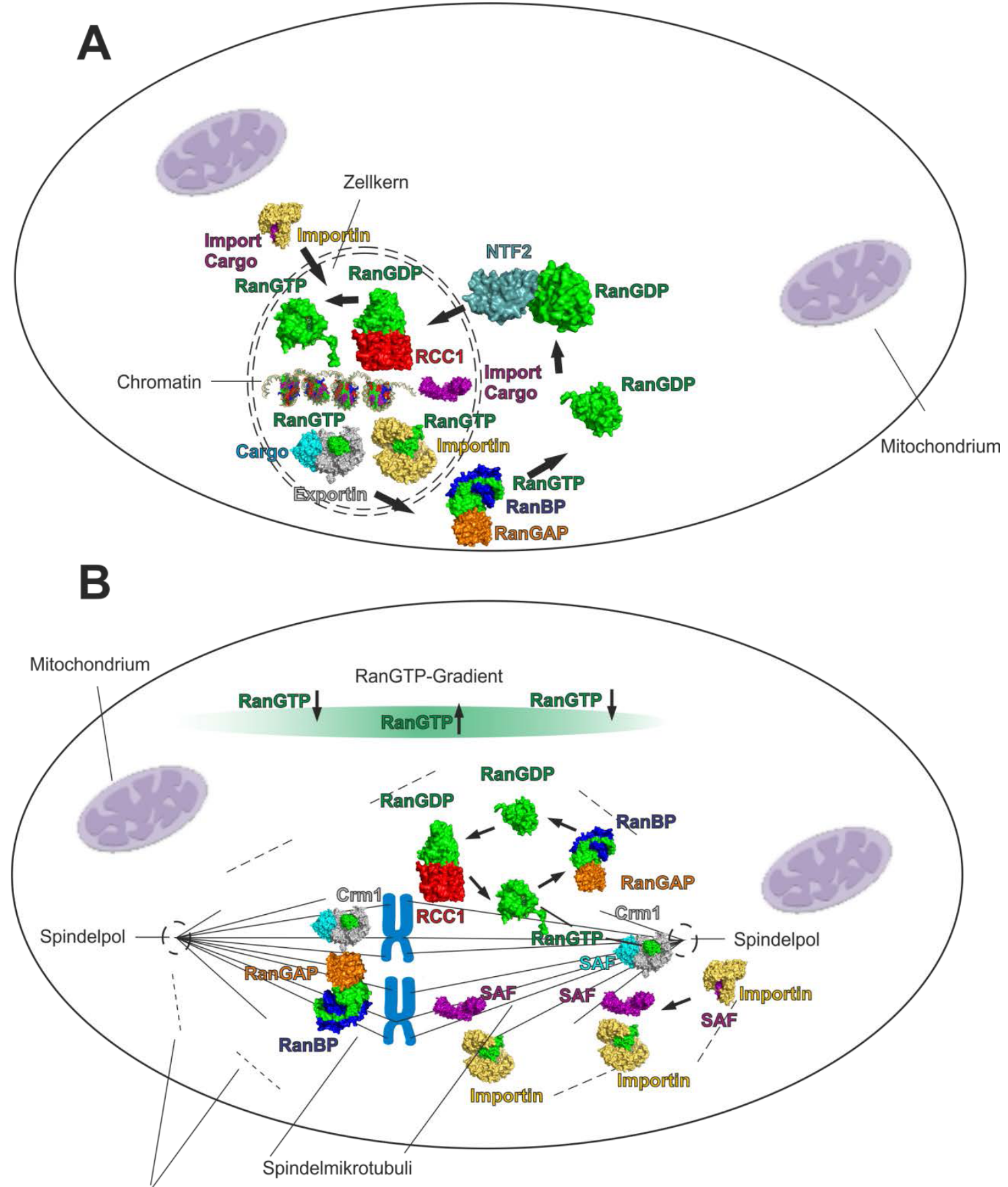

Fragment der Kernhülle

Abb.: 42: Übersichtsdarstellung der Aufgabenverteilung der kleinen GTPase Ran in der eukaryotischen Zelle. A) Zeigt eine schematische Darstellung einer Zelle in der Interphase des Zellzyklus mit Fokus auf den Kerntransport und der Beteiligung der kleinen GTPase Ran( grün). Im Kerntransport 
vermittelt RanGTP im Zellkern die Freisetzung von Importsubstart (magenta) von Importinen (gelb) und bildet einen Bestandteil der Bildung von Exportkomplexen mit Exportin (grau) und Substrat (Cargo, türkis). Mit diesen gelangt die kleine GTPase in das Zytoplasma, wo die Transportkomplexe unter Beteiligung von RanBP1 oder 2 (blau) auseinanderfallen und RanGAP1 (orange) die GTP-Hydrolyse vermittelt. Im Zytoplasma interagiert NTF2 mit RanGDP und im Zellkern tauscht RCC1 (rot) das GDP gegen GTP aus. B) Zeigt eine schematische Darstellung einer Zelle in der Mitose ungefähr zum Zeitpunkt der Prometaphase. Die Kernhülle ist auseinander gefallen. RanGTP interagiert mit Importin (gelb) und setzt an diese gebundene SAF frei. Zusammen mit Crm1 rekrutiert die klein GTPase Ran (grün) RanGAP1 (orange) und RanBP2 und bildet inhibitorische Komplexe mit SAF. Freies RanGAP1 (orange) induziert die GTP-Hydrolyse durch Ran, das entstehende RanGDP interagiert mit RCC1 (rot) an den Chromosomen, was zum Austausch des GDP gegen GTP führt und eine Steigerung der RanGTP Konzentration (RanGTP $\uparrow$ ) um die Chromosomen zur Folge hat. Mit zunehmendem Abstand von den Chromosomen verringert sich die RanGTP Konzentration (RanGTP $\downarrow$ ), der RanGTP-Gradient bleibt auch in der Mitose bestehen. Die verwendeten Komplexe und Einzelproteine stammen aus der RCSB Protein Datenbank, Exportin:Cargo:RanGTP Komplex PDB ID 3GJX, Importin:RanGTP PDB ID 1QGK, RanGTP:RanGAP1:RanBP Komplex PDB ID 1k5D, RanGDP PDB ID 3GJ0, NTF2:RanGDP Komplex PDB ID 1A2K, Rcc1:RanGDP Komplex PDB ID 1I2M, RanGTP PDB ID 1QBK. Für die Oberflächendarstellung der Proteine wurde Pymol verwendet

\subsection{Ausblick}

Die in dieser Arbeit dargestellten Ergebnisse lassen in letzter Konsequenz noch keine definitiven Aussagen zu. Jedoch ist aus diesen eine gewisse Tendenz für die Auswirkung einer Acetylierung an der kleinen GTPase Ran hinsichtlich seiner Bedeutung für den Kerntransport sowie der Mitose zu erkennen. Diese scheint in einer Feinabstimmung der GTPase hinsichtlich seiner Aktivität im Kerntarnsport, so wie der Mitose zu liegen. Jedoch besteht die Möglichkeit das die Acetylierung am K37 des Ran einen Einfluss auf das Auflösen von Importkomplexen zeigt, so wie dies bereits durch eine K37D/K152ARanGTP Mutante gezeigt werden konnte (Lee et al., 2005; Matsuura and Stewart, 2004). Für eine solche Vermutung fehlen allerdings zurzeit die notwendigen Experimente. Ran ist ein zentrales Protein eben jener genannten Prozesse und interagiert daher mit vielen Proteinen. Eine weitere Eigenschaft der Acetylierung besteht in der Fähigkeit zur Darstellung einer Signatur für Effektormoleküle durch erzeugen eine Andockstelle für Proteine die das acetylierte Lysin erkennen. Die Acetylierung der kleine GTPase Ran kann daher auch zur Interaktion selbiger mit bisher unbekannten Effektormolekülen führen und die GTPase in weitere zelluläre Prozesse einbinden. Dies lässt Raum für weitere Experimente zur Erweiterung und Vertiefung des Verständnisses einer Acetylierung der kleinen GTPase offen. Wie ein Pulldown Assay der Acetyllysin Mutanten mit Zelllysat und anschließender Analyse der interagierenden Proteine. Auch die Analyse bereits 
bekannter Interaktionspartner wie RCC1, NTF 2 und Transportrezeptoren (z.B. Imp 13, Tpn, Exp5, Exportin t und auch Cse1p)

Im Weiteren sind für Strukturelle Aussagen betreffend der Auswirkung der Acetylierung auf die Bindung von RanGTP an Transportrezeptoren verbesserte Kristalle der Crm1:Substrat:RanGTP K71Ac und K99Ac und damit verbunden verbesserte Beugungsdaten Empfehlenswert, sowie die Kristallisation von Komplexen bestehend aus Crm1:Substrat und den Ran Mutanten K37Ac, K38Ac, K60Ac und K159Ac. Im Zuge dessen auch die Kristallisation der Ran Acetyllysin Mutanten im Komplex mit Imp $\beta$, sowie RCC1, NTF2 und RanGAP1. Dies würde Strukturell den Ran Zyklus sowie die in der Mitose verwendeten Transportrezeptoren abdecken. Zur Ermittlung verlässlicherer $\mathrm{K}_{\mathrm{D}^{-}}$ Werte und Thermodynamischer Daten sollte über Isothermale Titrationskalometie (ITC) erfolgen. Für Genauere Erkenntnisse hinsichtlich der biologischen Funktion im Kerntransport lassen sich in vitro Kernimport und Kernexport Assay durchführen, sowie der Transportassay mit permeabilisierten Zellen. Des Weiteren lassen sich kinetische Daten (z.B. $\mathrm{K}_{\mathrm{m}}, \mathrm{V}_{\max }$ ) von acetyliertem Ran ermitteln. Über den Zeitpunkt, an dem die Acetylierung der kleinen GTPase Ran in der Zelle stattfindet ist bislang noch nichts bekannt. In dieser Arbeit wurde der Einfluss einer einzelnen Acetylgruppe auf die kleine GTPase Ran untersucht. Tatsächlich ist noch nicht geklärt, ob die kleine GTPase nur jeweils an einer Stelle acetyliert wird oder für eine jeweilige Einflussnahme seitens der Zelle eine bestimmte Kombination der Acetylierung bedarf. Um die Auswirkungen einer Acetylierung der kleinen GTPase Ran in ihrem vollen Umfang zu verstehen sind daher weitere Untersuchungen erforderlich. 


\section{Zusammenfassung}

Der Zellkern ist das herausragende Merkmal einer jeden eukaryotischen Zelle. Da der Zellkern nahezu die gesamte genetische Information enthält trennt er die Transkription von der Translation. Diese Trennung erfordert einen bidirektionalen Prozess aufgeteilt in Import und Export von Makromolekülen durch die Kernporenkomplex (NPC) den Kerntransport. Dieser Prozess wird weitgehend durch Rezeptoren der Karyopherin- $\beta$ Superfamilie vermittelt. Die treibende Kraft hinter dem Kerntransport ist ein Gradient der kleinen GTPase Ran über die Kernhülle. Dieses Protein und sein Gradient bilden zugleich einen wichtigen Bestandteil bei der Organisation der Mitosespindel und dem wieder Aufbau der Kernhülle in der Mitose. Ran erscheint in einer GTP- und einer GDPgebundenen Form. Die GTPase wechselt zwischen diesen beiden Konformationen aufgrund der Wirkung von regulatorischen Faktoren (in beiden Prozessen dieselben) und lenkt und regelt damit den Kerntransport, sowie die Organisation der Mitosespindel und den Neuaufbau der Kernhülle. Kürzlich wurde entdeckt, dass die kleine GTPase Ran einer posttranslationalen Acetylierung auf mehreren Lysinresten unterliegt (Choudhary et al., 2009).

In dieser Arbeit wurde die kleine GTPase Ran mit acetyliertem Lysin (K37, K38, K60, K71, K99 und K159) exprimiert, gereinigt und funktional sowie strukturell im Komplex mit dem Exportrezeptor Crm1 analysiert. Dabei konnte gezeigt werden, dass die Acetylierung der GTPase an nur einem Lysin keine Auswirkung auf die Bindung der GTPase an die Transportrezeptoren Crm1 und $\operatorname{Imp} \beta$ zeigt. Jedoch konnte festgestellt werden, dass die Acetylierung an einzelnen Lysinen eine Auswirkung auf die RanGAP1 induzierte GTP-Hydrolyse der GTPase im Komplex mit Crm1 und Imp7, sowie auf die GTPase alleine zeigt. Die Acetylierungen an bestimmten Lysinen zeigte auch bei hohen Konzentrationen Crm1/Imp7 noch GTP-Hydrolyse. In Kombination mit Imp $\beta$ konnte diese Beobachtung nicht gemacht werden. Diese Proteine sind sowohl am Kerntransport wie auch der Mitose beteiligt. Auf die GTPase alleine zeigt die Acetylierung, je nach acetyliertem Lysine, eine beschleunigende bzw. verlangsamende Wirkung. Strukturell zeigen die acetylierten Mutanten (K71Ac und K99Ac) bis auf eine zusätzliche Interaktion zwischen dem Asp91 ${ }^{\text {Ran }}$ und dem Arg887 ${ }^{\text {Crm1 }}$, sowie dem Auftreten des $K 71^{\text {Ran }}$ in einer Schleife der Switch 2 Region keinen gravierender Unterschied zu der bereits gelösten Struktur Crm1:RanGTP:SPN1(Monecke et al., 2009; PDB Id 3GJX). 
Die in dieser Arbeit vorgestellten Ergebnisse ermöglichen eine Eindruck der Funktion einer Acetylierung der kleinen GTPase Ran, die wahrscheinlich in der Modulation und Feinabstimmung der RanGTP abhängigen Vorgänge im Kerntransport und der Mitose.

\section{Summery}

The nucleus is the most prominent feature of every eukaryotic cell. Since the nucleus contains virtually all the genetic information it separates the transcription and translation. This separation requires a bidirectional process divided into import and export of macromolecules through the nuclear pore complex (NPC) the nuclear transport. This process is largely mediated by receptors of the karyopherin- $\beta$ superfamily. The driving force behind the nuclear transport is a gradient of the small GTPase Ran across the nuclear envelope. This protein and its gradient simultaneously form an important part in the organization of mitotic spindle and the reconstruction of the nuclear envelope in mitosis. Ran appears in a GTP- and a GDP-bound form. The GTPase switches between these two conformations due to the action of regulatory factors (in both processes the same) and thus directs and regulates the nuclear transport, as well as the organization of the mitotic spindle and the reconstruction of the nuclear envelope. Recently it was discovered that the small GTPase Ran is subject to posttranslational acetylation on multiple lysine residues (Choudhary et al., 2009b).

In this work the small GTPase Ran with acetylated lysine (K37, K38, K60, K71, K99 and K159) was expressed, purified and analyzed functionally as well as structurally in complex with the export receptor Crm1. It could be shown that acetylation of the GTPase at only one lysine has no effect on the binding of the GTPase to the transport receptors Crm 1 and $\operatorname{Imp} \beta$. However, it was found that acetylation of a single lysine effects the RanGAP1 induced GTP hydrolysis of GTPase in complex with Crm1 and Imp7 and on the GTPase alone. The acetylation at specific lysine's still showed GTP hydrolysis even at high concentrations of Crm1/Imp7. In combination with $\operatorname{Imp} \beta$ this could not be observed. These proteins are involved in both the nuclear transport as well as mitosis. On the GTPase alone the acetylation shows, depending on the acetylated lysine's, an accelerating or decelerating effect. Structurally the acetylated mutants (K71Ac and K99Ac) show an additional interaction between the Asp91 ${ }^{\text {Ran }}$ and the Arg887 ${ }^{\mathrm{Crm} 1}$, as well as the occurrence of $\mathrm{K} 71^{\text {Ran }}$ in a loop in the switch 2 region with no further significant difference to the already solved structure Crm1:RanGTP:SPN1 (Monecke et . al, 2009; PDB Id 3GJX). 
The results presented in this work allow an impression of the function of the acetylated small GTPase Ran, probably in the modulation and fine tuning of the RanGTP-dependent processes in nuclear transport and mitosis.

\section{Abkürzungsverzeichnis}

\begin{tabular}{|c|c|}
\hline ' & Minuten \\
\hline$"$ & Sekunden \\
\hline$\rho(x y z)$ & Elektronendichte \\
\hline$\alpha$ & alpha \\
\hline A & Absorption \\
\hline$\AA$ & Angström [1 $\AA$ = 0.1 nm] \\
\hline Abb. & Abbildung \\
\hline AS & Aminosäuren \\
\hline Asp & Aspartat \\
\hline ATP & Adenosintriphosphat \\
\hline $\mathrm{AU}$ & Asymmetrische Einheit \\
\hline$\beta$ & beta \\
\hline $\mathrm{B}$ & Temperaturfaktor $\left[\AA^{3}\right]$ \\
\hline bp & Basenpaare \\
\hline $\mathrm{C}$ & Konzentration [M] \\
\hline $\mathrm{C}$ & Cytosin \\
\hline${ }^{\circ} \mathrm{C}$ & Grad Celsius \\
\hline $\mathrm{CBC}$ & cap binding complex \\
\hline $\mathrm{CBP}$ & cap binding protein \\
\hline CIP & calf intestine phosphatase \\
\hline $\mathrm{cm}$ & Zentimeter \\
\hline cps & counts per second \\
\hline cNLS & classical nuclear localistion signal \\
\hline Crm1 & chromosome region maintenance 1 \\
\hline $\mathrm{CV}$ & Säulenvolumen \\
\hline $\mathrm{d}$ & Tage \\
\hline $\mathrm{Da}$ & Dalton $[\mathrm{g} / \mathrm{mol}]$ \\
\hline ddH2O & bidestilliertes Wasser \\
\hline
\end{tabular}




\begin{tabular}{|c|c|}
\hline ddNTP & Didesoxynukleotidtriphosphat \\
\hline DESY & Deutsches Elektronen-Synchrotron, Hamburg \\
\hline DMSO & Dimethylsulfoxid \\
\hline DNA & Desoxyribonukleinsäure \\
\hline dsDNA & doppelsträngige DNA \\
\hline DTT & Dithiothreitol \\
\hline E. coli & Escherichia coli \\
\hline EDTA & $\mathrm{N}, \mathrm{N}, \mathrm{N}^{\prime}, \mathrm{N}^{\prime}$ Ethylendiamintetraactetat \\
\hline et al. & et altera \\
\hline $\mathrm{EtOH}$ & Ethanol \\
\hline $\mathrm{F}_{\text {calc }}$ & Berechnete Strukturfaktoren \\
\hline $\mathrm{F}_{\mathrm{obs}}$ & Beobachtete Strukturfaktoren \\
\hline$\gamma$ & gamma \\
\hline G & Guanin \\
\hline GDPNP & 5'-Guanylylimidodiphosphat \\
\hline GSH & reduziertes Glutathion \\
\hline GST & Glutathion-S-Transferase \\
\hline GTP & Guanosintriphosphat \\
\hline h & Stunden \\
\hline $\mathrm{H}$ & Histidin \\
\hline h. s. & Homo sapiens \\
\hline HEAT & Huntingtin-Elongation-Factor-A-Subunit-TOR \\
\hline HeLa & Henrietta Lacks \\
\hline HEPES & N-(2-Hydroxyethyl)-piperazin-N'-2-ethansulfonat \\
\hline HPLC & High Performance Liquid Chromatography \\
\hline IMAC & Ion-Metal-Affinity-Chromatography \\
\hline Imp & Importin \\
\hline IPTG & Isopropyl- $\square$ D-isothiogalactosid \\
\hline ITC & Isotherme Titrationskalorimetrie \\
\hline $\mathrm{k}$ & kilo (als präfix) \\
\hline K, Lys & Lysin \\
\hline $\mathrm{K}_{\mathrm{d}}$ & Dissoziationskonstante \\
\hline $\mathrm{kb}$ & Kilobasen \\
\hline LB & Luria Bertani \\
\hline
\end{tabular}


$\lambda$

1

$\mu$

$\mathrm{m}$

M

$\mathrm{mAu}$

mRNA

MW

n

NES

NLS

NPC

NTF2

Nup

OD

PBS

PCR

PDB

PHAX

PIMT

PMSF

prä-mRNA

PRIP

Ran

RanBP

RanGAP

RanGEF

RNA

rpm

rRNA

RT

S. cerevisiae
Wellenlänge [nm]

Liter

mikro (als Präfix)

milli (als präfix)

Molarität

Milliabsorptionseinheiten

Messenger RNA

Molekulargewicht [g/mol]

nano (als Präfix)

Nuclear export signal

Nuclear localisation signal

nuclear pore complex, Kernporenkomplex

Nuclear transport factor 2

Nucleoporin

Optische Dichte

Phosphat-gepufferte Salzlösung

Polymerasekettenreaktion

Protein Data Bank

Phosphorylated adapter for RNA export

PRIP-interacting protein with methyltransferase

domain

Phenylmethylsulfonylfluorid

mRNA-Vorläufer

peroxisome proliferator-activated receptor

interacting protein

Ras-related nuclear antigen

Ran binding protein

Ran GTPase activating protein

Ran guanine nucleotide exchange factor

Ribonukleinsäure

rounds per minute

ribosomal RNA

Raumtemperatur

Saccharomyces cerevisiae 


\begin{tabular}{|c|c|}
\hline SDS & Natriumdodecylsulfat \\
\hline SDS-PAGE & SDS-Polyacrylamidgelelektrophorese \\
\hline snRNA & small nuclear RNA \\
\hline snRNP & small nuclear Ribonucleoprotein \\
\hline SPN1 & Snurportin 1 \\
\hline Tab. & Tabelle \\
\hline Taq & Thermus aquaticus \\
\hline TBE & Tris-Borsäure-EDTA-Puffer \\
\hline TEMED & $\mathrm{N}, \mathrm{N}, \mathrm{N}^{\prime}, \mathrm{N}^{\prime}$ Tetramethylethylendiamin \\
\hline $\mathrm{T}_{\mathrm{m}}$ & Schmelztemperatur \\
\hline Tris & Tris(hydroxymethyl)-aminomethan \\
\hline tRNA & transfer RNA \\
\hline $\mathrm{U}$ & Unit (Einheit der Enzymaktivität) \\
\hline U snRNP & Uridinrich small nuclear ribonucleoprotein \\
\hline UV & Ultraviolett \\
\hline $\mathrm{V}$ & Volumen \\
\hline vgl. & vergleiche \\
\hline $\mathrm{v} / \mathrm{v}$ & Volumenprozent (volume per volume) \\
\hline $\mathrm{w} / \mathrm{v}$ & Gewichtsprozent (weight per volume) \\
\hline $\mathrm{X}$. laevis & Xenopus laevis \\
\hline $\mathrm{x} \mathrm{g}$ & Vielfaches der Erdbeschleunigung ( $g=9,81 \mathrm{~m} / \mathrm{s}^{2}$ ) \\
\hline z.B. & zum Beispiel \\
\hline Xpo1 & Exportin1 \\
\hline$\varepsilon$ & molarer Extinktionskoeffizient [M-1 cm-1] \\
\hline
\end{tabular}

Nicht angegebene Abkürzungen für physikalische Größen und deren Einheiten entsprechen dem SISystem. 


\section{Literaturverzeichnis}

Akey, C.W., and Radermacher, M. (1993). Architecture of the Xenopus nuclear pore complex revealed by three-dimensional cryo-electron microscopy. J. Cell Biol. 122, 1-19.

Askjaer, P., Bachi, A., Wilm, M., Bischoff, F.R., Weeks, D.L., Ogniewski, V., Ohno, M., Niehrs, C., Kjems, J., Mattaj, I.W., et al. (1999). RanGTP-regulated interactions of CRM1 with nucleoporins and a shuttling DEAD-box helicase. Mol. Cell. Biol. 19, 6276-6285.

Baake, M., Bäuerle, M., Doenecke, D., and Albig, W. (2001). Core histones and linker histones are imported into the nucleus by different pathways. Eur. J. Cell Biol. 80, 669677.

Di Bari, M.G., Ciuffini, L., Mingardi, M., Testi, R., Soddu, S., and Barilà, D. (2006). c-Abl acetylation by histone acetyltransferases regulates its nuclear-cytoplasmic localization. EMBO Rep. 7, 727-733.

Bäuerle, M., Doenecke, D., and Albig, W. (2002). The requirement of H1 histones for a heterodimeric nuclear import receptor. J. Biol. Chem. 277, 32480-32489.

Beck, M., Förster, F., Ecke, M., Plitzko, J.M., Melchior, F., Gerisch, G., Baumeister, W., and Medalia, O. (2004). Nuclear pore complex structure and dynamics revealed by cryoelectron tomography. Science 306, 1387-1390.

Beck, M., Lucić, V., Förster, F., Baumeister, W., and Medalia, O. (2007). Snapshots of nuclear pore complexes in action captured by cryo-electron tomography. Nature 449, 611615.

Bird, S.L., Heald, R., and Weis, K. (2013). RanGTP and CLASP1 cooperate to position the mitotic spindle. Mol. Biol. Cell 24, 2506-2514.

Bischoff, F.R., and Görlich, D. (1997). RanBP1 is crucial for the release of RanGTP from importin beta-related nuclear transport factors. FEBS Lett. 419, 249-254.

Bischoff, F.R., and Ponstingl, H. (1991). Catalysis of guanine nucleotide exchange on Ran by the mitotic regulator RCC1. Nature 354, 80-82.

Bischoff, F.R., Klebe, C., Kretschmer, J., Wittinghofer, a, and Ponstingl, H. (1994).

RanGAP1 induces GTPase activity of nuclear Ras-related Ran. Proc. Natl. Acad. Sci. U. S. A. 91, 2587-2591.

Bischoff, F.R., Krebber, H., Smirnova, E., Dong, W., and Ponstingl, H. (1995). Coactivation of RanGTPase and inhibition of GTP dissociation by Ran-GTP binding protein RanBP1. EMBO J. 14, 705-715.

Blanco-García, N., Asensio-Juan, E., de la Cruz, X., and Martínez-Balbás, M.A. (2009). Autoacetylation regulates P/CAF nuclear localization. J. Biol. Chem. 284, 1343-1352. 
Bono, F., Cook, A.G., Grünwald, M., Ebert, J., and Conti, E. (2010). Nuclear import mechanism of the EJC component Mago-Y14 revealed by structural studies of importin 13. Mol. Cell 37, 211-222.

Bos, J.L., Rehmann, H., and Wittinghofer, A. (2007). Review GEFs and GAPs : Critical Elements in the Control of Small G Proteins. 865-877.

Chaillan-Huntington, C., Braslavsky, C. V, Kuhlmann, J., and Stewart, M. (2000). Dissecting the interactions between NTF2, RanGDP, and the nucleoporin XFXFG repeats. J. Biol. Chem. 275, 5874-5879.

Chook, Y.M., and Blobel, G. (1999). Structure of the nuclear transport complex karyopherin-beta2-Ran x GppNHp. Nature 399, 230-237.

Chook, Y.M., and Blobel, G. (2001). Karyopherins and nuclear import. Curr. Opin. Struct. Biol. 11, 703-715.

Chook, Y.M., and Gunter, B. (1999). Structure of the nuclear transport complex karyopherin-beta2-RanGppNHp. Nature 399.

Chook, Y.M., Cingolani, G., Conti, E., Stewart, M., Vetter, I., and Wittinghofer, A. (1999). Pictures in cell biology. Structures of nuclear-transport components. Trends Cell Biol. 9, 310-311.

Choudhary, C., Kumar, C., Gnad, F., Nielsen, M.L., Rehman, M., Walther, T.C., Olsen, J. V, and Mann, M. (2009). Lysine acetylation targets protein complexes and co-regulates major cellular functions. Science 325, 834-840.

Cingolani, G., Petosa, C., Weis, K., and Müller, C.W. (1999). Structure of importin-beta bound to the IBB domain of importin-alpha. Nature 399, 221-229.

Clarke, P.R., and Zhang, C. (2008). Spatial and temporal coordination of mitosis by Ran GTPase. Nat. Rev. Mol. Cell Biol. 9, 464-477.

Cohen, T., and Yao, T.-P. (2004). AcK-knowledge reversible acetylation. Sci. STKE 2004, pe42.

Conti, E., and Izaurralde, E. (2001). Nucleocytoplasmic transport enters the atomic age. Curr. Opin. Cell Biol. 13, 310-319.

Cook, A., Bono, F., Jinek, M., and Conti, E. (2007). Structural biology of nucleocytoplasmic transport. Annu. Rev. Biochem. 76, 647-671.

Corbett, A.H., Koepp, D.M., Schlenstedt, G., Lee, M.S., Hopper, A.K., and Silver, P.A. (1995). Rna1p, a Ran/TC4 GTPase activating protein, is required for nuclear import. J. Cell Biol. 130, 1017-1026.

Cronshaw, J.M., Krutchinsky, A.N., Zhang, W., Chait, B.T., and Matunis, M.J. (2002). Proteomic analysis of the mammalian nuclear pore complex. J. Cell Biol. 158, 915-927. 
Damelin, M., Silver, P.A., and Corbett, A.H. (2002). Nuclear protein transport. Methods Enzymol. 351, 587-607.

Denning, D.P., and Rexach, M.F. (2007). Rapid evolution exposes the boundaries of domain structure and function in natively unfolded FG nucleoporins. Mol. Cell. Proteomics 6, 272-282.

Dietschy, T., Shevelev, I., Pena-Diaz, J., Hühn, D., Kuenzle, S., Mak, R., Miah, M.F., Hess, D., Fey, M., Hottiger, M.O., et al. (2009). p300-mediated acetylation of the Rothmund-Thomson-syndrome gene product RECQL4 regulates its subcellular localization. J. Cell Sci. 122, 1258-1267.

Floer, M., and Blobel, G. (1996). The nuclear transport factor karyopherin $\beta$ binds stoichiometrically to Ran-GTP and inhibits the Ran GTPase activating protein. J. Biol. Chem. 271, 5313-5316.

Frey, S., and Görlich, D. (2009). FG/FxFG as well as GLFG repeats form a selective permeability barrier with self-healing properties. EMBO J. 28, 2554-2567.

Frey, S., Richter, R.P., and Görlich, D. (2006). FG-rich repeats of nuclear pore proteins form a three-dimensional meshwork with hydrogel-like properties. Science 314, 815-817.

Fried, H., and Kutay, U. (2003). Nucleocytoplasmic transport: taking an inventory. Cell. Mol. Life Sci. 60, 1659-1688.

Görlich, D., and Kutay, U. (1999). Transport between the cell nucleus and the cytoplasm. Annu. Rev. Cell Dev. Biol. 15, 607-660.

Görlich, D., and Mattaj, I.W. (1996). Nucleocytoplasmic transport. Science 271, 15131518.

Görlich, D., Panté, N., Kutay, U., Aebi, U., and Bischoff, F.R. (1996). Identification of different roles for RanGDP and RanGTP in nuclear protein import. EMBO J. 15, 55845594.

Guarguaglini, G., Renzi, L., D’Ottavio, F., Di Fiore, B., Casenghi, M., Cundari, E., and Lavia, P. (2000). Regulated Ran-binding protein 1 activity is required for organization and function of the mitotic spindle in mammalian cells in vivo. Cell Growth Differ. 11, 455465.

Guertin, D.A., Trautmann, S., and Mccollum, D. (2002). Cytokinesis in Eukaryotes Cytokinesis in Eukaryotes. 66.

Guiochon-Mantel, A., Delabre, K., Lescop, P., and Milgrom, E. (1994). Nuclear localization signals also mediate the outward movement of proteins from the nucleus. Proc. Natl. Acad. Sci. U. S. A. 91, 7179-7183.

Hughes, M., Zhang, C., Avis, J.M., Hutchison, C.J., and Clarke, P.R. (1998). The role of the ran GTPase in nuclear assembly and DNA replication: characterisation of the effects of Ran mutants. J. Cell Sci. 111 ( Pt 2, 3017-3026. 
Imoto, Y., Yoshida, Y., Yagisawa, F., Kuroiwa, H., and Kuroiwa, T. (2011). The cell cycle, including the mitotic cycle and organelle division cycles, as revealed by cytological observations. J. Electron Microsc. (Tokyo). 60 Suppl 1, S117-S136.

Inuzuka, H., Gao, D., Finley, L.W.S., Yang, W., Wan, L., Fukushima, H., Chin, Y.R., Zhai, B., Shaik, S., Lau, A.W., et al. (2012). Acetylation-dependent regulation of Skp2 function. Cell 150, 179-193.

Izaurralde, E., Kutay, U., von Kobbe, C., Mattaj, I.W., and Görlich, D. (1997). The asymmetric distribution of the constituents of the Ran system is essential for transport into and out of the nucleus. EMBO J. 16, 6535-6547.

Jäkel, S., Albig, W., Kutay, U., Bischoff, F.R., Schwamborn, K., Doenecke, D., and Görlich, D. (1999). The importin beta/importin 7 heterodimer is a functional nuclear import receptor for histone H1. EMBO J. 18, 2411-2423.

Joseph, J. (2006). Ran at a glance. J. Cell Sci. 119, 3481-3484.

Joseph, J., Liu, S.-T., Jablonski, S.A., Yen, T.J., and Dasso, M. (2004). The RanGAP1RanBP2 complex is essential for microtubule-kinetochore interactions in vivo. Curr. Biol. 14, 611-617.

Kalab, P., and Heald, R. (2008). The RanGTP gradient - a GPS for the mitotic spindle. J. Cell Sci. 121, 1577-1586.

Kalderon, D., Richardson, W.D., Markham, A.F., and Smith, A.E. (1984). Sequence requirements for nuclear location of simian virus 40 large-T antigen. Nature 311, 33-38.

Kamieniarz, K., and Schneider, R. (2009). Tools to tackle protein acetylation. Chem. Biol. 16, 1027-1029.

Kehlenbach, R.H., Dickmanns, A, Kehlenbach, A, Guan, T., and Gerace, L. (1999). A role for RanBP1 in the release of CRM1 from the nuclear pore complex in a terminal step of nuclear export. J. Cell Biol. 145, 645-657.

Kehlenbach, R.H., Assheuer, R., Kehlenbach, A, Becker, J., and Gerace, L. (2001). Stimulation of nuclear export and inhibition of nuclear import by a Ran mutant deficient in binding to Ran-binding protein 1. J. Biol. Chem. 276, 14524-14531.

Kent, H.M., Moore, M.S., Quimby, B.B., Baker, A M., McCoy, A J., Murphy, G. a, Corbett, a H., and Stewart, M. (1999). Engineered mutants in the switch II loop of Ran define the contribution made by key residues to the interaction with nuclear transport factor 2 (NTF2) and the role of this interaction in nuclear protein import. J. Mol. Biol. 289, 565-577.

Kim, G.-W., Gocevski, G., Wu, C.-J., and Yang, X.-J. (2010). Dietary, metabolic, and potentially environmental modulation of the lysine acetylation machinery. Int. J. Cell Biol. 2010, 632739. 
Kim, S.C., Sprung, R., Chen, Y., Xu, Y., Ball, H., Pei, J., Cheng, T., Kho, Y., Xiao, H., Xiao, L., et al. (2006). Substrate and functional diversity of lysine acetylation revealed by a proteomics survey. Mol. Cell 23, 607-618.

Klebe, C., Bischoff, F.R., Ponstingl, H., and Wittinghofer, a (1995). Interaction of the nuclear GTP-binding protein Ran with its regulatory proteins RCC1 and RanGAP1. Biochemistry 34, 639-647.

Kobayashi, J., and Matsuura, Y. (2013). Structural basis for cell-cycle-dependent nuclear import mediated by the karyopherin Kap121p. J. Mol. Biol. 425, 1852-1868.

Koyama, M. (2010). An allosteric mechanism to displace nuclear export cargo from CRM1 and RanGTP by RanBP1. EMBO J. 29, 2002-2013.

Kuersten, S., Ohno, M., and Mattaj, I.W. (2001). Nucleocytoplasmic transport: Ran, beta and beyond. Trends Cell Biol. 11, 497-503.

Lanford, R.E., and Butel, J.S. (1984). Construction and characterization of an SV40 mutant defective in nuclear transport of $\mathrm{T}$ antigen. Cell 37, 801-813.

Lanford, R.E., Kanda, P., and Kennedy, R.C. (1986). Induction of nuclear transport with a synthetic peptide homologous to the SV40 T antigen transport signal. Cell 46, 575-582.

Lee, S.J., Matsuura, Y., Liu, S.M., and Stewart, M. (2005). Structural basis for nuclear import complex dissociation by RanGTP. Nature 435, 693-696.

Liu, C.C., and Schultz, P.G. (2010). Adding new chemistries to the genetic code. Annu. Rev. Biochem. 79, 413-444.

Macara, I.G. (2001). Transport into and out of the nucleus. Microbiol. Mol. Biol. Rev. 65, 570-594, table of contents.

Maco, B., Fahrenkrog, B., Huang, N.-P., and Aebi, U. (2006). Nuclear pore complex structure and plasticity revealed by electron and atomic force microscopy. Methods Mol. Biol. 322, 273-288.

Madrid, A.S., and Weis, K. (2006). Nuclear transport is becoming crystal clear. Chromosoma 115, 98-109.

Matsuura, Y., and Stewart, M. (2004). Structural basis for the assembly of a nuclear export complex. Nature 432, 872-877.

Maurer, P., Redd, M., Solsbacher, J., Bischoff, F.R., Greiner, M., Podtelejnikov, A. V, Mann, M., Stade, K., Weis, K., and Schlenstedt, G. (2001). The nuclear export receptor Xpo1p forms distinct complexes with NES transport substrates and the yeast Ran binding protein 1 (Yrb1p). Mol. Biol. Cell 12, 539-549.

Melchior, F., Paschal, B., Evans, J., and Gerace, L. (1993). Inhibition of nuclear protein import by nonhydrolyzable analogues of GTP and identification of the small GTPase Ran/TC4 as an essential transport factor. J. Cell Biol. 123, 1649-1659. 
Mohr, D., Frey, S., Fischer, T., Güttler, T., and Görlich, D. (2009). Characterisation of the passive permeability barrier of nuclear pore complexes. EMBO J. 28, 2541-2553.

Monecke, T., Güttler, T., Neumann, P., Dickmanns, A., Görlich, D., and Ficner, R. (2009). Crystal structure of the nuclear export receptor CRM1 in complex with Snurportin1 and RanGTP. Science 324, 1087-1091.

Moore, M.S., and Blobel, G. (1993). The GTP-binding protein Ran/TC4 is required for protein import into the nucleus. Nature 365, 661-663.

Moore, M.S., and Blobel, G. (1994). A G protein involved in nucleocytoplasmic transport: the role of Ran. Trends Biochem. Sci. 19, 211-216.

Nanninga, N. (2001). Cytokinesis in Prokaryotes and Eukaryotes : Common Principles and Different Solutions Cytokinesis in Prokaryotes and Eukaryotes : Common Principles and Different Solutions. 65.

Nemergut, M.E., Mizzen, C.A., Stukenberg, T., Allis, C.D., and Macara, I.G. (2001). Chromatin docking and exchange activity enhancement of RCC1 by histones H2A and H2B. Science 292, 1540-1543.

Neumann, H., Peak-Chew, S.Y., and Chin, J.W. (2008). Genetically encoding N(epsilon)acetyllysine in recombinant proteins. Nat. Chem. Biol. 4, 232-234.

Neumann, H., Hancock, S.M., Buning, R., Routh, A., Chapman, L., Somers, J., OwenHughes, T., van Noort, J., Rhodes, D., and Chin, J.W. (2009). A method for genetically installing site-specific acetylation in recombinant histones defines the effects of H3 K56 acetylation. Mol. Cell 36, 153-163.

Nigg, E.A. (1997). Nucleocytoplasmic transport: signals, mechanisms and regulation. Nature 386, 779-787.

Okada, C., Yamashita, E., Lee, S.J., Shibata, S., Katahira, J., Nakagawa, A., Yoneda, Y., and Tsukihara, T. (2009). A high-resolution structure of the pre-microRNA nuclear export machinery. Science 326, 1275-1279.

Paine, P.L., Moore, L.C., and Horowitz, S.B. (1975). Nuclear envelope permeability. Nature 254, 109-114.

Panté, N., and Aebi, U. (1996). Molecular dissection of the nuclear pore complex. Crit. Rev. Biochem. Mol. Biol. 31, 153-199.

Partridge, J.R., and Schwartz, T.U. (2009). Crystallographic and biochemical analysis of the Ran-binding zinc finger domain. J. Mol. Biol. 391, 375-389.

Peters, R. (2006). Introduction to nucleocytoplasmic transport: molecules and mechanisms. Methods Mol. Biol. 322, 235-258.

Petosa, C., Schoehn, G., Askjaer, P., Bauer, U., Moulin, M., Steuerwald, U., Soler-López, M., Baudin, F., Mattaj, I.W., and Müller, C.W. (2004). Architecture of CRM1/Exportin1 
suggests how cooperativity is achieved during formation of a nuclear export complex. Mol. Cell 16, 761-775.

Polevoda, B., and Sherman, F. (2002). The diversity of acetylated proteins. Genome Biol. 3, reviews0006.

Pollard, T.D. (2010). Mechanics of cytokinesis in eukaryotes. Curr. Opin. Cell Biol. 22, 50-56.

Pollard, V.W., Michael, W.M., Nakielny, S., Siomi, M.C., Wang, F., and Dreyfuss, G. (1996). A novel receptor-mediated nuclear protein import pathway. Cell 86, 985-994.

Renault, L., Kuhlmann, J., Henkel, a, and Wittinghofer, a (2001). Structural basis for guanine nucleotide exchange on Ran by the regulator of chromosome condensation (RCC1). Cell 105, 245-255.

Ribbeck, K., Lipowsky, G., Kent, H.M., Stewart, M., and Görlich, D. (1998). NTF2 mediates nuclear import of Ran. EMBO J. 17, 6587-6598.

Robbins, J., Dilwortht, S.M., Laskey, R.A., and Dingwall, C. (1991). Two interdependent basic domains in nucleoplasmin nuclear targeting sequence: Identification of a class of bipartite nuclear targeting sequence. Cell 64, 615-623.

Rout, M.P., Aitchison, J.D., Suprapto, A., Hjertaas, K., Zhao, Y., and Chait, B.T. (2000). The yeast nuclear pore complex: composition, architecture, and transport mechanism. J. Cell Biol. 148, 635-651.

Sadoul, K., Wang, J., Diagouraga, B., and Khochbin, S. (2011). The tale of protein lysine acetylation in the cytoplasm. J. Biomed. Biotechnol. 2011, 970382.

Sasaki, K., Suzuki, A., Kagatsume, S., Ono, M., Matsuzawa, K., Taguchi, Y., and Kurihara, Y. (2012). Acetylation of Prrp K150 regulates the subcellular localization. Gene 491, 13-19.

Schwartz, T.U. (2005). Modularity within the architecture of the nuclear pore complex. Curr. Opin. Struct. Biol. 15, 221-226.

Seewald, M.J., Körner, C., Wittinghofer, A., and Vetter, I.R. (2002). RanGAP mediates GTP hydrolysis without an arginine finger. Nature 415, 662-666.

Seewald, M.J., Kraemer, A., Farkasovsky, M., Körner, C., Wittinghofer, A., and Vetter, I.R. (2003). Biochemical characterization of the Ran-RanBP1-RanGAP system: are RanBP proteins and the acidic tail of RanGAP required for the Ran-RanGAP GTPase reaction? Mol. Cell. Biol. 23, 8124-8136.

Söderqvist, H., Imreh, G., Kihlmark, M., Linnman, C., Ringertz, N., and Hallberg, E. (1997). Intracellular distribution of an integral nuclear pore membrane protein fused to green fluorescent protein--localization of a targeting domain. Eur. J. Biochem. 250, 808813. 
Sorokin, A. V., Kim, E.R., and Ovchinnikov, L.P. (2007). Nucleocytoplasmic transport of proteins. Biochem. 72, 1439-1457.

Spange, S., Wagner, T., Heinzel, T., and Krämer, O.H. (2009). Acetylation of non-histone proteins modulates cellular signalling at multiple levels. Int. J. Biochem. Cell Biol. 41, 185-198.

Stewart, M. (2007). Molecular mechanism of the nuclear protein import cycle. Nat. Rev. Mol. Cell Biol. 8, 195-208.

Stewart, M., Kent, H.M., and McCoy, a J. (1998a). Structural basis for molecular recognition between nuclear transport factor 2 (NTF2) and the GDP-bound form of the Ras-family GTPase Ran. J. Mol. Biol. 277, 635-646.

Stewart, M., Kent, H.M., and McCoy, a J. (1998b). The structure of the Q69L mutant of GDP-Ran shows a major conformational change in the switch II loop that accounts for its failure to bind nuclear transport factor 2 (NTF2). J. Mol. Biol. 284, 1517-1527.

Strasser, A., Dickmanns, A., Schmidt, U., Penka, E., Urlaub, H., Sekine, M., Lührmann, R., and Ficner, R. (2004). Purification, crystallization and preliminary crystallographic data of the m3G cap-binding domain of human snRNP import factor snurportin 1. Acta Crystallogr. Sect. D Biol. Crystallogr. 60, 1628-1631.

Tran, E.J., and Wente, S.R. (2006). Dynamic nuclear pore complexes: life on the edge. Cell 125, 1041-1053.

Vetter, I.R., Arndt, A., Kutay, U., Görlich, D., and Wittinghofer, A. (1999a). Structural view of the Ran-Importin beta interaction at 2.3 A resolution. Cell 97, 635-646.

Vetter, I.R., Arndt, A., Kutay, U., Görlich, D., and Wittinghofer, A. (1999b). Structural View of the Ran-Importin $\beta$ Interaction at $2.3 \AA$ Resolution. Cell 97, 635-646.

Wandke, C., and Kutay, U. (2013). Enclosing chromatin: reassembly of the nucleus after open mitosis. Cell 152, 1222-1225.

Weis, K. (2007). The Nuclear Pore Complex: Oily Spaghetti or Gummy Bear? Cell 130, 405-407.

Xue, J.Z., and Funabiki, H. (2014). Nuclear assembly shaped by microtubule dynamics. Nucleus 5, 40-46.

Yang, Q., Rout, M.P., and Akey, C.W. (1998). Three-dimensional architecture of the isolated yeast nuclear pore complex: functional and evolutionary implications. Mol. Cell 1, 223-234.

Yoneda, Y. (1997). How proteins are transported from cytoplasm to the nucleus. J. Biochem. 121, 811-817.

Yoneda, Y., Hieda, M., Nagoshi, E., and Miyamoto, Y. (1999). Nucleocytoplasmic protein transport and recycling of Ran. Cell Struct. Funct. 24, 425-433. 
Yudin, D., and Fainzilber, M. (2009). Ran on tracks--cytoplasmic roles for a nuclear regulator. J. Cell Sci. 122, 587-593.

\section{Anhang}

GSH-Sepharose

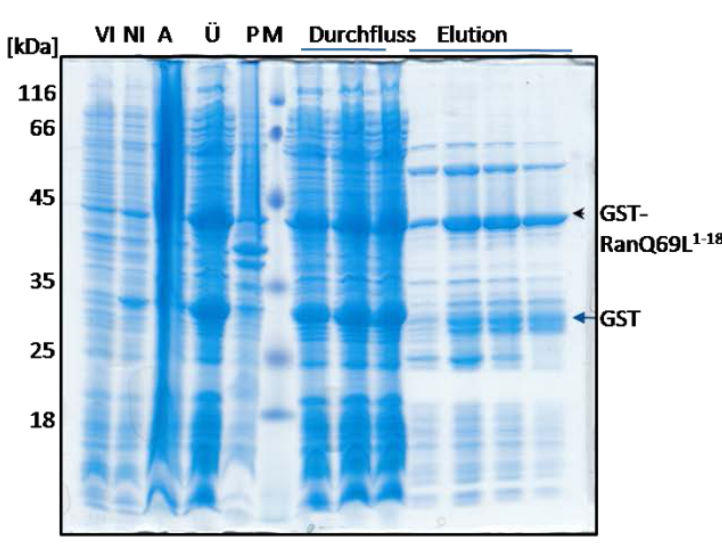

Superdex 75

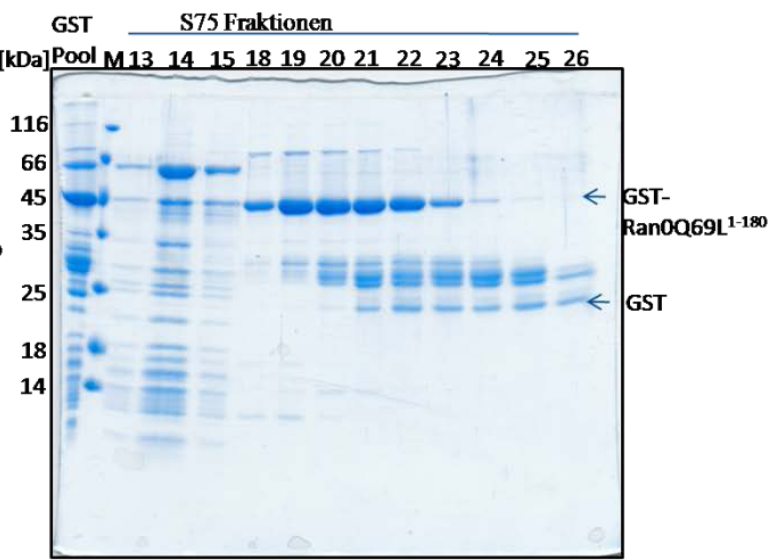

Abb. A1: Reinigung von GST-RanQ69L ${ }^{1-180}$. SDS-Gele der Reinigung von GST-RanQ69L ${ }^{1-180}$. Der jeweilige chrommatoraphische Schritt ist über dem SDS-Gel angegeben. M= Marker, Ein Pfeil markiert das GST-RanQ69L ${ }^{1-180}$ und GST. SDS -Gel der Affinitätschromatographie über GSH-Sepharose. In den ersten fünf Spuren des SDS-Gels sind Proben von vor der Induktion(VI), nach der Induktion (NI) und dem Aufschluss der Zellen aufgetragen ( $\mathrm{A}=$ Aufschluss nach Fluidizer, $\mathrm{P}$ das Pellet und Ü der Überstand nach Zentrifugation). In den ersten dreiSpuren nach dem Marker sind drei Fraktionen aus dem Durchfluss der GSH-Sepharose zu sehen, darauf folgt in den Spuren Proben der Elution. Im Durchfluss ist etwas GSTRanQ69L $\mathrm{L}^{1-180}$ zu erkennen. GST eluiert GST-RanQ69L ${ }^{1-180}$ bei einem apparenten Molekulargewicht von 47 kDa. Auf dem SDS-Gel der Gelfiltration Superdex 75 XK 26/60 sind die Elutionsfraktionen nummeriert angegeben, GST-Pool bezeichnet das nach GSH-Sepharose gepoolte und für die Gelfiltration eingesetzte Protein. 

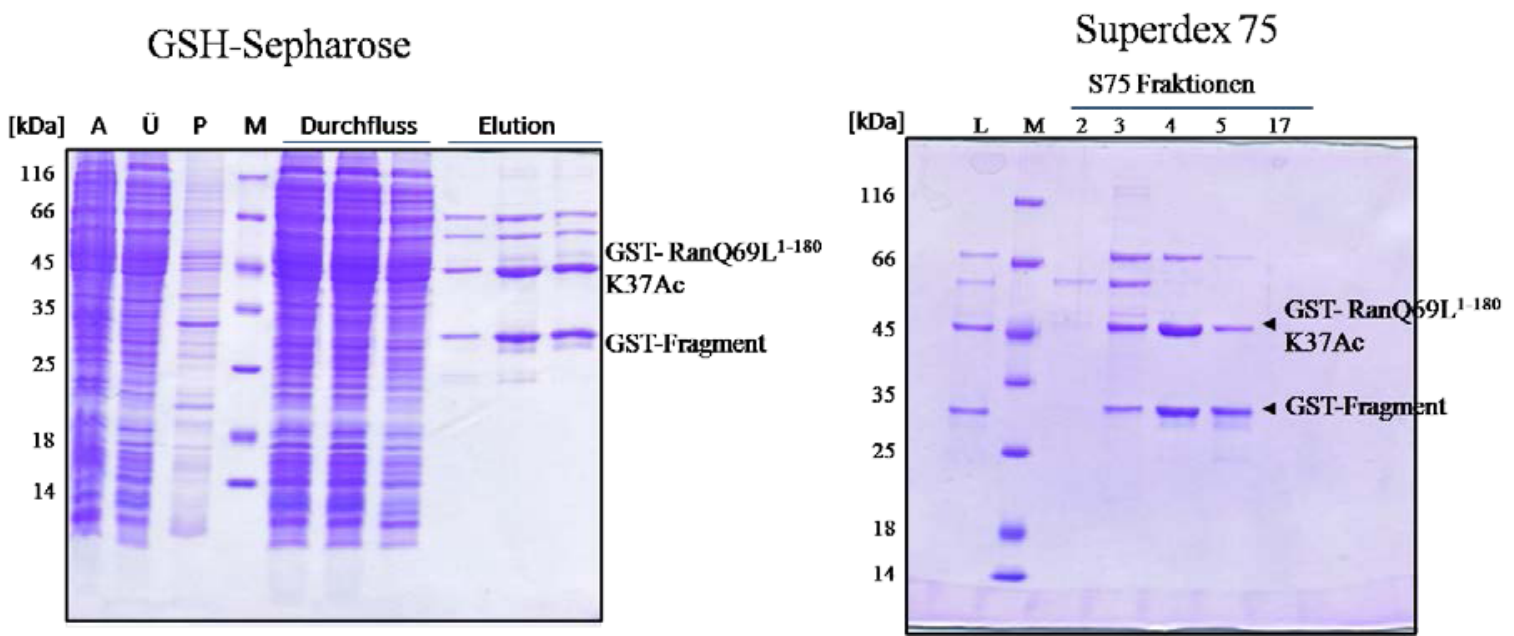

Abb. A2: Reinigung RanQ69L ${ }^{1-180}$ K37Ac. SDS-Gele der Reinigung von GST-RanQ69L ${ }^{1-180}$ K37Ac. Über den SDS-Gelen ist jeweilige chrommatoraphische Schritt angegeben. M= Marker, das GST-RanQ69L ${ }^{1-180}$ K37Ac und GST-Fragment markieren die jeweilige Proteinbande. Auf dem SDS -Gel der Affinitätschromatographie über GSH-Sepharose sind in den ersten drei Spuren des SDS-Gels sind Proben vom Aufschluss der Zellen aufgetragen $(\mathrm{A}=$ Aufschluss nach Fluidizer, $\mathrm{P}$ das Pellet und Ü der Überstand nach Zentrifugation) aufgetragen. In den ersten dreiSpuren nach dem Marker sind drei Fraktionen aus dem Durchfluss der GSH-Sepharose zu sehen, darauf folgt in den Spuren Proben der Elution. Im Durchfluss ist etwas GST-RanQ69L ${ }^{1-180}$ zu erkennen. Mit GST eluiert GST-RanQ69L ${ }^{1-180}$ bei einem apparenten Molekulargewicht von 47 kDa. Auf dem SDS-Gel der Gelfiltration Superdex 75 XK 26/60 sind die Elutionsfraktionen nummeriert angegeben, L bezeichnet das nach GSH-Sepharose gepoolte und für die Gelfiltration eingesetzte Protein.
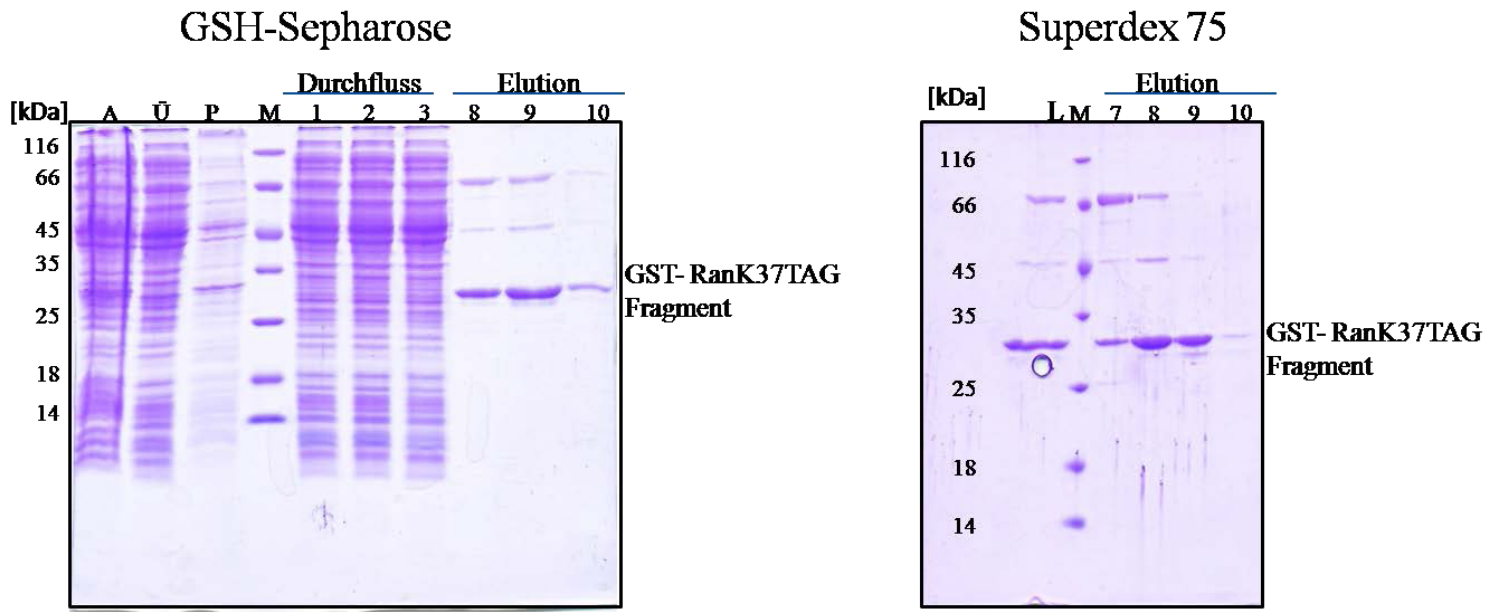

Abb. A3: Reinigung RanK37TAG Fragment. SDS-Gele der Reinigung von GST-RanQ69L ${ }^{1-180}$ K37Ac. Über den SDS-Gelen ist jeweilige chrommatoraphische Schritt angegeben. $\mathrm{M}=$ Marker, das GSTRanK37TAG Fragment markiert die jeweilige Proteinbande. Auf dem SDS -Gel der Affinitätschromatographie über GSH-Sepharose sind in den ersten drei Spuren des SDS-Gels sind Proben vom Aufschluss der Zellen aufgetragen $(\mathrm{A}=$ Aufschluss nach Fluidizer, $\mathrm{P}$ das Pellet und Ü der Überstand nach Zentrifugation) aufgetragen. In den ersten dreiSpuren nach dem Marker sind drei Fraktionen aus dem Durchfluss der GSH-Sepharose zu sehen, darauf folgt in den Spuren Proben der Elution. Mit GST eluiert das 
GST-RanK37TAG Fragment bei einem apparenten Molekulargewicht von 30 kDa. Auf dem SDS-Gel der Gelfiltration Superdex 75 XK 26/60 sind die Elutionsfraktionen nummeriert angegeben, L bezeichnet das nach GSH-Sepharose gepoolte und für die Gelfiltration eingesetzte Protein.
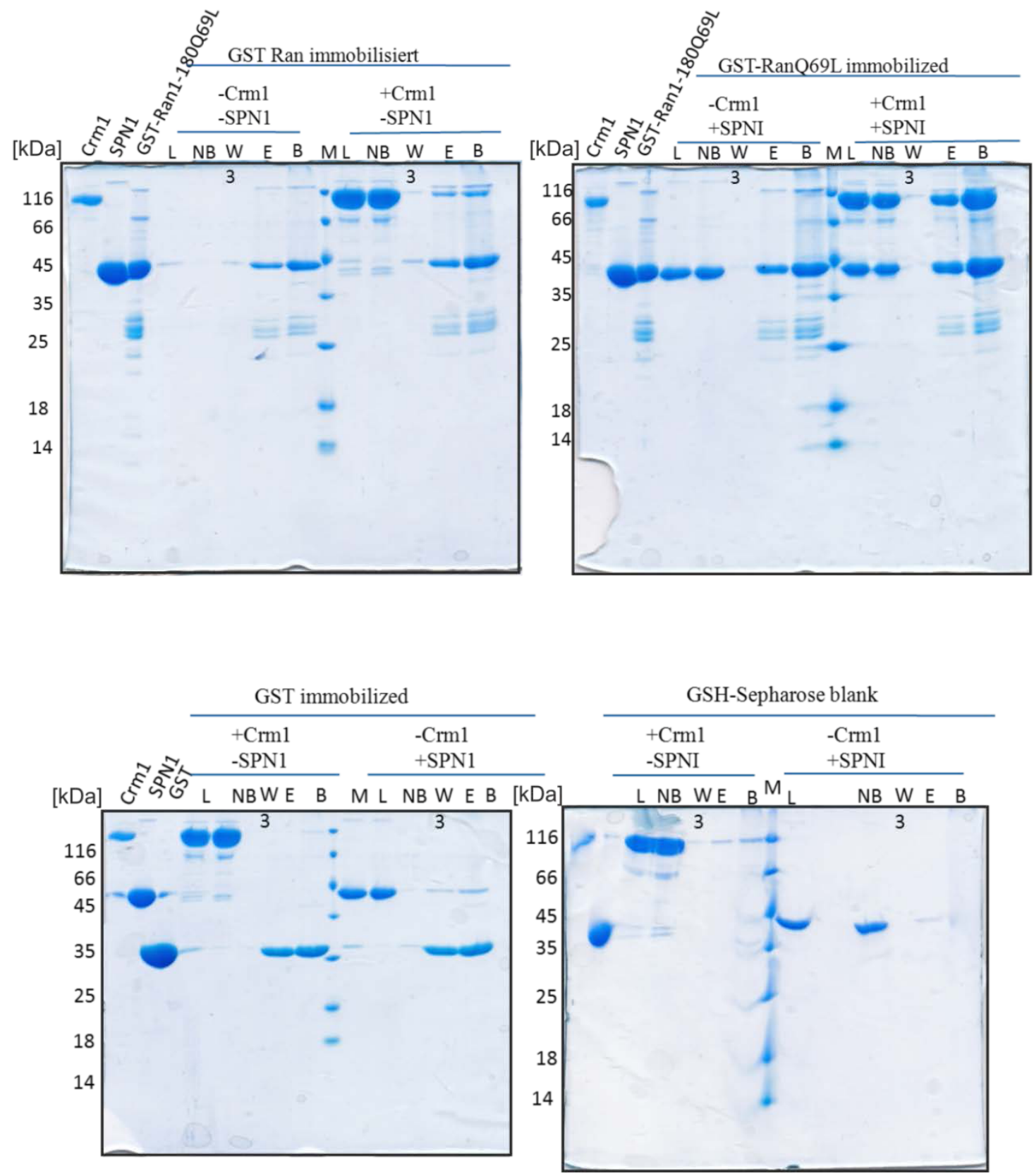

Abb. A4: Bindugsstudie von RanQ69L ${ }^{1-180}$ mit Crm1 über einen Pulldown-Assay. Gezeigt sind SDSGele nach erfolgter Coomassie-Färbung von immobilisiertem RanQ69L ${ }^{1-180}$, GST und die leerer GSHSepharose. Aufgetragen wurden Probe der Beladung mit Crm1 und/oder SPN1 (L), nach der Inkubation (NB), vom dritten Waschschritt (W3), der Elution des Pulldown-Assay (E) und der GSH-Sepharose nach der Elution. Der Marker (M) ist in kDa angegeben. Ein + Zeichen bezieht sich auf die Anwesenheit, während ein - Zeichen sich auf die Abwesenheit des damit bezeichneten Proteins. Crm1 interagiert mit immobilisiertem RanQ69L ${ }^{1-180}$, aber nicht mit GST oder der leeren GSH Separose 
A GST-RanQ69L ${ }^{1-180}$ immobilisiert
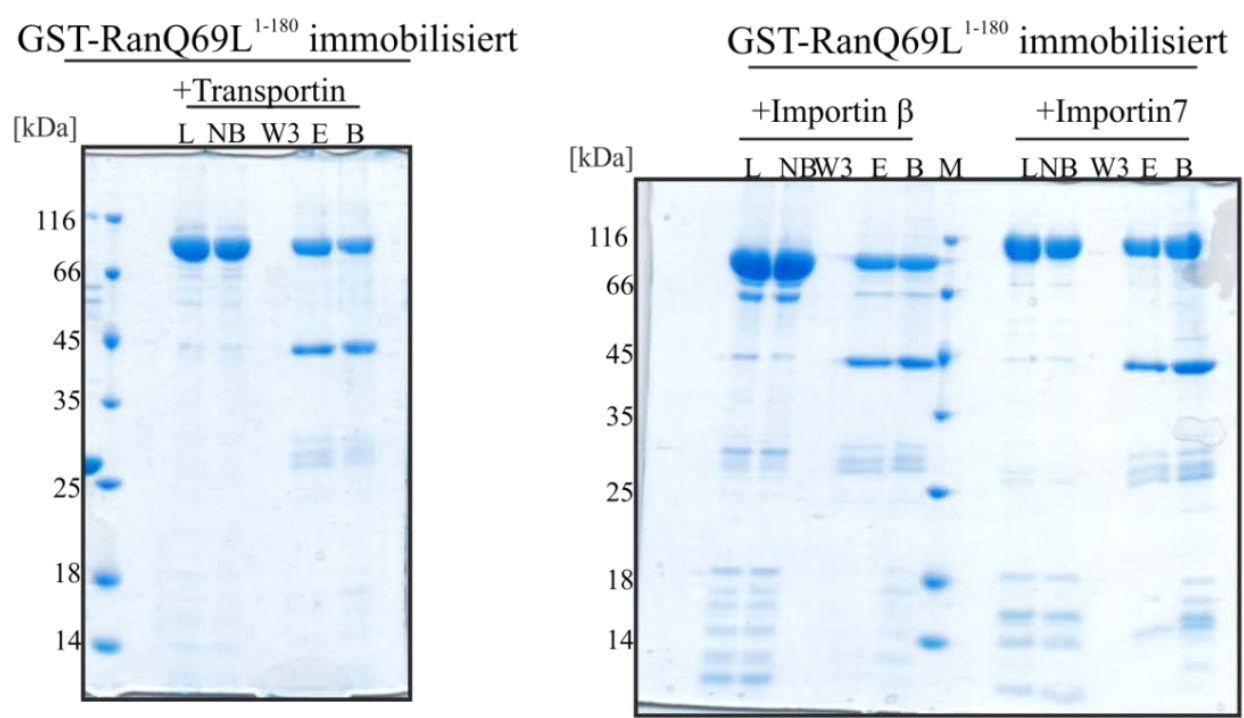

B

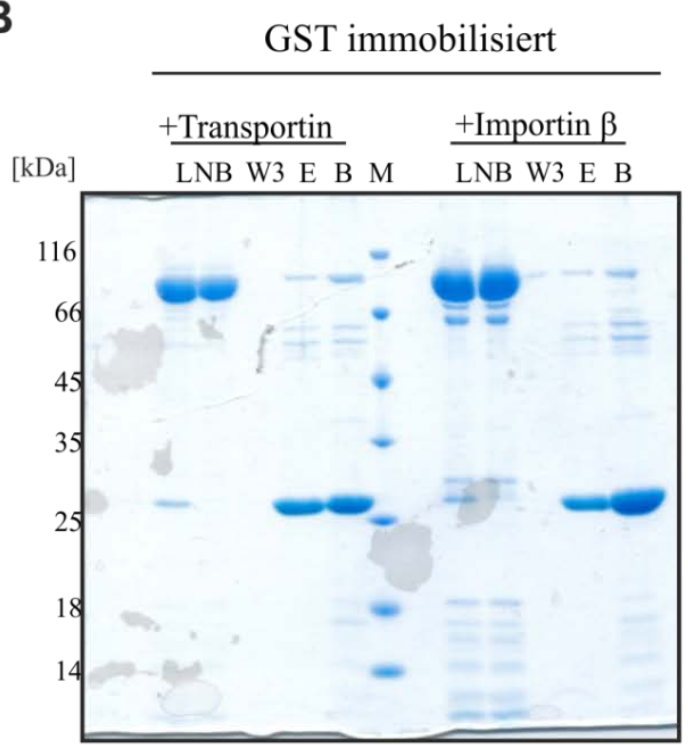

GST immobilisiert

C
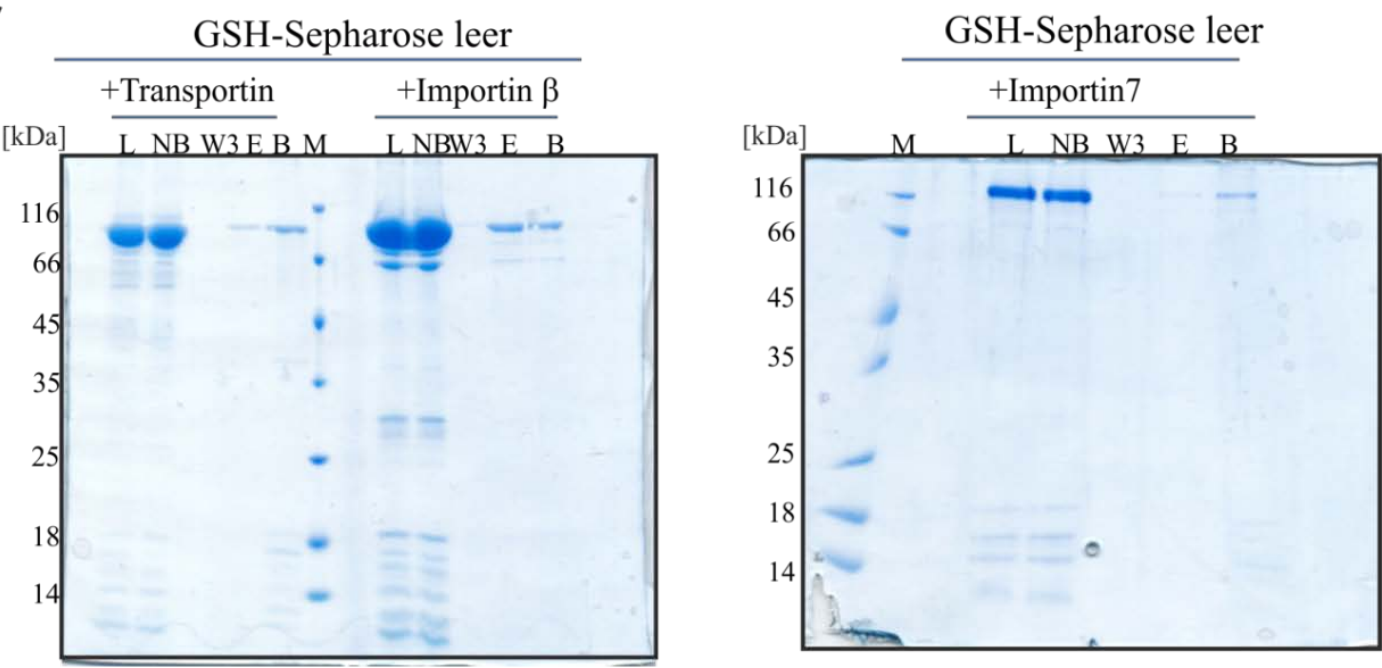

Abb. A5: Bindugsstudie von RanQ69L ${ }^{1-180}$ mit Importrezeporen über einen Pulldown-Assay. Gezeigt sind SDS-Gele nach Coomassie-Färbung von immobilisiertem RanQ69L ${ }^{1-180}$ (A), GST (B) und die leerer GSH-Sepharose (C). Aufgetragen wurden Probe der Beladung mit Importrezeptor (L), nach der Inkubation (NB), vom dritten Waschschritt (W3), der Elution des Pulldown-Assay (E) und der GSH-Sepharose nach der 
Elution. Der Marker (M) ist in kDa angegeben. Das + Zeichen bezieht sich auf die Anwesenheit des damit bezeichneten Proteins. Die untersuchten Importrezeptoren interagieren mit immobilisiertem RanQ69L ${ }^{1-180}$, aber nicht mit GST oder der leeren GSH Sepharose

A

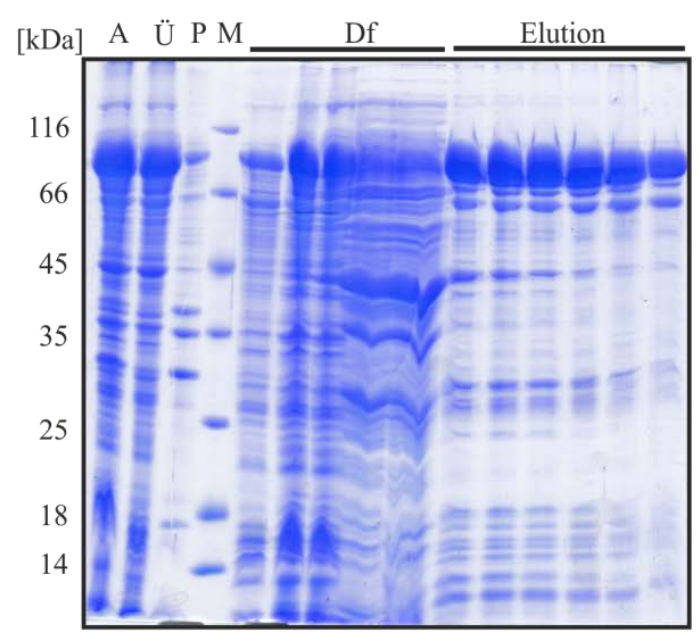

B

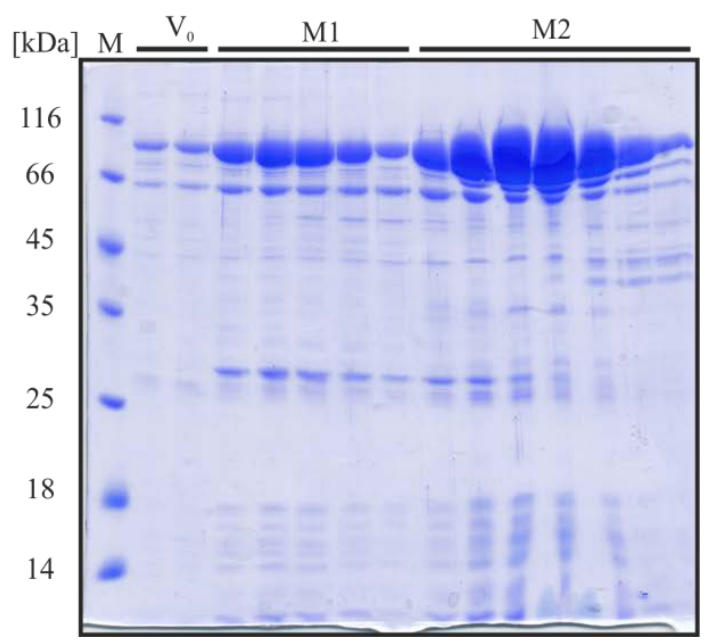

Abb. A6: Reinigung von Imp $\boldsymbol{\beta}$. A) SDS-Gel der Affinitätschromatographie über Ni-NTA Sepharose. In den ersten drei Spuren sind Proben aus dem Aufschluss der Expressionszellen aufgetragen (A= Aufschluss, Ü= Überstand, $\mathrm{P}=$ Pellet). In den nachfolgenden Spuren nach dem Marker (M) sind Proben aus dem Durchfluss (Df) und der Elution aufgetragen worden. B) SDS-Gel der Gelfiltration über Superdex 200 XK26/60. $V_{0}$ bezeichnet das Ausschlußvolumen der Gelfiltrationssäule, während das erste Maximum mit M1und das zweite mit M2 bezeichnet ist. Die Fraktionen aus M2 wurden für weiterführende Experiment verwendet. 


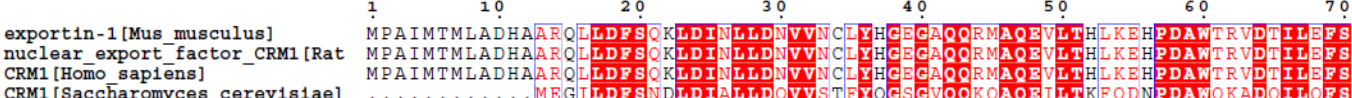

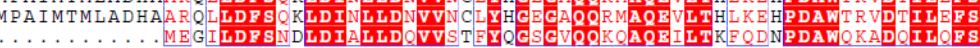

exportin-1 [Mus musculus] nuclear export factor CRM1 [Rat CRM1 [Homo sap1ens]

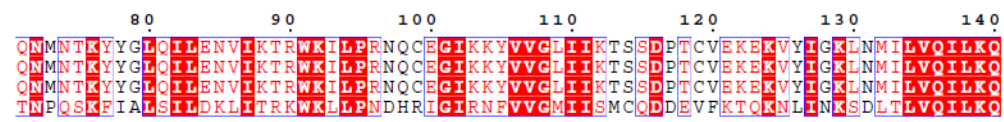

export1n-1 [Mus_musculus] nuclear_export ${ }_{\text {factor_CRM1 [Rat }}$ CRM1 [Homo sapièns]

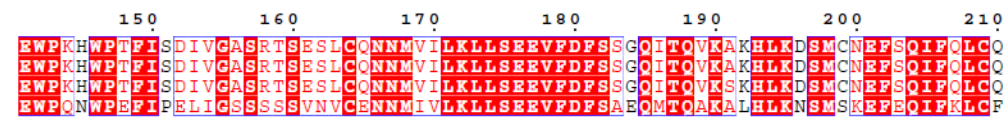

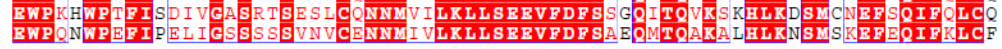

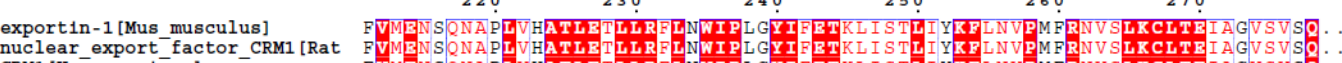

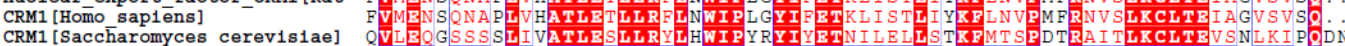

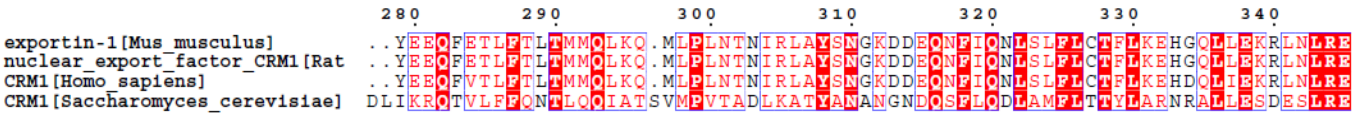

export1n-1 [Mus_musculus] nuclear_export_factor_CRM1 [Rat CRM1 [Homo sap1ens]

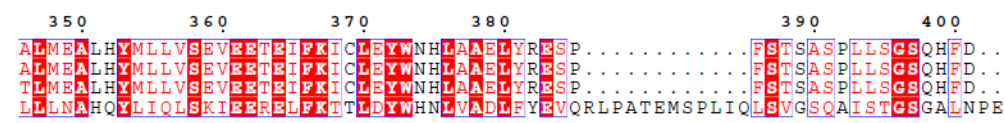
export1n-1 [Mus_musculus]
nuclear export factor_CRM1 [Rat $\begin{array}{llllll}410 & 420 & 430 & 440 & 450 & 460\end{array}$ CRM1 [Homo sapiēens]
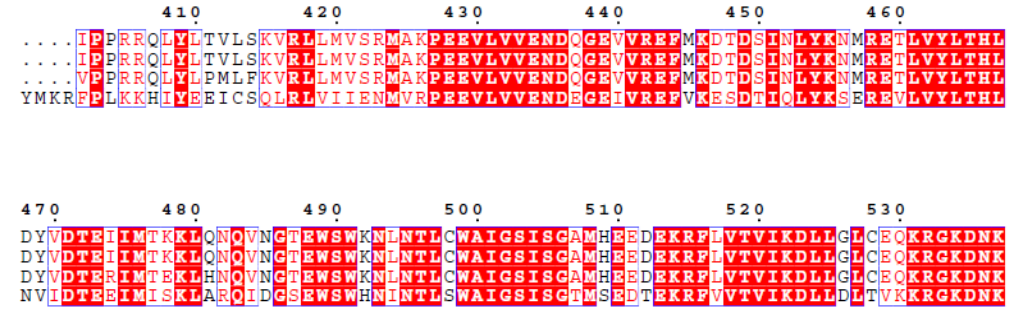

exportin-1 [Mus_musculus] CRM1 [Homo sapiens]

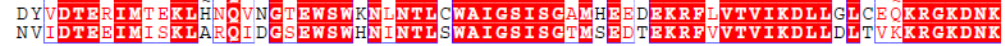

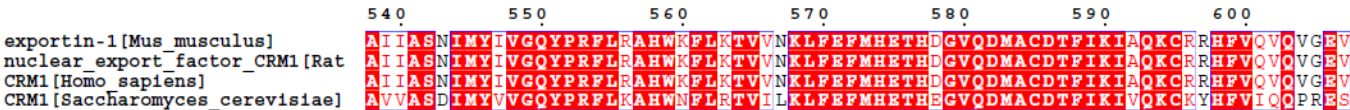

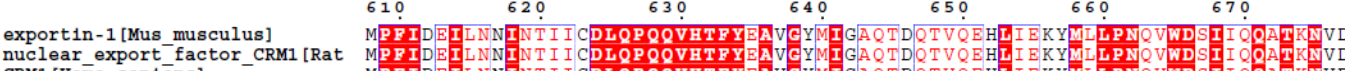

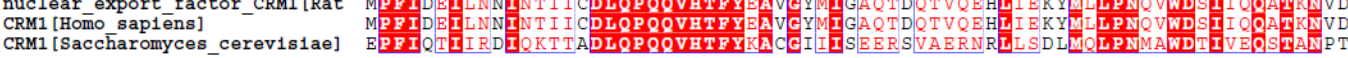



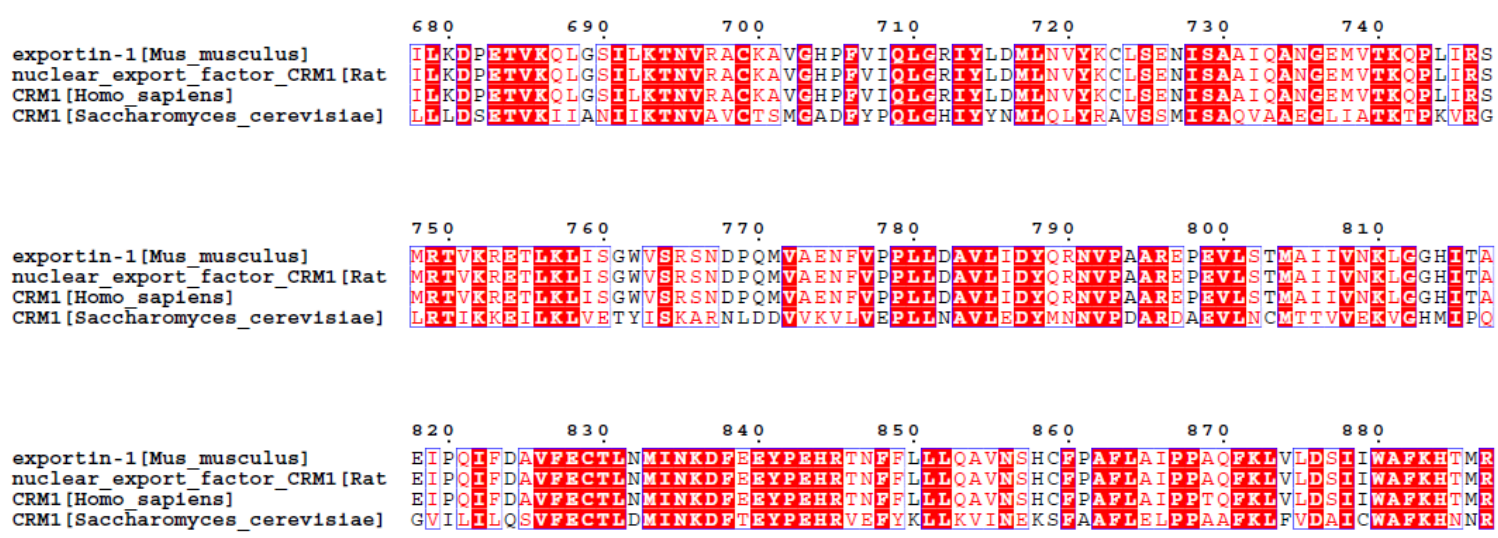

CRM1 [Homo sapiens]

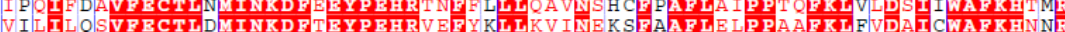

export1n-1 [Mus_musculus]
nuclear_export-factor_CRM1 [Rat
CRM1 [Homo sap1ens]
CRM1 [Saccharomyces_cerev1s1ae]

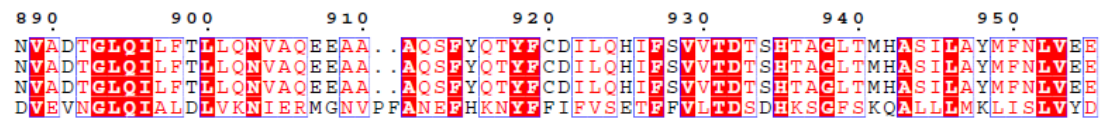

NVADTGLQI F TLLQNVAQEEAA.

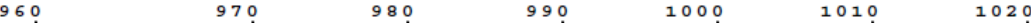

export1n-1 [Mus_musculus] CRM1 [Homo sapiens]

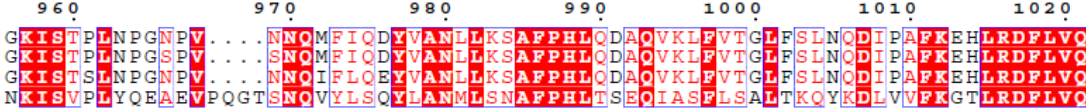

CRM1 [Homo sap1ens]

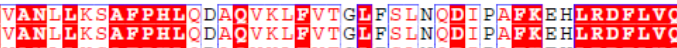

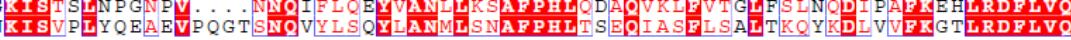

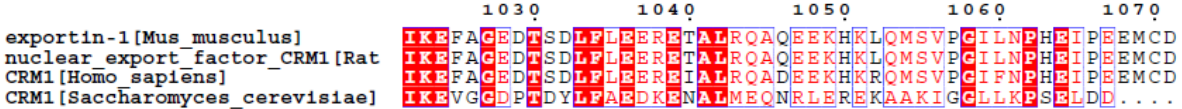

Abb. A7: Sequenzvergleich von Crm1 aus unterschiedlichen Organismen. Sequenzvergleich des humanen Crm1 (Homo sapiens) mit den Orthologen aus Maus (Exportin-1 Mus musculus), Wanderratte (Rattus norvegicus), und Bäckerhefe (Crm1 Saccharomyces cerevisiae). Konservierte Reste sind blau umrandet, wobei ähnliche und teilweise konservierte Reste rot sind und Reste, die in allen homologen Proteinen vorkommen rot hinterlegt sind. 


\section{Danksagung}

An dieser Stelle möchte ich die Gelegenheit ergreifen einigen Leuten zu danken, die mir durch ihre fachlich Kompetenz und/oder ihrer Freundschaft während dieser Arbeit beigestanden zu dessen Gelingen beigetragen haben:

Zuallererst möchte ich mich bei Herren Prof. Dr. Ralf Ficner bedanken, der mir die Möglichkeit gegeben hat diese Doktorarbeit in der Abteilung molekulare Strukturbiologie anzufertigen und diese interessante Aufgabestellung zu bearbeiten. Für sein mir gegenüber dargebrachtes Vertrauen und seine stete Unterstützung bin ich ihm sehr dankbar.

Herrn Jun.-Prof. Dr. Heinz Neumann danke ich sehr herzlich für die Übernahme des Korreferates und die damit verbundene Begutachtung der Arbeit. Dafür, dass er mir nach meiner Diplomarbeit durch eine Hiwi-Stelle die Möglichkeit gegeben hat weiter im Labor zu sein und für sein offenes Ohr für jedwede Frage bin ich ihm sehr dankbar

Ganz besonders danke ich Dr. Achim Dickmanns für die exzellente Betreuung bei dem Projekt, sowie die ihm entgegengebrachte Begeisterung, seine allseits gute Laune, für die zahlreichen Anregungen, ein offenes Ohr zur rechten Zeit und seine kleinen Stupser im richtigen Augenblick. Für die kritische Durchsicht der Arbeit bin ich ihm äußerst dankbar.

Ein ganz großer Dank geht an Dr. Piotr Neumann der mir stets meine Fragen zur Kristallographie beantwortete und bei jedwedem Problem in der Kristallographie mit Rat und Tat zur Seite stand. Danke!

Auch ein ganz besonderes danke schön gilt Dr. Thomas Monecke für die mir entgegengebrachte Hilfe bei Problem, die kritische Durchsicht der Arbeit zahlreiche Diskussionen, Anregungen, und die stets entgegengebrachte Begeisterung.

Ein besonderer Dank gilt auch Christoph Lammers, der mir in so mach schwieriger Phase weitergeholfen hat, sowie Bernhard Kuhle der mir immer mit Rat und Tat zur Seite stand wenn ich seine Hilfe brauchte. Die Diskussionen zu allen Themen waren immer sehr erhellend.

Herrn Dr. Ralf Kehlenbach danke ich für die Möglichkeit, RanGAP und Ran Protektions Assaay in seinem Labors durchführen zu können.

Des Weiteren bedanke ich mich bei den Mitgliedern der Transportgruppe (Marcel, Martje und Anette, Jessi Nehls, Carolin Thüne), sowie allen Mitarbeitern der Molekularen Strukturbiologie und der AG Neumann die mir immer mit Rat und Tat zur Seite standen und stets für eine angenehme Arbeitsatmosphäre sorgten.

Meiner ganzen Familie und im Besonderen meinen Eltern Gerhard und Almut Gloth, die mir das Studium ermöglicht haben, bin ich für die ständige Unterstützung und Geduld sehr dankbar. 


\section{Lebenslauf}

Name:

Adresse:

Telefon:

Geburtsdatum:

Geburtsort:

Staatsangehörigkeit:

\section{Bildungsweg:}

1990-1994

1994-1996

1996-2000

2000-2003

07/2003

\section{Studium:}

10/2003-10/2009

23. Oktober 2009

Seit 01/2011
Gloth, Daniel

Hermann-Löns Str. 2, 37186 Moringen

0151-65179484

02.02.1984

Northeim

deutsch

Grundschule Moringen

Orientierungsstufe der KGS Moringen

Realschulzweig der KGS Moringen

Wirtschaftsgymnasium der BBS1 Northeim

Abitur

Studium der Biologie (Diplom) an der Georg-August-

Universität Göttingen

Diplom in Biologie (Georg-August-Universität

Göttingen)

Promotionsstudium an der Georg-August-Universität

Göttingen im Fachbereich Biologie unter Anleitung von Prof.

Dr. Ralf Ficner 